Universidade de Brasília - UnB

Faculdade UnB Gama - FGA

Curso de Engenharia de Energia

\title{
AJUSTE DE PROTEÇÃO DE TRANSFORMADORES DE SISTEMAS ELÉTRICOS DE POTÊNCIA DA SE RONDONÓPOLIS, MATO GROSSO
}

Autor: Samuel Augusto da Cruz Santos Orientador: Luís F. J. Fernandes

Brasília, DF

2018 


\section{AJUSTE DE PROTEÇÃO DE TRANSFORMADORES DE SISTEMAS ELÉTRICOS DE POTÊNCIA DA SE RONDONÓPOLIS, MATO GROSSO}

Monografia submetida ao curso de graduação em Engenharia de Energia da Universidade de Brasília, como requisito parcial para obtenção do Título de Bacharel Engenharia de Energia.

Orientador: Luís F. J. Fernandes

Brasília, DF 


\section{CIP - Catalogação Internacional da Publicação*}

Santos, Samuel.

Ajuste de proteção de transformadores de sistemas elétricos de potência da SE Rondonópolis, Mato Grosso / Samuel Augusto da Cruz Santos. Brasília: UnB, 2018. 159 p.

Monografia (Graduação) - Universidade de Brasília

Faculdade do Gama, Brasília, 2018. Orientação: Luís F. J. Fernandes.

1. Proteção de sistemas de potência. 2. Proteção de transformadores de potência. 3. Proteção de sobrecorrente. 4. Proteção diferencial. I. Fernandes, Luís F. J. II. Ajuste de proteção de transformadores em sistemas elétricos de potência da SE Rondonópolis, Mato Grosso.

CDU Classificação 


\section{Y UnBGama \\ O novo endereço da tecnologia \\ REGULAMENTO E NORMA PARA REDAÇÃO DE RELATÓRIOS DE PROJETOS DE GRADUAÇÃO FACULDADE DO GAMA - FGA}

\section{Samuel Augusto da Cruz Santos}

Monografia submetida como requisito parcial para obtenção do Título de Bacharel em Engenharia de Energia da Faculdade UnB Gama - FGA, da Universidade de Brasília, apresentada e aprovada em ______ pela banca examinadora abaixo assinada:

Prof. (Doutor): Luís Filomeno de Jesus Fernandes, UnB/ FGA

Orientador

Prof. (Doutor): Flávio Henrique Justiniano Ribeiro da Silva, UnB/ FGA

Membro Convidado

Engenheiro: Salomão Ribeiro Fernandes, Eletronorte

Membro Convidado

Brasília, DF 


\section{AGRADECIMENTOS}

Primeiramente, gostaria de agradecer a Deus pelas ricas oportunidades que Ele tem proporcionado, por ter me dado força e conhecimento para concluir essa grande etapa da minha vida e me auxiliar sempre nos momentos em que, aos meus olhos naturais, não havia mais esperança.

Aos meus familiares que ao longo desta caminhada sempre me apoiaram e, de alguma forma, sempre tentaram me auxiliar em todos os momentos, nas minhas decisões me ensinando sempre a tomar as melhores decisões e ser uma pessoa melhor.

Gostaria de agradecer ao meu professor e orientador Doutor Luís Filomeno de Jesus Fernandez, pelos ensinamentos, sugestões e conselhos para a elaboração deste trabalho, sempre com muito zelo, competência e disponibilidade.

A todos os professores da Faculdade UnB - Gama, onde aprendi com cada um a ter um caráter profissional. Agradeço ao empenho de todos, que mesmo com as limitações, não perdem o foco de ensinar e transmitir o conhecimento. Seriam muitas linhas para agradecer a todos, mas gostaria de agradecer ao meu orientador de estágio, professor Doutor Eberth de Almeida Corrêa, por ter me proporcionado um rico aprendizado em seu projeto de iniciação científica e por diversas vezes estar disponível a me auxiliar nas questões pertinentes ao meu estágio supervisionado, sempre me orientando, motivando e me aconselhando profissionalmente.

Em especial, gostaria de agradecer a todos os funcionários do Departamento de Proteção, Medição e Controle (OEOP) da empresa Eletrobrás-Eletronorte. Na qual foram dois anos de muito aprendizado não somente na área de proteção, mas também um rico aprendizado profissional, onde estive em contato com profissionais conhecidos e renomados em todo o país. Meu agradecimento aos meus supervisores de estágio, os engenheiros Carlos Felipe e Salomão Ribeiro, que com muita paciência e zelo se dispuseram a me passar o máximo de conhecimento na área de proteção de sistemas elétricos. A todos os funcionários da área proteção, que seriam muitas linhas para falar de cada um: aos senhores engenheiros Carlos Floriano, Cesar La Torre, Ismael Telles Pires, João Edson, Joaquim Neto, Jorge Feitosa, Luiz Carlos, Luiz Fábio, Marcelo Belém, Marino Neves, Milton Knorr, Rogério Antônio, Rogério Coelho, Thiago Pereira, 
Ulisses Galvão, Yghor Peterson, dentre outros funcionários que tive contato na empresa. Meus sinceros agradecimentos.

Por fim, gostaria de agradecer a todos os amigos de graduação com que passei momentos que levarei para toda a vida, onde fui mais ajudado do que ajudei. Agradeço por me confiar vossas amizades. 


\section{RESUMO}

No intuito de garantir um alto nível de confiabilidade para os serviços de transmissão e distribuição de energia, os esquemas de proteção empregados nos Sistemas Elétricos de Potência devem atuar de forma rápida e segura a fim de eliminar as falhas que possam comprometer os equipamentos do sistema. Dentre os principais elementos que necessitam de um contínuo monitoramento, destacam-se os geradores e transformadores de potência por serem os mais importantes para as usinas de geração e para as subestações, respectivamente, além dos seus custos operacionais. O presente trabalho apresenta os esquemas de proteção mais empregados para a proteção dos principais elementos do SEP, sendo dada uma ênfase nas proteções de sobrecorrente e diferencial, por serem as mais utilizadas nos esquemas de proteção dos equipamentos do sistema elétrico. Através do software de SAPRE do CEPEL de simulação de curto-circuito, foram obtidas as correntes de curto-circuito a serem utilizadas para o ajuste dos relés de proteção, sendo utilizado o relé P143 da ALSTOM para as proteções de sobrecorrente e o relé 7UT61 da SIEMENS para a proteção diferencial. Na etapa final deste trabalho, apresentam-se os resultados para o estudo de proteção dos transformadores de potência da SE Rondonópolis, em Mato Grosso, de propriedade da empresa Eletronorte. Os resultados mostraram que os ajustes da proteção de sobrecorrente é capaz de fornecer retaguarda apenas para a barra de $138 \mathrm{kV}$ da SE Rondonópolis, para os defeitos fase-fase, e para as barras de $230 \mathrm{kV}$ e $138 \mathrm{kV}$ nos defeitos fase-terra, além de atuar de forma satisfatória como retaguarda para a proteção diferencial dos transformadores. $O$ ajuste da proteção diferencial foi verificado tanto pelo teste de busca da curva característica, como também através da leitura oscilográfica de uma falta real para a confirmação da atuação da proteção em comparação com o sistema de proteção existente na SE Rondonópolis. Por fim, os resultados do teste de restrição de $2^{\circ}$ e $5^{\circ}$ harmônicos mostram que de fato ocorre o bloqueio da proteção diferencial, não atuando de forma incorreta para as correntes de Inrush.

Palavras-chave: proteção de sistemas de potência, proteção de transformadores de potência, proteção de sobrecorrente, proteção diferencial. 


\begin{abstract}
In order to ensure a high level of reliability for power transmission and distribution services, the protection schemes used in Power Systems must act quickly and safely in order to eliminate failures that could compromise system equipment. Among the main elements that need continuous monitoring, the most important are the generators and power transformers, since they are the most important for the generation plants and for the substations respectively, in addition to their operational costs. The present work presents the most used protection schemes for the protection of the main elements of the SEP, being an emphasis on the overcurrent and differential protections, since they are the most used in the protection schemes of the electrical system equipment. Through CEPEL's SAPRE short-circuit simulation software, the short-circuit currents to be used to adjust the protection relays were obtained, using the relay P143 from ALSTOM for overcurrent protections and relay 7UT61 from SIEMENS for differential protection. In the final stage of this work, the results are presented for the study of protection of the power transformers of SE Rondonopolis, in Mato Grosso, owned by Eletronorte. The results showed that the overcurrent protection settings are able to provide rear only for the $138 \mathrm{kV}$ rod of the SE Rondonopolis, for the phase-to-phase faults, and for the $230 \mathrm{kV}$ and $138 \mathrm{kV}$ buses in the phase-to-ground faults, besides satisfactory as a rear end for differential protection of transformers. The adjustment of the differential protection was verified both by the characteristic curve search test and also by the oscillographic reading of a real fault to confirm the performance of the protection compared to the existing protection system at the SE Rondonopolis. Finally, the results of the 2 nd and 5 th harmonic restraint test show that the differential protection lock does not occur in an incorrect way for the Inrush currents.
\end{abstract}

Keywords: power systems protection, power transformers protection, overcurrent protection, differential protection. 


\section{LISTA DE FIGURAS}

Figura 1 - Mapa do Sistema Interligado Nacional [7].

Figura 2 - Esquemático simplificado para a proteção de um transformador de potêncial [30].

Figura 3 - Diagrama unifilar dos componentes de um sistema de energia elétrica radial [8] 35

Figura 4 - Representação do curto-circuito trifásico [11] 40

Figura 5 - Modelo de sequência positiva utilizado para os cálculos de curto-circuito trifásico [11].

Figura 6 - Representação do curto-circuito bifásico sem envolvimento de terra [11].......40

Figura 7 - Modelo de sequência positiva e negativa em paralelo para os cálculos de curto bifásico sem envolvimento de terra [11].....

Figura 8 - Representação do curto-circuito bifásico-terra [11]

Figura 9 - Modelos de sequência positiva, negativa e zero conectados em paralelo para os cálculos de curtos-circuitos bifásicos-terra [11].

Figura 10 - Modelos de sequência positiva, negativa e zero conectados em série para os cálculos de curtos-circuitos monofásicos-terra [11].

Figura 11 - Representação do curto-circuito monofásico-terra [11] .43

Figura 12 - Diagramas fasoriais das componentes simétricas de um conjunto trifásico [11]

Figura 13 - Circuito equivalente de sequência postiva para o gerador síncrono [11] .....48

Figura 14 - Circuito equivalente de sequência negativa [11]. 49

Figura 15 - Circuito equivalente de sequência zero para o gerador síncrono [11] 50

Figura 16 - Circuito equivalente de sequência positiva e negativa para transformadores de potência [10].

Figura 17 - Circuitos equivalentes de sequência zero para transformadores trifásicos de núcleo envolvente de dois e três enrolamentos, respectivamente [11]....

Figura 18 - Circuitos equivalentes de sequência positiva e negativa para as linhas de transmissão [11] .52

Figura 19 - Localização de um relé Buccholz na proteção de um transformador de potência [15] 
Figura 20 - Esquema da proteção de distância para uma linha de transmissão com falta [15]

Figura 21 - Esquema de proteção diferencial de barras [13]. 59

Figura 22 - Curva de operação para um relé de sobrecorrente de tempo inverso [17]...62

Figura 23 - Exemplo de curva IEC normal inversa [22].

Figura 24 - Esquemático do relé de sobrecorrente com controle de tensão 51V [25] 65

Figura 25 - Proteção diferencial para o sistema operando normalmente [15]................66

Figura 26 - Defeito fora da zona de proteção [15] .................................................66

Figura 27 - Atuação da proteção diferencial para um defeito interno [15]......................67

Figura 28 - Curva de operação do relé diferencial [18] ...............................................68

Figura 29 - Esquemático para as proteções de sobrecorrente em transformadores de

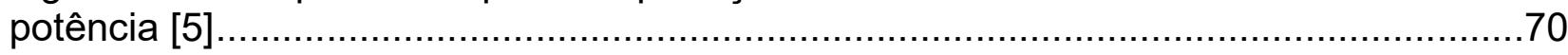

Figura 30 - Exemplo de curva de capacidade de um transformador de potência [20] ....71

Figura 31 - Coordenação do relé de sobrecorrente para um transformador $\Delta-Y$............72

Figura 32 - Curvas de atuação da proteção de sobrecorrente para três estágios [21] ...74

Figura 33 - Esquema de conexão dos TCs para a proteção diferencial de um

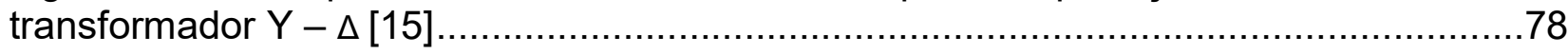

Figura 34 - Esquema de conexão dos TCs para a proteção diferencial de um

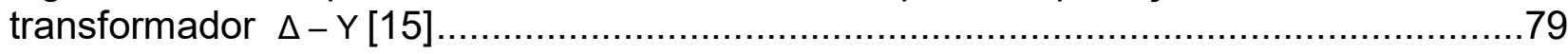

Figura 35 - Esquema de conexão dos TCs para a proteção diferencial de um transformador $\mathrm{Y}-\Delta[15]$ .83

Figura 36 - Diagrama unifilar simplificado da SE Rondonópolis-Mato Grosso.................85

Figura 37 - Curvas IEC do relé de proteção P143 da ALSTOM [29]..............................92

Figura 38 - Pontos de testes aprovados pela proteção 51 para o grupo de ajuste 1 ......95

Figura 39 - Pontos de testes aprovados pela proteção 51 para o grupo de ajuste 2 ......96

Figura 40 - Pontos de testes aprovados pela proteção 51 para o grupo de ajuste 3 ......98

Figura 41 - Teste ramping para a proteção de sobrecorrente instantânea (50) no lado de $230 \mathrm{kV}$ 100

Figura 42 - Pontos aprovados pelo teste da proteção 51V para o grupo de ajuste 1 ...102 
Figura 43 - Teste ramping para a verificação da partida da proteção $51 \mathrm{~V}$ após atingir $0,7 \mathrm{pu}$ 103

Figura 44 - Pontos aprovados pelo teste da proteção 51V para o grupo de ajuste 2... 104 Figura 45 - Pontos aprovados pelo teste da proteção 51V para o grupo de ajuste 3... 105 Figura 46 - Curva para a proteção $51 \mathrm{~N}$ e os pontos de testes provados 111

Figura 47 - Pontos aprovados pelo teste da proteção 51 para o grupo de ajuste 1 ......114 Figura 48 - Pontos aprovados pelo teste da proteção 51 para o grupo de ajuste 2 ......115 Figura 49 - Pontos aprovados pelo teste da proteção 51 para o grupo de ajuste 3 ......116 Figura 50 - Pontos aprovados pelo teste da proteção 51V para o grupo de ajuste 1.. .119 Figura 51 - Teste ramping evidenciando a partida da proteção 51V após a tensão atingir $0,7 \mathrm{pu}$ 120

Figura 52 - Pontos aprovados pelo teste da proteção 51V para o grupo de ajuste $2 \ldots 121$ Figura 53 - Teste ramping evidenciando a partida da proteção $51 \mathrm{~V}$ após a tensão atingir $0,7 \mathrm{pu}$ 122

Figura 54 - Pontos aprovados pelo teste da proteção 51V para o grupo de ajuste 4. 124

Figura 55 - Teste ramping evidenciando a partida da proteção $51 \mathrm{~V}$ após a tensão atingir $0,7 \mathrm{pu}$ 124

Figura 56 - Curva para a proteção $51 \mathrm{~N}$ e os pontos de testes aprovados 129

Figura 57 - Curva característica de atuação da proteção diferencial [27]. 130

Figura 58 - Valores dos ajuste da curva caracterísitca de atuação do relés diferencial [27]. 132

Figura 59 - Cálculo dos pontos da curva da proteção diferencial. 133

Figura 60 - Curva caracterísitica parametrizada no relé 7UT61 para a proteção diferencial 134

Figura 61 - Atuação do próprio sistema de proteção da SE Rondonópolis para uma falta real. 135

Figura 62 - Atuação da proteção diferencial ajustada nesse estudo para uma falta real na SE RP. 135

Figura 63 - Pontos para o teste de restrição de $2^{\circ}$ harmônico do relé 7 UT61 137

Figura 64 - Pontos para o teste de restrição de $5^{\circ}$ harmônico do relé 7 UT61 138 
Figura 65 - Oscilografia do bloqueio da proteção diferencial por $2^{\circ}$ harmônico..............139

Figura 66 - Oscilografia do bloqueio da proteção diferencial por $5^{\circ}$ harmônico.............139 


\section{LISTA DE TABELAS}

Tabela 2.1 - Porcentagem das ocorrências dos curtos-circuitos [11] .43

Tabela 3.1 - Coeficientes para a equação característica da curva dos relés de

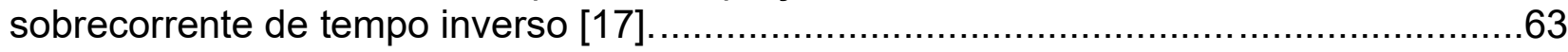

Tabela 4.1 - Correntes de faltas para um transformador $\Delta-\mathrm{Y}[1] \ldots \ldots \ldots \ldots \ldots \ldots \ldots \ldots \ldots \ldots . . .72$

Tabela 4.2 - Deslocamentos angulares para as diversas conexões entre o primário e o secundário de transformadores de potência [18] .......................................................76

Tabela 4.3 - Valores das combinações de taps para o relé diferencial [15].....................82

Tabela 5.1 - Parâmetros das linhas de transmissão ligadas a SE Rondonópolis ............86

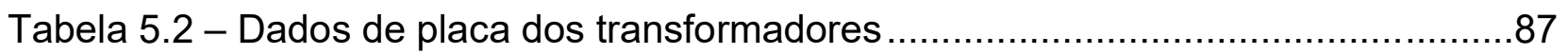

Tabela 5.3 - Valores das correntes de curto-circuito trifásicas para as quatro condições

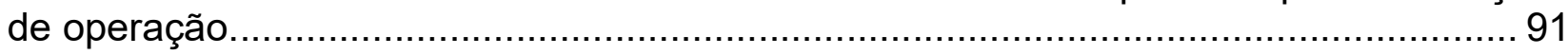

Tabela 5.4 - Coordenação da proteção de sobrecorrente de fase (51) no lado de $230 \mathrm{kV}$

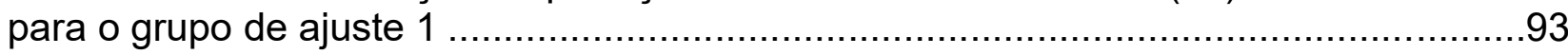

Tabela 5.5 - Resultados do teste da proteção de sobrecorrente temporizada de fase (51) no lado de $230 \mathrm{kV}$ para o grupo de ajuste 1 94

Tabela 5.6 - Coordenação da proteção de sobrecorrente temporizada de fase (51) no lado de $230 \mathrm{kV}$ para o grupo de ajuste 2 95

Tabela 5.7 - Resultados do teste da proteção de sobrecorrente temporizada de fase (51) no lado de $230 \mathrm{kV}$ para o grupo de ajuste 2 96

Tabela 5.8 - Coordenação da proteção de sobrecorrente de fase (51) no lado de grupo de ajuste 3

Tabela 5.9 - Resultados do teste da proteção de sobrecorrente temporizada de fase (51) no lado de $230 \mathrm{kV}$ para o grupo de ajuste 3 97

Tabela 5.10 - Coordenação da proteção de sobrecorrente de fase (51) no lado de 230 $k V$ para o grupo de ajuste 4 98

Tabela 5.11 - Coordenação da proteção de sobrecorrente de fase com controle de tensão (51V) no lado de $230 \mathrm{kV}$ para o grupo de ajuste 1 101

Tabela 5.12 - Resultados do teste da proteção de sobrecorrente com controle de tensão (51V) no lado de $230 \mathrm{kV}$ para o grupo de ajuste 1 102

Tabela 5.13 - Coordenação da proteção de sobrecorrente de fase com controle de tensão (51V) no lado de $230 \mathrm{kV}$ para o grupo de ajuste 2 
Tabela 5.14 - Resultados do teste da proteção de sobrecorrente com controle de tensão (51V) no lado de $230 \mathrm{kV}$ para o grupo de ajuste 2

Tabela 5.15 - Coordenação da proteção de sobrecorrente de fase com controle de tensão (51V) no lado de $230 \mathrm{kV}$ para o grupo de ajuste 3 105

Tabela 5.16 - Resultados do teste da proteção de sobrecorrente com controle de tensão (51V) no lado de $230 \mathrm{kV}$ para o grupo de ajuste 3 105

Tabela 5.17 - Coordenação da proteção de sobrecorrente de fase com controle de tensão (51V) no lado de $230 \mathrm{kV}$ para o grupo de ajuste 4 106

Tabela 5.18 - Valores das correntes de curto-circuito monofásicas-terra para as quatro condições de operação da SE Rondonópolis. 107

Tabela 5.19 - Coordenação da proteção de sobrecorrente de neutro $(51 \mathrm{~N})$ no lado de $230 \mathrm{kV}$ para o grupo de ajuste 1 108

Tabela 5.20 - Coordenação da proteção de sobrecorrente de neutro $(51 \mathrm{~N})$ no lado de $230 \mathrm{kV}$ para o grupo de ajuste 2 108

Tabela 5.21 - Coordenação da proteção de sobrecorrente de neutro $(51 \mathrm{~N})$ no lado de $230 \mathrm{kV}$ para o grupo de ajuste 3 109

Tabela 5.22 - Coordenação da proteção de sobrecorrente de neutro $(51 \mathrm{~N})$ no lado de $230 \mathrm{kV}$ para o grupo de ajuste 4 110

Tabela 5.23 - Resultados do teste da proteção de sobrecorrente de neutro temporizada $(51 \mathrm{~N})$ para os quatro grupos de ajustes 110

Tabela 5.24 - Valores das correntes de curto-circuito trifásico para as quatro condições de operação 112

Tabela 5.25 - Coordenação da proteção de sobrecorrente de fase (51) no lado de $138 \mathrm{kV}$ para o grupo de ajuste 1 113

Tabela 5.26 - Resultados do teste da proteção de sobrecorrente de fase temporizado (51) no lado de $138 \mathrm{kV}$ para o grupo de ajuste 1 113

Tabela 5.27 - Coordenação da proteção de sobrecorrente de fase (51) no lado de $138 \mathrm{kV}$ para o grupo de ajuste 2 114

Tabela 5.28 - Resultados do teste da proteção de sobrecorrente de fase temporizado (51) no lado de $138 \mathrm{kV}$ para o grupo de ajuste 2 115

Tabela 5.29 - Coordenação da proteção de sobrecorrente de fase (51) no lado de $138 \mathrm{kV}$ para o grupo de ajuste 3 116

Tabela 5.30 - Resultados do teste da proteção de sobrecorrente de fase temporizado (51) no lado de $138 \mathrm{kV}$ para o grupo de ajuste 3 116

Tabela 5.31 - Coordenação da proteção de sobrecorrente de fase (51) no lado de $138 \mathrm{kV}$ para o grupo de ajuste 4 
Tabela 5.32 - Coordenação da proteção de sobrecorrente com controle de tensão (51V) no lado de $138 \mathrm{kV}$ para ao grupo de ajuste 1 .

Tabela 5.33 - Resultados do teste da proteção de sobrecorrente com controle de tensão $(51 \mathrm{~V})$ no lado de $138 \mathrm{kV}$ para o grupo de ajuste 1

Tabela 5.34 - Coordenação da proteção de sobrecorrente com controle de tensão (51V) no lado de $138 \mathrm{kV}$ para ao grupo de ajuste 2 .

Tabela 5.35 - Resultados do teste da proteção de sobrecorrente com controle de tensão $(51 \mathrm{~V})$ no lado de $138 \mathrm{kV}$ para o grupo de ajuste 2

Tabela 5.36 - Coordenação da proteção de sobrecorrente com controle de tensão (51V) no lado de $138 \mathrm{kV}$ para ao grupo de ajuste 3 .

Tabela 5.37 - Coordenação da proteção de sobrecorrente com controle de tensão (51V) no lado de $138 \mathrm{kV}$ para o grupo de ajuste 4 .

Tabela 5.38 - Resultados do teste da proteção de sobrecorrente com controle de tensão $(51 \mathrm{~V})$ no lado de $138 \mathrm{kV}$ para o grupo de ajuste 4 124

Tabela 5.39 - Valores das correntes de curto-circuito monofásico-terra para as quatro condições de operação. 125

Tabela 5.40 - Coordenação da proteção de sobrecorrente de neutro $(51 \mathrm{~N})$ no lado de $138 \mathrm{kV}$ para o grupo de ajuste 1 126

Tabela 5.41 - Coordenação da proteção de sobrecorrente de neutro (51N) no lado de $138 \mathrm{kV}$ para o grupo de ajuste 2

Tabela 5.42 - Coordenação da proteção de sobrecorrente de neutro $(51 \mathrm{~N})$ no lado de $138 \mathrm{kV}$ para o grupo de ajuste 3

Tabela 5.43 - Coordenação da proteção de sobrecorrente de neutro $(51 \mathrm{~N})$ no lado de $138 \mathrm{kV}$ para o grupo de ajuste 4 128

Tabela 5.44 - Resultados do teste da proteção de sobrecorrente de neutro temporizada $(51 \mathrm{~N})$ para os quatro grupos de ajustes 128

Tabela 5.45 - Definição dos parâmetros gerais da proteção diferencial [27] 130

Tabela 5.46 - Definição dos parâmetros de corrente e da curva característica da proteção diferencial [27] 131

Tabela 5.47 - Resultados do teste trifásico para a avaliação da curva característica de atuação da proteção diferencial 134

Tabela 5.48 - Definição dos parâmetros para a restrição diferencial por segundo e quinto harmônico [27]. 136

Tabela 5.49 - Resultados do teste de restrição de segundo harmônico da proteção diferencial. 
Tabela 5.50 - Resultados do teste de restrição de quinto harmônico da proteção

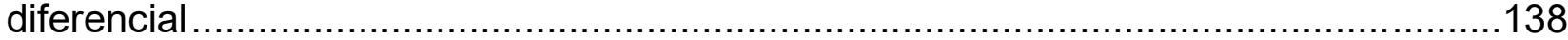




\section{LISTA DE SÍMBOLOS}

$D_{\text {cond }}$ - Distância, em km, do TC ao relé

$\dot{E}_{a_{1}}-$ Tensão de fase do gerador síncrono a vazio

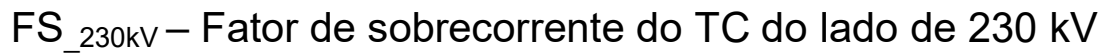

FS_138kV - Fator de sobrecorrente do TC do lado de $230 \mathrm{kV}$

$\dot{I}_{a}-$ Fasor de corrente na fase A

$\dot{I}_{b}-$ Fasor de corrente na fase B

$\dot{I}_{c}-$ Fasor de corrente na fase $\mathrm{C}$

$\dot{I}_{a 0}-$ Fasor de corrente de sequência zero na fase A

$\dot{I}_{b 0}-$ Fasor de corrente de sequência zero na fase B

$\dot{I}_{c 0}$ - Fasor de corrente de sequência zero na fase C

$\dot{I}_{a_{1}}-$ Fasor de corrente de sequência positiva na fase A

$\dot{I}_{b_{1}}-$ Fasor de corrente de sequência positiva na fase B

$\dot{I}_{c_{1}}-$ Fasor de corrente de sequência positiva na fase $\mathrm{C}$

$\dot{I}_{a_{2}}-$ Fasor de corrente de sequência negativa na fase A

$\dot{I}_{b_{2}}-$ Fasor de corrente de sequência negativa na fase B

$\dot{I}_{c_{2}}-$ Fasor de corrente de sequência negativa na fase $\mathrm{C}$

$\dot{I}_{0}-$ Fasor de corrente de sequência zero

$\dot{I}_{1}-$ Fasor de corrente de sequência positiva

$\dot{I}_{2}-$ Fasor de corrente de sequência negativa

$\mathrm{I}_{\mathrm{A}}{ }^{*}$ - Corrente na fase A sem a componente de sequência zero 
$\mathrm{I}_{\mathrm{B}}{ }^{*}$ - Corrente na fase $\mathrm{B}$ sem a componente de sequência zero

$\mathrm{I}^{*}{ }^{*}$ - Corrente na fase $\mathrm{C}$ sem a componente de sequência zero

$\mathrm{l}_{\mathrm{a}}^{* *}$ - Corrente na fase A com a compensação do deslocamento angular

$\mathrm{I}_{\mathrm{b}}{ }^{* *}$ - Corrente na fase B com a compensação do deslocamento angular

$\mathrm{I}_{\mathrm{C}}{ }^{* *}-$ Corrente na fase $\mathrm{C}$ com a compensação do deslocamento angular

$\dot{I}_{\text {ajuste do relé }}-$ Corrente de ajuste do relé

$\mathrm{I}_{\mathrm{cc} \_ \text {ext__138kV }}$ - Corrente de curto-circuito máxima externa medida no lado de $138 \mathrm{kV}$

$\mathrm{I}_{\mathrm{cc} \_ \text {ext_230kV }}$ - Corrente de curto-circuito máxima externa medida no lado de $230 \mathrm{kV}$

ICC_FFF_138_barra_1AT - Corrente de curto-circuito trifásico na barra de $138 \mathrm{kV}$ com 1 AT

ICC_FT_310_barra_138_01AT - Corrente de curto-circuito fase-terra na barra de $138 \mathrm{kV}$ com 1 AT

$\mathrm{I}_{\mathrm{CC} \text { max no TC }}$ - Corrente máxima de curto-circuito no TC

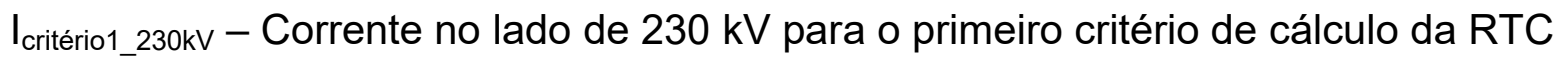

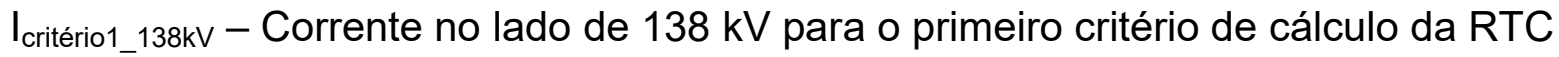

I critério2_230kV - Corrente no lado de 230 kV para o segundo critério de cálculo da RTC

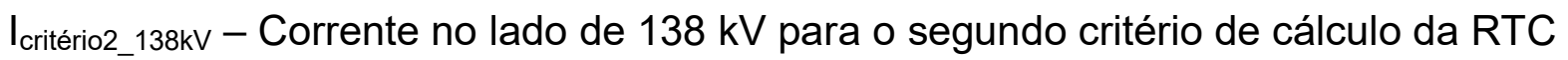

$\dot{I}_{\text {entrada }}$ - Corrente na entrada do relé

$I_{f}$ - Corrente de falta

$I_{\text {inrush }}$ - Corrente de magnetização do transformador

$I_{\text {inrush_s }}$ - Corrente de magnetização no lado secundário do TC

$I_{\text {min CC }}-$ Corrente mínima de curto-circuito

$I_{\text {nom }}$ - Corrente nominal

InO - Corrente nominal do relé diferencial 7UT61 em A 
$I_{\mathrm{np}}$ - Corrente nominal do lado primário em A

$I_{n s}-$ Corrente nominal do lado secundário em A

$I_{N, A T}-$ Corrente nominal no lado de alta tensão

$\mathrm{I}_{\mathrm{N}, \mathrm{BT}}-$ Corrente nominal no lado de baixa tensão

$I_{\text {n-prim-TC1 }}$ - Corrente nominal do TC do lado primário

In-prim-TC2 - Corrente nominal do TC do lado secundário

$\mathrm{I}_{\text {n_prim_TC230kV }}$ - Corrente nominal primária do TC de $230 \mathrm{kV}$

$\mathrm{I}_{\mathrm{n} \_ \text {sec_TC230kV }}$ - Corrente nominal secundária do TC de $230 \mathrm{kV}$

$\mathrm{I}_{\mathrm{N} \_138}-$ Corrente nominal no lado de $138 \mathrm{kV}$

$\mathrm{I}_{\mathrm{N} \_230}-$ Corrente nominal no lado de $230 \mathrm{kV}$

$\mathrm{I}_{\mathrm{N} \_138 \mathrm{~s}}$ - Corrente nominal no lado secundário do TC de $138 \mathrm{kV}$

$I_{N \_230 s}$ - Corrente nominal no lado secundário do TC de $230 \mathrm{kV}$

$I_{\text {Op }}$ - Corrente de operação

$I_{P(T C, A T)}-$ Corrente no primário do TC do lado de alta tensão

$\mathrm{I}_{\mathrm{P}(\mathrm{TC}, \mathrm{BT})}-$ Corrente no primário do TC do lado de baixa tensão

IPick-up_Uı_230p - Ajuste da proteção 50 no lado primário do TC de 230 kV

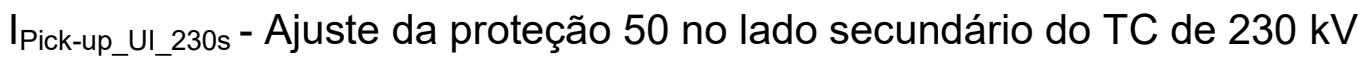

I Pick-up_Uln_230p - Ajuste da proteção 50N no lado primário do TC de 230 kV

IPick-up_UIn_230s - Ajuste da proteção 50N no lado secundário do TC de 230 kV

IPick-up_UT_138p - Ajuste da proteção 51 no lado primário do TC de 138 kV

IPick-up_UT_230p - Ajuste da proteção 51 no lado primário do TC de 230 kV

IPick-up_UT_138s - Ajuste da proteção 51 no lado secundário do TC de 138 kV

IPick-up_Ut_230s - Ajuste da proteção 51 no lado secundário do TC de 230 kV 


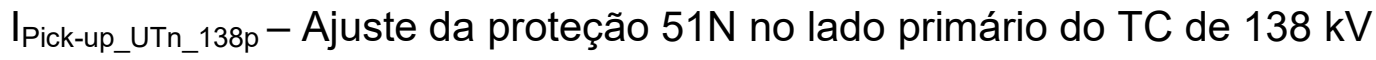

I Pick-up_UTn_230p - Ajuste da proteção $51 \mathrm{~N}$ no lado primário do TC de $230 \mathrm{kV}$

IPick-up_UTn_138s - Ajuste da proteção $51 \mathrm{~N}$ no lado secundário do TC de $138 \mathrm{kV}$

I Pick-up_UTn_230s - Ajuste da proteção 51N no lado secundário do TC de 230 kV

I pick-up_51V - Corrente de pick-up da proteção 51V

$I_{S(T C, A T)}-$ Corrente no secundário do TC do lado de alta tensão

$\mathrm{I}_{\mathrm{S}(\mathrm{TC}, \mathrm{BT})}-$ Corrente no secundário do TC do lado de baixa tensão

$\dot{I}_{\text {reléé }}-$ Corrente medida pelo relé

$I_{\text {Res }}$ - Corrente de restrição

Is - Corrente de pick-up do relé P143

$\dot{I}_{\text {saida }}-$ Corrente que sai do relé

$\mathrm{J}_{\mathrm{A}-\mathrm{sec}}$ - Corrente da fase A no secundário do TC para a proteção diferencial

$\mathrm{J}_{\mathrm{B}-\mathrm{sec}}$ - Corrente da fase B no secundário do TC para a proteção diferencial

$\mathrm{J}_{\mathrm{C}-\mathrm{sec}}$ - Corrente da fase $\mathrm{C}$ secundário do TC para a proteção diferencial

k- Constante que representação o número referente ao deslocamento angular

$K$ - Constante relacionada à capacidade térmica do transformador

$\mathrm{L}$ - Comprimento da linha de transmissão em km

M - Múltiplo do relé

Muı_230kV - Múltiplo da proteção 50 no lado de 230 kV

MUIn_230kV - Múltiplo da proteção $50 \mathrm{~N}$ no lado de 230 kV

$\mathrm{M}_{0}$ - Múltiplo para a corrente de Inrush

$M_{1}$ - Relação entre a corrente e o tap da bobina de restrição 1 
$M_{2}$ - Relação entre a corrente e o tap da bobina de restrição 2

$\mathrm{N}$ - Fator de sobredimensionamento nominal

NF_138kV - Fator de sobredimensionamento no lado de $138 \mathrm{kV}$

NF_230kV - Fator de sobredimensionamento no lado de $230 \mathrm{kV}$

$R_{\text {cond }}-$ Resistência do condutor de $4 \mathrm{~mm}^{2} \mathrm{em} \Omega / \mathrm{km}$

$\mathrm{R}_{\text {contato }}-$ Resistência no local do defeito

$R_{\text {espiras_TC }}-$ Resistência interna do enrolamento do TC/espira

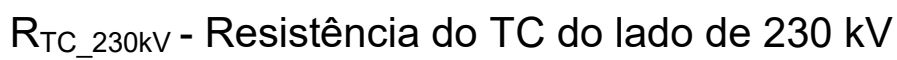

$\mathrm{R}_{\mathrm{TC} \_138 \mathrm{kV}}$ - Resistência do TC do lado de $138 \mathrm{kV}$

RTC, AT - Relação de tensão do TC do lado de alta tensão

RTC, BT - Relação de tensão do TC do lado de baixa tensão

RTC_$_{230 k V}$ - Relação de transformação do TC do lado de $230 \mathrm{kV}$

RTC_138kV - Relação de transformação do TC do lado de $138 \mathrm{kV}$

$R_{+}-$Resistência de sequência positiva em $\Omega$

$\mathrm{R}_{0}$ - Resistência de sequência zero em $\Omega$

$S_{\text {burden }}$ - Consumo de cada TC em VA

$\mathrm{S}_{\text {cond }}$ - Perdas no condutor em VA

$\mathrm{S}_{\mathrm{e}_{1} 138 \mathrm{kV}}-$ Perdas do TC de $138 \mathrm{kV}$ em VA

$\mathrm{S}_{\mathrm{e} \_230 \mathrm{kV}}-$ Perdas do TC de $230 \mathrm{kV}$ em VA

$S_{n}$ - Potência nominal do autotransformador em MVA

$S_{\text {Nominal }}$ - Potência nominal

$S_{\text {relé }}$ - Consumo do relé em VA

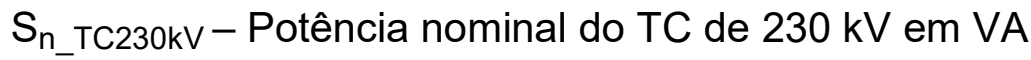


TAP,1 - Tap para a corrente da bobina de restrição 1

$T A P, 2$ - Tap para a corrente da bobina de restrição 2

tatuação do relé - Tempo de atuação do relé

tatuação_UI_230kV - Tempo de atuação da proteção 50 no lado de 230 kV

$t_{\text {atuação_Uln_230kV }}$ - Tempo de atuação da proteção $50 \mathrm{~N}$ no lado de $230 \mathrm{kV}$

$t_{51}(M)$ - Tempo de atuação da proteção 51 para o múltiplo $M$

$t_{51}\left(M_{0}\right)$ - Tempo de atuação da proteção 51 para a corrente de Inrush

$\mathrm{T}_{\text {curva }}-$ Múltiplo da curva de tempo

$T_{\text {curva51 }}$ - Valor da curva de atuação da proteção 51

$\dot{V}_{\mathrm{a}}-$ Fasor de tensão na fase A

$\dot{V}_{\mathrm{b}}-$ Fasor de tensão na fase B

$\dot{V}_{\mathrm{C}}-$ Fasor de tensão na fase C

$\dot{V}_{\mathrm{a} 0}-$ Fasor de tensão de sequência zero na fase A

$\dot{V}_{\text {bo }}-$ Fasor de tensão de sequência zero na fase B

$\dot{V}_{\mathrm{c} 0}-$ Fasor de tensão de sequência zero na fase C

$\dot{V}_{\mathrm{a} 1}-$ Fasor de tensão de sequência positiva na fase A

$\dot{V}_{\mathrm{b} 1}-$ Fasor de tensão de sequência positiva na fase B

$\dot{V}_{\mathrm{c} 1}-$ Fasor de tensão de sequência positiva na fase C

$\dot{V}_{\mathrm{a} 2}-$ Fasor de tensão de sequência negativa na fase A

$\dot{V}_{\mathrm{b} 2}-$ Fasor de tensão de sequência negativa na fase B

$\dot{V}_{\mathrm{c} 2}-$ Fasor de tensão de sequência negativa na fase C

$\mathrm{V}_{\mathrm{np}}-$ Tensão nominal do lado primário em $\mathrm{kV}$ 
$\mathrm{V}_{\mathrm{ns}}-$ Tensão nominal do lado secundário em $\mathrm{kV}$

$V_{\text {relé }}-$ Tensão medida pelo relé

$V_{\text {relé } A}-$ Tensão medida pelo relé do terminal A

$V_{\text {sat_TC230kV }}$ - Tensão de saturação do TC do lado de 230 kV em V

$V_{\text {sat_TC138kV }}$ - Tensão de saturação do TC do lado de $138 \mathrm{kV}$ em V

$\dot{V}_{0}-$ Fasor de tensão de sequência zero

$\dot{V}_{1}-$ Fasor de tensão de sequência positiva

$\dot{V}_{2}-$ Fasor de tensão de sequência negativa

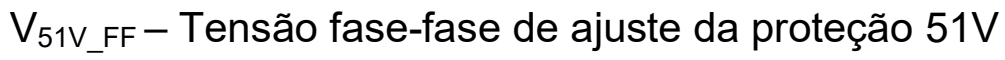

$V_{51 V_{-} F N}-$ Tensão fase-neutro de ajuste da proteção $51 \mathrm{~V}$

X - Reatância subtransitória do gerador síncrono

X' - Reatância transitória do gerador síncrono

X" - Reatância em regime permanente do gerador síncrono

X" ${ }_{d}$ - Reatância subtransitória de eixo direto do gerador síncrono

$X_{0}-$ Reatância de sequência zero

$\mathrm{X}_{+}-$Reatância de sequência positiva em $\Omega$

$X_{1}$ - Reatância de sequência positiva

$X_{2}-$ Reatância de sequência negativa

Y - Conexão em estrela

$\dot{Z}_{0}$ - Impedância de sequência zero

$\dot{Z}_{1}$ - Impedância de sequência positiva

$\dot{Z}_{2}-$ Impedância de sequência negativa

$Z_{L T}$ - Impedância da linha de transmissão 
$Z_{\text {relé 21 }}$ - Impedância vista pelo relé 21

$Z_{\text {relé } 21, A}$ - Impedância vista pelo relé 21 no terminal A

$\dot{\alpha}$ - Operador matemático usado para a transformação das componentes simétricas

$\alpha, \beta, \mathrm{L}, \mathrm{K}$ - Constantes para a curva de tempo inversa

$\Delta$ - Conexão em delta

$\varepsilon_{\text {erro total }}-$ Erro total do relé 87

$\varepsilon_{T C s}$ - Erro devido às relações de transformação dos TCs

$\varepsilon_{\text {classe de exatidão }}-$ Erro referente à classe de exatidão do TC

$\varepsilon_{\text {comutação }}$ - Erro introduzido pela máxima comutação de tap

$\varepsilon_{\text {taps do relé } 87}$ - Erro devido ao tap do relé

$\varepsilon_{\text {segurança }}$ - Margem de segurança

21 - Proteção de distância

24 - Proteção de sobreexcitação

27 - Proteção de subtensão

40 - Proteção contra perda de excitação

50/51 - Proteções de sobrecorrente de fase instantânea/temporizada

59 - Proteção de sobretensão

63 - Proteção Buchholz

67 - Proteção de sobrecorrente direcional

71 - Proteção contra baixo nível de óleo

87 - Proteção diferencial 


\section{LISTA DE ABREVIATURAS}

ANSI American National Standards Institute (Instituto Nacional Americano de Padrões)

CEPEL Centro de Pesquisas de Energia Elétrica

FS Fator de Sobrecorrente

HVDC High Voltage Direct Current (Alta Tensão em Corrente Contínua)

IEC International Electrotechnical Commission (Comissão Eletrotécnica Internacional)

IEEE Institute of electrical and electronics engineers (Instituto de engenheiros elétricos e eletrônicos)

LT Linha de Transmissão

ONS Operador Nacional do Sistema Elétrico

RTC Relação de transformação do Transformador de Corrente

SAPRE Sistema de Análise e Projeto de Redes Elétricas

SE Subestação

SE RP Subestação de Rondonópolis

SEPs Sistemas Elétricos de Potência

SIN Sistema Interligado Nacional

TC Transformador de Corrente

TP Transformador de Potencial

TR Transformador de Potência 


\section{SUMÁRIO}

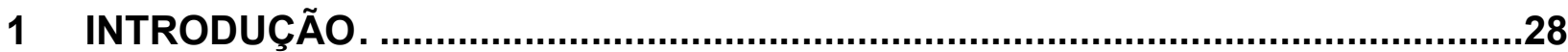

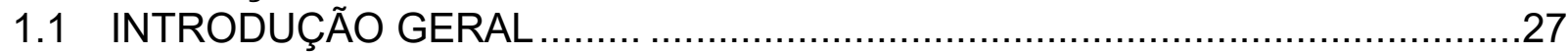

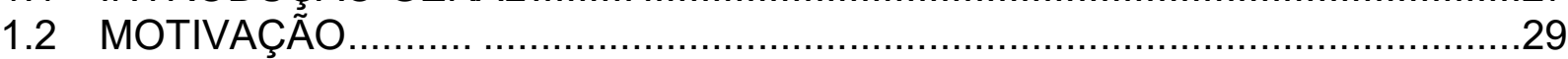

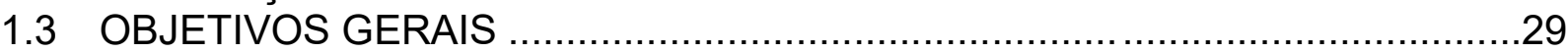

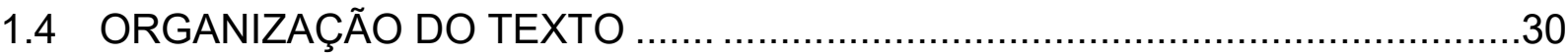

2 PROTEÇÃO DOS SISTEMAS ELÉTRICOS DE POTÊNCIA .................................31

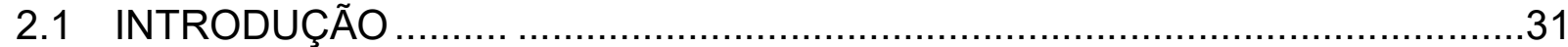

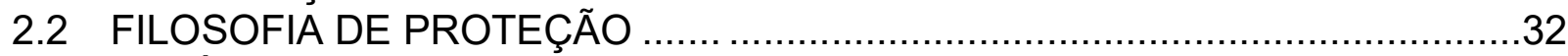

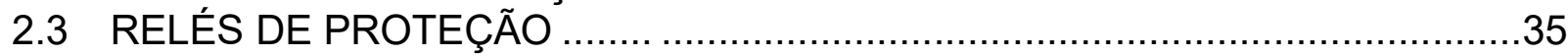

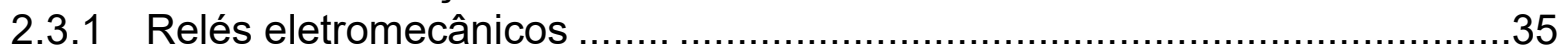

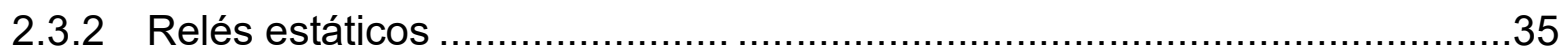

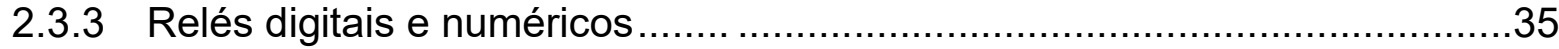

2.4 CARACTERÍSTICAS FUNCIONAIS DOS RELÉS DE PROTEÇÃO …..............36

2.5 FALTAS NOS SISTEMAS ELÉTRICOS DE POTÊNCIA ….............................38

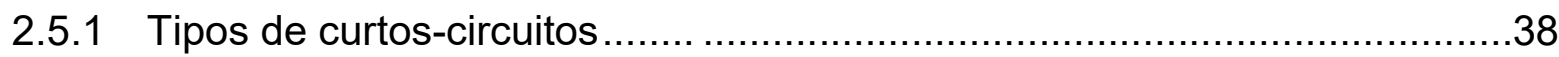

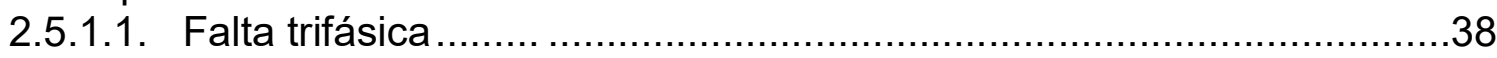

2.5.1.2. Falta bifásica sem envolvimento de terra ........................................39

2.5.1.3. Falta bifásica com envolvimento de terra .......................................40

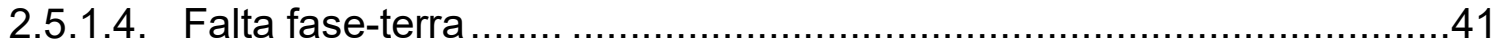

2.5.2 Método das componentes simétricas ................................................43

2.5.3 Impedâncias de sequência dos principais equipamentos dos SEPs ...........46

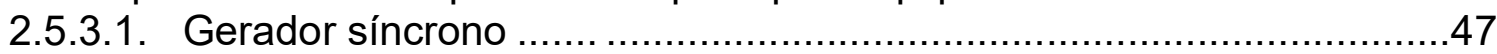

2.5.3.2. Transformadores de potência ....................................................49

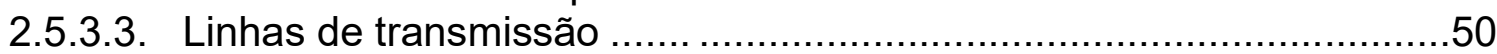

2.6 PROTEÇÃO DOS PRINCIPAIS ELEMENTOS DO SEP ..............................51

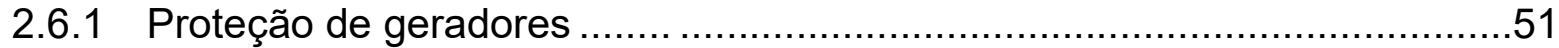

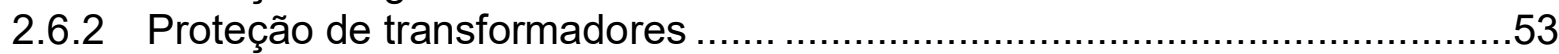

2.6.3 Proteção de linhas de transmissão....................................................54

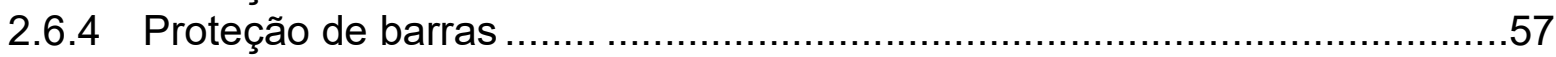

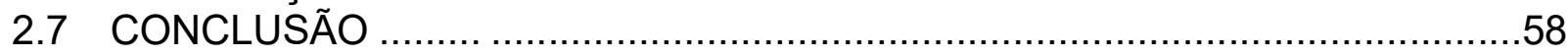

\section{CONCEITOS FUNDAMENTAIS: PROTEÇÕES DE SOBRECORRENTE E}

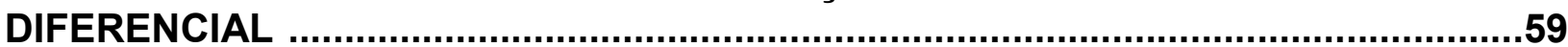

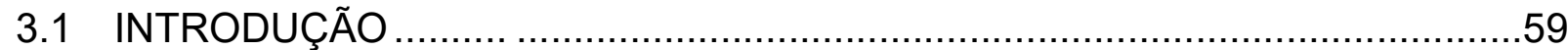

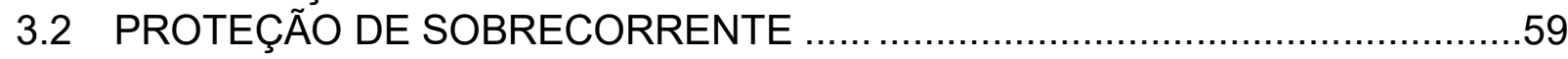

3.2.1 Relé de sobrecorrente instantâneo (50) .............................................60

3.2.2 Relé de sobrecorrente temporizado (51) .........................................60

3.2.2.1. Relé de sobrecorrente de tempo inverso ..................................60

3.2.3 Relé de sobrecorrente com controle de tensão (51V).............................63

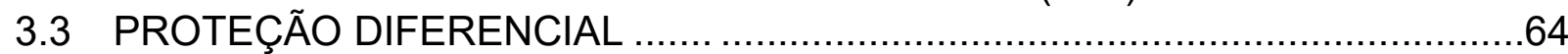

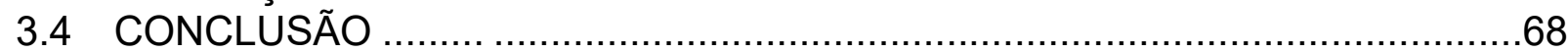

4 METODOLOGIA DE AJUSTE DAS PROTEÇÕES DE SOBRECORRENTE E DIFERENCIAL EM TRANSFORMADORES DE POTÊNCIA .................................69

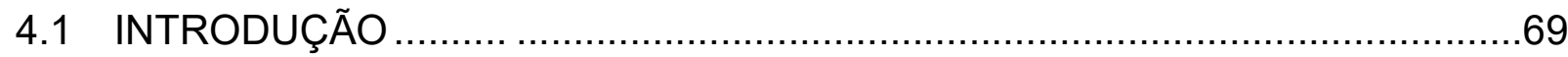


4.2 PROTEÇÃO DE SOBRECORRENTE DE TRANSFORMADORES. 69

4.2.1 Metodologia de ajuste da proteção de sobrecorrente em transformadores ..70

4.3 PROTEÇÃO DIFERENCIAL DE TRANSFORMADORES ..............................73

4.3.1 Metodologia de ajuste da proteção diferencial em transformadores .............79

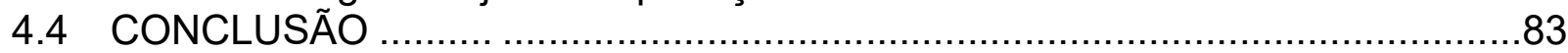

5 RESULTADOS DO ESTUDO DE PROTEÇÃO..................................................84

5.1 ESTUDO DE GRADUAÇÃO DA PROTEÇÃO DOS ATs 230/138/13,8 kV de 100

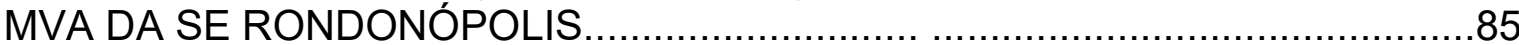

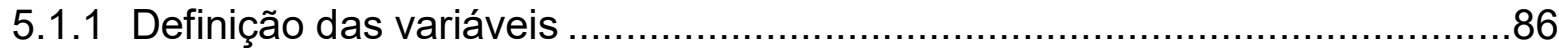

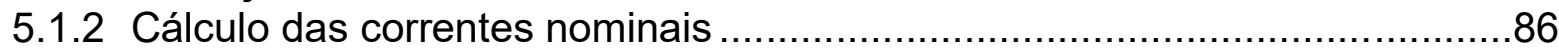

5.1.3 Determinação da relação de transformação do TC do lado de 230 kV .........86

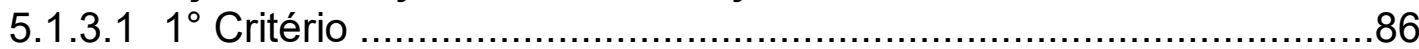

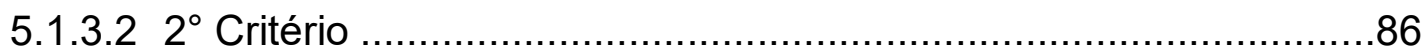

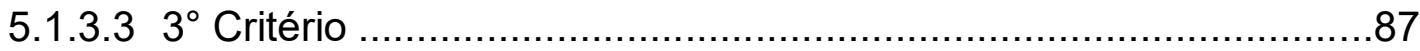

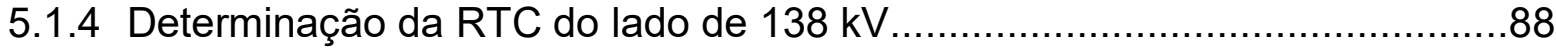

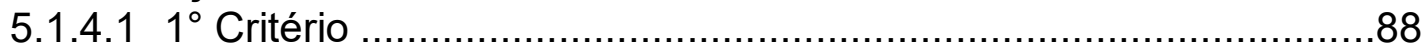

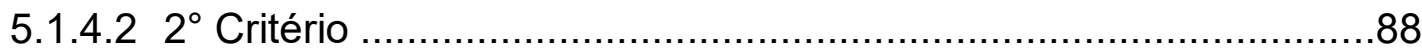

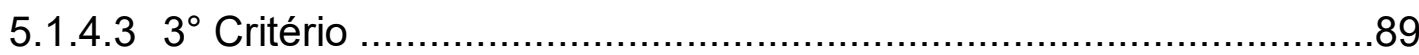

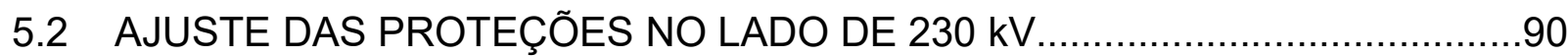

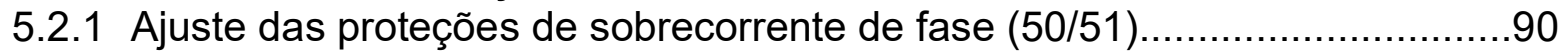

5.2.1.1 Ajuste da unidade de sobrecorrente temporizada (51).................91

5.2.1.2 Ajuste da unidade de sobrecorrente instantânea (50) ....................98

5.2.1.3 Ajuste da proteção de sobrecorrente com controle de tensão

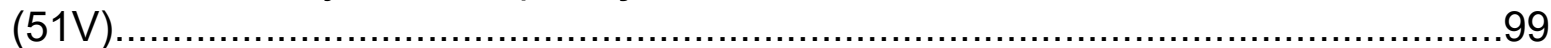

5.2.2 Ajuste das proteções de sobrecorrente de neutro $(50 \mathrm{~N} / 51 \mathrm{~N}) \ldots \ldots \ldots \ldots \ldots \ldots \ldots . .106$

5.2.2.1 Ajuste da unidade de sobrecorrente de neutro temporizada

5.2.2.2 Ajuste da unidade de sobrecorrente de neutro instantânea

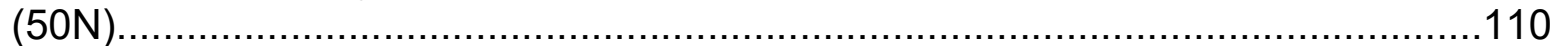

5.3 AJUSTE DAS PROTEÇÕES NO LADO DE 138 kV ..................................110

5.3.1 Ajuste das proteções de sobrecorrente de fase (50/51) ..........................111

5.3.1.1 Ajuste da unidade de sobrecorrente temporizada (51) ................111

5.3.1.2 Ajuste da unidade de sobrecorrente instantânea (50) .................117

5.3.1.3 Ajuste da proteção de sobrecorrente com controle de tensão

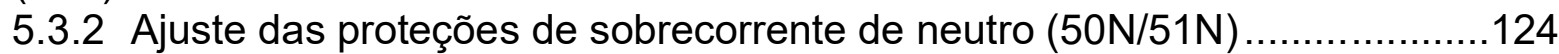

5.3.2.1 Ajuste da unidade de sobrecorrente de neutro temporizada $(51 \mathrm{~N}) 124$

5.3.2.2 Ajuste da unidade de sobrecorrente de neutro instantânea (50N) 128

5.4 AJUSTE DA PROTEÇAO DIFERENCIAL ..............................................129

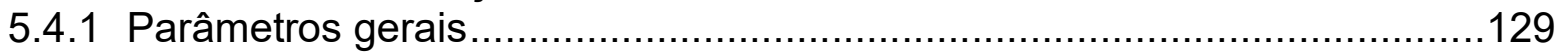

5.4.2 Corrente diferencial e característica de operação....................................129

5.4.3 Restrição por segundo e quinto harmônico...........................................133

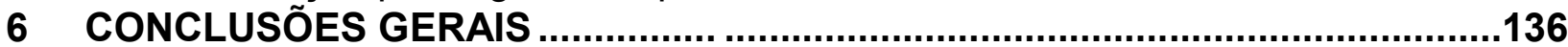

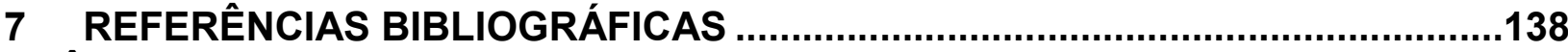

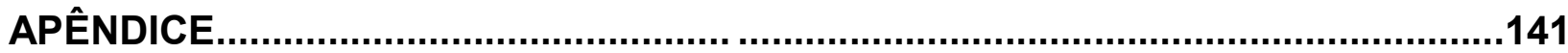




\section{Capítulo 1 INTRODUÇÃo}

\subsection{INTRODUÇÃO GERAL}

O nível de confiabilidade do serviço prestado nos Sistemas Elétricos de Potência (SEPs) para o suprimento e disposição de energia é um dos principais fatores necessários para garantir o desenvolvimento econômico de uma determinada região. Pode-se dizer que um Sistema Elétrico de Potência é basicamente constituído pela geração, transmissão e distribuição de energia elétrica [1].

As usinas geradoras estão em pontos estratégicos, próximas dos recursos naturais. No caso do Brasil, em que a matriz energética é basicamente proveniente das hidroelétricas, elas estão principalmente perto de rios e de formações de água. Entretanto, o nível de tensão gerado nestas usinas é muito baixo e economicamente inviável de ser transmitido a longas distâncias. Com isso, é necessário o uso de transformadores que apresentam a função de elevar o nível de tensão, de dezenas para centenas de quilovolts $(\mathrm{kV})$. Por fim, as linhas de transmissão são responsáveis por transportar a energia elétrica por todo o Sistema Interligado Nacional (SIN), em alta tensão, a fim de distribuir atendendo aos grandes centros de consumo, em média e baixa tensão [2].

No intuito de minimizar as horas perdidas no atendimento dos clientes consumidores de energia devido às falhas ocasionadas nas redes elétricas, o sistema deve apresentar um alto nível de segurança. Para isso, os esquemas de proteção das linhas de transmissão e dos equipamentos deverão estar configurados para atuarem de forma bastante rápida, eliminando assim as falhas no menor tempo possível para que não interfiram no suprimento do produto aos consumidores [1].

No Brasil, cabe ao Operador Nacional do Sistema Elétrico (ONS) definir o tempo de atuação para a eliminação das faltas pelos equipamentos de proteção, estando na ordem de milissegundos $(m s)$ para que não haja perda de estabilidade no sistema, danos nos equipamentos e interrupção no fornecimento de energia.

Devido as suas dimensões físicas e por se estenderem por todo o país, as linhas de transmissão são mais suscetíveis às falhas. Geralmente as principais causas de 
desligamento de uma linha de transmissão são as descargas atmosféricas, queimadas, deterioração dos isolamentos e vandalismos (furtos). O valor da corrente de falta numa linha de transmissão é bastante elevado e, se não eliminada, pode vir a causar danos aos outros componentes do sistema, como os transformadores e geradores. Portanto, é necessário que o esquema de proteção desconecte qualquer elemento sob falha evitando que a corrente de falta não danifique os elementos adjacentes [3].

Dentre os elementos citados, os geradores nas estações geradoras e os transformadores de potência, por serem considerados equipamentos essenciais de uma geração ou subestação, merecem um contínuo monitoramento e rápida proteção. Uma falta interna no gerador ou no transformador pode causar sérios danos e consequente perda de estabilidade no sistema. No intuito de evitar as interrupções de energia no sistema, são utilizados diferentes esquemas para a proteção dos geradores e transformadores. Dentre as principais proteções utilizadas, podemos destacar a proteção diferencial, capaz de detectar se uma falta é interna ou externa ao elemento protegido, as proteções de sobrecorrentes, instantâneas e temporizadas, e a proteção por aumento de pressão e gás Bulchholz [4].

Além disso, os relés são outros equipamentos importantes para a proteção dos sistemas elétricos pelo fato de serem os dispositivos responsáveis por responderem as condições de entradas especificadas ou por mudanças abruptas (elétrica, mecânica, térmica, etc) nos elementos protegidos. Juntamente com os disjuntores, os relés de proteção são responsáveis por desligar os equipamentos defeituosos que sofreram um curto-circuito ou que está operando em condições anormais [5].

Atualmente, com o avanço da tecnologia e dos softwares de simulação, é possível realizar estudos detalhados dos efeitos causados nos sistemas elétricos ao operar em condições normais ou anormais (sob curto-circuito ou nas variações de carga) e, sempre que necessário, observar as condições de operação do sistema no caso de possíveis expansões [6]. 


\subsection{MOTIVAÇÃO}

Diante do exposto, torna-se evidente a motivação do estudo da proteção de sistemas elétricos, sendo aqui centrada na proteção de transformadores de potência. Foi escolhido o transformador devido à sua importância crucial tanto na geração como na transmissão de energia. Geralmente, o critério adotado para os ajustes das proteções diferencial e de sobrecorrente, instantânea e temporizada, se baseia no cálculo das correntes de falta. Embora possam usar-se igualmente proteção contra gases, temperatura, nível de óleo, etc. Por meio disso, será tomado como base um determinado sistema de potência real que necessita da parametrização e ajuste da proteção de um transformador de potência.

As ferramentas computacionais a serem utilizadas serão basicamente os softwares de cálculo das correntes de curto circuito, de ajuste do relé de proteção e de aquisição e leitura de oscilografias. Primeiramente, o sistema elétrico analisado será modelado no software SAPRE do CEPEL, onde será possível obter os valores das correntes de falta. Os relés de proteção utilizados são os dispositivos SIPROTEC 4 7UT61 da SIEMENS, onde serão ajustadas a proteção diferencial, e o relé P143 da ALSTOM, para o ajuste das proteções de sobrecorrente. Para a realização dos testes, será utilizada a mala OMICRON CMC 256-6 juntamente com seu software Test Universe que contempla alguns módulos de testes, como por exemplo, Overcurrent, Diferencial, Harmonics, respectivamente para os testes das proteções de sobrecorrente, diferencial e para o bloqueio de harmônicos. Por fim, será utilizada a ferramenta Transview, também disponível no software Test Universe, para a visualização e leitura das oscilografias dos testes.

\subsection{OBJETIVOS GERAIS}

Como mencionado anteriormente, o principal objetivo deste trabalho é apresentar a fundamentação teórica e o cálculo das correntes de falta a serem utilizadas para a parametrização e ajuste do relé de proteção de um transformador, mais especificamente, as proteções diferencial e de sobrecorrente.

Além disso, como objetivos específicos, considera-se dado um sistema, obter:

- As correntes de curto circuito para ajuste das proteções. 
- Os ajustes do relé de proteção do transformador.

- Teste do bloqueio por $2^{\circ}$ e $5^{\circ}$ harmônico da proteção diferencial.

\subsection{ORGANIZAÇÃO DO TEXTO}

- No capítulo 2, serão apresentados os conceitos básicos dos sistemas de proteção e dos tipos de faltas, além de uma abordagem sobre as proteções mais utilizadas nos principais elementos de um sistema elétrico.

- No capítulo 3, serão apresentados os conceitos fundamentais das proteções diferencial e de sobrecorrente de um transformador de potência.

- No capítulo 4, será de fato abordada como é feita a aplicação e os ajustes das proteções de sobrecorrente e diferencial para os transformadores de potência.

- No capítulo 5, serão apresentados os resultados do estudo de proteção dos transformadores de potência do sistema elétrico real estudado. 


\section{Capítulo 2 PROTEÇÃO DOS SISTEMAS ELÉTRICOS DE POTÊNCIA}

\subsection{INTRODUÇÃO}

As principais características que um sistema de potência deve apresentar é o fornecimento da energia elétrica, de forma segura e eficaz, satisfazendo todas as exigências de seus clientes consumidores. A transmissão é responsável por transferir grandes blocos de energia dos centros geradores para os centros de carga através das distribuidoras de energia, que também fazem o papel de atender aos consumidores finais.

Os sistemas de transmissão de energia possuem níveis que vão de 138 kV a 1250 $\mathrm{kV}$, variando a classe de acordo com cada país. Assim, no Brasil os sistemas de alta tensão que transportam grandes quantidades de energia operam na faixa de $230 \mathrm{kV}$ atingindo o valor de $745 \mathrm{kV}$ em corrente alternada. Entretanto, há um grande avanço no transporte de energia por corrente contínua (HVDC) que atinge maiores valores de tensão, chegando a $745 \mathrm{kV}$.

Devido à sua forma operacional, o sistema elétrico brasileiro é denominado Sistema Interligado Nacional (SIN), onde a transmissão de energia é operada de forma interconectada, permitindo a transferência de energia entre os diversos subsistemas e a integração dos recursos de geração e transmissão de forma mais econômica e segura. $\mathrm{Na}$ Figura 1 mostra-se o Sistema Interligado Nacional Brasileiro. 


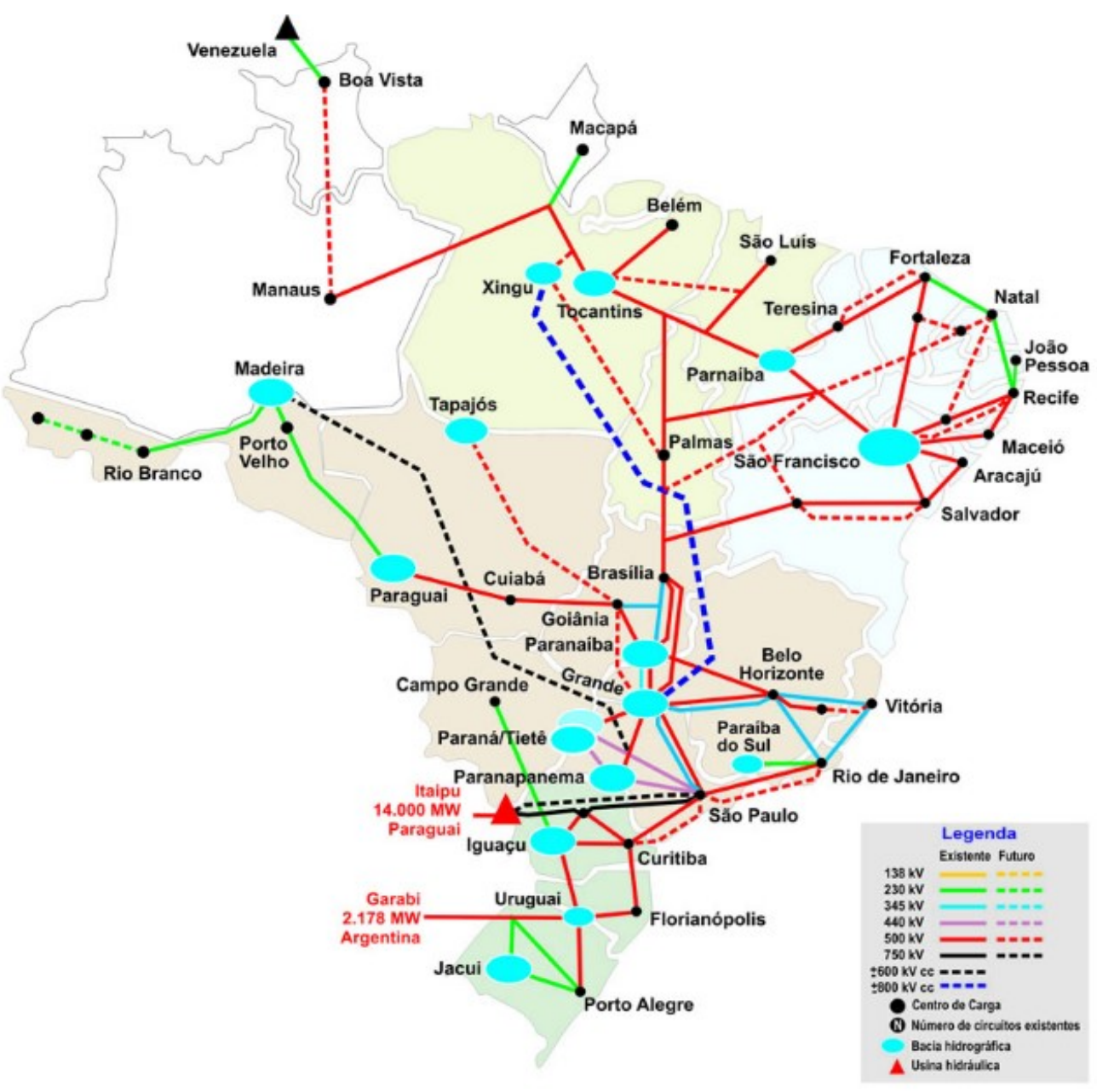

Figura 1 - Mapa do Sistema Interligado Nacional [7].

\subsection{FILOSOFIA DE PROTEÇÃO}

Segundo [5], para manter a continuidade do serviço, os sistemas de energia elétrica devem sempre operar de forma a garantir a continuidade do serviço, minimizando o tempo de interrupção nas condições intoleráveis. Dentre essas condições anormais podem-se citar os eventos naturais, os acidentes físicos, as falhas nos equipamentos e os erros operacionais humanos.

As principais causas de faltas nos sistemas elétricos devido aos eventos naturais são ocasionadas por raios (de forma direta ou por indução de tensão), por ventos, terremotos, queimadas, aves e etc. Há também os casos de interrupção do serviço devido aos acidentes envolvendo a colisão de veículos nos postes de energia ou até de seres vivos em contato com os equipamentos vivos, além de outras causas. Percebe-se então que há a possibilidade somente de minimizar os possíveis danos causados no 
sistema, porém é impossível a eliminação de todas as fontes desses problemas, visto que muitas delas são naturais.

Portanto, os sistemas de proteção têm a função de manter, de forma bastante rápida, o isolamento da área afetada pela falta, sendo que o restante do sistema ainda continue em operação. Os sistemas de proteção são constituídos por equipamentos e esquemas adequados, envolvendo relés, transformadores de corrente e de tensão, seccionadores e disjuntores. Obviamente, para a operação destes equipamentos precisam-se dos serviços auxiliares, onde geralmente encontram-se as baterias e os fusíveis. A Figura 2 mostra o esquemático do circuito para a proteção de um transformador de potência. No caso de um defeito, os relés de proteção (87A, 87B, 87C) são sensibilizados fazendo com que a bobina do relé de bloqueio (86) seja energizada, promovendo então a abertura do disjuntor e acionamento de outras funções, como por exemplo, as sinalizações e os alarmes. [30]

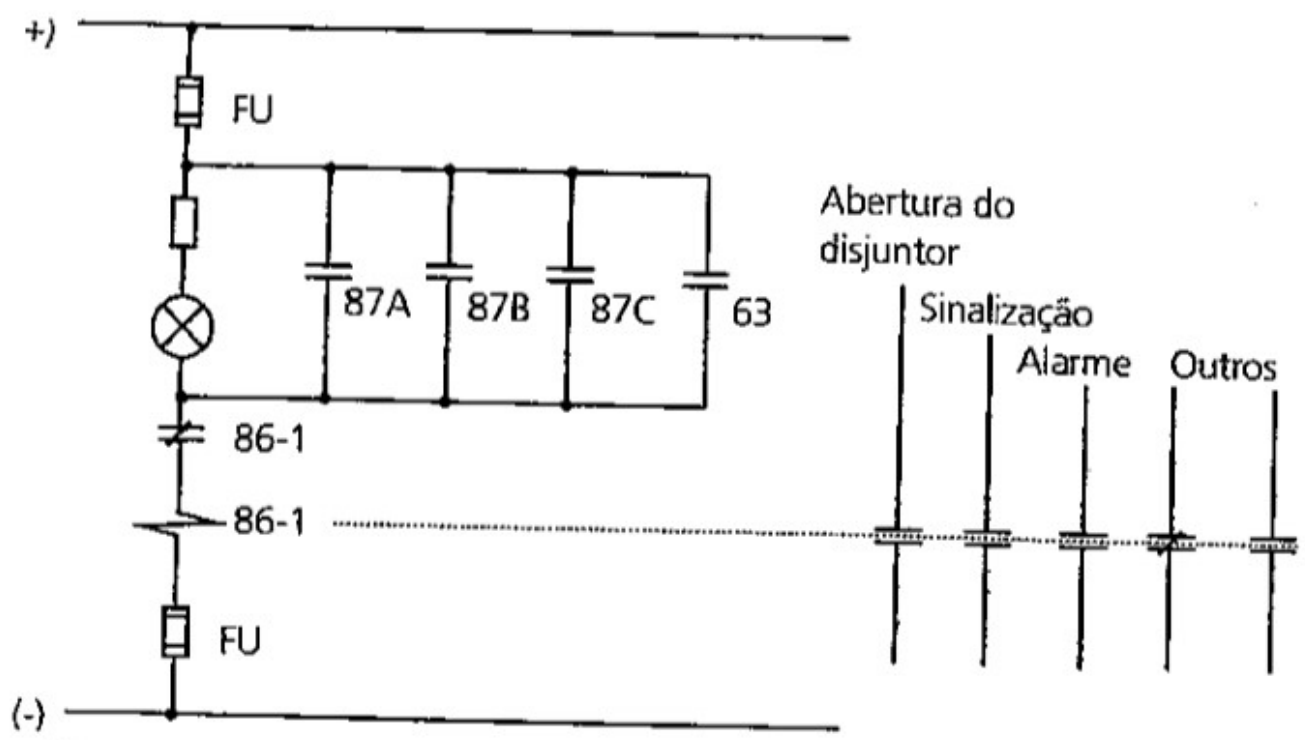

Figura 2 - Esquemático simplificado para a proteção de um transformador de potência. [30]

Por meio do comando dos relés de proteção, os disjuntores são acionados para desligarem o elemento que está em defeito. Ambos os equipamentos estão geralmente localizados, de uma forma geral, entre os geradores, transformadores, os barramentos e as linhas de transmissão. Além disso, os relés são responsáveis por medir a corrente de curto circuito, cabendo aos disjuntores à interrupção dessas correntes. 
A Figura 3 apresenta a disposição dos elementos que protegem um sistema de transmissão radial de energia elétrica. É possível observar que eles protegem cada componente do sistema para que nos casos de curto circuito, o elemento defeituoso seja retirado dos demais. Constata-se que existem zonas de proteção para cada elemento, a fim de que se houver uma falha dentro de determinada zona, haverá a abertura somente dos disjuntores desta zona [8].

Além disso, pode-se questionar o fato de que no caso de uma falha onde há zonas adjacentes e, consequentemente, regiões sobrepostas, haverá o trip de apenas um disjuntor a fim de eliminar o defeito. Eventualmente, dependendo da configuração do sistema de proteção pode ocorrer a operação de dois ou mais disjuntores. Neste caso, podem atuar apenas a proteção de uma ou das duas zonas havendo então a sobreposição de proteções. O uso da sobreposição de proteções nos sistemas elétricos é pequeno, pois dificilmente uma proteção principal falha na atuação. Nota-se que as zonas de proteção sobrepõem os disjuntores da zona adjacente com intuito de que o relé de proteção mande o sinal de trip não apenas para o seu disjuntor, mas também para o disjuntor da zona adjacente, a fim de que a falha seja totalmente eliminada. [8]

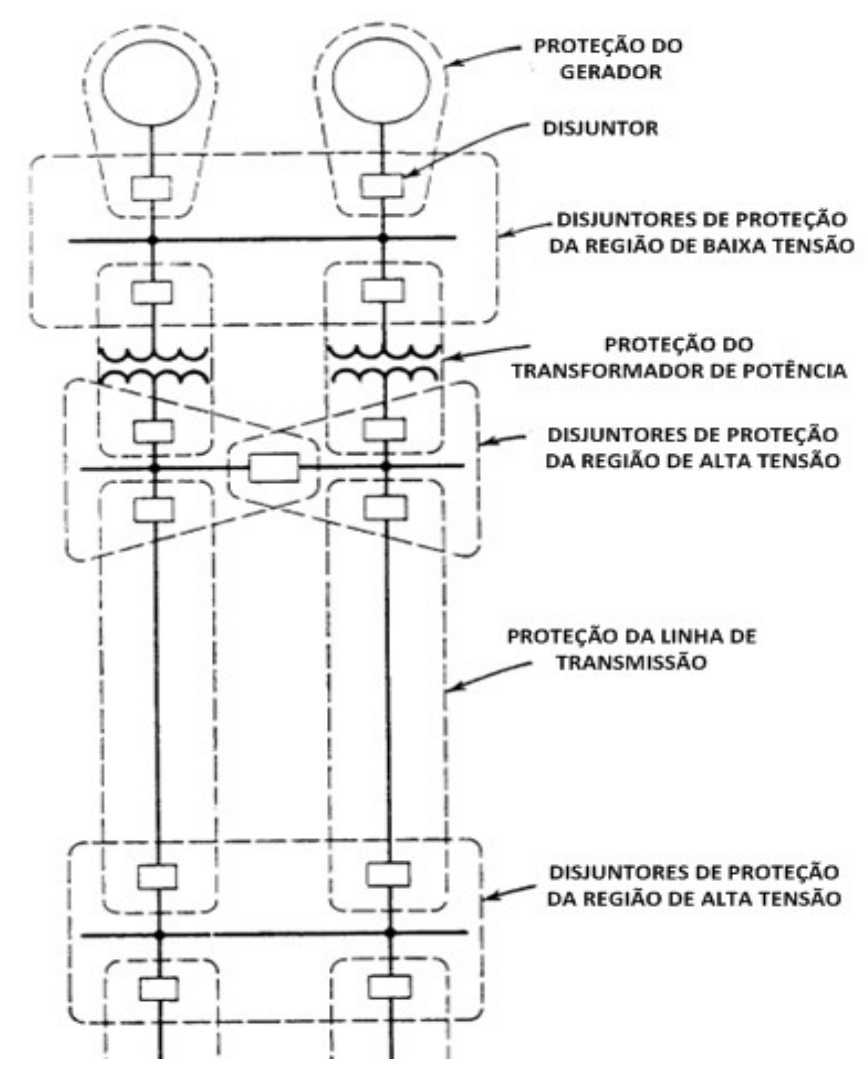

Figura 3 - Diagrama unifilar dos componentes de um sistema de energia elétrica radial [8]. 


\subsection{RELÉS DE PROTEÇÃo}

Os dispositivos primordiais dos sistemas de proteção são os relés. De acordo com a tecnologia empregada, os relés de proteção podem ser classificados como eletromecânicos, analógicos, digitais e numéricos. No intuito de garantir a velocidade ideal de atuação do sistema de proteção, foi necessário o desenvolvimento de relés que apresentam diversas funções para a medição das quantidades das variáveis do sistema elétrico expressas de forma gráfica ou matemática.

Nas próximas seções descrevem-se os três principais tipos de relés.

\subsubsection{Relés eletromecânicos}

Há mais de 100 anos, foram os primeiros relés a serem empregados para a proteção dos sistemas elétricos. O princípio de funcionamento é baseado na força mecânica que provoca o acionamento de um contato do relé em resposta ao estímulo. Esta força é proveniente do fluxo de corrente que flui nos enrolamentos do núcleo magnético. O uso deste tipo de relé é considerado obsoleto, mas é importante mencionar a sua principal vantagem de operar de forma segura e econômica, fazendo com que ainda haja a sua utilização nos casos de simples comutações de contatos [2].

\subsubsection{Relés estáticos}

Os relés estáticos, que foram introduzidos no início da década de 1960, se baseiam no uso de dispositivos eletrônicos analógicos, diferentemente dos relés eletromecânicos que utilizam bobinas e ímãs. Inicialmente, utilizavam-se dispositivos discretos, como por exemplo, transistores, diodos, resistores, capacitores, mas com o avanço da eletrônica, foi permitida a utilização de circuitos integrados lineares e digitais permitindo assim os processamentos de sinais e a implementação de funções lógicas. [3]

\subsubsection{Relés digitais e numéricos}

Com a utilização de microcontroladores e microprocessadores, os relés digitais substituíram os circuitos analógicos utilizados nos relés estáticos. Basicamente, esses relés usam a conversão analógica - digital das medidas do sistema elétrico para serem 
utilizadas nos algoritmos de proteção dos relés. Entretanto, devido à limitação do processamento e da memória dos microprocessadores, esses equipamentos apresentam certas restrições com relação às funções de proteção, como por exemplo, o número limitado de amostras medidas por ciclo, podendo interferir nos tempos de operação. Por isso, essa tecnologia está sendo substituída pelos relés numéricos que nada mais é do que um avanço dos relés digitais [2].

\subsection{CARACTERÍSTICAS FUNCIONAIS DOS RELÉS DE PROTEÇÃO}

No item 2.1 foi mencionado que os sistemas de potência são divididos em zonas, sendo que em cada uma delas haverá um grupo de relé para a sua proteção. Além disso, para projeto de um sistema de proteção eficiente é necessário que cada grupo de relé apresente os seguintes critérios funcionais:

\section{a) Confiabilidade e segurança}

O primeiro critério está relacionado com o grau de certeza de que haverá o funcionamento correto no caso de um problema no sistema, enquanto que o segundo representa o grau de certeza de que a atuação do relé não será incorreta. Geralmente, é possível que esses dois aspectos se contraponham, pois no intuito de se aumentar a segurança de um sistema, o nível de confiabilidade tende a diminuir, e vice-versa. Atualmente, os relés fabricados são altamente confiáveis e seguros devido às supervisões contínuas, o uso de técnicas numéricas e dos testes realizados em laboratórios [9].

\section{b) Seletividade}

Além da atuação dos relés em sua zona de proteção principal, pode haver também a atuação correta fora desta zona, sendo que este tipo de atuação é chamado de proteção de retaguarda. Assim, no processo de configuração é necessário parametrizar o relé de proteção para que atue de forma mais rápida na sua zona principal, mas com certo tempo de atraso nas zonas de retaguarda. Logo, pode-se observar que o conjunto de relés poderá atuar nas áreas excedidas, também chamadas de sobrealcance, tanto de forma primária como por retaguarda [5]. 


\section{c) Velocidade}

Segundo [9], é a capacidade do relé de enviar sinais para que a proteção atue e, assim, isole a zona o mais rápido possível. É necessário salientar que o desenvolvimento de relés muito rápidos pode interferir nos casos em que a operação é indesejada ou desnecessária, sendo o tempo um critério bastante relevante para distinguir os tipos de problema. É importante mencionar de que quando se fala em alta velocidade, o tempo de atuação não deve exceder $50 \mathrm{~ms}$. Já nos casos de atuação instantânea, não existe nenhum tempo de atraso que interfira na operação.

\section{d) Desempenho e economia}

O custo é sempre um dos fatores mais importantes para o projeto de um determinado sistema que visa à máxima proteção. Portanto, um custo mínimo inicial para o projeto deste sistema deve ser bastante avaliado, pois poderá acarretar em maiores custos e dificuldades nos processos de instalação, operação e manutenção. Por exemplo, se as zonas do sistema forem bem definidas, teremos como consequência uma maior seletividade, porém maior custo para isto. O mesmo vale para o conjunto de relés com alta velocidade de atuação, que proporcionam uma maior continuidade para o serviço, reduzindo o perigo de falhas dos equipamentos, mas apresentando um custo inicial bastante elevado [9]

\section{e) Simplicidade}

É recomendável que o sistema de proteção seja mantido na sua forma mais simples. Portanto, cada componente que não seja necessariamente básico ao sistema de proteção deverá ser analisado minuciosamente antes de ser adicionado ao sistema devido ao fato de se tornar mais uma fonte de problemas e de manutenção. Entretanto, vale lembrar que nem sempre um sistema de proteção mais simples será o mais econômico.

Além dos relés, um aspecto de grande importância nos sistemas elétricos diz respeito às severidades dos fenômenos naturais e do próprio sistema que originam as faltas nos SEPs. Assim, apresentam-se a seguir os conceitos de faltas nos SEPs e as impedâncias de sequência dos geradores, transformadores e linhas de transmissão. 


\subsection{FALTAS NOS SISTEMAS ELÉTRICOS DE POTÊNCIA}

Nos SEPs a análise de faltas é de suma importância para os estudos de proteção. Geralmente, os curtos-circuitos ocorrem nos casos de falha no isolamento dos equipamentos, na contaminação dos isoladores, no contato dos condutores sob potenciais diferentes, de forma direta (metálica) ou indireta (arco voltaico) [6]. O valor da corrente de curto-circuito será resultado dos valores de tensão interna da máquina síncrona e das impedâncias entre a máquina e a falta.

Com o intuito de evitar maiores danos ao sistema e a danificação de equipamentos, realizam-se os estudos de curto-circuito a fim de dimensionar os diversos equipamentos do sistema para quando estiverem sujeitos aos efeitos térmicos e dinâmicos provenientes de faltas, além de auxiliar na seleção dos disjuntores e na capacidade de sua câmara de extinção de arco-elétrico, na coordenação dos relés de proteção e das especificações de para-raios.

Dentre as principais causas de curtos-circuitos nos sistemas de potência, podemos citar as descargas atmosféricas, falhas na cadeia de isoladores, poluição, queimadas, vegetação, animais em contato com os equipamentos, vandalismo, fadiga nos equipamentos, manobras incorretas [10].

\subsubsection{Tipos de curtos-circuitos}

Os curtos-circuitos nos sistemas elétricos podem ser classificados como simétrico e assimétrico. O primeiro abrange o tipo de falta que não provoca desequilíbrio no sistema, pois neste caso que os condutores apresentam o mesmo valor eficaz para a corrente de curto-circuito. Já no segundo caso, o curto é desequilibrado sendo necessária a utilização do método de componentes simétricas para efetuar os cálculos. A seguir, são apresentados os tipos de curtos-circuitos existentes.

\subsubsection{Falta trifásica}

É um tipo de curto-circuito em que as correntes estão equilibradas, portanto, é um tipo de curto simétrico. Na Figura 4 mostram-se as representações dos curtos- 
circuitos trifásicos, com envolvimento ou não de terra. Nos cálculos das correntes de falta, utilizam-se somente os circuitos equivalentes de sequência positiva, como pode ser observado na Figura 5. Além disso, vale lembrar que neste tipo de falta não há diferença se o curto envolve ou não o neutro (ou terra). Os fasores de tensão $\left(\dot{V}_{\mathrm{a}}, \dot{V}_{\mathrm{b}} \mathrm{e}\right.$ $\dot{V}_{\mathrm{c}}$ ) são iguais a zero nessa condição.
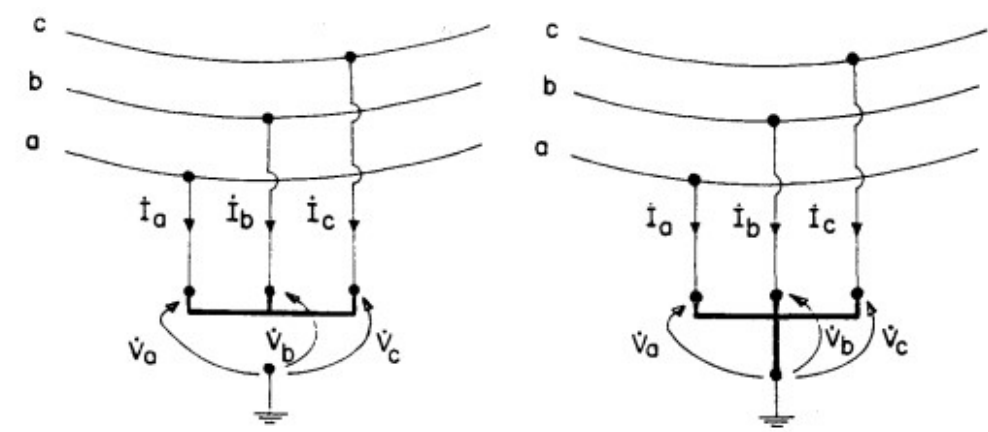

Figura 4 - Representação do curto-circuito trifásico [11].

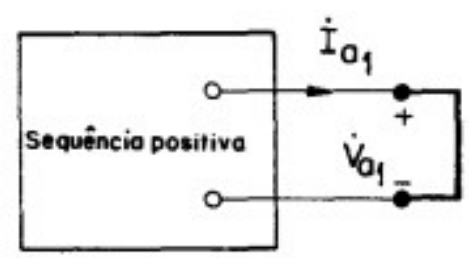

Figura 5 - Modelo de sequência positiva utilizado para os cálculos de curto trifásico [11].

\subsubsection{Falta bifásica sem envolvimento de terra}

É um tipo de curto-circuito assimétrico, portanto deve ser utilizado o modelo de componentes simétricas para o cálculo das correntes de falta. Na Figura 6 mostra-se a representação deste tipo de falta.

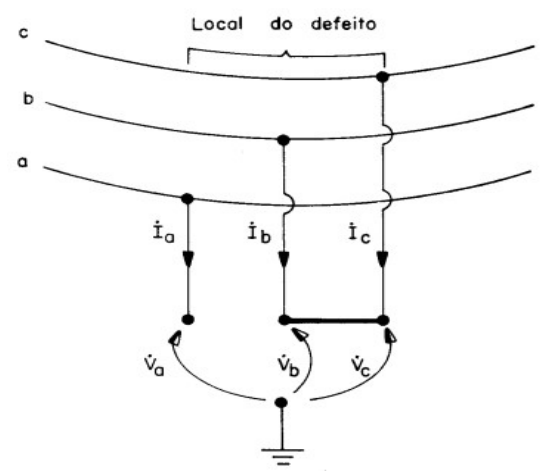

Figura 6 - Representação do curto-circuito bifásico sem envolvimento de terra [11]. 
Como não há envolvimento de terra, não é necessário utilizar a componente de sequência zero, apenas a conexão em paralelo dos modelos de sequência positiva e negativa, como mostra a Figura 7.

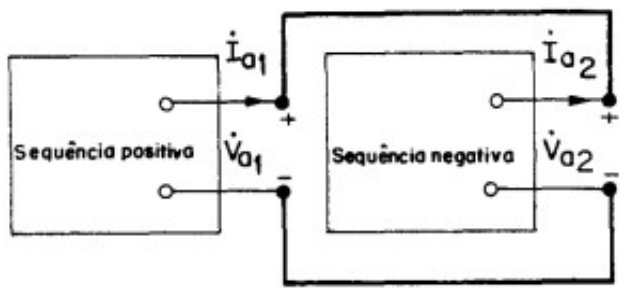

Figura 7 - Modelo de sequência positiva e negativa em paralelo para os cálculos de curto bifásico sem envolvimento de terra [11].

Se considerar que o curto-circuito envolve as fases $\mathrm{B}$ e $\mathrm{C}$, temos as seguintes condições:

$$
\begin{gathered}
\dot{I}_{b}+\dot{I}_{c}=0 \\
\dot{V}_{b}=\dot{V}_{c}
\end{gathered}
$$

\subsubsection{Falta bifásica com envolvimento de terra}

O curto-circuito bifásico a terra é também de natureza assimétrica. Devido ao envolvimento da terra, nos cálculos das correntes de curto são utilizados os circuitos equivalentes de sequência positiva, negativa e zero. Para uma falta entre as fases $B$ e C com contato a terra, teremos as seguintes condições:

$$
\begin{gathered}
\dot{I}_{a}=0 \\
\dot{I}_{b}+\dot{I}_{c}=3 \dot{I}_{a 0} \\
\dot{V}_{b}=\dot{V}_{c}=0
\end{gathered}
$$

Nas Figuras 8 e 9 mostram-se a representação desse tipo de falta e a conexão das redes de sequência. 


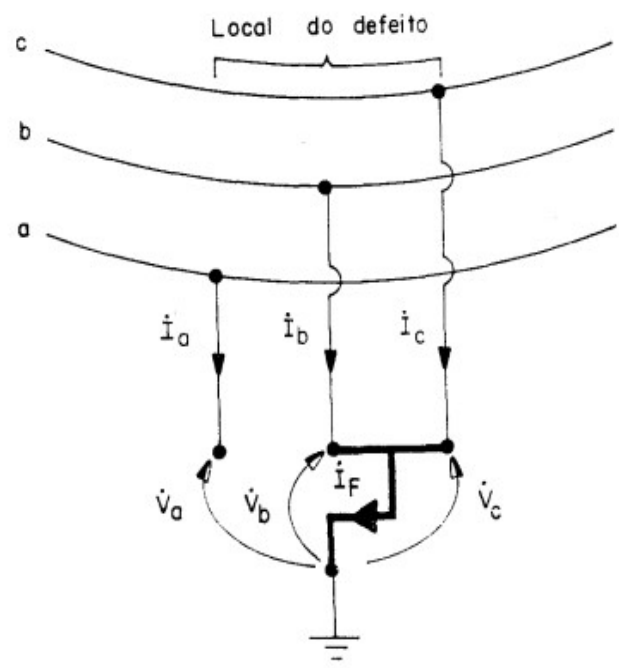

Figura 8 - Representação do curto-circuito bifásico- terra [11].

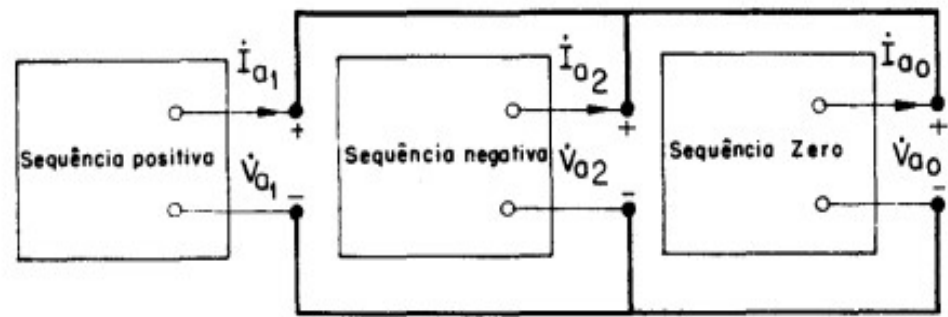

Figura 9 - Modelos de sequência positiva, negativa e zero conectados em paralelo para os cálculos de curtos-circuitos bifásicos-terra [11].

\subsubsection{Falta fase-terra}

Por último, a falta que apresenta menor grau de severidade é a falta monofásica a terra, porém sendo a mais comum nos SEPs. Esse é um tipo de defeito assimétrico. $\mathrm{Na}$ modelagem das redes, os circuitos de sequência positiva, negativa e zero são conectados em série, como mostra a Figura 10.

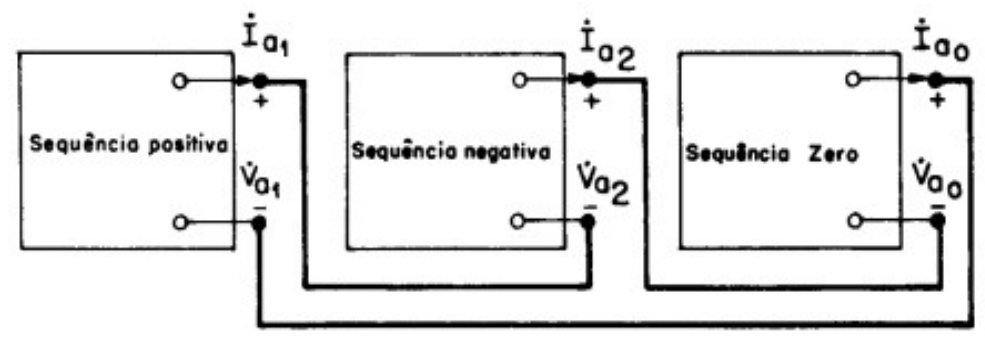

Figura 10 - Modelos de sequência positiva, negativa e zero conectados em série para os cálculos de curtos-circuitos monofásicos-terra [11]. 
Na Figura 11 apresenta-se a representação de uma falta monofásica a terra. Nesta figura, a falta ocorre na fase A com interação a terra, portanto, teremos as condições abaixo:

$$
\begin{gathered}
\dot{I}_{b}=\dot{I}_{c}=0 \\
\dot{V}_{a}=0
\end{gathered}
$$

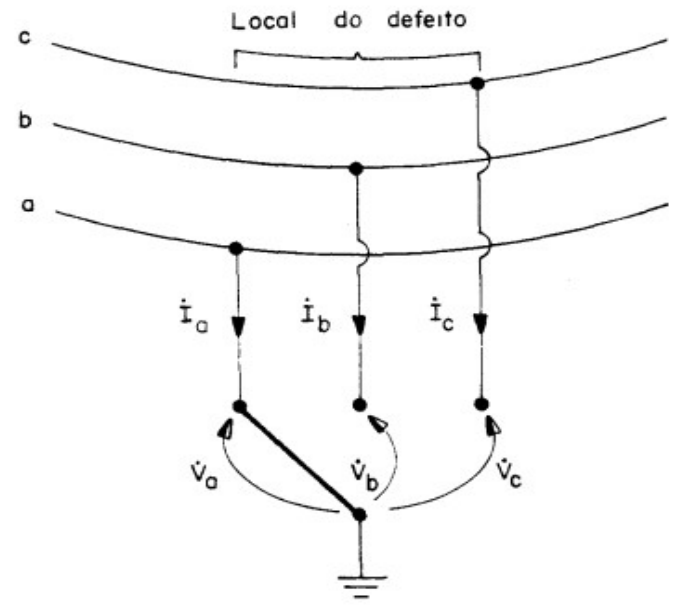

Figura 11 - Representação do curto-circuito monofásico-terra [11].

A Tabela 2.1 apresenta as porcentagens médias das ocorrências para os quatros tipos de curtos-circuitos mencionados anteriormente. Devido à sua natureza física, as faltas trifásicas são as mais raras. Os curtos-circuitos monofásicos são os mais frequentes, normalmente provocados por descargas atmosféricas, queimadas, vegetações, dentre outros tipos de causas envolvendo apenas uma das fases do sistema.

Tabela 2.1 - Porcentagem das ocorrências dos curtos-circuitos [11].

\begin{tabular}{|c|c|}
\hline Tipos de curtos-circuitos & Ocorrências (\%) \\
\hline Trifásicos & 06 \\
\hline Bifásicos & 15 \\
\hline Bifásicos à terra & 16 \\
\hline Monofásicos & 63 \\
\hline
\end{tabular}




\subsubsection{Método das componentes simétricas}

Para os estudos de proteção, o modelo mais adequado para os cálculos das correntes de curto-circuito é a utilização de componentes simétricas. Nos casos de curtos-circuitos simétricos, os cálculos podem ser realizados utilizando os valores por fase. Porém, para as faltas assimétricas, haverá um desequilíbrio no sistema o que torna inviável o cálculo se utilizadas as Leis de Kirchhoff, sendo recomendável o método das componentes simétrico estudo primeiramente por C.L. Fortescue.

Portanto, pelo Teorema de Fortescue, um sistema desequilibrado de $n$ fasores pode ser resolvido em $n$ grupos de fasores equilibrados. Logo, as correntes de um sistema trifásico desequilibrado com sequência de fase a, b e c, podem ser divididas em outros três grupos com fasores simétricos produzidos por três campos magnéticos: dois deles girando em direções opostas e o terceiro estático [11].

a) Sistema trifásico de sequência positiva: é um sistema trifásico balanceado cuja defasagem é de $120^{\circ}$ e os fasores estão na mesma sequência de fase que o sistema desequilibrado original. Logo, os fasores giram na velocidade síncrona que o sistema original.

b) Sistema trifásico de sequência negativa: é um sistema trifásico balanceado que gira na sequência de fase contrária a do sistema original desbalanceado, logo, com velocidade síncrona contrária à da sequência positiva.

c) Sistema trifásico de sequência zero: é o sistema trifásico balanceado em fase que gira na mesma sequência do sistema original, assim, de forma igual à sequência positiva.

Os diagramas fasoriais para as componentes simétricas das tensões trifásicas podem ser observados na Figura 12. 


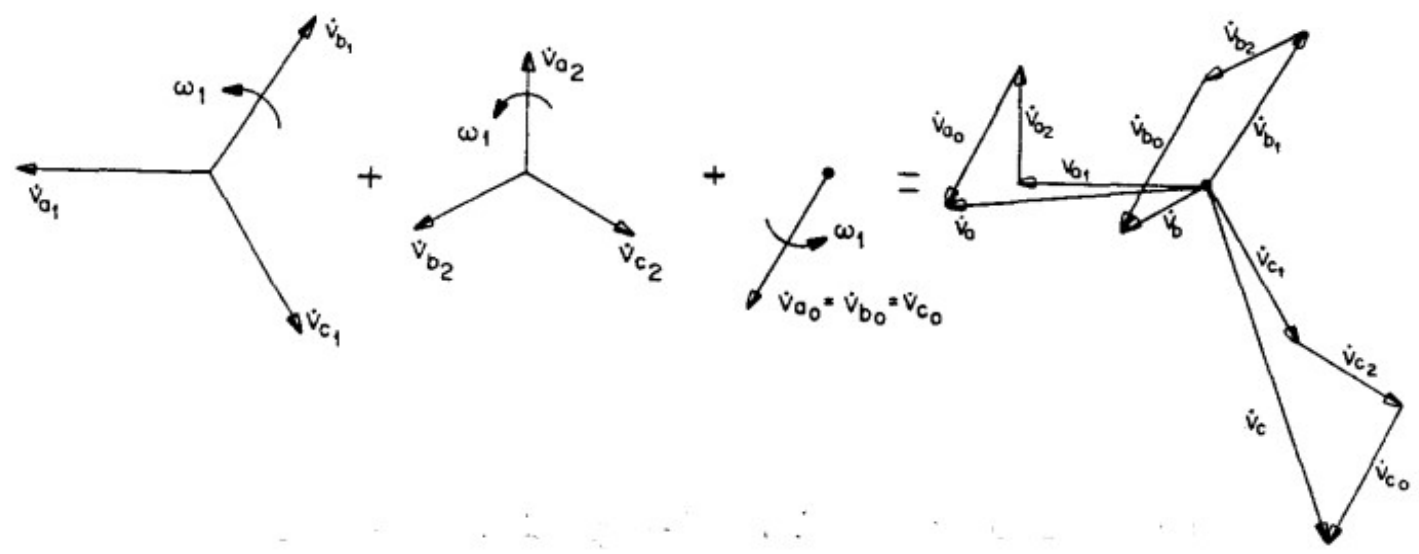

Figura 12 - Diagramas fasoriais das componentes simétricas de um conjunto trifásico [11].

As componentes simétricas representadas estão relacionadas pelo seguinte operador:

$$
\dot{\alpha}=1\left\lfloor 120^{\circ}=e^{j 12}\right. \text { 。 }
$$

- Sequência positiva:

$$
\begin{gathered}
\dot{V}_{\mathrm{a} 1}=\dot{V}_{\mathrm{a} 1} \\
\dot{V}_{\mathrm{b} 1}=\dot{\alpha}^{2} \cdot \dot{V}_{\mathrm{a} 1} \\
\dot{V}_{\mathrm{c} 1}=\dot{\alpha} \cdot \dot{V}_{\mathrm{a} 1}
\end{gathered}
$$

- Sequência negativa:

$$
\begin{gathered}
\dot{V}_{\mathrm{a} 2}=\dot{V}_{\mathrm{a} 2} \\
\dot{V}_{\mathrm{b} 2}=\dot{\alpha} \cdot \dot{V}_{\mathrm{a} 2} \\
\dot{V}_{\mathrm{c} 2}=\dot{\alpha}^{2} \cdot \dot{V}_{\mathrm{a} 2}
\end{gathered}
$$

- Sequência zero:

$$
\dot{V}_{\mathrm{a} 0}=\dot{V}_{\mathrm{a} 0}
$$




$$
\begin{aligned}
& \dot{V}_{\mathrm{b} 0}=\dot{V}_{\mathrm{a} 0} \\
& \dot{V}_{\mathrm{c} 0}=\dot{V}_{\mathrm{a} 0}
\end{aligned}
$$

Para representação do sistema trifásico desequilibrado, necessitamos da representação correspondente de seus sistemas de sequência zero, positiva e negativa, como pode ser observado em (2.18), (2.19) e (2.20).

$$
\begin{gathered}
\dot{V}_{\mathrm{a}}=\dot{V}_{\mathrm{a} 0}+\dot{V}_{\mathrm{a} 1}+\dot{V}_{\mathrm{a} 2} \\
\dot{V}_{\mathrm{b}}=\dot{V}_{\mathrm{b} 0}+\dot{V}_{\mathrm{b} 1}+\dot{V}_{\mathrm{b} 2} \\
\dot{V}_{\mathrm{c}}=\dot{V}_{\mathrm{c} 0}+\dot{V}_{\mathrm{c} 1}+\dot{V}_{\mathrm{c} 2}
\end{gathered}
$$

Para melhor representação, podemos substituir:

$$
\begin{aligned}
& \dot{V}_{\mathrm{a} 0}=\dot{V}_{0} \\
& \dot{V}_{\mathrm{a} 1}=\dot{V}_{1} \\
& \dot{V}_{\mathrm{a} 2}=\dot{V}_{2}
\end{aligned}
$$

Obtemos então a matriz de Fortescue em que é possível determinar o sistema trifásico desequilibrado por meio dos valores de suas componentes simétricas, em (2.24) ou o contrário, por meio do cálculo de sua matriz inversa em (2.25).

$$
\begin{gathered}
{\left[\begin{array}{c}
\dot{V}_{a} \\
\dot{V}_{b} \\
\dot{V}_{c}
\end{array}\right]=\left[\begin{array}{ccc}
1 & 1 & 1 \\
1 & \dot{\alpha}^{2} & \dot{\alpha} \\
1 & \dot{\alpha} & \dot{\alpha}^{2}
\end{array}\right]\left[\begin{array}{l}
\dot{V}_{0} \\
\dot{V}_{1} \\
\dot{V}_{2}
\end{array}\right]} \\
{\left[\begin{array}{l}
\dot{V}_{0} \\
\dot{V}_{1} \\
\dot{V}_{2}
\end{array}\right]=\frac{1}{3}\left[\begin{array}{ccc}
1 & 1 & 1 \\
1 & \dot{\alpha} & \dot{\alpha}^{2} \\
1 & \dot{\alpha}^{2} & \dot{\alpha}
\end{array}\right]\left[\begin{array}{l}
\dot{V}_{a} \\
\dot{V}_{b} \\
\dot{V}_{c}
\end{array}\right]}
\end{gathered}
$$

Por fim, podemos representar o Teorema de Fortescue em termos dos fasores de corrente: 


$$
\begin{gathered}
{\left[\begin{array}{l}
\dot{I}_{a} \\
\dot{I}_{b} \\
\dot{I}_{c}
\end{array}\right]=\left[\begin{array}{ccc}
1 & 1 & 1 \\
1 & \dot{\alpha}^{2} & \dot{\alpha} \\
1 & \dot{\alpha} & \dot{\alpha}^{2}
\end{array}\right]\left[\begin{array}{c}
\dot{I}_{0} \\
\dot{I}_{1} \\
\dot{I}_{2}
\end{array}\right]} \\
{\left[\begin{array}{l}
\dot{I}_{0} \\
\dot{I}_{1} \\
\dot{I}_{2}
\end{array}\right]=\frac{1}{3}\left[\begin{array}{ccc}
1 & 1 & 1 \\
1 & \dot{\alpha} & \dot{\alpha}^{2} \\
1 & \dot{\alpha}^{2} & \dot{\alpha}
\end{array}\right]\left[\begin{array}{c}
\dot{I}_{a} \\
\dot{I}_{b} \\
\dot{I}_{c}
\end{array}\right]}
\end{gathered}
$$

\subsubsection{Impedâncias de sequência dos principais equipamentos dos SEPs}

Com o desenvolvimento do Teorema de Fortescue foi possível ampliar o conhecimento sobre os sistemas trifásicos que era antes limitado apenas para os sistemas equilibrados. Entretanto, foi necessário o estudo detalhado de cada componente do sistema elétrico para a obtenção de seus valores de impedâncias de sequências, principalmente de sequência negativa e zero. Portanto, na análise de um sistema elétrico trifásico desequilibrado, é necessário obter um modelo de representação para cada uma das sequências (positiva, negativa e zero) e realizar os cálculos considerando apenas uma das fases [11].

Os valores das impedâncias de sequência podem ser determinados através dos ensaios em laboratórios, das características do material e da forma de ligação. O equipamento é então submetido a cada tipo de sequência de forma individual e o valor de impedância é então medido. Assim:

$$
\begin{gathered}
\dot{Z}_{0} \text { é a impedância de sequência zero } \\
\dot{Z}_{1} \text { é a impedância de sequência positiva } \\
\dot{Z}_{2} \text { é a impedância de sequência negativa }
\end{gathered}
$$

Os equipamentos a serem considerados nos cálculos de curto circuito são os geradores, transformadores e linhas de transmissão.

A seguir serão determinados os modelos de sequência positiva, negativa e zero para cada componente descrito. 


\subsubsection{Gerador síncrono}

O gerador é um dos equipamentos mais importantes do sistema elétrico sendo o responsável por suprir a quantidade de energia necessária para o atendimento das cargas e manter o sistema dentro dos níveis de tensão a fim de garantir a estabilidade do sistema.

Por ser o elemento ativo do sistema, no momento de uma falta, ele injeta uma elevada corrente de curto circuito, sendo assim necessária a atuação correta da proteção a fim de eliminá-la com a abertura de disjuntores [11].

Para a obtenção dos valores das impedâncias de sequência são realizados testes, como por exemplo, de curto-circuito e circuito aberto. O importante aqui é apresentar os circuitos equivalentes para cada sequência. Realça-se também que durante um curto-circuito a reatância do gerador síncrono varia, apresentando três valores para cada período: sub-transitório $\left(X^{\prime}\right)$, transitório $\left(X^{\prime}\right)$ e no regime permanente $(X)$. É recomendado adotar o valor da reatância sub-transitória na modelagem de um gerador, pelo fato de apresentar como consequência uma corrente de curto-circuito maior. Assim, o equipamento estará superdimensionado acarretando em mais segurança para o sistema.

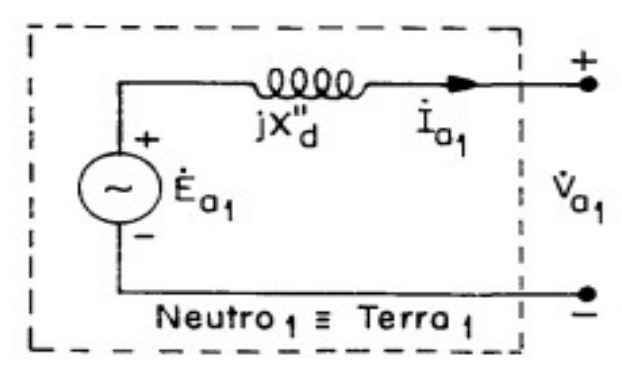

Figura 13 - Circuito equivalente de sequência positiva para o gerador síncrono [11].

$\mathrm{Na}$ Figura 13 mostra-se a representação de um gerador síncrono para a sequência positiva. Por ser um elemento ativo, temos a representação de uma fonte de tensão com tensão $\dot{E}_{a_{1}}$ juntamente com a reatância sub-transitória de eixo direto (X"d). A tensão de fase de sequência positiva $\left(\dot{V}_{a_{1}}\right)$ pode ser obtida através de (2.28).

$$
\dot{V}_{a_{1}}=\dot{E}_{a_{1}}-X_{d}^{\prime \prime} \cdot \dot{I}_{a_{1}}
$$


Em que:

$\dot{E}_{a_{1}}$ é a tensão de fase do gerador síncrono a vazio.

$\dot{V}_{a_{1}}$ é a tensão de fase - neutro de sequência positiva.

$\dot{I}_{a_{1}}$ é a corrente de sequência positiva que flui do gerador para o sistema.

Para o circuito equivalente de sequência negativa, pode-se desprezar o períodos sub-transitório e transitório, logo a reatância será a própria reatância de sequência negativa $\left(X_{2}\right)$. Como o ensaio em laboratório é feito com o enrolamento da máquina em curto, o circuito equivalente para este tipo de sequência é passivo, portanto não representamos nenhuma fonte de tensão. A tensão de sequência negativa $\left(\dot{V}_{a_{2}}\right)$ é obtida em função da reatância de sequência negativa $\left(X_{2}\right)$ e da corrente de sequência negativa $\left(\dot{I}_{a_{2}}\right)$ que flui do gerador para o sistema, como pode ser observado em (2.29).

$$
\dot{V}_{a_{2}}=-X_{2} \cdot \dot{I}_{a_{2}}
$$

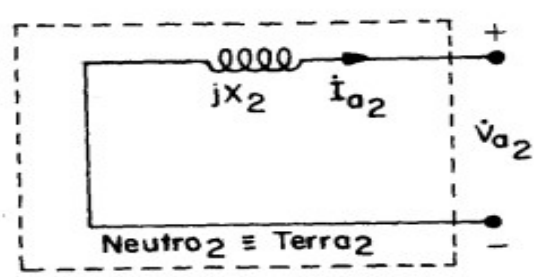

Figura 14 - Circuito equivalente de sequência negativa [11].

Por fim, obtêm-se uma representação bastante semelhante à anterior para o circuito equivalente do gerador na sequência zero, pois novamente teremos um circuito passivo, devido ao fato do teste ser também realizado com os enrolamentos em curto. De acordo com (2.30), obtêm-se o valor da tensão de sequência zero $\left(\dot{V}_{a_{0}}\right)$ utilizando o valor da reatância de sequência zero $\left(\mathrm{X}_{0}\right)$ e da corrente de sequência zero $\left(\dot{I}_{a_{2}}\right)$ que flui do gerador para o sistema.

$$
\dot{V}_{a_{0}}=-X_{0} \cdot \dot{I}_{a_{0}}
$$




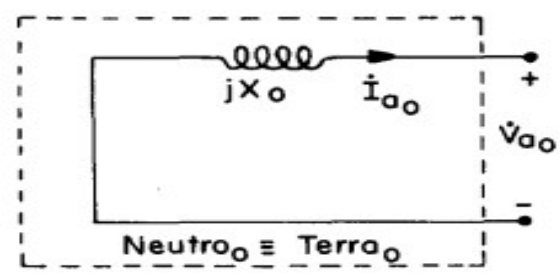

Figura 15 - Circuito equivalente de sequência zero para o gerador síncrono [11].

\subsubsection{Transformadores de potência}

Do ponto de vista físico, o transformador conecta-se sempre entre duas extremidades. Então, o transformador é representado por uma impedância conectada às outras impedâncias do sistema. Para a representação dos circuitos de sequências equivalentes de um transformador, é necessário primeiramente analisar o tipo de transformador e como ele está conectado. Logo, os transformadores de núcleo envolvente ou de núcleo envolvido apresentarão configurações diferentes, principalmente com relação ao circuito equivalente de sequência zero. Na literatura [11], apresenta-se uma explicação bem detalhada para cada tipo de transformador.

Através do ensaio de curto-circuito é possível obter a impedância de sequência positiva $\dot{Z}_{1}$. O transformador é um elemento passivo e estático, assim como uma linha de transmissão, o que implica que o valor de qualquer sequência de fase será a própria sequência positiva e o valor da impedância de sequência negativa terá o mesmo valor que a sequência positiva. Desta forma:

$$
\dot{Z}_{1}=\dot{Z}_{2}
$$

Na Figura 16 mostra-se o circuito equivalente de sequência positiva e negativa para transformadores de potência.
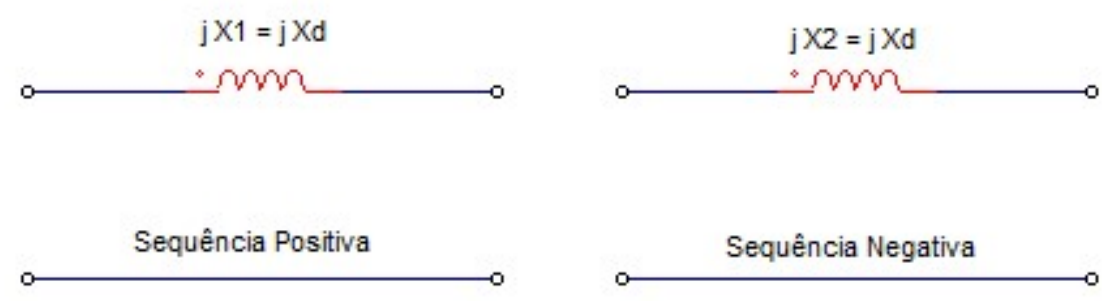

Figura 16 - Circuito equivalente de sequência positiva e negativa para transformadores de potência [10]. 
O modelo para a representação de sequência zero do transformador dependerá de seu tipo e de como são feitas as suas ligações entre as bobinas primárias, secundárias e terciárias. Assim, haverá a presença de correntes de sequência zero se houver um caminho de retorno. Para o caso da ligação em delta $(\Delta)$, se houverem correntes de sequência zero oriundas do lado primário, estas circularão dentro de seus enrolamentos, ou seja, estarão confinadas dentro da configuração delta. Na Figura 17 são apresentadas as representações de sequência zero para cada tipo de ligação dos transformadores de núcleo envolvente para dois e de três enrolamentos, respectivamente.
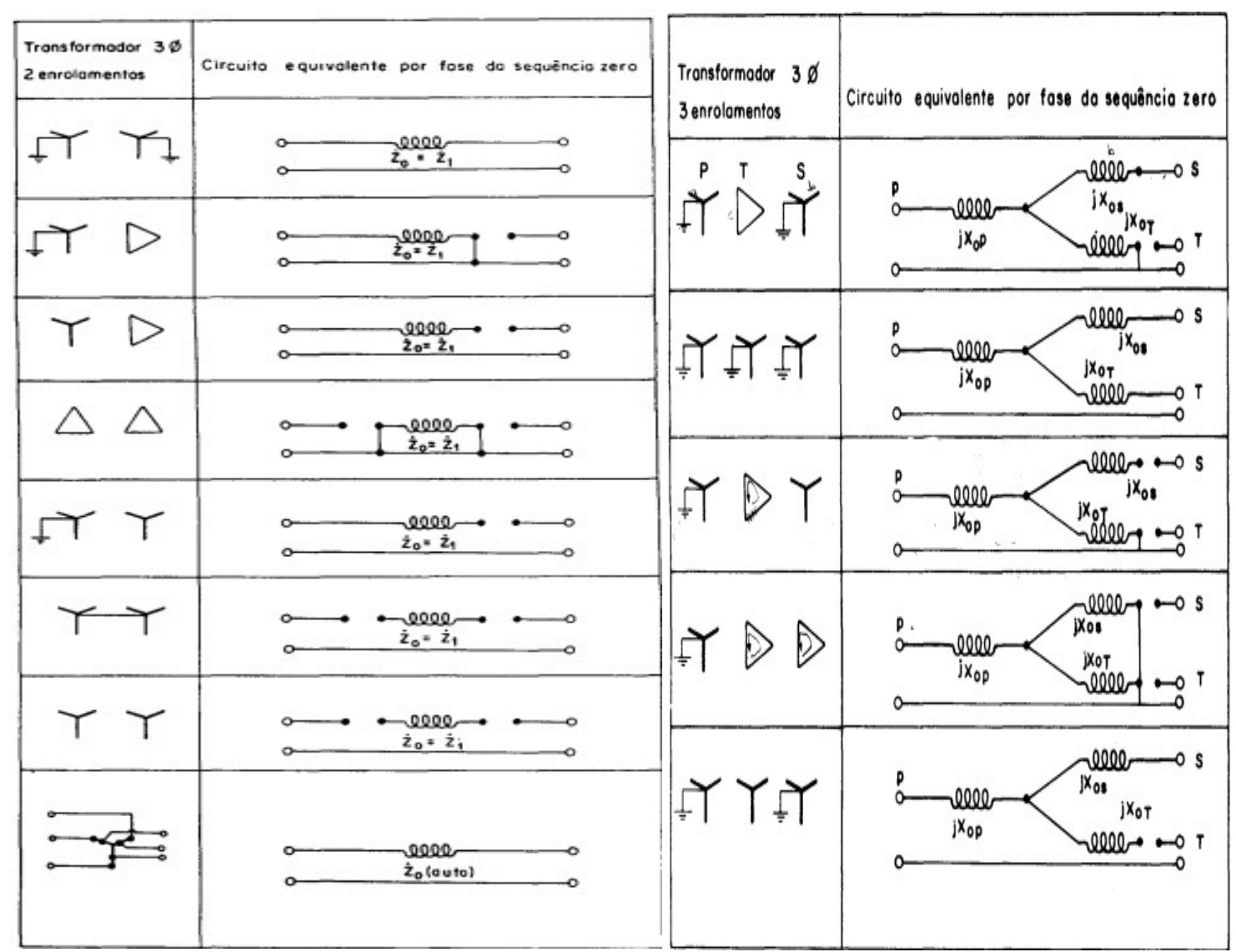

Figura 17 - Circuitos equivalentes de sequência zero para transformadores trifásicos de núcleo envolvente de dois e três enrolamentos, respectivamente [11].

\subsubsection{Linhas de transmissão}

O último elemento do SEP a ser considerado é a linha de transmissão. As impedâncias de sequência para as linhas de transmissão também são obtidas, como nos outros equipamentos, por meio de ensaios onde são levados em consideração alguns parâmetros, como por exemplo, as características físicas dos cabos condutores, 
a geometria e disposição das torres o que influenciará principalmente no valor da impedância de sequência zero. Além disso, os resultados obtidos para os valores de impedância de sequência positiva e negativa são os mesmos.

$$
\dot{Z}_{1}=\dot{Z}_{2}
$$

Na Figura 18 mostra-se o circuito equivalente de sequência positiva e negativa para linhas de transmissão.
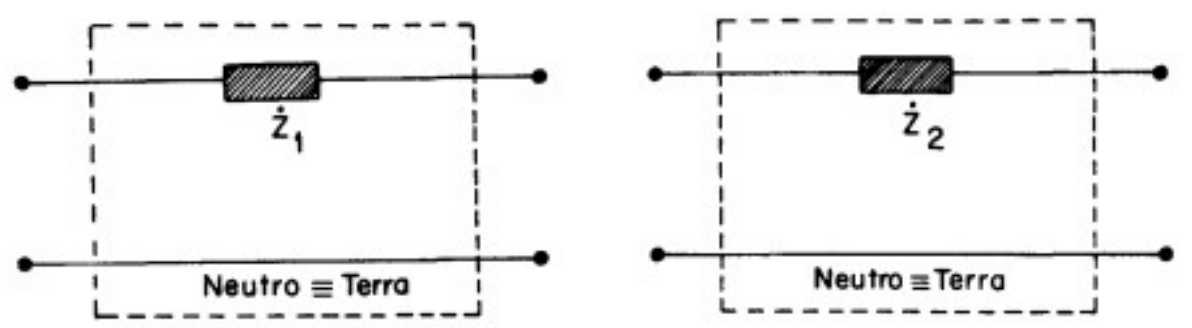

Figura 18 - Circuitos equivalentes de sequência positiva e negativa para as linhas de transmissão [11].

Os valores das correntes de sequência zero são influenciados pela resistividade do solo, da geometria dos cabos, dentre outros fatores, pelo fato de que essas correntes tendem a retornar pelo menor caminho, seja por cabos guarda ou para-raios ou através do solo, a fim de fechar o circuito. Assim, devido aos diversos caminhos que a corrente poderá percorrer, há grande dificuldade na determinação do valor da impedância de sequência zero. Alguns autores adotam que este valor como sendo entre 2 e 6 vezes a mais que o da sequência positiva [11].

\subsection{PROTEÇÃO DOS PRINCIPAIS ELEMENTOS DO SEP}

Uma vez apresentados os conceitos de faltas, das componentes simétricas relacionadas aos tipos de faltas e dos equipamentos básicos dos sistemas de proteção. Desta forma, nos próximos itens são apresentados os tipos de proteção para os geradores, transformadores, barras e linhas de transmissão.

\subsubsection{Proteção de geradores}

Os geradores síncronos são considerados os equipamentos mais caros do sistema elétrico, por isso faz-se necessário o emprego de proteções que visam 
minimizar os danos ocasionados nas condições anormais de operação, como por exemplo, faltas internas, desligamentos inesperados, desequilíbrios de cargas, fases abertas, entre outras. Entretanto, o nível de proteção pode interferir de forma negativa, pois o desligamento indevido de uma unidade geradora pode causar uma catástrofe maior do que uma simples falha de proteção [12].

Segundo [13], o sistema de proteção para geradores pode ser dividido em dois principais grupos a fim de identificar as falhas envolvendo curtos-circuitos entre espiras, sejam elas monofásicas, bifásicas ou trifásicas, além de detectar condições anormais de operação, como por exemplo, perdas de campo, desequilíbrio no estator, sobrevelocidade, sobrecarga, entre outros funcionamentos prejudiciais ao gerador.

A proteção do gerador, tal como a dos demais componentes, deve ter como principais características o rápido funcionamento contra as faltas internas, cujos danos são proporcionais ao quadrado da corrente pelo tempo, não atuar para as faltas externas à sua zona de proteção, detectar e eliminar as condições anormais.

Dentre as principais funções de proteção aplicadas nos geradores, podemos citar as proteções de sobrecorrente (50/51), diferencial (87), subtensão (27), sobretensão (59), perda de excitação (40), distância (21), balanço de tensão (61).

De forma sucinta, por meio dos valores das correntes de curto-circuito para as possíveis falhas, como por exemplo, nos enrolamentos da armadura do gerador síncrono, é feito o ajuste das correntes de pick-up dos relés de sobrecorrente $(50,51)$. A proteção diferencial (87) é utilizada para detectar os defeitos nos enrolamentos das bobinas do estator. Esses dois tipos de proteções serão mais bem detalhados nos capítulos seguintes, por também envolverem os esquemas de proteção de outros equipamentos do sistema elétrico.

Assim, outras proteções primordiais para situações específicas são: proteção por perda de excitação (40) e a proteção de sobreexcitação (24). É importante lembrar que a energia transferida pelo gerador é proveniente do acoplamento entre o campo girante do rotor e o campo girante do estator e, além disso, é por meio da máquina primária que ocorre à transferência de energia, originando este acoplamento. 
A fonte de tensão contínua responsável por gerar a corrente de excitação da bobina do rotor é a excitatriz. Nos casos de perda de excitação, o gerador síncrono acelera rapidamente passando a operar como um gerador de indução e, ao invés de fornecer, retira o reativo do sistema. Como principais defeitos na máquina síncrona, podemos citar o sobreaquecimento do rotor, e consequentemente, do estator, devido à sobrevelocidade do rotor [14].

Para a proteção de sobreexcitação é importante realçar-se que o fluxo magnético da máquina é diretamente proporcional à tensão e inversamente a frequência. Assim, o aumento de tensão provoca também o aumento do fluxo magnético e, consequentemente, o sobreaquecimento da máquina. Portanto, através da relação V/Hz é possível ter uma noção de possíveis danos no gerador [14].

\subsubsection{Proteção de transformadores}

As principais condições anormais de operação, no caso dos transformadores de potência, são os curtos circuitos nos enrolamentos, circuitos abertos ou superaquecimento. Os transformadores modernos apresentam um grau elevado de segurança oriunda do avanço das técnicas utilizadas nos processos de construção apresentando, como consequência, baixos índices de falhas.

Quando um transformador de potência é submetido a uma condição anormal, será necessário o seu desligamento, podendo vir a implicar nas operações de manobra para a sua substituição ou até mesmo em ações de manutenção que demandem maior tempo de serviço [13].

No entanto, casos de circuito aberto são raros devido às características construtivas dos transformadores. O sistema de proteção deverá atuar nos casos de curtos-circuitos internos e como forma de retaguarda, no caso de falta externa. $\mathrm{Na}$ proteção de um transformador de potência de grande porte, utilizam-se as seguintes proteções: diferencial (87), de sobrecorrente (50/51), de gás ou Buchholz (63), térmicas $(26,49)$, de baixo nível de óleo (71), dentre outras [15].

Dentre as proteções citadas anteriormente, destaca-se a proteção pelo relé Buchholz (63) que tem como função atuar quando detecta um aumento anormal da 
pressão do óleo do transformador, devido à formação de arcos elétricos resultantes de pequenas falhas nos isolamentos das bobinas ou nas conexões internas. Segundo [15], o óleo passa a se decompor gerando bolhas que tendem a se direcionar para a parte superior do equipamento.

Na Figura 19 mostra-se a instalação do relé Buchholz na parte superior, entre o transformador e o tanque de óleo. Desta maneira, a formação de gás fecha o contato que aciona um alarme de tal modo que medidas corretivas sejam adotadas, evitando uma falta interna.

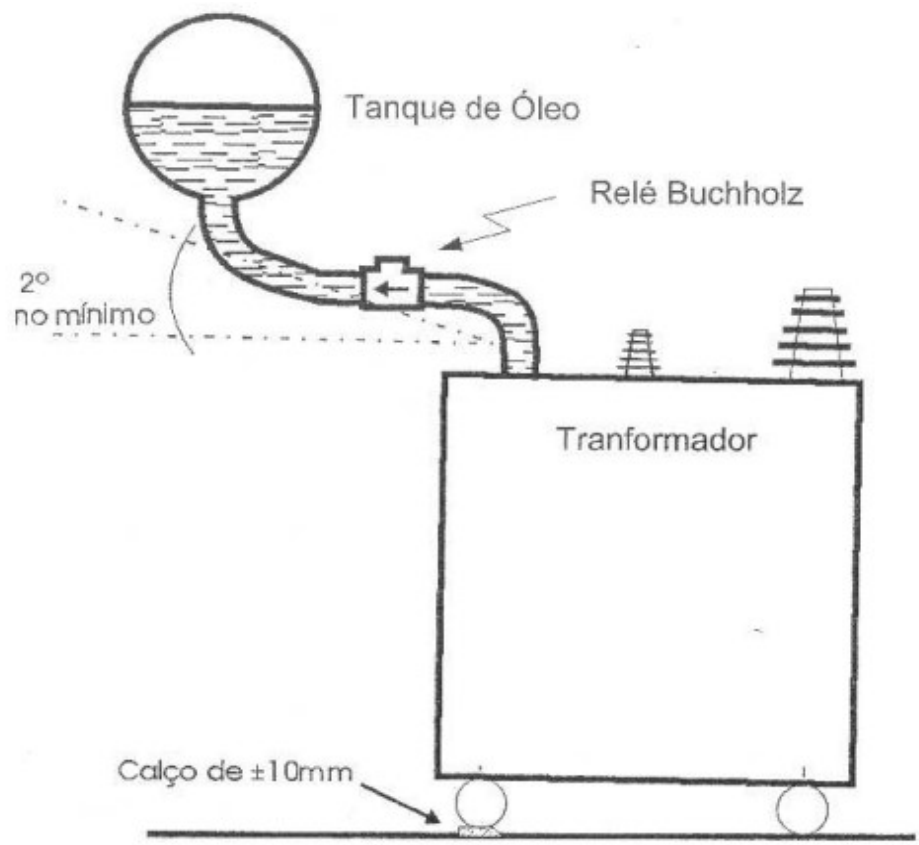

Figura 19 - Localização de um relé Buccholz na proteção de um transformador de potência [15].

\subsubsection{Proteção de linhas de transmissão}

A essência é garantir que o circuito defeituoso seja desligado o mais rápido possível até que o defeito seja eliminado. Os sistemas de proteção envolvem além do relé de distância (21), os relés de sobrecorrente instantâneos (50) ou temporizados (51), relés sobrecorrente direcional (67), relé de distância (21), relé diferencial (87), dentre outros.

As proteções de sobrecorrente, instantânea e temporizada, e diferencial serão melhores enfatizadas no capítulo seguinte. Aqui será explorada a proteção de distância 
e os esquemas de teleproteção, característicos dos esquemas empregados nas linhas de transmissão.

A proteção de distância tem como filosofia de funcionamento a impedância, admitância ou reatância, vista pelo relé no momento da falta, sendo estes parâmetros proporcionais à distância. Assim, no momento da falta, o relé fará a medição do parâmetro da linha de transmissão até o ponto do curto-circuito, por meio dos valores de tensão e corrente medidos pelos TC e TP, respectivamente, seguindo a equação (2.33).

$$
Z_{\text {relé } 21}=\frac{V_{\text {relé }}}{I_{\text {defeito }}}
$$

No caso da existência de resistência no local do defeito $\left(R_{\text {contato }}\right)$, este valor será somado ao valor de impedância vista pelo relé. Na Figura 20 mostra-se o esquema de proteção de distância para o caso de uma falta na linha.

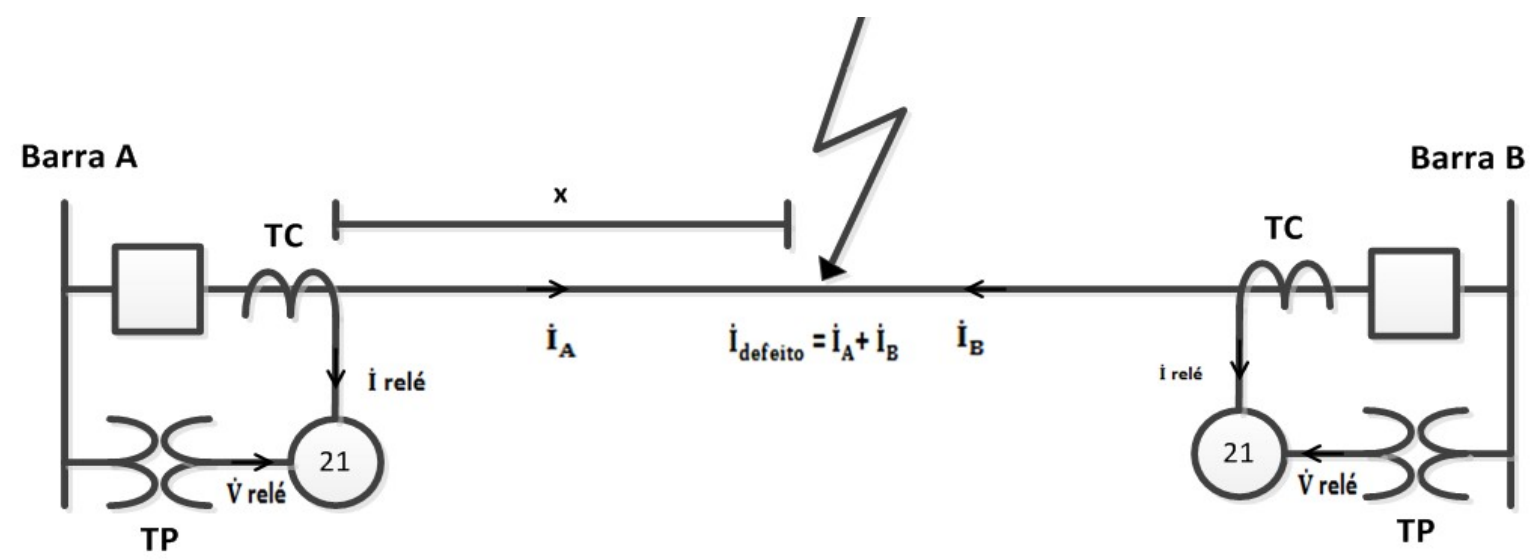

Figura 20 - Esquema da proteção de distância para uma linha de transmissão com falta [15].

Neste caso, a impedância vista pelo relé de distância do terminal $A$ ( $\left.Z_{\text {relé } 21, A}\right)$ é dada em (2.34).

$$
Z_{\text {relé } 21, A}=\frac{V_{\text {relé } A}}{I_{A}}=\frac{x \cdot Z_{L T} \cdot I_{A}+R_{\text {contato }}\left(I_{A}+I_{B}\right)}{I_{A}}
$$

Podem-se destacar alguns termos importantes, como por exemplo, o valor da porcentagem da linha em que se localiza o defeito $(x)$, o valor parametrizado de 
impedância da linha $\left(Z_{L T}\right)$, as contribuições de correntes de ambos os terminais $\left(I_{A}\right.$ e $\left.I_{B}\right)$ e a resistência do contato ( $\left.R_{\text {contato }}\right)$.

O ajuste do relé distância é feito por meio de zonas de proteção prédeterminadas. As proteções de linhas de transmissão dividem-se em 3 zonas sendo estas apresentadas abaixo, segundo as zonas de alcance dos relés de distância.

- $1^{\text {a }}$ Zona: Atuação de forma instantânea

$$
-Z_{1^{\mathrm{a}} \text { zona }}=(80-85) \% \text { da LT. }
$$

- $\mathbf{2}^{\mathrm{a}}$ Zona: Atuação de forma temporizada

$$
-Z_{2^{a}} \text { zona }=100 \% \text { da } L T+(50-60) \% \text { da } L T \text { adjascente. }
$$

- $3^{a}$ Zona: Atuação de forma temporizada

$-Z_{3^{a} \text { zona }}=100 \%$ da $L T+100 \%$ da $L T$ adjascente $+(20-30) \%$ da $L T$ a jusante.

Ainda é possível ajustar uma $4^{\mathrm{a}}$ zona de proteção, denominada proteção reversa, com direção oposta as demais zonas.

É importante mencionar que a proteção de distância apresenta alguns erros inerentes que podem vir a influênciar na determinação da real zona de atuação do relé. Dentre eles, destacam-se os erros devido a resistência no ponto de falta, erros de TPs e TCs ou do próprio relé de proteção, além de erros devido a alimentação da corrente de curto de outras linhas [16].

No intuito de contorná-los, são empregados os esquemas de teleproteção que ajudam a determinar se a falta está localizada dentro da LT protegida, além de acelerar o processo de tomada de decisão reduzindo o tempo de eliminação do defeito e, consequentemente, aumentando a seletividade do sistema de proteção. A comunicação baseia-se no na transmissão do sinal de um relé a outro por meio de canais pilotos, dentre eles, o fio piloto, onda portadora (carrier), microondas, cabo OPGW, onda portadora - OPLAT. Como estes sistemas de comunicação abrangem todo o comprimento da linha e também estão sujeitos aos riscos de vandalismos. 


\subsubsection{Proteção de barras}

Geralmente, os defeitos nos barramentos envolvem altos valores de correntes devido ao fato de conectarem os diversos elementos do sistema. Portanto, torna-se necessário que a proteção de barras atue de forma rápida, para limitar os efeitos perniciosos aos elementos a ela conectados, e de forma seletiva, mantendo a maior quantidade possível de carga.

O esquema de proteção do barramento de uma subestação relaciona-se com sua importância para o sistema. Além da própria proteção de barras, podem-se destacar a proteção através do ajuste da segunda zona do relé distância, incluindo a barra da subestação adjacente, o ajuste da proteção de distância local para cobrir a zona reversa ou por meio do ajuste das funções de sobrecorrentes dos transformadores de potência garantindo a proteção de retaguarda para a barra [13]. Geralmente, para a proteção de um barramento importante, utilizam-se os esquemas proteção diferencial de barras juntamente com relé de sobrecorrente, sobretensão, diferencial percentual ou relé de sobrecorrente direcional, entre outros.

A proteção diferencial baseia-se na $1^{\text {a }}$ lei de Kirchhoff, onde em condições normais de operação, a soma fasorial das correntes entrando e saindo da barra deve ser nula e, no caso de um defeito na barra, a soma das correntes é diferente de zero. Assim, o relé fica inoperante para o caso de falta externa, pois a soma das correntes no secundário do TC é nula indicando que não há diferença entre as correntes que chegam com relação às correntes que saem da barra. Na Figura 21 mostra-se o esquema de conexão para a proteção diferencial de barras. 


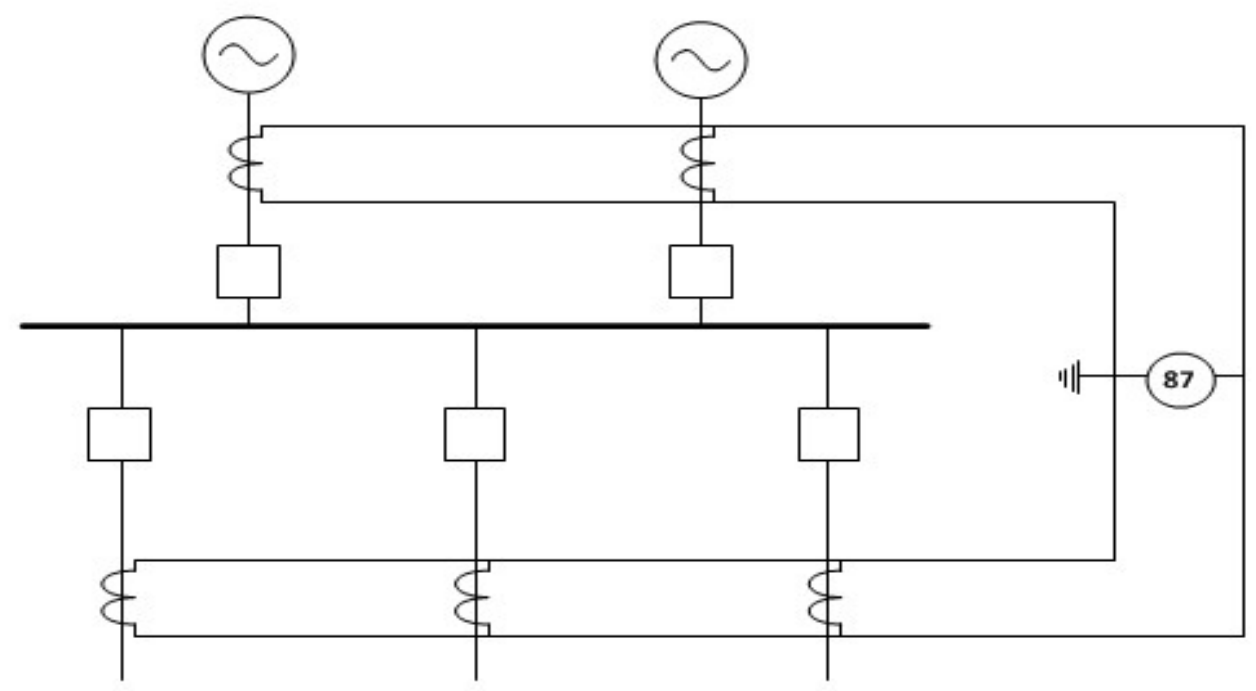

Figura 21 - Esquema de proteção diferencial de barras [13].

Na proteção de barras, também é possível a utilização de relés de sobrecorrente conectados de forma diferencial. Nestes casos, alguns cuidados deverão ser observados, como por exemplo, garantir que os TCs apresentam a mesma relação nominal e que não haja indícios de saturação, podendo resultar em correntes diferenciais que possam vir a provocar a operação indevida da proteção. Realça-se que a utilização desses esquemas de proteção diferenciais é recomendada nos sistemas de pequeno porte com menor quantidade de conexão nas barras, onde os níveis de curtoscircuitos não são elevados [14].

Os esquemas das proteções diferencial e de sobrecorrente de transformadores, que são o cerne desse trabalho, serão explicados no capítulo seguinte.

\subsection{CONCLUSÃO}

O objetivo deste capítulo foi apresentar uma descrição sobre a proteção de sistemas elétricos de potência, apresentando suas principais características funcionais. Fez-se uma revisão dos tipos de faltas, apresentou-se o método das componentes simétricas necessário para obtenção das correntes de curto-circuito. Por fim, mencionou-se as proteções dos principais equipamentos do sistema elétrico de potência, tais como geradores, transformadores, linhas de transmissão e barras. 


\section{Capítulo 3 CONCEITOS FUNDAMENTAIS: PROTEÇÕES DE SOBRECORRENTE E DIFERENCIAL}

\subsection{INTRODUÇÃO}

No geral, um mesmo esquema pode ser utilizado para a proteção de mais de um equipamento do sistema elétrico. Na elaboração e implementação dos sistemas de proteção, os relés são cruciais. Atualmente, com o avanço tecnológico, é normal encontrar mais de uma função de proteção para o mesmo relé. Alguns equipamentos elétricos, geradores, transformadores, linhas de transmissão e barras, têm em comum os esquema de proteção de sobrecorrente e diferencial.

O objetivo deste capítulo é apresentar os princípios básicos de funcionamento dessas duas usuais proteções.

\subsection{PROTEÇÃO DE SOBRECORRENTE}

A proteção de sobrecorrente (instantânea ou temporizada) baseia-se no relé de sobrecorrente. Os relés de sobrecorrente são ajustados para atuar quando detectam uma corrente maior do que um valor pré-ajustado, de forma instantânea ou temporizada. Para o ajuste e configuração desses relés é necessário o conhecimento prévio, no mínimo:

a) do sistema elétrico a ser aplicado, por meio de seu diagrama unifilar, contendo os principais equipamentos de proteção e medição;

b) dos parâmetros característicos dos equipamentos, como por exemplo, os valores de impedância;

c) dos valores obtidos para as correntes de curto-circuito que irá fluir nos equipamentos;

O ajuste do relé de sobrecorrente poderá ser feito para a configuração de temporização ou instantânea. No ajuste temporizado, inicialmente configura-se o relé para obter o tempo mínimo de operação para o nível mais elevado de falha e avalia, em 
seguida, se o ajuste será capaz de atender a condição mínima de falha. Esse ajuste é feito a partir de uma curva que relaciona as correntes de curto circuito e o tempo.

No ajuste instantâneo, o relé de sobrecorrente é ajustado para um valor mínimo (pick-up) de corrente, que causa a operação do relé. Podem-se utilizar os esquemas de proteção de sobrecorrente instantânea, temporizada ou a combinação de ambos.

\subsubsection{Relé de sobrecorrente instantâneo (50)}

A atuação de forma instantânea ocorre quando o relé detecta uma corrente maior do que o seu valor de ajuste, sendo então de forma não é temporizada. Entretanto, esta atuação dependerá da velocidade de atuação do relé de proteção. De acordo com a norma ANSI/IEC, a função da proteção de sobrecorrente instantânea é representada pelo número 50 .

\subsubsection{Relé de sobrecorrente temporizado (51)}

O nome por si só sugestivo da forma de atuação deste tipo de relé. A norma ANSI/IEC estabelece o número 51 para representação desta função de proteção temporizada. Além disso, os relés de proteção de sobrecorrente temporizados podem ser de tempo definido ou de tempo inverso [17]. O de maior interesse é o relé de sobrecorrente de tempo inverso, pois proporciona a coordenação para diversos pontos da zona de proteção.

\subsubsection{Relé de sobrecorrente de tempo inverso}

Neste tipo de relé, escolhe-se uma curva de atuação e a coordenação far-se-á por meio de diferentes tempos para um mesmo valor de corrente de curto-circuito. Com isso, é possível coordenar de forma seletiva a atuação da proteção e a consequente abertura dos disjuntores a fim de que continue com o máximo atendimento das cargas conectadas ao sistema.

De acordo com a tecnologia utilizada, os relés de sobrecorrente de tempo inverso classificam-se em eletromecânicos, estáticos e digitais. 
No caso dos relés eletromecânicos, os fabricantes apresentam as curvas que representam a posição da alavanca de tempo, onde é alterado somente o valor da constante $\mathbf{K}$, que representa a posição da alavanca com relação aos contatos fixo e móvel do relé. No eixo da abscissa, encontram-se os múltiplos ( $\mathbf{M})$ da corrente de atuação do relé.

Quando o múltiplo é unitário $(\mathrm{M}=1)$, a corrente de operação será igual a corrente do seu tap. O desempenho e atuação do relé são comprometidos, devido ao baixo torque para o fechamento do contato, quando este opera entre os múltiplos 1 e 1,5. Assim, a curva de operação não é traçada para esta região, como é possível observar na Figura 22.

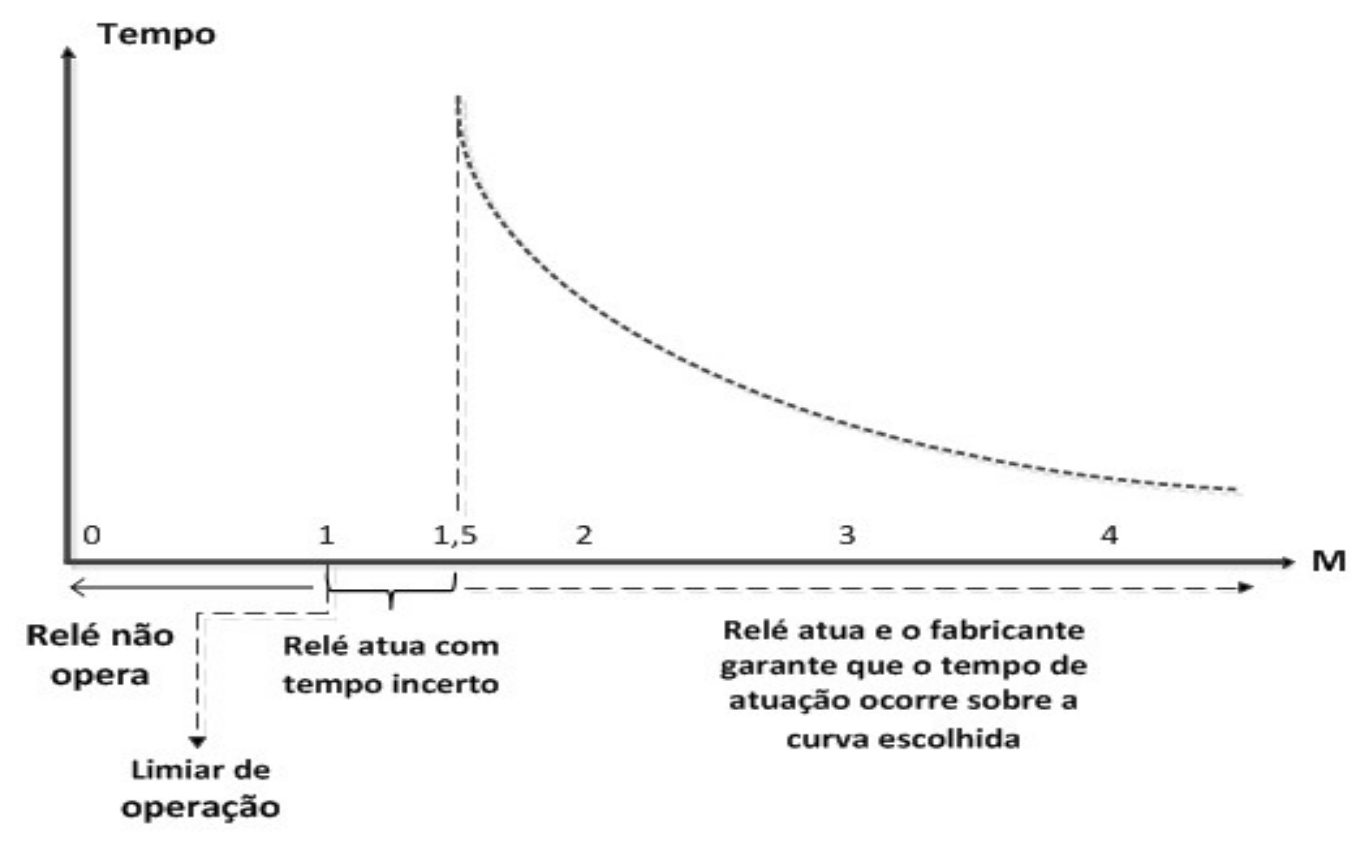

Figura 22 - Curva de operação para um relé de sobrecorrente de tempo inverso [17].

Para os relés digitais, não há a necessidade das curvas de tempo no papel, pois os próprios relés possuem a sua própria curva de atuação, sendo capazes de ajustar as inclinações das curvas de acordo com a necessidade do esquema de proteção. Geralmente, os relés digitais operam a partir do múltiplo 1,1. Estes relés associam a curva de operação a uma função que representa a curva normalizada, como pode ser observada na equação 18. 


$$
\mathrm{t}_{\text {atuação do relé }}=\mathrm{T}_{\text {curva }} \cdot\left(\frac{\mathrm{K}}{\mathrm{M}^{\alpha}-\beta}+\mathrm{L}\right)
$$

Em que:

- Tcurva é o múltiplo da curva de tempo, para a curva 100\%, $T_{\text {curva }}$ é igual a 1.

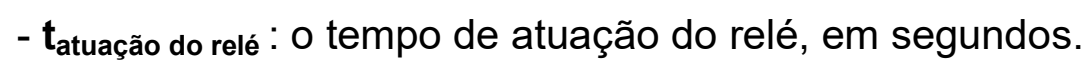

- $\mathbf{M}=\frac{\mathbf{I}}{\mathbf{I}_{\text {ajuste }}}$ : múltiplo do relé, maior ou igual a 1 , onde I é a corrente medida pelo relé e $\mathrm{I}_{\mathrm{ajuste}}$ é a corrente de pick-up.

- K,L, $\boldsymbol{\alpha}$ e $\boldsymbol{\beta}$ : são coeficientes tabelados que dependem do tipo de curva utilizado e da norma adotada, de acordo com a Tabela 3.1.

Tabela 3.1 - Coeficientes para a equação característica da curva dos relés de sobrecorrente de tempo inverso [17].

\begin{tabular}{|c|c|c|c|c|c|}
\hline Norma & Tipo de curva & $\mathbf{K}$ & $\mathbf{L}$ & $\boldsymbol{\alpha}$ & $\boldsymbol{\beta}$ \\
\hline \multirow{4}{*}{ IEC } & Curva inversa & 0,14 & 0 & 0,02 & 1 \\
\cline { 2 - 6 } & Moderadamente Inversa & 0,05 & 0 & 0,04 & 1 \\
\cline { 2 - 6 } & Muito Inversa & 13,5 & 0 & 1 & 1 \\
\cline { 2 - 6 } & Extremamente Inversa & 80 & 0 & 2 & 1 \\
\hline \multirow{3}{*}{ IEEE } & Moderadamente Inversa & 0,515 & 0,14 & 0,02 & 1 \\
\cline { 2 - 6 } & Muito Inversa & 196,1 & 4,91 & 2 & 1 \\
\cline { 2 - 6 } & Extremamente Inversa & 282 & 1,217 & 2 & 1 \\
\hline \multirow{2}{*}{ I2t $^{2}$ Todas } & Curva I2t & 100 & 2 & 0 & 0 \\
\hline
\end{tabular}

Na Figura 23 mostra-se um exemplo para a curva normal inversa, em escala log log, segundo a norma IEC. Para o uso das curvas de atuação moderadamente inversa, 
muito inversa e extremamente inversa, utilizam-se os valores das constantes da Tabela 3.1.

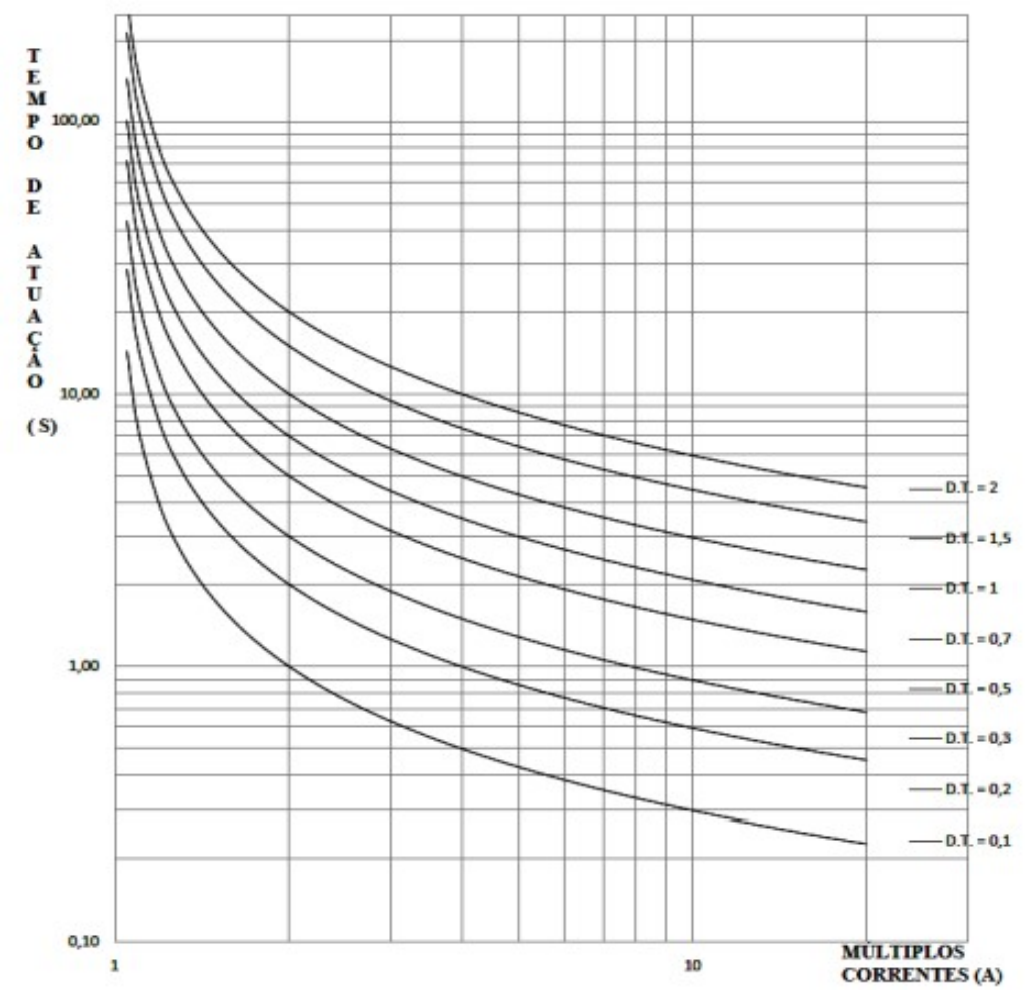

Figura 23 - Exemplo de curva IEC normal inversa [22].

As proteções de sobrecorrente (temporizada e instantânea) são associadas de forma coordenada com o intuito de aumentar ainda mais a seletividade do sistema de proteção. Assim, o defeito passa a ser eliminado da maneira mais rápida possível e com o mínimo de corte das cargas conectadas ao sistema.

\subsubsection{Relé de sobrecorrente com controle de tensão (51V)}

No intuito de aumentar a confiabilidade do sistema de proteção a fim de promover uma melhor retaguarda para os equipamentos adjacentes, utiliza-se a função de sobrecorrente com controle de tensão. Nestes casos, as correntes de falta medidas são menores que a corrente nominal dos transformadores de potência, portanto, o relé precisa determinar se o valor de corrente medida é de carga ou de falta. Para isso, é necessário que a proteção de sobrecorrente supervisione também a tensão do sistema. Assim, a polarização do relé de sobrecorrente com controle de tensão é tanto pela corrente como pela tensão como mostra a Figura 24. 
De acordo com a norma ANSI/IEC, a função da proteção de sobrecorrente com controle de tensão é representada por 51V.

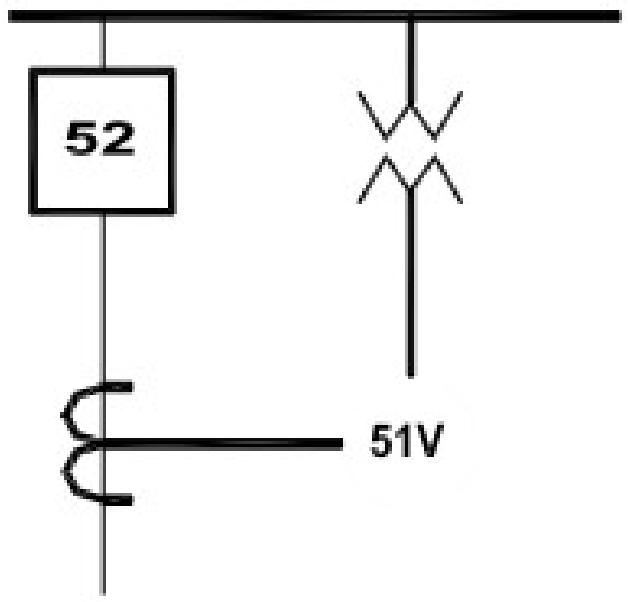

Figura 24 - Esquemático do relé de sobrecorrente com controle de tensão 51V. [25]

\subsection{PROTEÇÃO DIFERENCIAL}

O princípio básico de funcionamento do esquema de proteção diferencial é a comparação dos valores de corrente elétrica de entrada e saída do elemento protegido. Essa comparação pode ser feita utilizando os valores instantâneos ou fasorial, com base na $1^{\text {a }}$ Lei de Kirchhoff, que afirma que as correntes que entram e saem de um nó deve ser igual à zero para qualquer instante de tempo [18].

Segundo a norma ANSI/IEC, essa função de proteção é representada pelo número 87 , sendo as nomenclaturas $87 \mathrm{~T}$, $87 \mathrm{~B}$ e $87 \mathrm{~L}$, respectivamente, as proteções dos transformadores de potência, barramentos e linhas de transmissão.

Os TCs são utilizados para a comparação dos valores de correntes, sendo possível encontrar as condições descritas abaixo:

- $\quad \dot{\mathbf{I}}_{\text {entrada }}=\dot{\mathbf{I}}_{\text {saída }}$, logo a corrente que flui no relé é igual a zero ( $\left.\dot{\mathbf{I}}_{\text {relé }}=0\right)$ e não há atuação da proteção, pois não há defeito no equipamento protegido.

Na Figura 25 é apresentado o funcionamento normal do sistema elétrico, em que as correntes de entrada e saída do relé são iguais, não havendo atuação da proteção. 


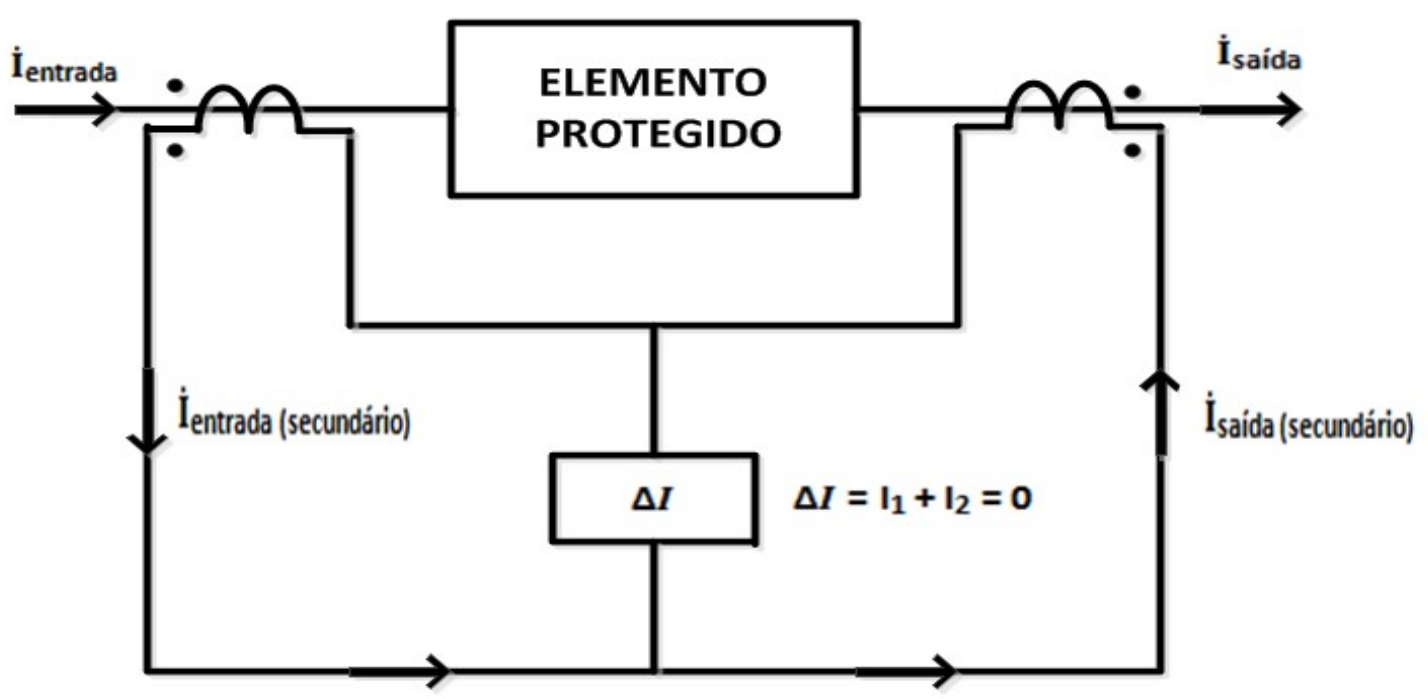

Figura 25 - Proteção diferencial para o sistema operando normalmente [15].

- $\dot{I}_{\text {entrada }}-\dot{I}_{\text {saida }} \leq \dot{I}_{\text {ajuste do relé }}$ também não há atuação da proteção, pois a diferença da corrente é menor que o valor de pick-up do relé.

Na Figura 26 é apresentado o esquema de proteção diferencial para caso de uma falta externa a zona de proteção do relé. As correntes de ambos os lados tendem a alimentar o defeito e os TCs passam a registrar o mesmo valor. Portanto, também não há atuação da proteção.

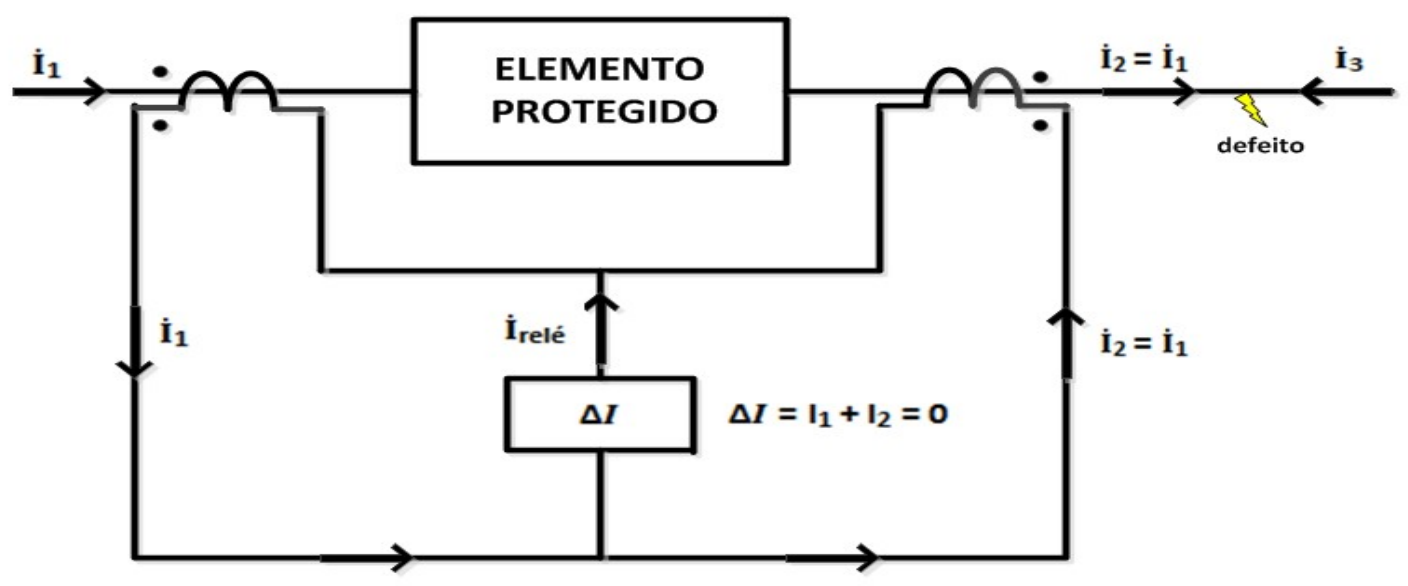

Figura 26 - Defeito fora da zona de proteção [15].

- $\dot{I}_{\text {entrada }}-\dot{I}_{\text {saida }}>\dot{I}_{\text {ajuste do relé }}$, há atuação da proteção pois a corrente diferencial é maior que o valor de pick-up do relé. Portanto, o elemento protegido encontra-se sob defeito. 
Por fim, é representado na Figura 27 o esquema de proteção diferencial no caso de um defeito interno ao elemento protegido. A corrente diferencial será igual a soma das correntes de ambos os TCs e, portanto, opera o relé.

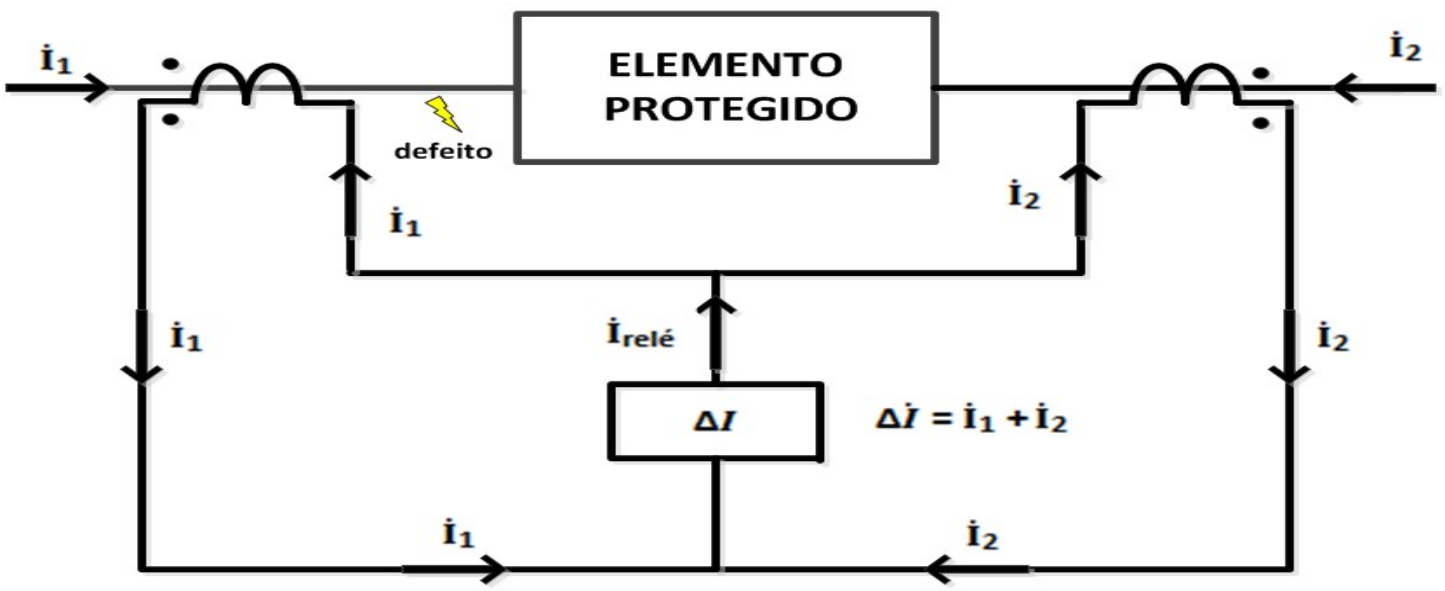

Figura 27 - Atuação da proteção diferencial para um defeito interno [15].

No relé de proteção diferencial eletromecânico, há a interação de duas principais bobinas: as bobinas de restrição e a de operação, cujos campos magnéticos resultantes geram forças contrárias. A atuação do relé diferencial acontecerá se o torque positivo, relacionado à bobina de operação, for maior que o torque negativo, referente à bobina de restrição [15].

Os relés digitais também calculam os valores das correntes de restrição $\left(I_{\text {Res }}\right)$ e de operação $\left(I_{O p}\right)$ a fim de detectar se o defeito está na zona da proteção diferencial. Entretanto, cada fabricante adota um método de cálculo para o seu relé de proteção. Segundo [18], os manuais dos fabricantes adotam a regra do sinal em que as correntes que fluem no relé são somadas positivamente. As correntes de operação (lop), corrente diferencial, e a restrição $\left(I_{\text {Res }}\right)$ destes relés podem ser obtidas através de (3.2) e (3.3) para os relés tradicionais.

$$
\begin{array}{r}
I_{\text {Op }}=\left|\dot{I}_{1}+\dot{I}_{2}\right| \\
I_{\text {Res }}=\left|I_{1}+I_{2}\right|
\end{array}
$$


No caso dos relés numéricos, a corrente de restrição é usualmente obtida através de (3.4). No caso do relé 7UT61 da Siemens, que será utilizado neste trabalho, o valor da corrente de restrição é também obtido através de (3.4).

$$
I_{\text {Res }}=\left|I_{1}\right|+\left|I_{2}\right|
$$

Vale mencionar que a principal diferença para o cálculo das correntes de restrição entre os fabricantes é o valor da constante $\mathbf{k}$ que divide a soma das correntes medidas pelo relé de proteção.

$$
I_{\text {Res }}=\frac{\left|I_{1}\right|+\left|I_{2}\right|}{k}
$$

Da curva de operação do relé diferencial, mostrada na Figura 28, são extraídos os valores das correntes de operação, no eixo vertical, e de suas correntes de operação correspondentes, no eixo horizontal.

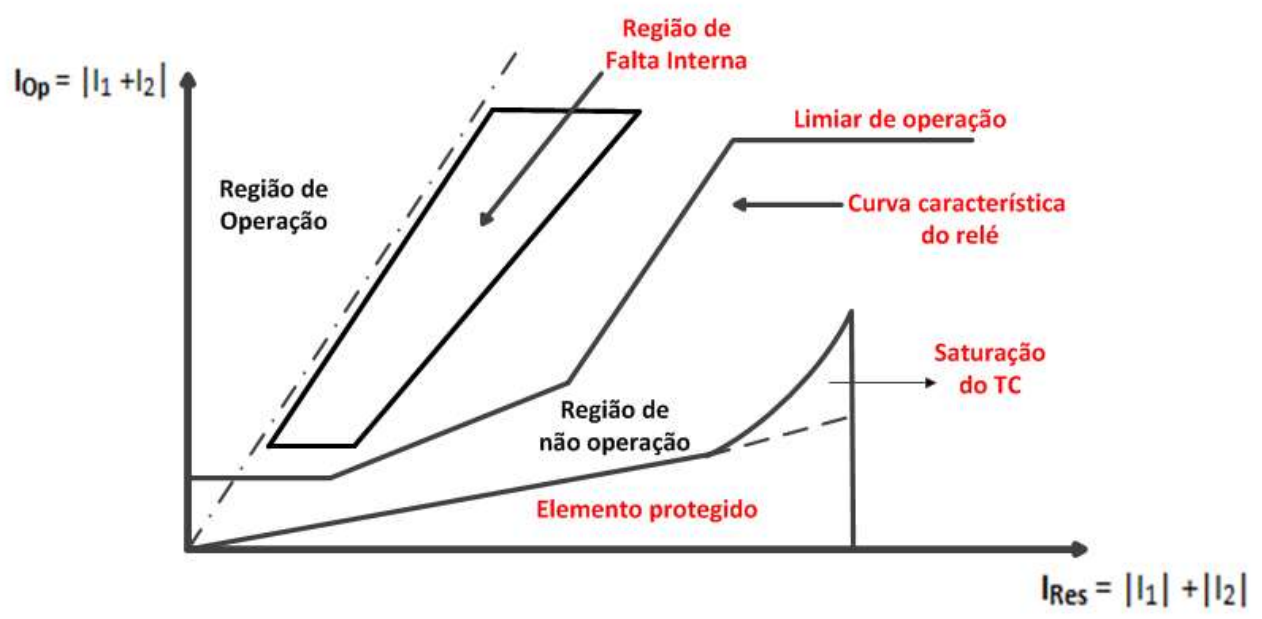

Figura 28 - Curva de operação do relé diferencial [18].

Ainda da Figura 28, observa-se que na região de não operação do relé há uma região em que o elemento está protegido. $O$ ideal seria que não houvesse nenhuma corrente diferencial, porém, devido aos ajustes de tap e erros dos TCs, é possível que uma falsa corrente diferencial flua através do elemento protegido, sendo esta incrementada rapidamente no caso de saturação do TC [18]. 
Por fim, nota-se que a curva de operação do relé apresenta algumas declividades, também conhecidas como slopes. As inclinações das retas variam dependendo do equipamento a ser protegido. O valor da corrente pick-up do relé também varia de acordo com as recomendações dos fabricantes.

\subsection{CONCLUSÃO}

Neste capítulo foram abordados os conceitos fundamentais das funções de sobrecorrente, instantânea e temporizada, e diferencial dos relés de proteção. A ênfase dada a esses dois esquemas de proteção foi devido ao fato de serem os mais aplicados para a proteção dos principais equipamentos do sistema elétrico. Além disso, o intuito

principal deste trabalho é o ajuste dessas duas funções para a proteção de transformadores de potência. 


\section{Capítulo 4 METODOLOGIA DE AJUSTE DAS PROTEÇÕES DE SOBRECORRENTE E DIFERENCIAL EM TRANSFORMADORES DE POTÊNCIA}

\subsection{INTRODUÇÃO}

O objetivo deste capítulo é apresentar de forma detalhada como são utilizados os esquemas das proteções diferencial e de sobrecorrente nos transformadores de potência. Serão apresentados os fundamentos teóricos necessários para o ajuste dessas proteções em transformadores de potência, que é o objetivo deste trabalho.

\subsection{PROTEÇÃO DE SOBRECORRENTE DE TRANSFORMADORES}

A proteção de sobrecorrente é comum nos transformadores de média e pequena potência, podendo ser utilizada em unidades maiores como retaguarda para a proteção diferencial. Para transformadores com potência abaixo de $10 \mathrm{MVA}$, o esquema de proteção pode ser feito por meio de relés de sobrecorrente de tempo inverso, relés de distância ou até mesmo por fusíveis [5].

O esquema de proteção de transformadores com relés de sobrecorrente apresentam como principais vantagens o seu custo-benefício, simplicidade e confiabilidade. Entretanto, a principal desvantagem está relacionada aos casos de falhas internas no transformador, por apresentar menor sensibilidade e também possíveis atrasos na atuação [19]. Na Figura 29 é apresentado um esquemático básico de aplicação da proteção de sobrecorrente em transformadores de potência. Empregam-se, além das proteções de sobrecorrente instantânea (50) e temporizada (51) de fase, as proteções de sobrecorrente de neutro (50N/51N) para faltas à terra.

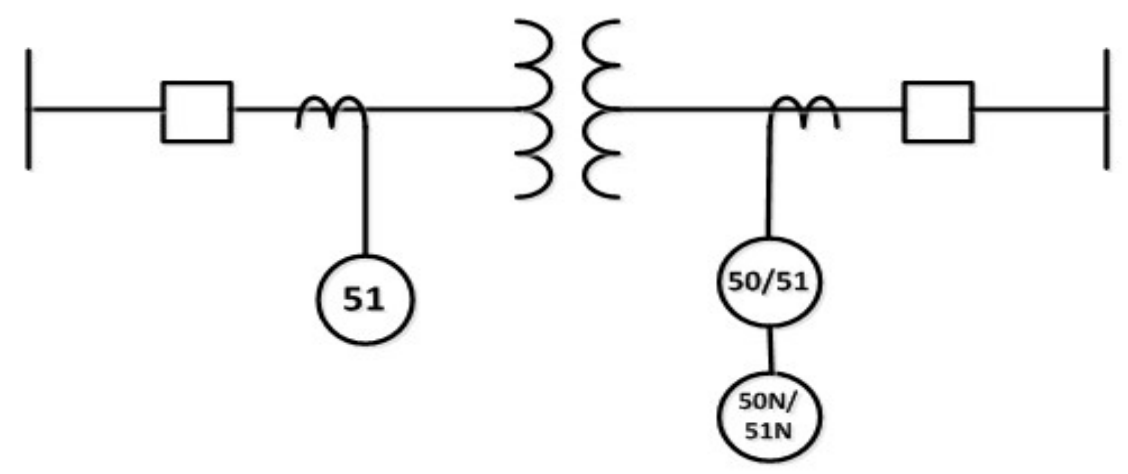

Figura 29 - Esquemático para as proteções de sobrecorrente em transformadores de potência [5]. 
No que se refere à curva da proteção de sobrecorrente, é necessário verificar se ela encontra-se abaixo das curvas que representam as capacidades térmicas dos equipamentos a serem protegidos. No caso dos transformadores, a magnitude da corrente de falta suportada num determinado instante de tempo é limitada pela sua impedância [1].

$\mathrm{Na}$ Figura 30 mostra-se um exemplo para a curva de capacidade de um transformador de potência que apresenta os valores máximos de correntes que o transformador de potência é capaz de suportar sem danificar a sua estrutura. As proteções deverão atuar antes que as correntes atinjam os pontos desta curva.

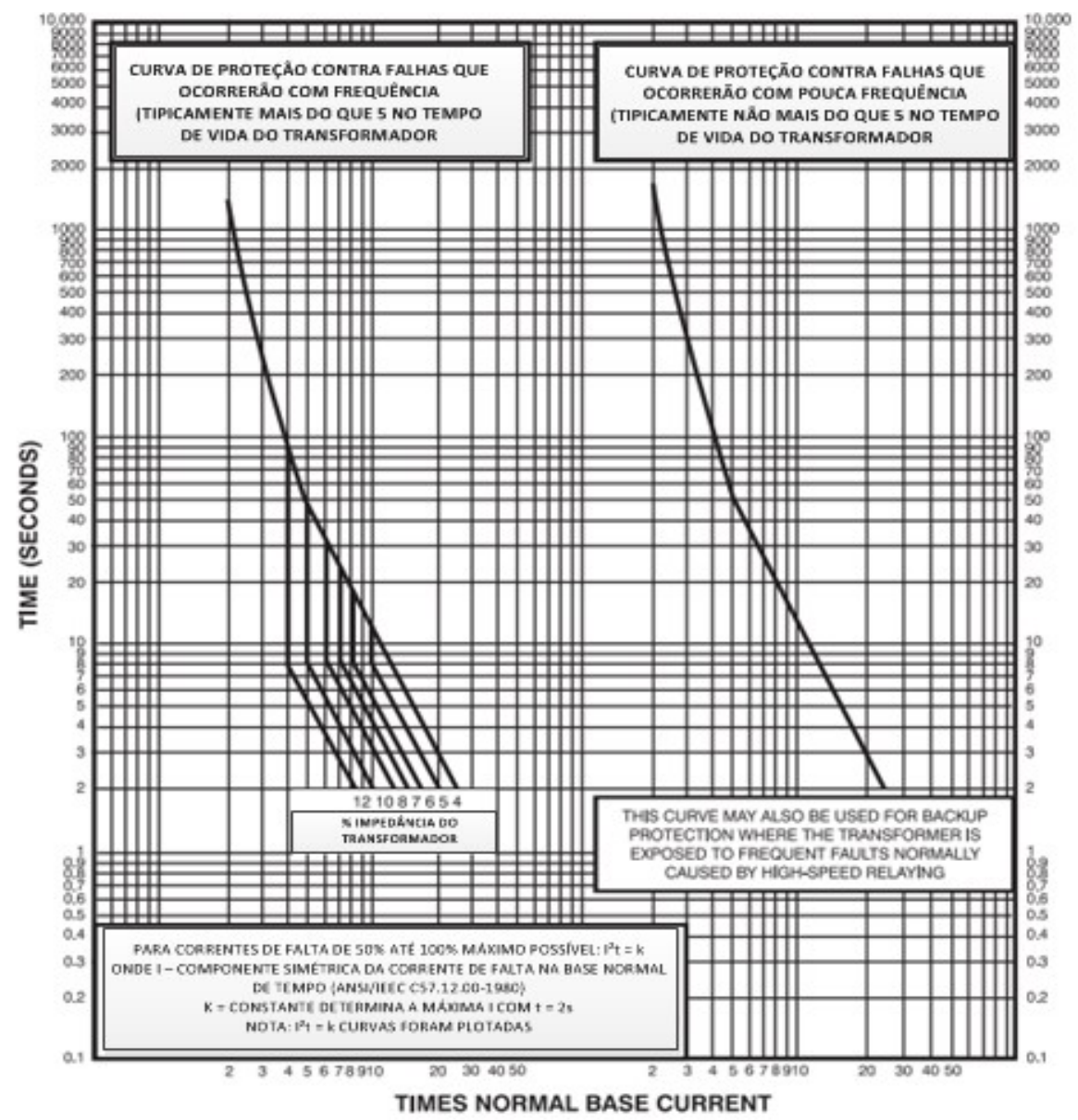

Figura 30 - Exemplo de curva de capacidade de um transformador de potência [20].

\subsubsection{Metodologia de ajuste da proteção de sobrecorrente em transformadores}

No ajuste dos valores das correntes de pick-up do relé, deverão ser levadas em consideração as variações devido à energização dos equipamentos. Na energização de um transformador de potência, a corrente de magnetização ( $\boldsymbol{I}_{\text {inrush }}$ ) pode ser obtida 
através de (4.1), em que $\mathbf{I}_{\text {nom }}$ é a corrente nominal do TC e $K$ é uma constante que depende da capacidade térmica do transformador.

$$
I_{\text {inrush }}=K \times I_{\text {nom }}
$$

Com o intuito de exemplificar a coordenação da proteção de sobrecorrente para um transformador $\Delta-Y$ é necessário verificar os valores das correntes para as faltas trifásicas, bifásicas e monofásicas. A Tabela 4.1 apresenta o resumo das correntes para os três tipos de faltas mencionados.

Tabela 4.1 - Correntes de faltas para um transformador $\Delta-\mathrm{Y}[1]$.

\begin{tabular}{|c|c|c|}
\hline Tipo de falta & $\boldsymbol{I}_{\text {primário }}$ & $\boldsymbol{I}_{\text {secundário }}$ \\
\hline Trifásica & $I$ & $I$ \\
\hline Bifásica & $I$ & $I \sqrt{3} / 2$ \\
\hline Monofásica - terra & $I$ & $I \sqrt{3}$ \\
\hline
\end{tabular}

Por meio da tabela, verifica-se que o caso crítico para a coordenação do relé encontra-se na falta bifásica, pois nos relés do lado secundário tem-se um valor de corrente inferior aos relés do lado primário, podendo interferir na seletividade da proteção. No intuito de contornar esse problema, é obtida uma margem de discriminação utilizando o valor de $I_{f} \sqrt{3} / 2$ nos relés do lado secundário e o valor de $I_{f}$, no lado primário, em que $I_{f}$ é a corrente de falta, como pode ser observado na Figura 31.

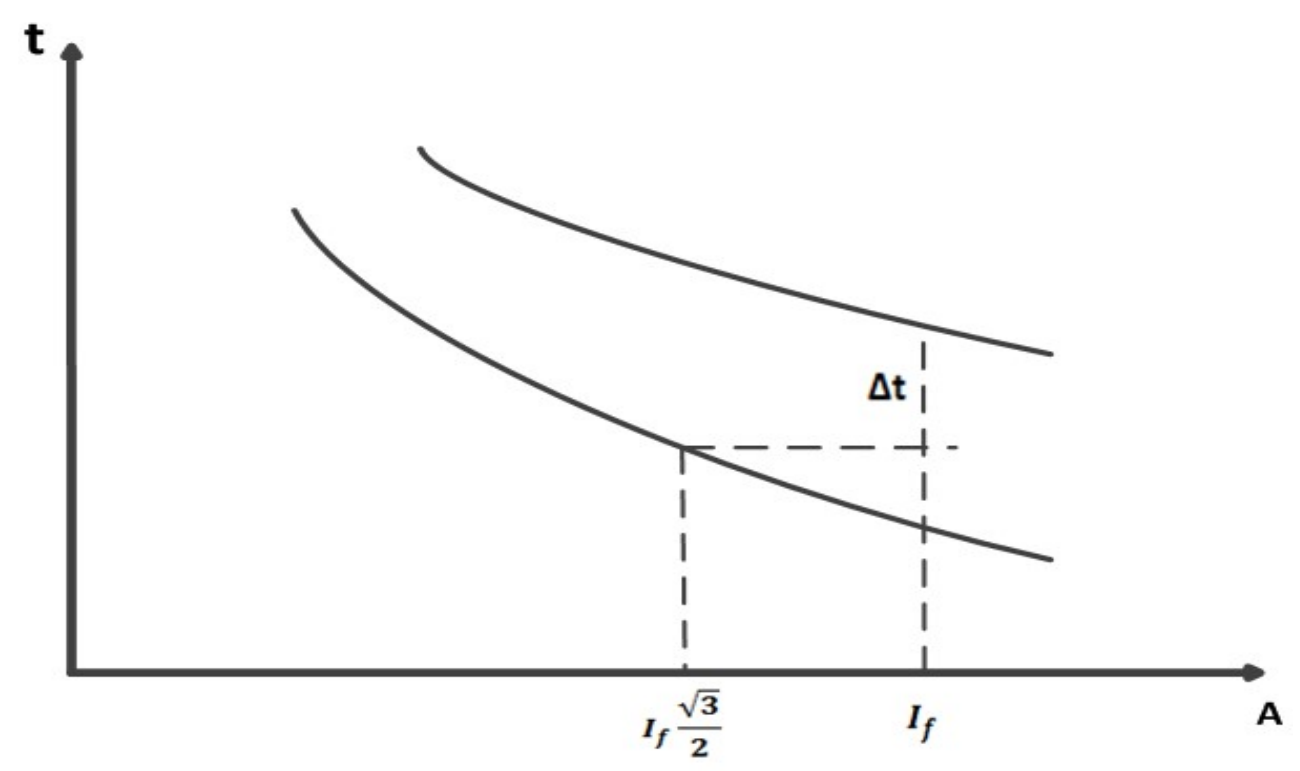

Figura 31 - Coordenação do relé de sobrecorrente para um transformador $\Delta-\mathrm{Y}$ [1]. 
No procedimento de ajuste deve-se levar em consideração a curva normal inversa das proteções de sobrecorrente podendo ser obtida através de (3.1). Nos relés digitais, é possível escolher as curvas e os parâmetros a serem adotados. Normalmente empregam-se as curvas ANSI e IEC. As principais etapas empregadas para o ajuste de sobrecorrente em transformadores é descrita abaixo:

a) Determinar a relação de transformação do TC (RTC) através dos valores da corrente nominal do transformador com relação à corrente que flui através do secundário do TC, normalmente iguais a $1 \mathrm{~A}$ e $5 \mathrm{~A}$.

b) Considerar o fator de sobrecorrente (FS) do TC igual a 20 que representa a relação máxima da corrente que pode atravessar o primário do TC em relação a sua corrente nominal.

$$
\mathrm{I}_{\mathrm{nom}}=\frac{\mathrm{I}_{\mathrm{CC} \max \text { no TC }}}{20}
$$

c) Verificar o carregamento (burden) no circuito secundário do TC garantindo que a queda de tensão da impedância do cabo e da bobina do relé não exceda o valor máximo permitido.

d) O valor escolhido para a corrente de pick-up deve seguir a equação descrita em (4.3) em que considera-se a corrente mínima de curto-circuito ( $\left.I_{\min } \mathrm{CC}\right)$.

$$
\frac{I_{\text {nom }}}{\text { RTC }} \leq I_{\text {pick-up }} \leq \frac{I_{\min \text { CC }}}{\text { RTC.1,5 }}
$$

e) Recomenda-se que a corrente de pick-up para o relé de sobrecorrente de neutro esteja entre os valores descritos em (4.4).

$$
0,1 . I_{\text {nom }} \leq I_{\text {pick-up do relé de neutro }} \leq 0,45 \text {. } I_{\text {nom }}
$$

f) Para proteção de sobrecorrente com controle de tensão, adota-se geralmente um ajuste $70 \%$ da tensão nominal com uma corrente de pick-up de $30 \%$ da corrente nominal do elemento protegido. 
g) O tempo de atuação da proteção de sobrecorrente é obtido com base nos valores descritos e através da equação (3.1).

No caso dos relés digitais, geralmente são adotados três estágios para a proteção de sobrecorrente. No primeiro estágio utiliza-se a curva de tempo inverso, sendo que nos outros dois estágios empregam-se as curvas de tempo definido devido ao fato de estarem relacionadas aos valores mais elevados para as correntes de curto-circuito.

A Figura 32 mostra um exemplo de curva de atuação para a proteção de sobrecorrente de três estágios.

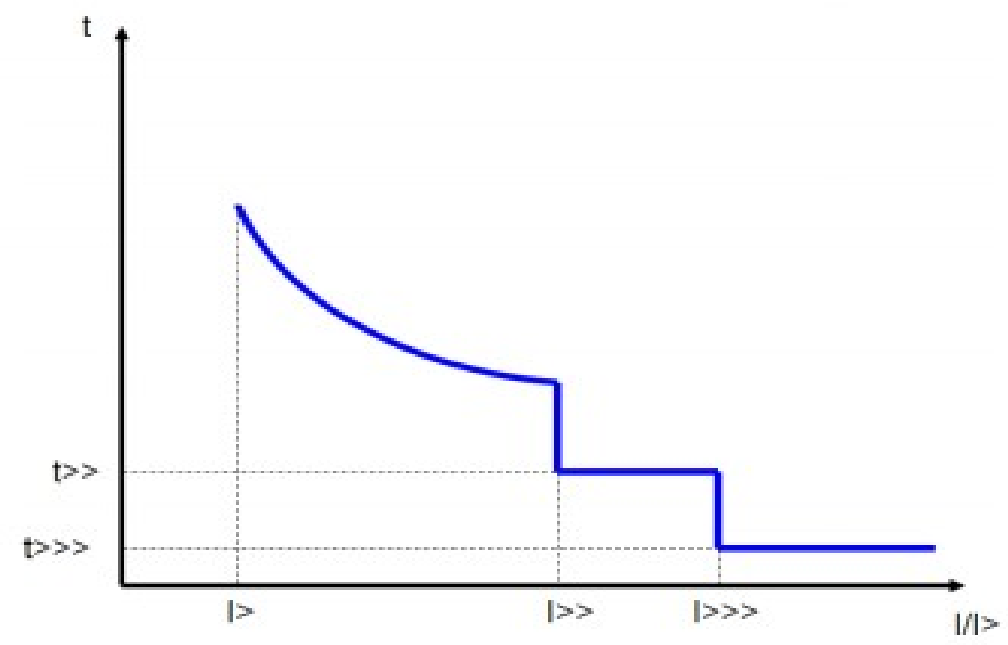

Figura 32 - Curvas de atuação da proteção de sobrecorrente para três estágios [21].

\subsection{PROTEÇÃO DIFERENCIAL DE TRANSFORMADORES}

A função diferencial é uma rápida e seletiva proteção de transformadores nos casos de curtos-circuitos internos ou até mesmo como complemento para o relé Buchholz [18].

Devido ao fato de serem encontradas diferentes formas de constituição e de ligação dos transformadores de potência do sistema elétrico, o esquema de proteção diferencial se altera. Assim, cada forma de ligação resultará numa análise peculiar para a obtenção do esquema de proteção diferencial.

É importante relembrar que determinados tipos de conexão de transformadores apresentam rotação de fase entre as suas conexões primária e secundária. Por 
exemplo, a conexão $\Delta-\mathrm{Y}$ apresenta uma defasagem nas correntes de linha de $30^{\circ}$, $60^{\circ}, 120^{\circ}, 150^{\circ}$ e $180^{\circ}$ do lado primário $(\Delta)$, com relação ao lado secundário $(Y)$.

As seguintes conexões não apresentam deslocamento angular entre as correntes de linha do lado primário e secundário dos transformadores de potência:

- $Y-Y$

- $\Delta-\Delta$

- $\Delta-$ zig-zag

Segundo [15], adotam-se as seguintes convenções para as diferentes conexões dos transformadores de potência:

a) A primeira letra é maiúscula e representa o primário do transformador:

- D - primário conectado em delta $(\Delta)$;

- $\mathrm{Y}$ - primário conectado em estrela $(\mathrm{Y})$;

- Z - primário conectado em zig-zag;

b) A segunda letra, minúscula, representa o secundário do transformador:

- $\mathrm{d}$ - secundário conectado em delta $(\Delta)$;

- $\mathrm{y}$ - secundário conectado em estrela (Y);

- z - secundário conectado em zig-zag;

c) O número, que varia de 0 a 11, representa o deslocamento angular entre as correntes de linha do lado primário e do lado secundário, podendo ser obtido através de (4.5).

$$
\text { Deslocamento angular }=30^{\circ} \text {.número }
$$

Assim, um transformador representando por Dy5 está com o primário conectado em delta $(\Delta)$ e o secundário em estrela $(Y)$. As correntes de linha do lado primário estão adiantadas em $30^{\circ} \times 5=150^{\circ}$ com relação às correntes do lado secundário.

Na Tabela 4.2 mostram-se os deslocamentos angulares para os diferentes tipos de conexão de transformadores. 
Tabela 4.2 - Deslocamentos angulares para as diversas conexões entre o primário e o secundário de transformadores de potência [18].

\begin{tabular}{|c|c|c|c|}
\hline $\begin{array}{c}\text { Deslocamento } \\
\text { Anqular }\end{array}$ & \multicolumn{3}{|c|}{ Conexões } \\
\hline $0^{\circ}$ & 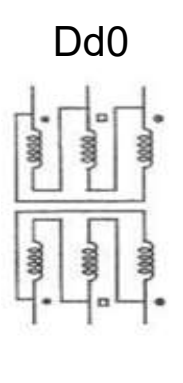 & 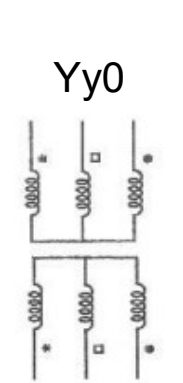 & 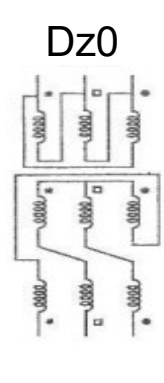 \\
\hline $30^{\circ}$ & 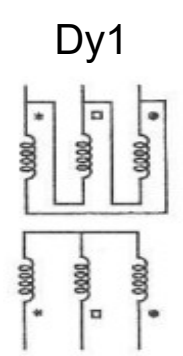 & 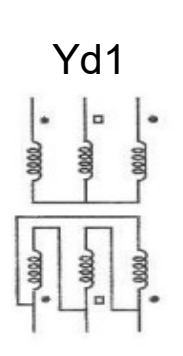 & 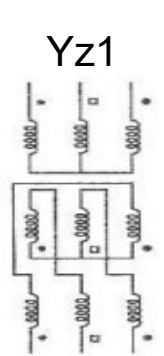 \\
\hline $60^{\circ}$ & 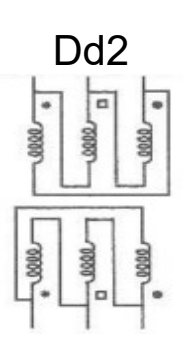 & - & 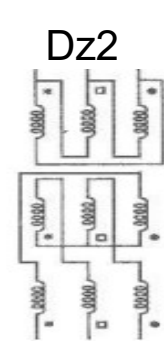 \\
\hline $120^{\circ}$ & 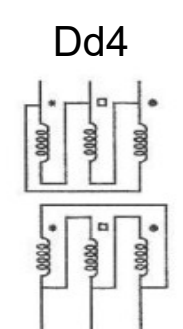 & - & 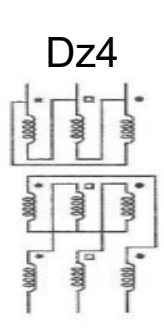 \\
\hline $150^{\circ}$ & 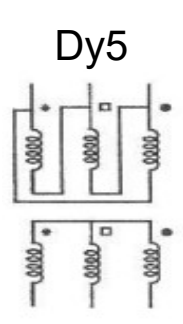 & 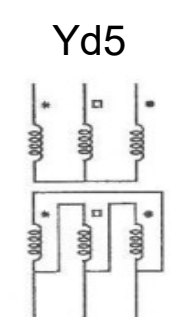 & 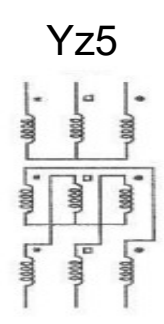 \\
\hline
\end{tabular}




\begin{tabular}{|c|c|c|c|}
\hline $180^{\circ}$ & 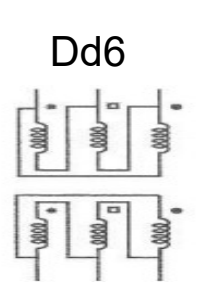 & 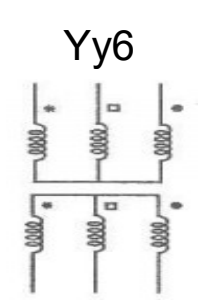 & 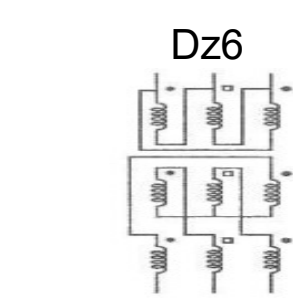 \\
\hline$-150^{\circ}$ & 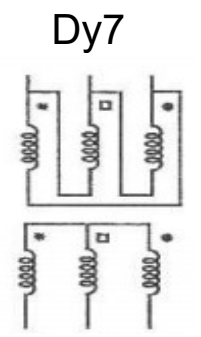 & 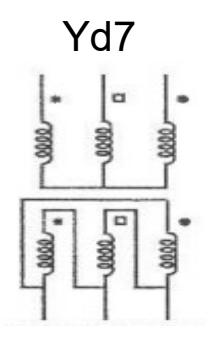 & 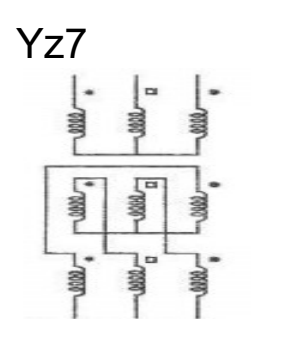 \\
\hline$-120^{\circ}$ & 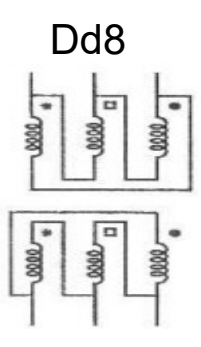 & - & 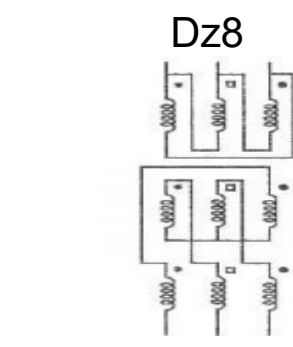 \\
\hline$-60^{\circ}$ & 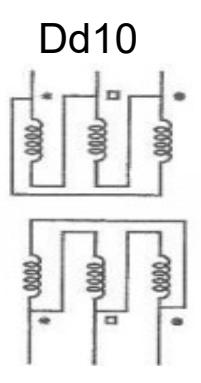 & - & 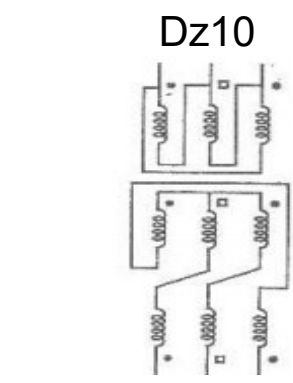 \\
\hline$-30^{\circ}$ & 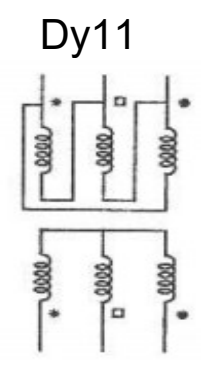 & 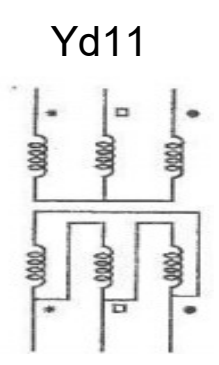 & 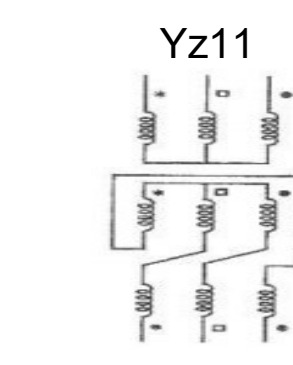 \\
\hline
\end{tabular}


No caso de relés eletromecânicos, os deslocamentos angulares produzem diferenças nas correntes do relé diferencial e um consequente defasamento entre as correntes que fluem nas bobinas de restrição do relé, interferindo no desempenho da proteção. No intuito de garantir que as correntes das bobinas de restrição estão em fase, é necessário compensar as rotações angulares provocadas pelas ligações do transformador por meio do esquema de ligação dos TCs [15].

Portanto, orientam-se as seguintes regras para contornar o problema de deslocamento angular:

- Conectar o secundário dos TCs em $\mathbf{Y}$ no lado $\Delta$ do transformador de potência;

- Conectar em $\boldsymbol{\Delta}$ o secundário do TCs conectado ao lado $\mathbf{Y}$ do transformador;

A Figura 33 apresenta o esquema de conexão do relé diferencial e dos TCs para um transformador $\mathrm{Y}-\Delta$.

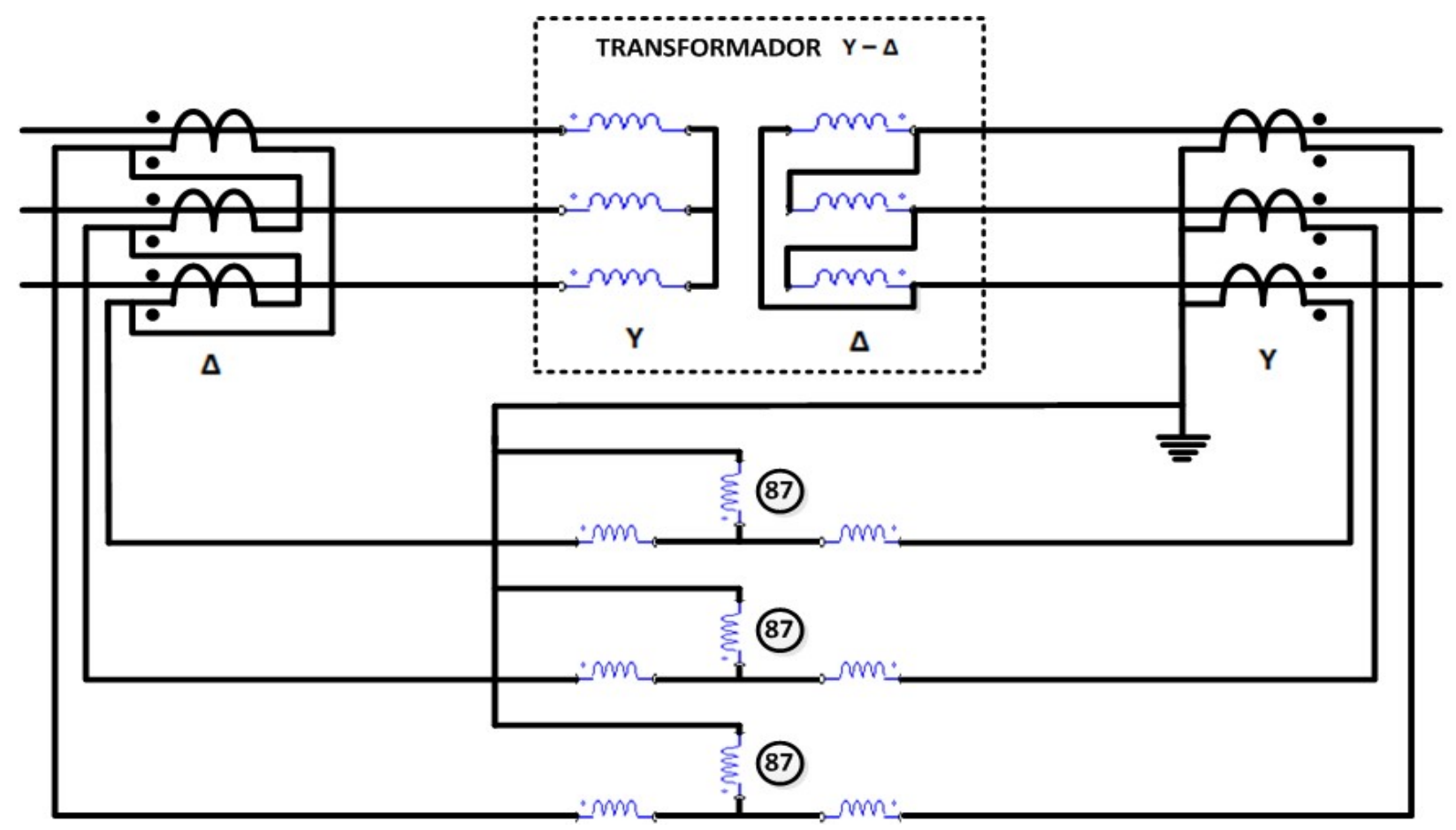

Figura 33 - Esquema de conexão dos TCs para a proteção diferencial de um transformador $Y-\Delta[15]$.

Na Figura 34 mostra o esquema de ligação do relé diferencial e dos TCs para um transformador conectado em $\Delta-\mathrm{Y}$, onde também são conectados em $\mathrm{Y}$ os TCs conectados ao lado $\Delta$ do transformador de potência, e vice-versa. 


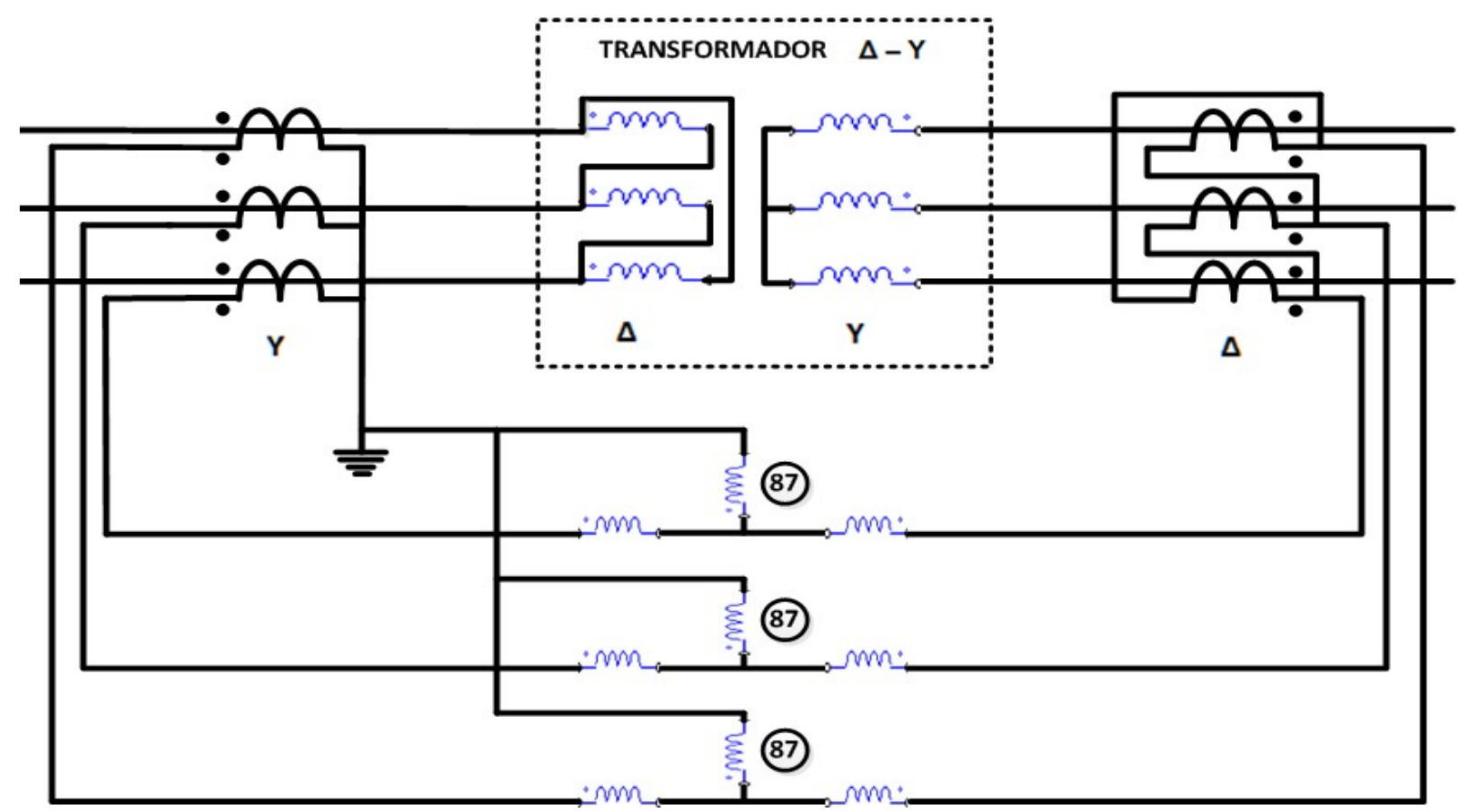

Figura 34 - Esquema de conexão dos TCs para a proteção diferencial de um transformador $\Delta-Y$ [15].

É importante mencionar que no caso dos relés de proteção digitais e numéricos, a compensação da defasagem angular da ligação dos transformadores de potência é feita no próprio software disponibilizado pelo fabricante para o ajuste de proteção.

Ainda se tratando da proteção diferencial, empregam-se alguns métodos para evitar que sua atuação seja indevida para os casos de energização dos transformadores de potência. Segundo [23], a corrente de magnetização (Inrush) apresenta valores altos devido ao fato de que o transformador é energizado com o lado secundário em aberto. A consequência é o elevado valor da corrente diferencial ocasionando a atuação indevida da proteção. Foram desenvolvidos alguns métodos para melhorar o desempenho da proteção, dentre os mais utilizados destacam-se o bloqueio da proteção diferencial e a restrição de harmônicas [24].

Normalmente, adota-se o bloqueio da proteção diferencial por 100 ms no momento da energização do transformador. No método da restrição de harmônicas, utilizam-se filtros que separam as correntes de $60 \mathrm{~Hz}$. Assim, o relé será capaz de distinguir se a corrente é de falta, onde há o predomínio da corrente fundamental em $60 \mathrm{~Hz}$ e poucas harmônicas, operando normalmente, ou se a corrente é de energização, apresentando um elevado conteúdo de harmônicas, principalmente da $2^{\mathrm{a}}$ harmônica, não havendo atuação da proteção.

O relé de proteção 7 UT61 da Siemens adota o método da restrição de harmônicos, pois apresenta algumas vantagens se comparado ao método de bloqueio 
da proteção diferencial, principalmente no caso de energização de transformador sob curto-circuito, onde o tempo adotado para o bloqueio da proteção pode vir a ser crucial para danificá-lo.

\subsubsection{Metodologia de ajuste da proteção diferencial em transformadores}

Primeiramente, deve-se garantir que as correntes que fluem nas bobinas de restrição no lado primário do transformador de potência são iguais as correntes do lado secundário. Além disso, os erros associados aos TCs que alimentam o relé diferencial deverão ser compensados e levados em consideração para o ajuste da proteção diferencial.

Destacam-se os erros dos TCs devido à sua classe de exatidão, geralmente de $2,5 \%, 5 \%$ ou $10 \%$. Assim, se ambos os TCs estiverem com erros iguais aos valores mencionados, o relé diferencial apresentará um erro total de 5\%, $10 \%$ e $20 \%$ respectivamente, ou seja, equivalente ao dobro. A comutação dos taps dos transformadores de potência também é uma fonte de erro para a proteção. $O$ ajuste da proteção deve considerar a condição normal de operação. A sensibilidade deve ser maior do que o erro produzido para a comutação do tap na condição limite, normalmente igual a $\pm 10 \%$ da tensão nominal do transformador de potência. [15]

O erro total do relé 87 é obtido em (4.6) sendo que o ajuste de sensibilidade do relé de proteção deverá ser maior que o valor encontrado.

$$
\varepsilon_{\text {erro total }}=\varepsilon_{\mathrm{TCs}}+\varepsilon_{\text {classe de exatidão }}+\varepsilon_{\text {comutação }}+\varepsilon_{\text {taps do relé } 87}+\varepsilon_{\text {segurança }}
$$

Em que $\varepsilon_{\mathrm{TCs}}$ é o erro devido à diferença nas relações de transformação dos TCs da mesma fase em ambos os lados do transformador de potência, $\boldsymbol{\varepsilon}_{\text {classe de exatidão refere- }}$

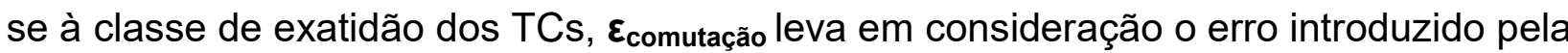
máxima comutação, $\boldsymbol{\varepsilon}_{\text {taps }}$ os erros devido aos taps do relé e $\boldsymbol{\varepsilon}_{\text {segurança }}$ é uma margem de segurança [15]. 
A metodologia para o ajuste de proteção diferencial para os relés eletromecânicos consiste basicamente nas seguintes etapas:

a) Ligação dos TCs no transformador de potência adotando a regra para compensar as diferenças angulares entre as correntes dos lados primários e secundário.

b) Cálculo das correntes nominais no lado de alta $\left(\mathrm{I}_{N, A T}\right)$ e baixa $\left(\mathrm{I}_{\mathrm{N}, \mathrm{BT}}\right)$ do transformador de potência através de (4.8) e (4.9), respectivamente, utilizando os valores nominais de tensão $\left(V_{N}\right)$, corrente $\left(I_{N}\right)$ e potência $\left(S_{\text {Nominal }}\right)$ do transformador.

$$
\begin{gathered}
\mathrm{S}_{\text {Nominal }}=\sqrt{3} \mathrm{~V}_{N} \mathrm{I}_{N} \\
\mathrm{I}_{\mathrm{N}, \mathrm{AT}}=\frac{\mathrm{S}_{\mathrm{Nominal}}}{\sqrt{3} V_{N, A T}} \\
\mathrm{I}_{\mathrm{N}, \mathrm{BT}}=\frac{\mathrm{S}_{\text {Nominal }}}{\sqrt{3} V_{N, B T}}
\end{gathered}
$$

c) Escolher as relações de transformação dos TCs (RTCs) dos lados primário e secundário do transformador. A corrente que flui no secundário do TC $\left(I_{S}\right)$ é obtida através da RTC escolhida e do valor do da corrente que flui no primário do TC $\left(I_{P}\right)$, sendo esta igual ao valor da corrente nominal para cada lado do transformador. A corrente do secundário do TC para o lado de alta $I_{S(T C, A T)}$ é obtida através de (4.10) e a corrente do secundário do TC do lado de baixa IS(TC,BT) em (4.11).

$$
\begin{aligned}
& \mathrm{I}_{\mathrm{S}(\mathrm{TC}, \mathrm{AT})}=\frac{\mathrm{I}_{\mathrm{P}, \mathrm{AT}}}{\mathrm{RTC}, \mathrm{AT}} \\
& \mathrm{I}_{\mathrm{S}(\mathrm{TC}, \mathrm{BT})}=\frac{\mathrm{I}_{\mathrm{P}, \mathrm{BT}}}{\mathrm{RTC}, \mathrm{BT}}
\end{aligned}
$$

d) Para os relés diferenciais que apresentam taps, deve-se escolher a relação a fim de que os valores das correntes das bobinas de restrição em ambos os lados sejam iguais. É necessário que a expressão (4.12) seja satisfeita.

$$
\frac{\mathrm{I}_{\text {Restrição,1 }}}{T A P, 1}=\frac{\mathrm{I}_{\text {Restrição,2 }}}{T A P, 2}
$$


$\mathrm{Na}$ Tabela 4.3 apresentam-se as possíveis combinações para as relações dos taps para as bobinas de restrição.

Tabela 4.3 - Valores das combinações de taps para o relé diferencial [15].

\begin{tabular}{|c|c|c|c|c|c|c|c|c|}
\hline Taps & $\mathbf{2 , 9}$ & $\mathbf{3 , 2}$ & $\mathbf{3 , 5}$ & $\mathbf{3 , 8}$ & $\mathbf{4 , 2}$ & $\mathbf{4 , 6}$ & $\mathbf{5 , 0}$ & $\mathbf{8 , 7}$ \\
\hline $\mathbf{2 , 9}$ & 1,000 & 1,103 & 1,207 & 1,310 & 1,448 & 1,586 & 1,724 & 3,000 \\
\hline $\mathbf{3 , 2}$ & & 1,000 & 1,094 & 1,188 & 1,313 & 1,438 & 1,563 & 2,719 \\
\hline $\mathbf{3 , 5}$ & & & 1,000 & 1,086 & 1,200 & 1,314 & 1,429 & 2,486 \\
\hline $\mathbf{3 , 8}$ & & & & 1,000 & 1,105 & 1,211 & 1,316 & 2,289 \\
\hline $\mathbf{4 , 2}$ & & & & & 1,000 & 1,905 & 1,190 & 2,071 \\
\hline $\mathbf{4 , 6}$ & & & & & & 1,000 & 1,087 & 1,890 \\
\hline $\mathbf{5 , 0}$ & & & & & & & 1,000 & 1,740 \\
\hline $\mathbf{8 , 7}$ & & & & & & & & 1,000 \\
\hline
\end{tabular}

e) Calcular o erro total para o relé diferencial

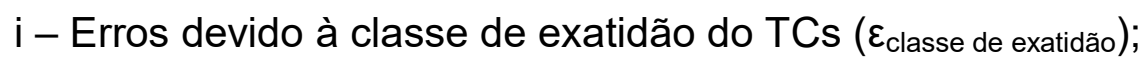

ii - Erros relacionados à comutação de tap do transformador de potência,

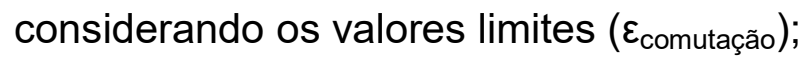

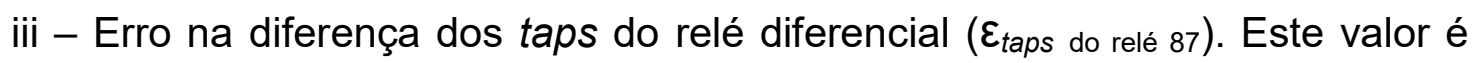
obtido pela expressão (4.15), que leva em consideração as correntes das

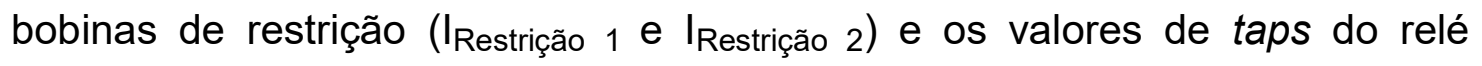
diferencial $\left(\operatorname{Tap}_{1}\right.$ e $\left.\mathrm{Tap}_{2}\right)$.

$$
\begin{gathered}
M_{1}=\frac{I_{\text {Restrição,1 }}}{\text { TAP, } 1} \\
M_{2}=\frac{I_{\text {Restrição, } 2}}{\text { TAP,2 }} \\
\varepsilon_{\text {taps do relé } 87}=\left(\frac{M_{1}-M_{2}}{M_{2}}\right) \times 100 \%
\end{gathered}
$$

O erro total é obtido em (4.6), sendo a soma de erro de cada parcela descrita. É necessário que o ajuste de sensibilidade do relé seja superior a este valor. Geralmente, usam-se ajustes de sensibilidade iguais a $25 \%, 35 \%$ e $45 \%$. Para os relés digitais, a faixa para a escolha do ajuste de sensibilidade varia de 15 a $80 \%$, dependendo do fabricante [15].

O procedimento realizado pelo relé da Siemens 7UT61 que será adotado neste trabalho segue basicamente os mesmos passos descritos anteriormente. Para os 
transformadores de potência conectados à terra, é necessário eliminar a componente de sequência zero. O deslocamento angular também deverá ser compensado. Na Figura 35 mostram-se os processos realizados por este relé para a proteção de um transformador de potência com o seu lado primário conectado em estrela-aterrado e em delta no seu lado secundário.

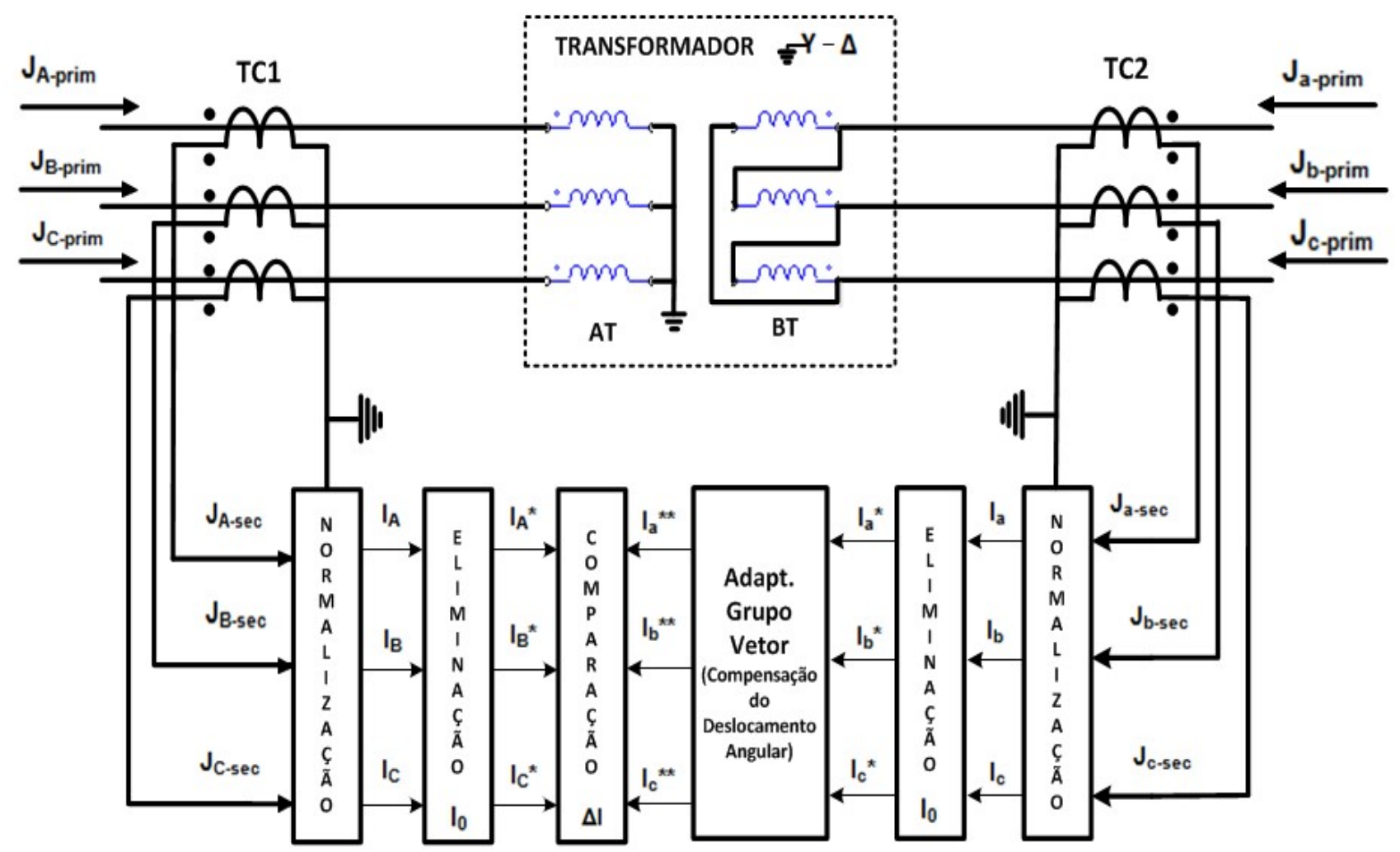

Figura 35 - Procedimento realizado pelo relé 7 UT6 da Siemens para a proteção diferencial [18].

A metodologia adotada por este relé de proteção é descrita abaixo:

a) $\mathrm{Na}$ etapa de normalização deve-se escolher a mesma base $\left(S_{\text {nominal }}\right)$ para que sejam efetuados os cálculos das correntes nominais do lado primário $\left(\mathrm{I}_{\mathrm{N}-\mathrm{AT}}\right)$ e secundário $\left(\mathrm{I}_{\mathrm{N}-\mathrm{BT}}\right)$ do transformador de potência, também obtidas através das expressões (4.8) e (4.9). As correntes de cada fase no lado primário $\left(\mathrm{I}_{\mathrm{A}}, \mathrm{I}_{\mathrm{B}}, \mathrm{I}_{\mathrm{C}}\right)$ e secundário $\left(I_{a}, I_{b}, I_{c}\right)$ são obtidas em (4.16) e (4.17), respectivamente, com base nas correntes nominais dos seus respectivos TCs $\left(I_{n-p r i m-T C 1}\right.$ e $\left.I_{n-p r i m-T C 2}\right)$, normalmente iguais a $1 \mathrm{~A}$ ou $5 \mathrm{~A}$. 


$$
\begin{aligned}
& {\left[\begin{array}{l}
I_{A} \\
I_{B} \\
I_{C}
\end{array}\right]=\frac{\mathrm{I}_{\mathrm{n}-\text { prim}-\mathrm{TC} 1}}{\mathrm{I}_{\mathrm{N}-\mathrm{AT}}} \cdot\left[\begin{array}{l}
\mathrm{J}_{\mathrm{A}-\mathrm{s}} \\
\mathrm{J}_{\mathrm{B}-\mathrm{sec}} \\
\mathrm{J}_{\mathrm{C}-\mathrm{sec}}
\end{array}\right]} \\
& {\left[\begin{array}{l}
I_{a} \\
I_{b} \\
I_{c}
\end{array}\right]=\frac{\mathrm{I}_{\mathrm{n}-\text { prim-TC2 }}}{\mathrm{I}_{\mathrm{N}-\mathrm{BT}}} \cdot\left[\begin{array}{l}
\mathrm{J}_{\mathrm{a}-\mathrm{s}} \\
\mathrm{J}_{\mathrm{b}-\mathrm{sec}} \\
\mathrm{J}_{\mathrm{c}-\mathrm{sec}}
\end{array}\right]}
\end{aligned}
$$

b) A eliminação da componente de sequência zero será necessária sempre que houver ligação à terra na conexão do transformador de potência. Por meio de (4.18) obtêm-se as correntes nas fases $A, B$ e $C\left(I_{A}^{*}, I_{B}{ }^{*}, I_{C}{ }^{*}\right)$ sem a contribuição da componente de sequência zero.

$$
\left[\begin{array}{l}
I_{A} * \\
I_{B} * \\
I_{C} *
\end{array}\right]=\frac{1}{3} \cdot\left[\begin{array}{ccc}
2 & -1 & -1 \\
-1 & 2 & -1 \\
-1 & -1 & 2
\end{array}\right] \cdot\left[\begin{array}{c}
I_{A} \\
I_{B} \\
I_{C}
\end{array}\right]
$$

c) A compensação do deslocamento angular é realizada somente no lado secundário, pois o lado de alta é adotado como referência. No cálculo, utilizase a constante $k$ que é o número que representa a defasagem angular da ligação. Os valores das correntes compensadas $\left(\mathrm{I}_{\mathrm{a}}{ }^{* *}, \mathrm{I}_{\mathrm{b}}{ }^{* *}\right.$ e $\left.\mathrm{I}_{\mathrm{c}}{ }^{* *}\right)$ são obtidas em (4.19).

$$
\left[\begin{array}{l}
I_{a} * * \\
I_{b} * * \\
I_{C} * *
\end{array}\right]=\frac{2}{3}\left[\begin{array}{ccc}
\cos \left[k \cdot 30^{\circ}\right] & \cos \left[(k+4) \cdot 30^{\circ}\right] & \cos \left[(k-4) \cdot 30^{\circ}\right] \\
\cos \left[(k-4) \cdot 30^{\circ}\right] & \cos \left[k \cdot 30^{\circ}\right] & \cos \left[(k+4) \cdot 30^{\circ}\right] \\
\cos \left[(k+4) \cdot 30^{\circ}\right] & \cos \left[(k-4) \cdot 30^{\circ}\right] & \cos \left[k \cdot 30^{\circ}\right]
\end{array}\right] \cdot\left[\begin{array}{c}
I_{A} \\
I_{B} \\
I_{C}
\end{array}\right]
$$

Por fim, depois de efetuadas todas essas etapas, a corrente diferencial para o relé de proteção é calculada.

\subsection{CONCLUSÃO}

O objetivo deste capítulo foi apresentar os procedimentos empregados para o ajuste das proteções de sobrecorrente e diferencial em transformadores de potência. Procurou-se apresentar a metodologia empregada pelo relé de proteção 7 UT6 da Siemens, pois será utilizado neste trabalho para o ajuste destas proteções. 


\section{Capítulo 5. RESULTADOS DO ESTUDO DE PROTEÇÃO}

Este capítulo destina-se a apresentação dos resultados dos ajustes das proteções de sobrecorrente e diferencial por meio da parametrização dos relés de proteção P143 da Alstom e 7UT61 da Siemens, respectivamente. O sistema escolhido para o estudo será o da SE Rondonópolis, em Mato Grosso, operado pela empresa Eletronorte, que apresenta 4 Transformadores de Potência (TRs) com níveis de tensão de 230/138/13,8kV com potência nominal de 100 MVA ligados em paralelo. No intuito de simplificar o estudo, serão somente parametrizadas as proteções dos lados de $230 \mathrm{kV}$ e $138 \mathrm{kV}$ dos TRs devido ao fato de que apenas um transformador utiliza o lado de $13,8 \mathrm{kV}$. Para isso, serão analisadas as contingências para o sistema, ou seja, a SE operando com os seus quatros, três, dois ou somente um TR. A Figura 36 mostra o diagrama unifilar simplificado dos TRs da SE Rondonópolis em que também é possível observar as LTs adjacentes.

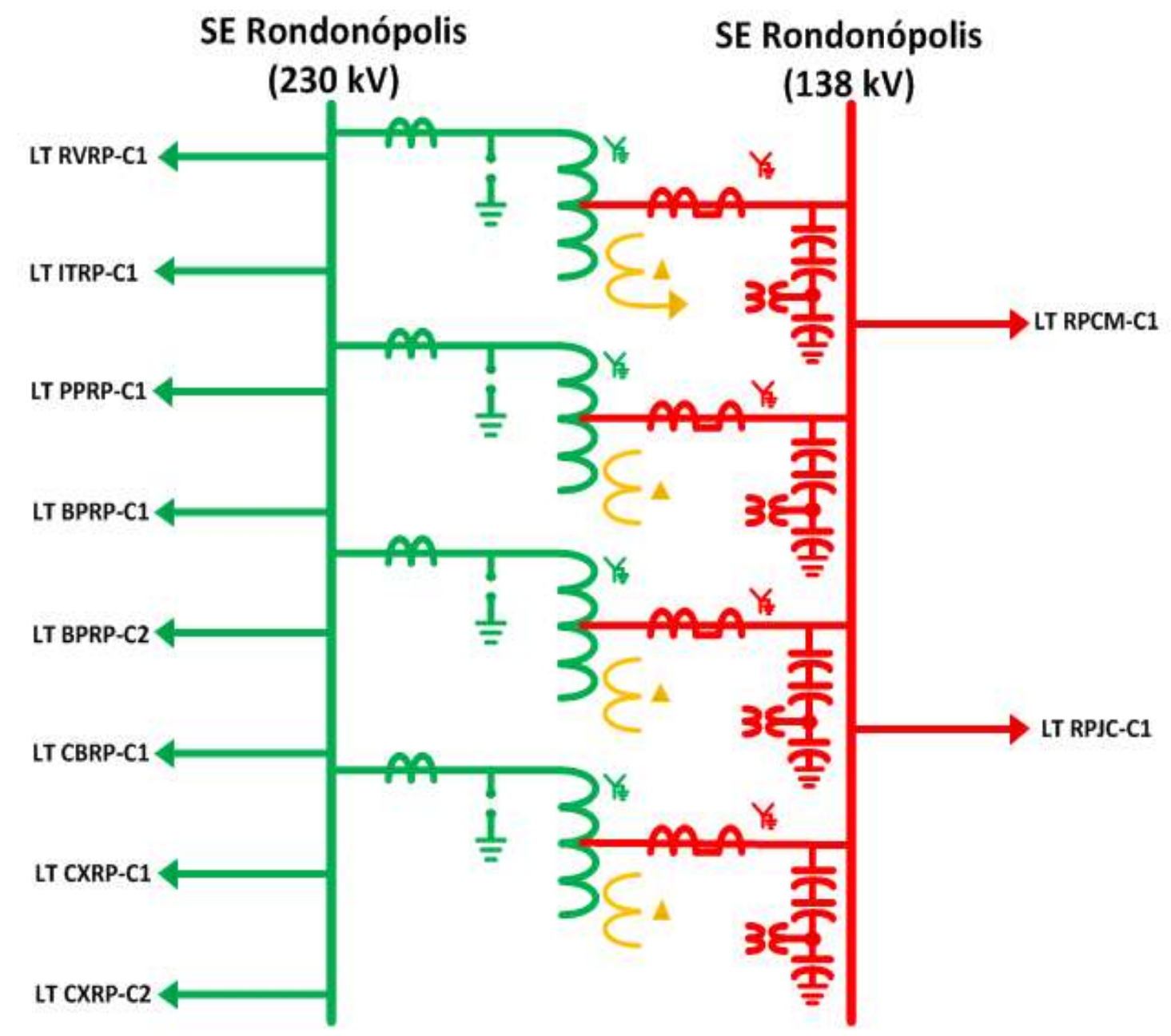

Figura 36 - Diagrama unifilar simplificado da SE Rondonópolis (MT). 


\subsection{ESTUDO DE GRADUAÇÃO DA PROTEÇÃO DOS ATs $230 / 138 / 13,8$ kV de 100 MVA DA SE RONDONÓPOLIS}

A Tabela 5.1 mostra os parâmetros das LTs ligadas a SE Rondonópolis (RP). Por meio dos valores, será escolhida a LT com menor impedância, representando um maior nível de curto-circuito, para o ajuste das proteções de retaguarda por meio das unidades de sobrecorrente. No lado de alta dos TRs foi escolhida a LT Itiquira Rondonópolis 230 kV e, no lado de baixa, a LT Rondonópolis - Jaciara 138 kV.

Tabela 5.1 - Parâmetros das linhas de transmissão ligadas a SE Rondonópolis.

\begin{tabular}{|c|c|c|c|c|c|}
\hline Circuito & L (km) & $R_{+}(\Omega)$ & $X_{+}(\Omega)$ & $R_{0}(\Omega)$ & $\mathrm{X}_{0}(\Omega)$ \\
\hline $\begin{array}{l}\text { LT Rondonópolis/ } \\
\text { Jaciara C1 } 138 \mathrm{kV} \\
\text { (LT RPJC-C1) }\end{array}$ & 69,0 & 13,3184 & 35,3781 & 37,2800 & 135,786 \\
\hline $\begin{array}{l}\text { LT Rondonópolis/ } \\
\text { Couto Magalhães C1 } 138 \mathrm{kV} \\
\text { (LT RPCM-C1) }\end{array}$ & 176,0 & 13,3184 & 35,3781 & 37,2800 & 135,786 \\
\hline $\begin{array}{l}\text { LT Rondonópolis/ } \\
\text { Cuiabá C1 230 kV } \\
\text { (LT CBRP-C1) }\end{array}$ & 171,5 & 6,7341 & 51,0379 & 51,7256 & 269,393 \\
\hline $\begin{array}{l}\text { LT Rondonópolis/ } \\
\text { Coxipó C1 230 kV } \\
\text { (LT CXRP-C1) }\end{array}$ & 188,0 & 17,1925 & 94,7968 & 82,4711 & 295,394 \\
\hline $\begin{array}{l}\text { LT Rondonópolis/ } \\
\text { Coxipó C2 230 kV } \\
\text { (LT CXRP-C2) }\end{array}$ & 188,0 & 17,1925 & 94,7968 & 82,4711 & 295,394 \\
\hline $\begin{array}{l}\text { LT Rondonópolis/ } \\
\text { Ponte de Pedra C1 230 kV } \\
\text { (LT PPRP-C1) }\end{array}$ & 130,0 & 12,0612 & 65,3315 & 60,0090 & 215,039 \\
\hline $\begin{array}{l}\text { LT Rondonópolis/ } \\
\text { Itiquira C1 230 kV } \\
\text { (LT ITRP-C1) }\end{array}$ & 82,0 & 8,09370 & 40,2040 & 33,3799 & 103,631 \\
\hline $\begin{array}{l}\text { LT Rondonópolis/ } \\
\text { Barra do Peixe C1 } 230 \mathrm{kV} \\
\text { (LT BPRP-C1) }\end{array}$ & 217,0 & 8,5698 & 64,7496 & 96,2780 & 312,526 \\
\hline $\begin{array}{l}\text { LT Rondonópolis/ } \\
\text { Barra do Peixe C2 } 230 \mathrm{kV} \\
\text { (LT BPRP-C2) }\end{array}$ & 217,1 & 8,5698 & 64,7496 & 96,2780 & 312,526 \\
\hline
\end{tabular}


A Tabela 5.2 apresenta os dados de placa dos TRs.

Tabela 5.2 - Dados de placa dos transformadores.

\begin{tabular}{|c|c|c|c|}
\hline Variável & Lado primário & Lado secundário & Lado terciário \\
\hline Potência de saída (MVA) & 100 & 100 & 2 \\
\hline Corrente nominal (A) & 251,0 & 418,4 & 83,7 \\
\hline Tensão nominal (kV) & 230 & 138 & 13,8 \\
\hline
\end{tabular}

\subsubsection{Definição das variáveis}

$$
\begin{aligned}
& S_{n}=100 \mathrm{MVA} \\
& V_{n p}=230 \mathrm{kV} \\
& V_{n s}=138 \mathrm{kV}
\end{aligned}
$$

\subsubsection{Cálculo das correntes nominais}

$$
\begin{aligned}
& I_{n p}=\frac{S_{n} \cdot 1000}{\sqrt{3} \cdot V_{n p}}=251,02 A \\
& I_{n s}=\frac{S_{n} \cdot 1000}{\sqrt{3} \cdot V_{n s}}=418,37 \mathrm{~A}
\end{aligned}
$$

\subsubsection{Determinação da relação de transformação do TC (RTC) do lado de $230 \mathrm{kV}$}

As relações disponíveis para os TCs são 400/800/1200/2000-5-5-5-5 A. A relação adotada deverá levar em consideração os seguintes critérios:

\subsubsection{1) $1^{\circ}$ Critério:}

A corrente nominal do TC deverá ser maior ou igual a 1,5 vezes a corrente de máximo carregamento do transformador. Portanto, a corrente nominal mínima do primário do TC deverá ser igual a:

$$
I_{\text {critério1_230kV }}=1,5 \cdot I_{n p}=376,53 \mathrm{~A}
$$

\subsubsection{2) $2^{\circ}$ Critério:}

A corrente nominal no lado primário do TC deverá ser maior que a máxima corrente de curto-circuito do transformador dividida por 20, levando em consideração o valor do fator de sobrecorrente (FS). O valor de máxima corrente de falta que circula no TC é obtida por meio de um curto-circuito trifásico no lado de $230 \mathrm{kV}$ do transformador, sendo igual a 9865 A como mostra a Tabela A.1 do Apêndice A. 


$$
\mathrm{I}_{\text {critério2_230kV }}=\frac{9865}{20}=493,25 \mathrm{~A}
$$

5.1.3.3) $3^{\circ}$ Critério: Sobredimensionamento do TC

a) De acordo com a norma IEC 6044-6 e adotando o TC de 800/5 A do tipo 10B800. O número 10 representa o erro máximo, em \%, a letra B significa que o TC é de baixa impedância e o número 800 , o valor de tensão, em volts, que o TC consegue entregar para a carga.

$$
\begin{aligned}
& \mathrm{RTC}_{-230 \mathrm{kV}}=\frac{800}{5} \\
& \mathrm{FS}_{-230 \mathrm{kV}}=20 \\
& \mathrm{~V}_{\text {sat_tC230kV }}=800 \mathrm{~V} \\
& \mathrm{I}_{\mathrm{n} \_ \text {prim_tC230kV }}=800 \mathrm{~A} \\
& \mathrm{I}_{\mathrm{n} \_ \text {sec_t }} \mathrm{TC230kV}=5 \mathrm{~A} \\
& \mathrm{~S}_{\mathrm{n}_{-} \mathrm{TC} 230 \mathrm{kV}}=\frac{\text { Vsat_TC230kV.In_sec_TC230kV }}{\mathrm{FS}}=\frac{800.5}{20}=200 \mathrm{VA}
\end{aligned}
$$

b) Cálculo do consumo do TC para a corrente nominal:

$$
\begin{gathered}
S_{\text {relé }}=0,3 \mathrm{VA} \\
\mathrm{D}_{\text {cond }}=0,20 \mathrm{~km} \\
\mathrm{R}_{\text {cond }}=5,52 \Omega / \mathrm{km} \\
\mathrm{S}_{\text {cond }}=2 \cdot \mathrm{R}_{\text {cond }} \cdot \mathrm{D}_{\text {cond }} \cdot \mathrm{I}_{\mathrm{n}_{\text {_sec_TC230 }}}{ }^{2}=55,2 \mathrm{VA} \\
\mathrm{S}_{\text {burden }}=\mathrm{S}_{\text {cond }}+\mathrm{S}_{\text {relé }}=55,5 \mathrm{VA}
\end{gathered}
$$

c) Cálculo de perdas do TC

$$
\begin{aligned}
& R_{\text {espiras_tc }}=0,0025 \Omega / \text { espira } \\
& R_{T C}=R_{\text {espiras_tc }} \cdot R_{T C} C_{230 k V}=0,4 \Omega \\
& S_{e}=R_{T C} . I_{n \_s e c \_T C 230^{2}}=10 \mathrm{VA}
\end{aligned}
$$

d) Cálculo do Fator NF (sobredimensionamento)

$$
N=20
$$




$$
\mathrm{NF} \_230 \mathrm{kV}=\mathrm{N} \cdot \frac{\mathrm{S}_{\mathrm{n} \_\mathrm{TC} 230 \mathrm{kV}}+\mathrm{S}_{\mathrm{e}}}{\mathrm{S}_{\mathrm{burden}}+\mathrm{S}_{\mathrm{e}}}=20 \cdot \frac{200+10}{55,5+10}=64,12
$$

A corrente de curto-circuito máxima externa passante no lado de $230 \mathrm{kV}$ é obtida por meio de uma falta trifásica na barra de $138 \mathrm{kV}$ da SE Rondonópolis operando com apenas 1 TR, como mostra a Tabela A.8 do Apêndice A.

$$
\mathrm{I}_{\text {CC_ext_230kV }}=2254,8 \mathrm{~A}
$$

Se o fator NF_230kV $\geq N F$, o TC atende ao critério de sobredimensionamento estabelecido pela norma:

$$
\mathrm{NF}=\frac{\mathrm{I}_{\text {CC_ext_230kV }}}{\mathrm{I}_{\mathrm{n} \_ \text {prim_tC230kV }}}=\frac{2254,8}{800}=2,8185
$$

Como NF_230 $\geq$ NF, o TC está sobredimensionado. Portanto, o TC será do tipo 10B800, com RTC igual a 800/5.

\subsubsection{Determinação da RTC do lado de 138 kV}

As relações disponíveis para os TCs são 400/800/1200/2000-5-5-5-5A. A relação adotada deverá levar em consideração os seguintes critérios:

\subsubsection{1) $1^{\circ}$ Critério:}

A corrente nominal do TC deverá ser maior ou igual a 1,5 vezes a corrente de máximo carregamento do transformador. Portanto, a corrente nominal mínima do primário do TC deverá ser igual a:

$$
\mathrm{I}_{\text {critério1_138kV }}=1,5 . \mathrm{INs}=627,55 \mathrm{~A}
$$

\subsubsection{2) $2^{\circ}$ Critério:}

A corrente nominal no lado primário do TC deverá ser maior que a máxima corrente de curto-circuito do transformador dividida por 20 . O valor de máxima corrente de falta que circula no TC é obtida por meio de uma falta trifásica no lado de $138 \mathrm{kV}$ do transformador, sendo esta igual a 16441,7 A.

$$
\mathrm{I}_{\text {critério__138 }}=\frac{16441,7}{20}=822,1 \mathrm{~A}
$$

Logo, o TC escolhido deverá possuir no lado secundário uma corrente superior a $800 \mathrm{~A}$, sendo, portanto igual a $1200 \mathrm{~A}$. 
5.1.4.3) $3^{\circ}$ Critério: Sobredimensionamento do TC

a) De acordo com a norma IEC 6044-6 e levando em consideração o resultado encontrado no $2^{\circ}$ critério, será analisado o TC 1200/5 A - 10B1200:

$$
\begin{aligned}
& \mathrm{RTC}_{-} 138 \mathrm{kV}=\frac{1200}{5} \\
& \mathrm{FS}_{-} 138 \mathrm{kV}=20 \\
& \mathrm{~V}_{\text {sat__C } 138 \mathrm{kV}}=1200 \mathrm{~V} \\
& I_{n \_p r i m \_T C 138 k V}=1200 \mathrm{~A} \\
& \mathrm{I}_{\mathrm{n} \_\mathrm{sec}} \mathrm{TC} 138 \mathrm{kV}=5 \mathrm{~A} \\
& \mathrm{~S}_{\mathrm{n}_{-} \mathrm{TC} 138 \mathrm{kV}}=\frac{\mathrm{Vsat}_{\mathrm{TC} 138 \mathrm{kV} \cdot \mathrm{In} \_\mathrm{sec} \_\mathrm{TC} 138 \mathrm{kV}}}{\mathrm{FS}}=\frac{1200.5}{20}=300 \mathrm{VA}
\end{aligned}
$$

b) Cálculo do consumo do TC para a corrente nominal

$$
\begin{gathered}
S_{\text {rele }}=0,3 \mathrm{VA} \\
D_{\text {cond }}: 0,20 \mathrm{~km} \\
R_{\text {cond }}=5,52 \Omega / \mathrm{km} \\
S_{\text {cond }}=2 \cdot R_{\text {cond }} \cdot D_{\text {cond. }} I_{n_{-} \text {sec_CT }_{-} 38^{2}}=55,2 \mathrm{VA} \\
S_{\text {burden }}=S_{\text {cond }}+S_{\text {rele }}=55,5 \mathrm{VA}
\end{gathered}
$$

c) Cálculo de perdas no TC

$$
\begin{aligned}
& R_{\text {espiras_tC }}=0,0025 \Omega / \text { espiras } \\
& \mathrm{R}_{\mathrm{TC} \_138 \mathrm{kV}}=\mathrm{R}_{\text {espiras__tC }} \cdot \mathrm{RTC}_{138}=0,6 \Omega
\end{aligned}
$$

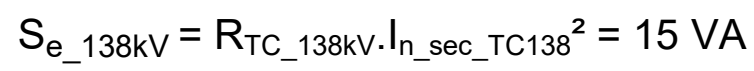

d) Cálculo do Fator NF (sobredimensionamento)

$$
N F \_138 \mathrm{kV}=\mathrm{N} \cdot \frac{\mathrm{S}_{\mathrm{n} \_\mathrm{TC} 138 \mathrm{kV}}+\mathrm{S}_{\mathrm{e}_{\_} 138 \mathrm{kV}}}{\mathrm{S}_{\text {burden }}+\mathrm{S}_{\mathrm{e}_{\_} 138 \mathrm{kV}}}=20 \cdot \frac{300+15}{55,5+15}=89,4
$$

A corrente de curto-circuito máxima externa passante no lado de $138 \mathrm{kV}$ se refere ao valor para a falta trifásica na barra de $138 \mathrm{kV}$ da SE Rondonópolis operando com 1 TR, como mostra a Tabela A.8 do Apêndice A. 


$$
\mathrm{I}_{\mathrm{cC} \_ \text {ext_138kV }}=3758 \mathrm{~A}
$$

Se o fator NF_138 $\geq N F$, o TC atende ao critério de sobredimensionamento estabelecido pela norma:

$$
\mathrm{NF}=\frac{\text { Icc_ext_138kV }}{\text { In_prim_TC138kV }}=\frac{3758}{1200}=3,13
$$

Como NF_138 $\geq \mathrm{NF}$, o TC está sobredimensionado. Logo, a RTC para o lado de $138 \mathrm{kV}$ é igual a 1200/5.

\subsection{AJUSTE DAS PROTEÇÕES NO LADO DE 230 kV}

O ajuste das proteções levará em consideração tanto os valores das correntes de curto-circuito, obtidas por meio do software de curto-circuito SAPRE do CEPEL, para as faltas internas ao transformador, como também para as faltas externas. Lembrando que a RTC obtida foi de $800 / 5 \mathrm{~A}$.

\subsubsection{Ajuste das proteções de sobrecorrente de fase (50/51)}

Como mencionado anteriormente, as proteções serão ajustadas conforme as quatro condições de contingências de operação da SE Rondonópolis. A Tabela 5.3 mostra os valores das correntes de curto-circuito trifásicas obtidas para as quatro condições de operação da SE Rondonópolis.

Tabela 5.3 - Valores das correntes de curto-circuito trifásicas para as quatro condições de operação.

\begin{tabular}{|c|c|c|c|c|}
\hline Descrição da falta & 1 TR & 2 TRs & 3 TRs & 4 TRs \\
\hline $\begin{array}{c}\text { Corrente de curto-circuito trifásico } \\
\text { no bay de 230kV da SE RP } \\
\text { medida no lado de 230 kV }\end{array}$ & $9178 \mathrm{~A}$ & $9608 \mathrm{~A}$ & $9775 \mathrm{~A}$ & $9865 \mathrm{~A}$ \\
\hline $\begin{array}{c}\text { Corrente de curto-circuito trifásico } \\
\text { no bay de 138kV da SE RP } \\
\text { medida no lado de 230 kV }\end{array}$ & $1164,6 \mathrm{~A}$ & $3096 \mathrm{~A}$ & $4345,8 \mathrm{~A}$ & $5249,4 \mathrm{~A}$ \\
\hline $\begin{array}{c}\text { Corrente de curto-circuito trif́́sico } \\
\text { na barra de 230kV da SE RP } \\
\text { medida no lado de 230 kV }\end{array}$ & $731 \mathrm{~A}$ & $408 \mathrm{~A}$ & $283 \mathrm{~A}$ & $215 \mathrm{~A}$ \\
\hline $\begin{array}{c}\text { Corrente de curto-circuito trif́sico } \\
\text { na barra de 138kV da SE RP } \\
\text { medida no lado de 230 kV }\end{array}$ & $2254,8 \mathrm{~A}$ & $1173 \mathrm{~A}$ & $1460,4 \mathrm{~A}$ & $1234,2 \mathrm{~A}$ \\
\hline $\begin{array}{c}\text { Corrente de curto-circuito trifásico } \\
\text { na barra de 230kV da SE IT } \\
\text { medida no lado de 230 kV }\end{array}$ & $193 \mathrm{~A}$ & $107 \mathrm{~A}$ & $74 \mathrm{~A}$ & $56 \mathrm{~A}$ \\
\hline $\begin{array}{c}\text { Corrente de curto-circuito trif́́sico } \\
\text { na barra de 138kV da SE JC } \\
\text { medida no lado de 230 kV }\end{array}$ & $11110,6 \mathrm{~A}$ & $681,6 \mathrm{~A}$ & $491,4 \mathrm{~A}$ & $381 \mathrm{~A}$ \\
\hline
\end{tabular}




\subsubsection{Ajuste da unidade de sobrecorrente temporizada (51)}

O relé de proteção utilizado para o ajuste das proteções de sobrecorrente será o P143 da ALSTOM. Na Figura 37 mostram-se as curvas IEC deste dispositivo, onde é possível observar que para as curvas normal inversa, muito inversa e de tempo muito inverso, o relé estabiliza para o múltiplo de corrente igual a 30, por outro lado, na curva extremamente inversa, este valor é igual a 20. Este valor será necessário para os estudos de coordenação das proteções.

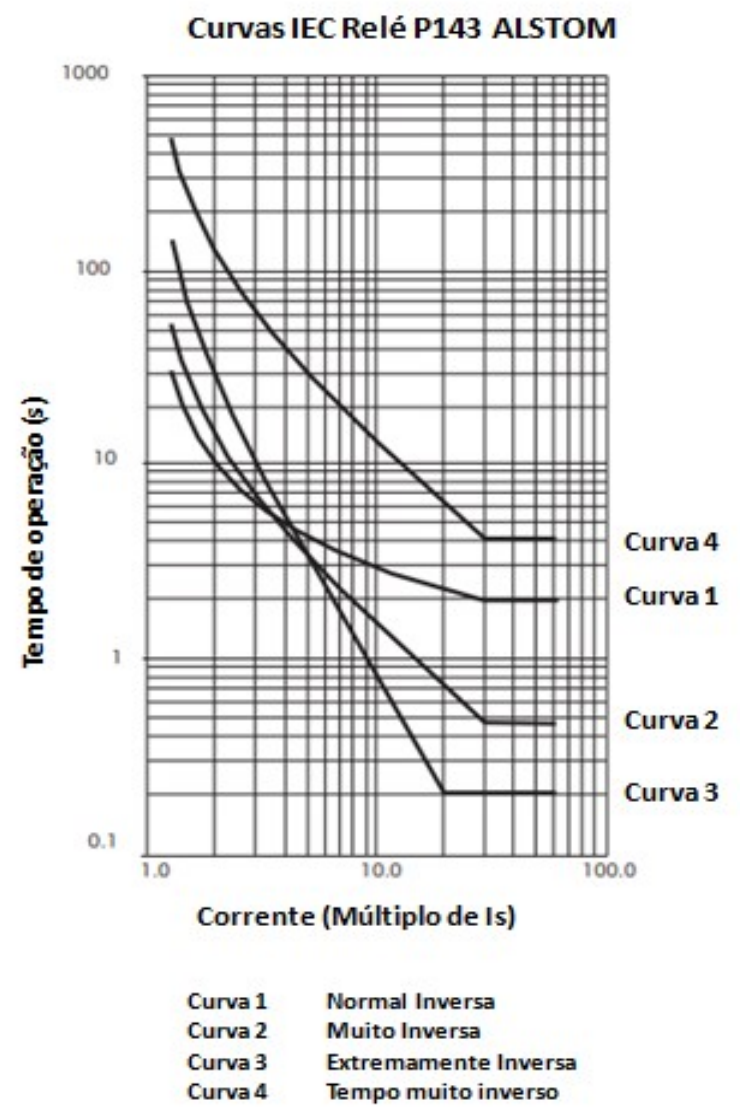

Figura 37 - Curvas IEC do relé de proteção P143 da ALSTOM. [29]

O ajuste da proteção deverá levar em consideração $150 \%$ para a condição de sobrecarga dos transformadores. Portanto, os seguintes passos são efetuados para a obtenção da corrente de pick-up do relé:

$$
\begin{gathered}
I_{N \_230}=251,02 \mathrm{~A} \\
I_{N \_230 s}=\frac{I N \_230}{R T C \_230}=1,569 \mathrm{~A} \\
I_{\text {Pick-up_UT_230s }}=1,5 . I_{N \_230 s}=2,35 \mathrm{~A}
\end{gathered}
$$


Portanto, o ajuste das proteções temporizadas será de 2,35 A. A curva escolhida foi do tipo normal inversa, cujo tempo de atuação é obtido por meio da equação (5.48) em que $\mathrm{M}$ é o múltiplo da corrente de curto-circuito com relação a corrente de pick-up,

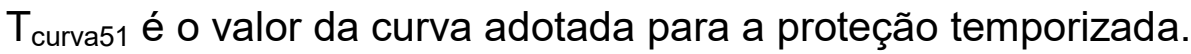

$$
t_{51}(M)=0,14 \cdot\left(\frac{\text { Tcurva51 }}{(M)^{0,02}-1}\right)
$$

Além disso, o ajuste da proteção deverá levar em consideração a corrente de Inrush, normalmente entre 8 a 10 vezes o valor da corrente nominal do TR.

- $\mathbf{M}_{\mathbf{0}}$ : Corrente de Inrush

$$
\begin{gathered}
I_{\text {inrush }}=8 . I_{N_{\_} 230}=2008,16 \mathrm{~A} \\
I_{\text {inrush_s }}=\frac{I_{\text {inrush }}}{\text { RTC_230kV }}=12,551 \mathrm{~A} \\
M_{0}=\frac{I_{\text {inrush_s }}}{I_{\text {Pick-u_UT_230s }}}=5,341 \\
t\left(M_{0}\right)=0,822 \mathrm{~s}
\end{gathered}
$$

A seguir serão apresentados os resultados para os tempos de atuações para os quatro grupos de ajustes, sendo utilizado o mesmo procedimento para a obtenção do tempo de atuação para a corrente de Inrush, descrito anteriormente.

\section{a) Grupo de Ajuste 1 - SE Rondonópolis operando com 1 TR}

A Tabela 5.4 mostra que para o Grupo de Ajuste 1 foi escolhida a curva IEC normal inversa com valor igual a 0,2 .

Tabela 5.4 - Coordenação da proteção de sobrecorrente de fase (51) no lado de $230 \mathrm{kV}$ para o grupo de

\begin{tabular}{|c|c|c|c|c|}
\hline \multirow{2}{*}{ Curva 51} & \multirow{2}{*}{$=$} & \multirow{2}{*}{0,2} & \multirow{2}{*}{$\begin{array}{l}\text { Sobrecorrente temporizada de } \\
\text { fase (51) no lado de } 230 \mathrm{kV}\end{array}$} & Ipick-up (A) \\
\hline & & & & 2,35 \\
\hline \multicolumn{5}{|c|}{ Tempo de atuação $=\left(0,14^{*}\right.$ Curva51) $/\left(\mathrm{M}^{\wedge} 0,02-1\right)$} \\
\hline Descrição da falta & $\mathbf{M}$ & Valor & tempo de atuação (s) & Icc $230 \mathrm{kV}(\mathrm{A})$ \\
\hline Inrush & MO & 5,341 & 0,822 & 12,551 \\
\hline Lado de $230 \mathrm{kV}$ do TR & M1 & 24,410 & 0,424 & 57,363 \\
\hline Lado de $138 \mathrm{kV}$ do TR & M2 & 3,097 & 1,224 & 7,279 \\
\hline Barra de $230 \mathrm{kV}$ da SE RP & M3 & 1,944 & 2,092 & 4,568 \\
\hline Barra 138 kV da SE RP & M4 & 5,997 & 0,768 & 14,093 \\
\hline Barra de 230 kV da SE IT & M5 & 0,511 & "n/o" & 1,200 \\
\hline Barra de 138 kV da SE JC & M6 & 2,954 & 1,279 & 6,941 \\
\hline
\end{tabular}
ajuste 1.

\section{1}

\section{Grupo de Ajuste 1 - SE Rondonópolis operando com 1 transformador}

Estudo de coordenação da proteção de fase (51) no lado de 230 kV dos TRs da SE Rondonópolis - MT 
O tipo da curva escolhido do tipo normal inversa por facilitar na coordenação com as outras proteções das LTs adjacentes. Quanto aos resultados, observa-se que o tempo de atuação para a corrente de Inrush é bastante superior ao seu tempo de decaimento, da ordem de $100 \mathrm{~ms}$ [26], portanto a proteção de sobrecorrente não atuará de forma incorreta no instante da energização do TR.

O intuito principal foi coordenar com as proteções das LTs a jusante, ou seja, com nível de tensão igual a $138 \mathrm{kV}$, sendo que o tempo de atuação adotado para a retaguarda destas LTs e para a barra de $138 \mathrm{kV}$ da SE Rondonópolis foi superior ao tempo de segunda zona das proteções de distância, da ordem de 650ms, garantindo os critérios de coordenação e a seletividade com essas LTs.

Os resultados mostram que a proteção levará mais de 1 segundo para eliminar uma falta trifásica na LT Rondonópolis - Jaciara $138 \mathrm{kV}$, valor este considerado elevado podendo vir a causar danos nos equipamentos das SEs. Além disso, o termo "n/o" (não operação) revela que o relé não será sensível na eliminação do curto-circuito na LT Itiquira - Rondonópolis $230 \mathrm{kV}$, devido ao valor de tempo obtido mediante a equação (5.48).

O relé de proteção $\mathrm{P} 143$ da Alstom foi parametrizado com os ajustes definidos para este grupo de ajuste. A Tabela 5.5 mostra que os pontos dos testes foram todos aprovados. O termo Is representa a corrente de pick-up, In a corrente nominal no secundário do relé, igual a 5A, e L1-L2-L3 representam as correntes nas fases A, B e C.

Tabela 5.5 - Resultados do teste da proteção de sobrecorrente temporizada de fase (51) no lado de $230 \mathrm{kV}$ para o grupo de ajuste 1.

\begin{tabular}{|c|c|c|c|c|c|}
\hline Falta & $(I / / n * \mid s)$ & Tempo nominal (s) & Tempo real (s) & Desvio (\%) & Resultado \\
\hline L1 - L2- L3 & 1,200 & 7,665 & 7,842 & 2,311 & Aprovado \\
\hline L1 - L2- L3 & 1,500 & 3,439 & 3,488 & 1,430 & Aprovado \\
\hline L1 - L2- L3 & 1,800 & 2,368 & 2,406 & 1,620 & Aprovado \\
\hline L1 - L2- L3 & 2,100 & 1,873 & 1,904 & 1,677 & Aprovado \\
\hline L1 - L2- L3 & 2,400 & 1,585 & 1,607 & 1,345 & Aprovado \\
\hline L1 - L2- L3 & 2,700 & 1,396 & 1,416 & 1,429 & Aprovado \\
\hline L1 - L2- L3 & 3,000 & 1,260 & 1,285 & 1,913 & Aprovado \\
\hline L1 - L2- L3 & 3,300 & 1,159 & 1,183 & 2,127 & Aprovado \\
\hline L1 - L2- L3 & 3,600 & 1,079 & 1,101 & 2,001 & Aprovado \\
\hline L1 - L2- L3 & 3,900 & 1,015 & 1,029 & 1,366 & Aprovado \\
\hline L1 - L2- L3 & 4,200 & 0,961 & 0,979 & 1,849 & Aprovado \\
\hline L1 - L2- L3 & 4,500 & 0,916 & 0,931 & 1,595 & Aprovado \\
\hline L1 - L2- L3 & 4,800 & 0,878 & 0,896 & 2,028 & Aprovado \\
\hline
\end{tabular}

A Figura 38 apresenta a curva de atuação, em escala logarítmica, para o teste trifásico com os pontos testados e aprovados, na cor verde, pelo relé de proteção P143. 


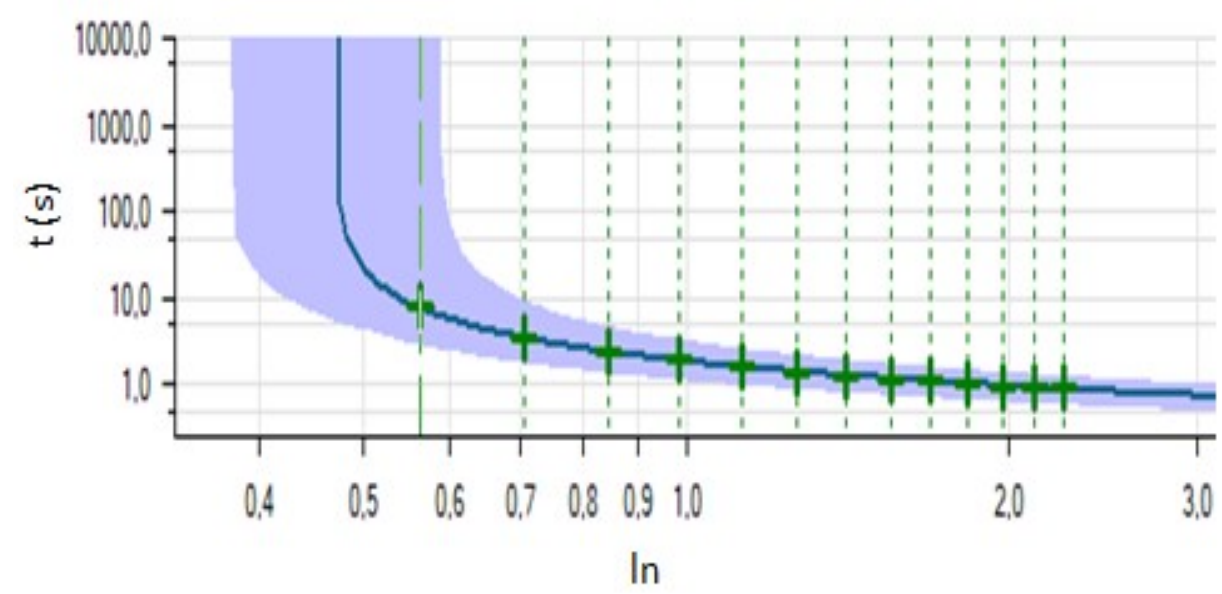

Figura 38 - Pontos aprovados no teste da proteção 51 para o grupo de ajuste 1.

\section{b) Grupo de Ajuste 2 - SE Rondonópolis operando com 2 TRs}

A curva de atuação adotada para este grupo de ajuste também foi do tipo normal inversa com valor igual a 0,175. A Tabela 5.6 mostra o estudo de coordenação com os tempos de atuação para este grupo de ajuste.

Tabela 5.6 - Coordenação da proteção de sobrecorrente temporizada de fase (51) no lado de $230 \mathrm{kV}$ para o grupo de ajuste 2 .

\section{1}

\section{Grupo de Ajuste 2 - SE Rondonópolis operando com 2 transformadores}

Estudo de coordenação da proteção de fase (51) no lado de 230 kV dos TRs da SE Rondonópolis - MT

\begin{tabular}{|c|c|c|c|c|}
\hline \multirow{2}{*}{ Curva 51} & \multirow{2}{*}{$=$} & \multirow{2}{*}{0,175} & \multirow{2}{*}{$\begin{array}{l}\text { Sobrecorrente temporizada de } \\
\text { fase (51) no lado de } 230 \mathrm{kV}\end{array}$} & Ipick-up (A) \\
\hline & & & & 2,35 \\
\hline \multicolumn{5}{|c|}{ Tempo de atuação $=\left(0,14^{*}\right.$ Curva51) $/\left(\mathrm{M}^{\wedge} 0,02-1\right)$} \\
\hline Descrição & $\mathbf{M}$ & Valor & tempo de atuação (s) & Icc $230 \mathrm{kV}(\mathrm{A})$ \\
\hline Inrush & M) & 5,341 & 0,719 & 12,551 \\
\hline Lado de $230 \mathrm{kV}$ do TR & M1 & 25,553 & 0,366 & 60,050 \\
\hline Lado de $138 \mathrm{kV}$ do TR & $\mathrm{M} 2$ & 8,234 & 0,569 & 19,350 \\
\hline Barra 230 kV da SE RP & M3 & 1,085 & 14,986 & 2,550 \\
\hline Barra 138 kV da SE RP & M4 & 4,715 & 0,778 & 11,081 \\
\hline Barra de $230 \mathrm{kV}$ da SE IT & M5 & 0,281 & "n/o" & 0,660 \\
\hline Barra de $138 \mathrm{kV}$ da SE JC & M6 & 1,813 & 2,047 & 4,260 \\
\hline
\end{tabular}

O tempo de atuação da proteção para a retaguarda da barra de $138 \mathrm{kV}$ da SE Rondonópolis continuou atendendo ao critério de considerar o tempo de segunda zona das LTs. Os resultados mostram que os tempos de atuação obtidos para a eliminação da falta na LT Rondonópolis - Jaciara 138 kV e na barra de 230 kV da SE Rondonópolis foram bastante elevados, podendo causar riscos físicos aos equipamentos das SEs. Porém, este risco será minimizado com o ajuste da proteção de sobrecorrente com 
controle de tensão 51V. Novamente, a proteção não foi sensível à falta na LT Itiquira Rondonópolis $230 \mathrm{kV}$, devido ao baixo valor da corrente de curto-circuito.

A Tabela 5.7 mostra que os pontos para o teste trifásico da proteção de sobrecorrente temporizada foram todos aprovados. Os tempos de atuação real da proteção se aproximam dos tempos nominais, com desvios abaixo de $3 \%$, o que mostra que o relé P143 atua com bastante exatidão na eliminação das faltas. A Figura 39 apresenta a curva parametrizada com os pontos aprovados pelo teste.

Tabela 5.7 - Resultados do teste da proteção de sobrecorrente temporizada de fase (51) no lado de 230kV para o grupo de ajuste 2.

\begin{tabular}{|c|c|c|c|c|c|}
\hline Falta & $(I / / n * \mid s)$ & Tempo nominal (s) & Tempo real (s) & Desvio (\%) & Resultado \\
\hline L1 - L2- L3 & 1,200 & 6,707 & 6,880 & 2,579 & Aprovado \\
\hline L1 - L2- L3 & 1,500 & 3,009 & 3,060 & 1,689 & Aprovado \\
\hline L1 - L2- L3 & 1,800 & 2,072 & 2,105 & 1,590 & Aprovado \\
\hline L1 - L2- L3 & 2,100 & 1,639 & 1,666 & 1,656 & Aprovado \\
\hline L1 - L2- L3 & 2,400 & 1,387 & 1,414 & 1,944 & Aprovado \\
\hline L1 - L2- L3 & 2,700 & 1,221 & 1,236 & 1,219 & Aprovado \\
\hline L1 - L2- L3 & 3,000 & 1,103 & 1,123 & 1,855 & Aprovado \\
\hline L1 - L2- L3 & 3,300 & 1,014 & 1,029 & 1,536 & Aprovado \\
\hline L1 - L2- L3 & 3,600 & 0,944 & 0,966 & 2,337 & Aprovado \\
\hline L1 - L2- L3 & 3,900 & 0,887 & 0,900 & 1,442 & Aprovado \\
\hline L1 - L2- L3 & 4,200 & 0,841 & 0,861 & 2,327 & Aprovado \\
\hline L1 - L2- L3 & 4,500 & 0,802 & 0,824 & 2,797 & Aprovado \\
\hline L1 - L2- L3 & 4,800 & 0,768 & 0,785 & 2,139 & Aprovado \\
\hline
\end{tabular}

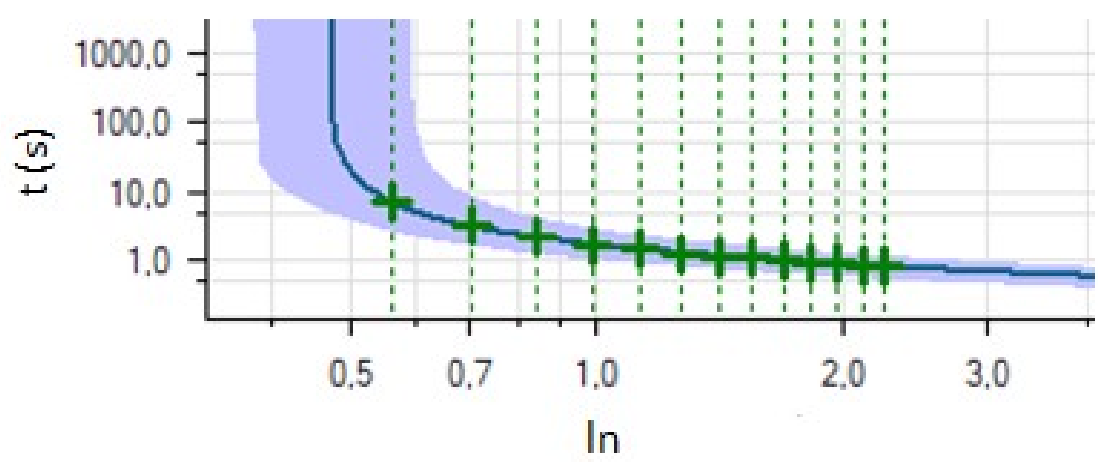

Figura 39 - Pontos de testes aprovados pela proteção 51 para o grupo de ajuste 2.

\section{c) Grupo de Ajuste 3 - SE Rondonópolis operando com 3 TRs}

A curva adotada para este grupo de ajuste também foi do tipo normal inversa com valor igual a 0,15 . A Tabela 5.8 mostra os tempos de atuação da proteção para este grupo de ajuste. A proteção de retaguarda da barra de 138kV da SE Rondonópolis continua obedecendo ao requisito de coordenação com as segundas zonas das LTs adjacentes. Entretanto, é possível observar que o tempo para a retaguarda da LT Rondonópolis - Jaciara $138 \mathrm{kV}$ é bastante elevado podendo comprometer o sistema. Além disso, a proteção não consegue ser sensibilizada para defeitos na barra de $230 \mathrm{kV}$ 
da SE Rondonópolis e nem na LT Itiquira - Rondonópolis de $230 \mathrm{kV}$, devido ao fato de que os valores das correntes de curto-circuito são inferiores à corrente de pick-up. Este que será minimizado por meio do ajuste da proteção de sobrecorrente com controle de tensão (51V).

Tabela 5.8 - Coordenação da proteção de sobrecorrente de fase (51) no lado de 230 kV para o grupo de ajuste 3 .

\section{1}

Grupo de Ajuste 3 - SE Rondonópolis operando com 3 transformadores

Estudo de coordenação da proteção de fase (51) no lado de 230 kV dos TRs da SE Rondonópolis - MT

\begin{tabular}{|c|c|c|c|c|}
\hline \multirow{2}{*}{ Curva 51} & \multirow{2}{*}{$=$} & \multirow{2}{*}{0,15} & \multirow{2}{*}{$\begin{array}{l}\text { Sobrecorrente temporizada de } \\
\text { fase (51) no lado de } 230 \mathrm{kV}\end{array}$} & Ipick-up (A) \\
\hline & & & & 2,35 \\
\hline \multicolumn{5}{|c|}{ Tempo de atuação $=\left(0,14^{*}\right.$ Curva51) $/\left(\mathrm{M}^{\wedge} 0,02-1\right)$} \\
\hline Descrição & $\mathbf{M}$ & Valor & tempo de atuação (s) & Icc 230kV (A) \\
\hline Inrush & MO & 5,341 & 0,616 & 12,551 \\
\hline Lado de $230 \mathrm{kV}$ do TR & M1 & 25,996 & 0,312 & 61,090 \\
\hline Lado de $138 \mathrm{kV}$ do TR & $\mathrm{M} 2$ & 11,558 & 0,419 & 27,161 \\
\hline Barra $230 \mathrm{kV}$ da SE RP & M3 & 0,749 & $" n / o "$ & 1,760 \\
\hline Barra 138 kV da SE RP & M4 & 3,884 & 0,763 & 9,128 \\
\hline Barra de $230 \mathrm{kV}$ da SE IT & M5 & 0,196 & "n/o" & 0,460 \\
\hline Barra de $138 \mathrm{kV}$ da SE JC & M6 & 1,307 & 3,912 & 3,071 \\
\hline
\end{tabular}

Na Tabela 5.9 é possível observar que os pontos testados para este grupo de ajuste foram todos aprovados com tempos de atuação bastante próximos dos tempos nominais.

Tabela 5.9 - Resultados do teste da proteção de sobrecorrente temporizada de fase (51) no lado de $230 \mathrm{kV}$ para o grupo de ajuste 3.

\begin{tabular}{|c|c|c|c|c|c|}
\hline Falta & $\mathbf{( I / I n * I s )}$ & Tempo nominal (s) & Tempo real (s) & Desvio (\%) & Resultado \\
\hline $\mathrm{L} 1-\mathrm{L} 2-\mathrm{L} 3$ & 1,200 & 5,749 & 5,894 & 2,530 & Aprovado \\
\hline $\mathrm{L} 1-\mathrm{L} 2-\mathrm{L} 3$ & 1,500 & 2,579 & 2,625 & 1,759 & Aprovado \\
\hline $\mathrm{L} 1-\mathrm{L} 2-\mathrm{L} 3$ & 1,800 & 1,776 & 1,800 & 1,347 & Aprovado \\
\hline $\mathrm{L} 1-\mathrm{L} 2-\mathrm{L} 3$ & 2,100 & 1,405 & 1,435 & 2,176 & Aprovado \\
\hline $\mathrm{L} 1-\mathrm{L} 2-\mathrm{L} 3$ & 2,400 & 1,189 & 1,219 & 2,533 & Aprovado \\
\hline $\mathrm{L} 1-\mathrm{L} 2-\mathrm{L} 3$ & 2,700 & 1,047 & 1,062 & 1,484 & Aprovado \\
\hline $\mathrm{L} 1-\mathrm{L} 2-\mathrm{L} 3$ & 3,000 & 0,945 & 0,968 & 2,413 & Aprovado \\
\hline $\mathrm{L} 1-\mathrm{L} 2-\mathrm{L} 3$ & 3,300 & 0,869 & 0,885 & 1,888 & Aprovado \\
\hline $\mathrm{L} 1-\mathrm{L} 2-\mathrm{L} 3$ & 3,600 & 0,809 & 0,827 & 2,304 & Aprovado \\
\hline $\mathrm{L} 1-\mathrm{L} 2-\mathrm{L} 3$ & 3,900 & 0,761 & 0,783 & 2,923 & Aprovado \\
\hline $\mathrm{L} 1-\mathrm{L} 2-\mathrm{L} 3$ & 4,200 & 0,721 & 0,734 & 1,856 & Aprovado \\
\hline $\mathrm{L} 1-\mathrm{L} 2-\mathrm{L} 3$ & 4,500 & 0,687 & 0,702 & 2,130 & Aprovado \\
\hline $\mathrm{L} 1-\mathrm{L} 2-\mathrm{L} 3$ & 4,800 & 0,658 & 0,683 & 3,667 & Aprovado \\
\hline
\end{tabular}

A Figura 40 apresenta a curva adotada com os pontos aprovados pelo teste. 


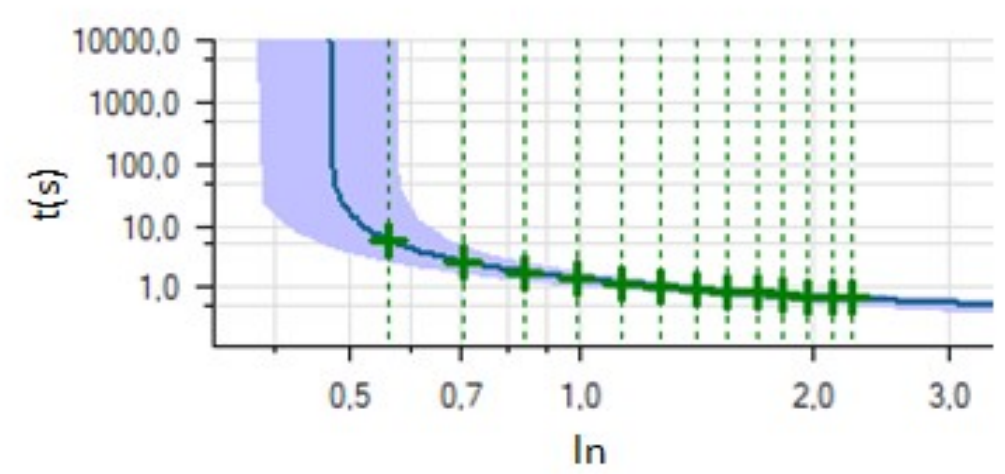

Figura 40 - Pontos de testes aprovados pela proteção 51 para o grupo de ajuste 3.

\section{d) Grupo de Ajuste 4 - SE Rondonópolis operando com 4 TRs}

A curva escolhida para este grupo de ajuste também foi do tipo normal inversa com valor igual a 0,15. A Tabela 5.10 mostra que a proteção é capaz de eliminar os defeitos na zona de proteção dos TRs com tempo de atuação de, aproximadamente, $300 \mathrm{~ms}$, valor este bastante adequado para a retaguarda da proteção diferencial dos ATs. O termo "n/o" revela que para as faltas na barra de $230 \mathrm{kV}$ da SE Rondonópolis e na LT Itiquira - Rondonópolis $230 \mathrm{kV}$, a proteção não é sensível devido aos baixos valores das correntes de curto-circuito. Além disso, o tempo de eliminação para a LT Rondonópolis - Jaciara 138 kV é bastante elevado (79,473s) podendo causar sérios danos nos equipamentos das SEs caso não ocorra atuação das proteções das LTs. Devido ao fato de que o ajuste da curva é igual ao do Grupo de Ajuste 3, os resultados para os pontos de testes e a curva são iguais, seguindo a Tabela 5.9 e a Figura 40.

Tabela 5.10 - Coordenação da proteção de sobrecorrente de fase (51) no lado de $230 \mathrm{kV}$ para o grupo de ajuste 4 .

51

Grupo de Ajuste 4 - SE Rondonópolis operando com 4 transformadores

Estudo de coordenação da proteção de fase (51) do lado de 230 kV dos TRs da SE Rondonópolis - MT

\begin{tabular}{|c|c|c|c|c|}
\hline \multirow{2}{*}{ Curva 51} & \multirow{2}{*}{$=$} & \multirow{2}{*}{0,15} & \multirow{2}{*}{$\begin{array}{l}\text { Sobrecorrente temporizado de } \\
\text { fase (51) no lado de } 230 \mathrm{kV}\end{array}$} & \multirow{2}{*}{$\frac{\text { Ipick-up (A) }}{2,35}$} \\
\hline & & & & \\
\hline \multicolumn{5}{|c|}{ Tempo de atuação $=\left(0,14^{*} \operatorname{Curva51}\right) /\left(\mathrm{M}^{\wedge} 0,02-1\right)$} \\
\hline Descrição & $\mathbf{M}$ & Valor & tempo de atuação (s) & $\operatorname{Icc} 230 \mathrm{kV}(\mathrm{A})$ \\
\hline Inrush & M0 & 5,341 & 0,616 & 12,551 \\
\hline Lado de $230 \mathrm{kV}$ do TR & M1 & 26,234 & 0,311 & 61,650 \\
\hline Lado de 138 kV do TR & $\mathrm{M} 2$ & 13,957 & 0,388 & 32,800 \\
\hline Barra 230 kV da SE RP & M3 & 0,570 & "n/o" & 1,340 \\
\hline Barra 138 kV da SE RP & M4 & 3,282 & 0,873 & 7,714 \\
\hline Barra de $230 \mathrm{kV}$ da SE IT & M5 & 0,149 & "n/o" & 0,350 \\
\hline Barra de 138 kV da SE JC & M6 & 1,013 & 79,473 & 2,381 \\
\hline
\end{tabular}




\subsubsection{Ajuste da unidade de sobrecorrente instantânea (50)}

A proteção de sobrecorrente instantânea deverá ser ajustada acima da corrente de Inrush e não deverá atuar para as faltas na barra de $138 \mathrm{kV}$. A maior corrente de curto-circuito é obtida na condição de operação de apenas 1 TR (ICC_FFF_138_barra_1AT), sendo igual a 2254,8 A como mostra a na Tabela A.8 do Apêndice A.

$$
I_{\text {Pick-up_UI_230p }}=1,5 . I_{\text {CC_FFF_138_barra_1AT }}=3382,2 \mathrm{~A}
$$

Logo, o ajuste da unidade instantânea satisfaz a condição $I_{\text {pick-up_Ul_230p }}>I_{\text {inrush }}$.

O ajuste escolhido para unidade instantânea será:

$$
\begin{gathered}
\text { I Pick-up_UI_230p }=3500 \mathrm{~A} \\
\text { I }_{\text {Pick-up_UI_230s }}=\frac{\text { Ipick-up_UI_230p }}{\text { RTC_230kV }}=21,875 \mathrm{~A} \\
\text { IPick-up_UI_230s }=22 \mathrm{~A}
\end{gathered}
$$

O múltiplo da corrente de pick-up da proteção instantânea com relação ao pick-up da proteção temporizada é obtido em (5.57), sendo o tempo de atuação igual à zero.

$$
\begin{gathered}
\text { MUI_230kV }=\frac{\text { Ipick-up_UI_230s }}{\text { Ipick-up_UT_230s }}=\frac{22}{2,35}=9,36 \\
t_{\text {atuação_UI_230kV }}=0 \mathrm{~s}
\end{gathered}
$$

O ajuste foi verificado por meio do módulo de teste ramping em que é possível aumentar ou diminuir dois tipos de parâmetros de forma linear. Neste caso, a corrente de falta foi aumentada até a corrente de pick-up para verificar o sinal de trip. Devido às limitações quanto à máxima corrente de saída que a mala de teste OMICRON CMC 256-6 injeta, equivalente a 12.5 A, o teste foi realizado com uma corrente de pick-up menor, igual a $10 \mathrm{~A}$, e com a rampa variando de $9.2 \mathrm{~A}$ até $11 \mathrm{~A}$. A Figura 41 mostra a atuação da proteção instantânea em que é possível observar que quando a corrente atinge o valor igual a $10 \mathrm{~A}$, ocorre o trip. 


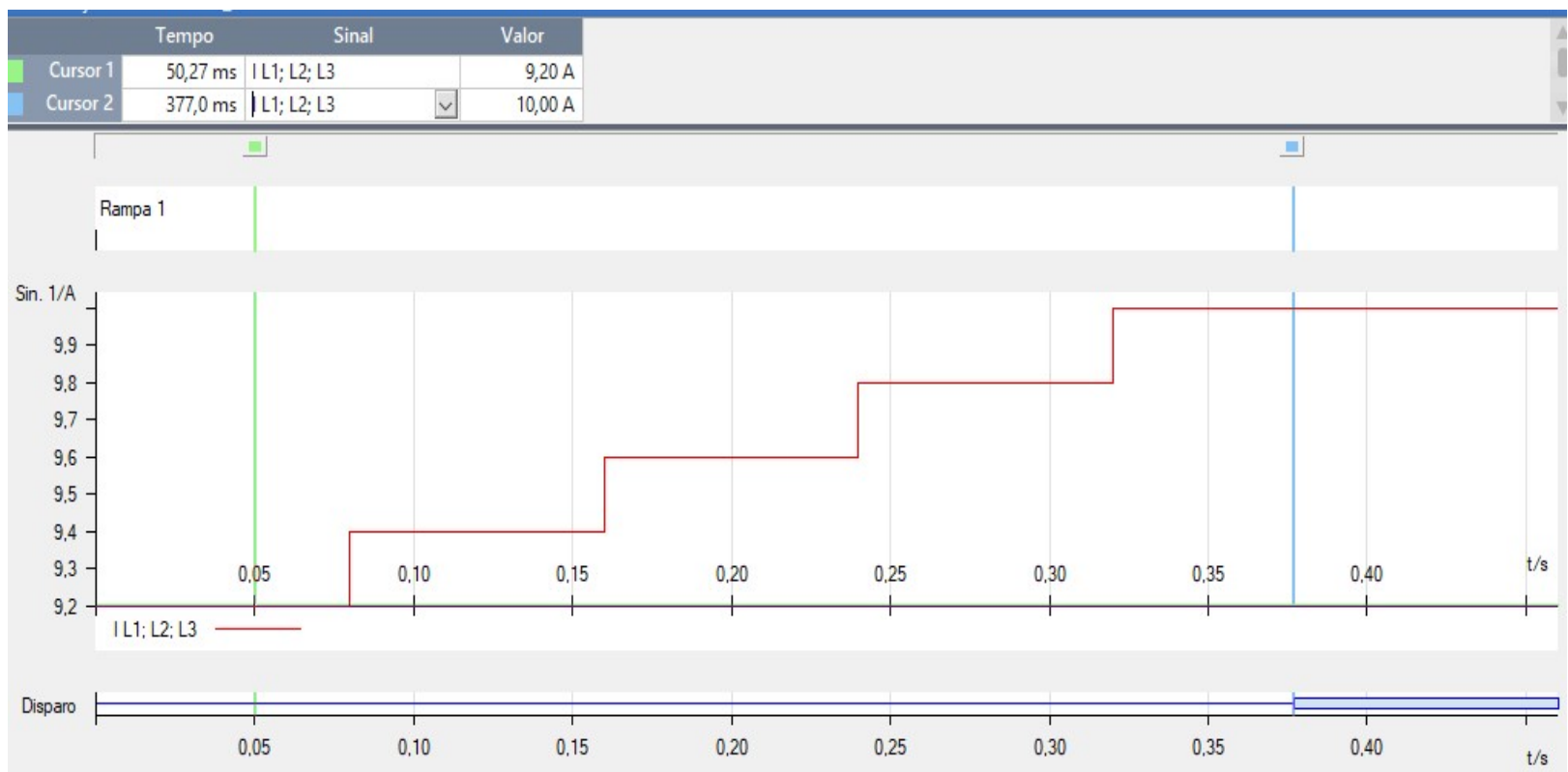

Figura 41 - Teste ramping para a proteção de sobrecorrente instantânea (50) no lado de 230 kV.

\subsubsection{Ajuste da proteção de sobrecorrente com controle de tensão (51V)}

Como mencionado anteriormente, esta função de proteção é habilitada quando o intuito é proteger um elemento cujo nível de curto-circuito é inferior a corrente nominal, dificultando então a determinação por parte do relé se a corrente medida é de carga ou de falta, sendo que nesta última há um decaimento da tensão. Geralmente, habilita-se esta função a partir de um valor de tensão abaixo de 0,7pu e verifica-se o valor da corrente para esta queda de tensão, normalmente da ordem de $30 \%$ da corrente nominal do elemento protegido.

O valor de ajuste da tensão é obtida por (5.59) em que considera como referência a tensão secundária do relé, igual a 115V.

$$
\begin{gathered}
V_{51 V_{-} F F}=0,7.115 \mathrm{~V}=80,5 \mathrm{~V} \\
V_{51 V_{-} F N}=46,48 \mathrm{~V}
\end{gathered}
$$

A corrente de pick-up é obtida por meio do valor medido para queda de tensão equivalente ao curto-circuito, sendo igual a 89 A para uma falta trifásica a $50 \%$ da LT entre a SE Rondonópolis e a SE Itiquira operando com seus quatro transformadores devido ao fato de que a proteção deverá ser sensível ao menor nível de corrente de curto-circuito. Portanto, no lado secundário teremos:

$$
I_{\text {pick-up_51V }}=\frac{89 \mathrm{~A}}{800 / 5}=0,55 \mathrm{~A}
$$


Portanto, a corrente de pick-up para a proteção esta proteção será ajustada em 0,5 A. A seguir serão apresentados os tempos de atuação para os quatro grupos de ajuste. O ajuste levou em consideração que esta função de proteção oferecerá retaguarda para todo o comprimento da LT Rondonópolis - Jaciara $138 \mathrm{kV}$ e apenas $50 \%$ da LT Itiquira - Rondonópolis.

\section{a) Grupo de Ajuste 1 - SE Rondonópolis operando com 1 TR}

A curva utilizada para este grupo também foi do tipo normal inversa com valor igual a 0,35. A Tabela 5.11 apresenta o estudo de coordenação para esta configuração.

Tabela 5.11 - Coordenação da proteção de sobrecorrente de fase com controle de tensão (51V) no lado de $230 \mathrm{kV}$ para o grupo de ajuste 1.

$51 \mathrm{~V}$

Grupo de Ajuste 1 - SE Rondonópolis operando com 1 Autotransformador

Estudo de coordenação da proteção de sobrecorrente com controle de tensão (51V) dos TRs da SE RP - MT

\begin{tabular}{|c|c|c|c|c|}
\hline \multirow{2}{*}{ Curva 51V } & \multirow{2}{*}{$=$} & \multirow{2}{*}{0,35} & \multirow{2}{*}{$\begin{array}{l}\text { Sobrecorrente com controle de tensão } \\
(51 \mathrm{~V}) \text { no lado de } 230 \mathrm{kV}\end{array}$} & Ipick-up (A) \\
\hline & & & & 0,5 \\
\hline \multicolumn{5}{|c|}{ Tempo de atuação $=\left(0,14^{*}\right.$ Curva51V) $/\left(\mathrm{M}^{\wedge} 0,02-1\right)$} \\
\hline Descrição & M & Valor & tempo de atuação (s) & $\operatorname{Icc} 230 \mathrm{kV}(\mathrm{A})$ \\
\hline Inrush & M0 & 25,102 & 0,736 & 12,551 \\
\hline Lado de 230 kV do TR & M1 & 30,000 & 0,696 & 57,363 \\
\hline Lado de 138 kV do TR & $\mathrm{M} 2$ & 14,558 & 0,891 & 7,279 \\
\hline Barra 230 kV da SE RP & M3 & 9,136 & 1,083 & 4,568 \\
\hline Barra 138 kV da SE RP & M4 & 28,185 & 0,710 & 14,093 \\
\hline $50 \%$ da LT ITRP 230 kV & M5 & 3,813 & 1,806 & 1,906 \\
\hline Barra de 138 kV SE JC & M6 & 13,883 & 0,907 & 6,941 \\
\hline
\end{tabular}

Observa-se que agora a proteção tornou-se sensível aos defeitos na barra de 230kV da SE Rondonópolis e na LT Itiquira - Rondonópolis 230 kV devido ao fato de que a corrente de pick-up desta proteção ser inferior a corrente nominal, resultando em tempos de atuação menores de acordo com a equação (5.48). Entretanto, verifica-se que os tempos de atuação para as eliminações dessas faltas são considerados elevados, superiores a 1 segundo, podendo vir a causar danos aos equipamentos elétricos. Ainda, houve uma melhora no tempo de atuação para as faltas na LT Rondonópolis - Jaciara $138 \mathrm{kV}$, onde a proteção é capaz de prover a retaguarda tanto para esta LT, como também para a barra de $138 \mathrm{kV}$ da SE Rondonópolis, com um tempo superior ao de segunda zona da proteção de distância 
O teste foi realizado em duas etapas: na primeira foi observado o desempenho da curva de atuação parametrizada e, em seguida, mostrou-se que a partida da proteção $51 \mathrm{~V}$ ocorre apenas quando o valor de tensão atinge $0,7 \mathrm{pu}$ da nominal do secundário do relé, sendo este igual a 44,6 V fase-neutro. A Tabela 5.12 apresenta os pontos testados pelo relé de proteção para o teste trifásico. A Figura 42 mostra a curva com os pontos aprovados pelo teste.

Tabela 5.12 - Resultados do teste da proteção de sobrecorrente com controle de tensão (51V) no lado de $230 \mathrm{kV}$ para o grupo de ajuste 1.

\begin{tabular}{|c|c|c|c|c|c|}
\hline Falta & $(\mathbf{I} / \mathbf{I n} \times \mathbf{s})$ & Tempo nominal (s) & Tempo real (s) & Desvio (\%) & Resultado \\
\hline $\mathrm{L} 1-\mathrm{L} 2-\mathrm{L} 3$ & 2,000 & 3,510 & 3,566 & 1,594 & Aprovado \\
\hline $\mathrm{L} 1-\mathrm{L} 2-\mathrm{L} 3$ & 4,000 & 1,743 & 1,763 & 1,164 & Aprovado \\
\hline $\mathrm{L} 1-\mathrm{L} 2-\mathrm{L} 3$ & 6,000 & 1,343 & 1,362 & 1,406 & Aprovado \\
\hline $\mathrm{L} 1-\mathrm{L} 2-\mathrm{L} 3$ & 8,000 & 1,154 & 1,170 & 1,415 & Aprovado \\
\hline $\mathrm{L} 1-\mathrm{L} 2-\mathrm{L} 3$ & 10,00 & 1,040 & 1,059 & 1,846 & Aprovado \\
\hline $\mathrm{L} 1-\mathrm{L} 2-\mathrm{L} 3$ & 12,00 & 0,961 & 0,981 & 2,095 & Aprovado \\
\hline $\mathrm{L} 1-\mathrm{L} 2-\mathrm{L} 3$ & 14,00 & 0,904 & 0,923 & 2,093 & Aprovado \\
\hline $\mathrm{L} 1-\mathrm{L} 2-\mathrm{L} 3$ & 16,00 & 0,859 & 0,874 & 1,702 & Aprovado \\
\hline $\mathrm{L} 1-\mathrm{L} 2-\mathrm{L} 3$ & 18,00 & 0,823 & 0,873 & 1,703 & Aprovado \\
\hline $\mathrm{L} 1-\mathrm{L} 2-\mathrm{L} 3$ & 20,00 & 0,793 & 0,807 & 1,730 & Aprovado \\
\hline $\mathrm{L} 1-\mathrm{L} 2-\mathrm{L} 3$ & 22,00 & 0,768 & 0,781 & 1,749 & Aprovado \\
\hline $\mathrm{L} 1-\mathrm{L} 2-\mathrm{L} 3$ & 24,00 & 0,746 & 0,762 & 2,106 & Aprovado \\
\hline
\end{tabular}

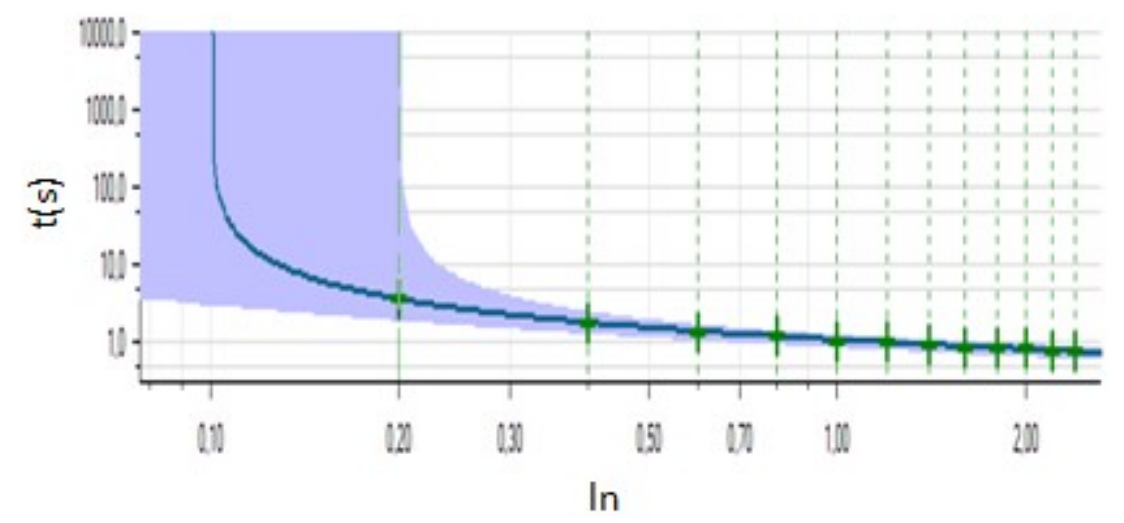

Figura 42 - Pontos aprovados pelo teste da proteção 51V para o grupo de ajuste 1.

A segunda etapa do teste verificou que a partida da proteção $51 \mathrm{~V}$ se daria somente após a tensão atingir o valor ajustado de $0.7 \mathrm{pu}$, equivalente a $46,4 \mathrm{~V}$ da tensão nominal fase-neutro. Para isso, foi utilizado o módulo de teste ramping onde o sinal de corrente foi mantido constante a uma corrente superior ao pick-up do relé e o sinal de tensão variou a partir do seu valor nominal fase-neutro $(66,4 \mathrm{~V})$.

A Figura 41 apresenta o resultado do teste em que é possível observar, por meio do Cursor 1, que a partida (Início) deu-se somente após o valor da tensão ser equivalente a 46,4V como definido. O sinal de trip (Disparo) deu-se somente após 3.3s, valor este de acordo com o tempo de atuação conforme a equação (5.48). 


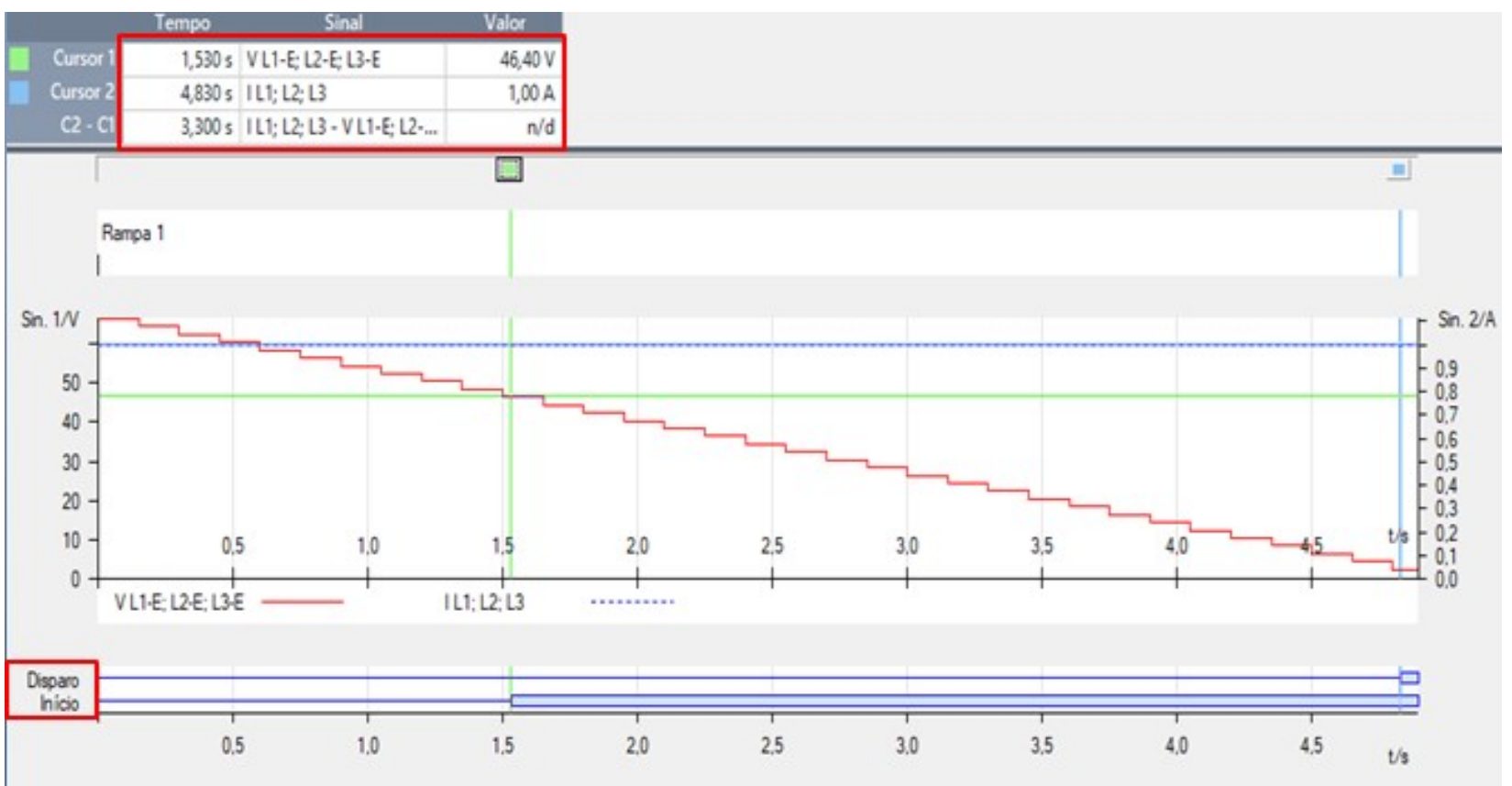

Figura 43 - Teste ramping para a verificação da partida da proteção 51V após atingir 0,7pu.

\section{b) Grupo de Ajuste 2 - SE Rondonópolis operando com 2 ATs}

A curva utilizada para este grupo de ajuste também foi do tipo normal inversa igual a 0,325 . Por meio da Tabela 5.13 é possível observar que a proteção é sensível aos defeitos na barra de $230 \mathrm{kV}$ da SE Rondonópolis e a $50 \%$ da LT ItiquiraRondonópolis, porém os tempos para a eliminação da falta são considerados críticos aos equipamentos elétricos. Porém, a proteção atua com um tempo adequado e superior aos tempos de segunda zona das LTs adjacentes nas eliminações das faltas na barra de 138 kV da SE Rondonópolis e na LT Rondonópolis - Jaciara 138 kV.

Tabela 5.13 - Coordenação da proteção de sobrecorrente de fase com controle de tensão (51V) no lado de $230 \mathrm{kV}$ para o Grupo de Ajuste 2.

\begin{tabular}{|c|c|c|c|c|}
\hline \multicolumn{5}{|c|}{$51 \mathrm{~V}$} \\
\hline \multicolumn{5}{|c|}{ Grupo de Ajuste 2 - SE Rondonópolis operando com 2 transformadores } \\
\hline \multicolumn{5}{|c|}{ Estudo de coordenação das proteção de sobrecorrente com controle de tensão (51V) dos TRs da SE RP - MT } \\
\hline \multirow{2}{*}{ Curva 51V } & \multirow{2}{*}{$=$} & \multirow{2}{*}{0,325} & \multirow{2}{*}{$\begin{array}{l}\text { Sobrecorrente com controle de tensão } \\
\text { (51V) no lado de } 230 \mathrm{kV}\end{array}$} & Ipick-up (A) \\
\hline & & & & 0,5 \\
\hline \multicolumn{5}{|c|}{ Tempo de atuação $=\left(0,14^{*}\right.$ Curva51V) $/\left(\mathrm{M}^{\wedge} 0,02-1\right)$} \\
\hline Descrição & M & Valor & tempo de atuação (s) & Icc 230kV (A) \\
\hline Inrush & M0 & 25,102 & 0,683 & 12,551 \\
\hline Lado de $230 \mathrm{kV}$ do TR & M1 & 30,000 & 0,646 & 60,050 \\
\hline Lado de $138 \mathrm{kV}$ do TR & M2 & 30,000 & 0,646 & 19,350 \\
\hline Barra 230 kV da SE RP & M3 & 5,100 & 1,374 & 2,550 \\
\hline Barra 138 kV da SE RP & M4 & 22,163 & 0,712 & 11,081 \\
\hline $50 \%$ da LT ITRP $230 \mathrm{kV}$ & M5 & 2,113 & 3,019 & 1,056 \\
\hline Barra de $138 \mathrm{kV}$ da SE JC & M6 & 8,520 & 1,039 & 4,260 \\
\hline
\end{tabular}


A Tabela 5.14 mostra que os pontos testados foram todos aprovados. A Figura 44 apresenta a curva de atuação com estes pontos.

Tabela 5.14 - Resultados do teste da proteção de sobrecorrente com controle de tensão (51V) no lado de $230 \mathrm{kV}$ para o grupo de ajuste 2.

\begin{tabular}{|c|c|c|c|c|c|}
\hline Falta & $(\mathbf{I} / \mathbf{I n}+\mathbf{s})$ & Tempo nominal (s) & Tempo real (s) & Desvio (\%) & Resultado \\
\hline $\mathrm{L} 1-\mathrm{L} 2-\mathrm{L} 3$ & 2,000 & 3,259 & 3,308 & 1,487 & Aprovado \\
\hline $\mathrm{L} 1-\mathrm{L} 2-\mathrm{L} 3$ & 4,000 & 1,618 & 1,639 & 1,265 & Aprovado \\
\hline $\mathrm{L} 1-\mathrm{L} 2-\mathrm{L} 3$ & 6,000 & 1,247 & 1,271 & 1,893 & Aprovado \\
\hline $\mathrm{L} 1-\mathrm{L} 2-\mathrm{L} 3$ & 8,000 & 1,072 & 1,084 & 1,162 & Aprovado \\
\hline $\mathrm{L} 1-\mathrm{L} 2-\mathrm{L} 3$ & 10,00 & 0,965 & 0,976 & 1,176 & Aprovado \\
\hline $\mathrm{L} 1-\mathrm{L} 2-\mathrm{L} 3$ & 12,00 & 0,893 & 0,913 & 2,322 & Aprovado \\
\hline $\mathrm{L} 1-\mathrm{L} 2-\mathrm{L} 3$ & 14,00 & 0,839 & 0,850 & 1,358 & Aprovado \\
\hline $\mathrm{L} 1-\mathrm{L} 2-\mathrm{L} 3$ & 16,00 & 0,798 & 0,808 & 1,254 & Aprovado \\
\hline $\mathrm{L} 1-\mathrm{L} 2-\mathrm{L} 3$ & 18,00 & 0,764 & 0,781 & 2,267 & Aprovado \\
\hline $\mathrm{L} 1-\mathrm{L} 2-\mathrm{L} 3$ & 20,00 & 0,736 & 0,750 & 1,833 & Aprovado \\
\hline $\mathrm{L} 1-\mathrm{L} 2-\mathrm{L} 3$ & 22,00 & 0,713 & 0,724 & 1,474 & Aprovado \\
\hline $\mathrm{L} 1-\mathrm{L} 2-\mathrm{L} 3$ & 24,00 & 0,693 & 0,710 & 2,490 & Aprovado \\
\hline
\end{tabular}

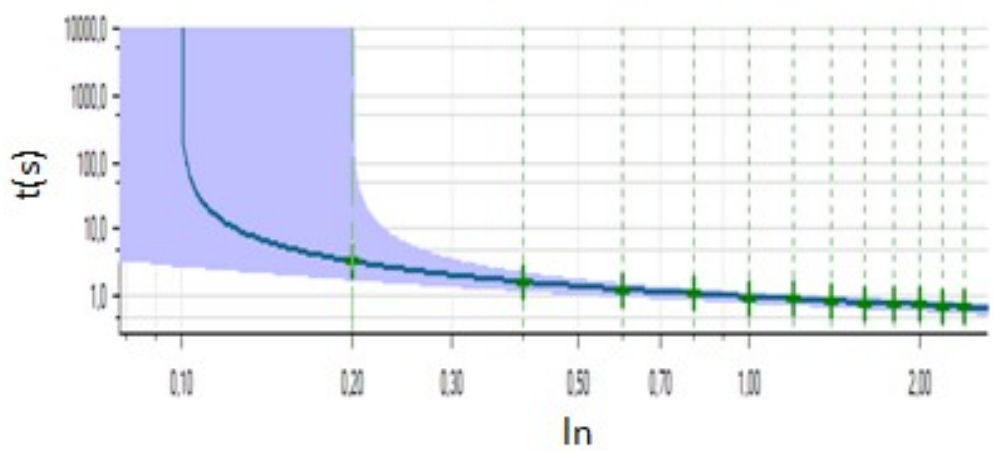

Figura 44 - Pontos aprovados pelo teste da proteção 51V para o grupo de ajuste 2.

\section{c) Grupo de Ajuste 3 - SE Rondonópolis operando com 3 TRs}

A curva adotada também foi do tipo normal inversa igual à com valor igual a 0,3. A Tabela 5.15 mostra os tempos de atuação para este grupo de ajuste. Os resultados mostram que a proteção é sensível aos defeitos na barra de $230 \mathrm{kV}$ da SE Rondonópolis e $50 \%$ da LT Itiquira - Rondonópolis $230 \mathrm{kV}$, porém com tempos de atuação altíssimos (1,648s e 5,503s, respectivamente) causando riscos aos equipamentos das SEs. Entretanto, a proteção provê retaguarda para a barra de $138 \mathrm{kV}$ da SE Rondonópolis levando em consideração a coordenação com os tempos de segunda zona das LTs. 
Tabela 5.15 - Coordenação da proteção de sobrecorrente de fase com controle de tensão (51V) no lado de $230 \mathrm{kV}$ para o grupo de ajuste 3.

\begin{tabular}{|c|c|c|c|c|}
\hline \multicolumn{5}{|c|}{$51 \mathrm{~V}$} \\
\hline \multicolumn{5}{|c|}{ Grupo de Ajuste 3 - SE Rondonópolis operando com 3 Autotransformadores } \\
\hline studo de coordenação da & oteçầ & le sobre & ente com controle de tensão (51V) do & da SE RP - MT \\
\hline \multirow{2}{*}{ Curva 51V } & \multirow{2}{*}{$=$} & \multirow{2}{*}{0,3} & \multirow{2}{*}{$\begin{array}{l}\text { Sobrecorrente com controle de tensão } \\
\text { (51V) no lado de } 230 \mathrm{kV}\end{array}$} & Ipick-up (A) \\
\hline & & & & 0,5 \\
\hline \multicolumn{5}{|c|}{ Tempo de atuação $=\left(0,14^{*}\right.$ Curva51V $) /\left(\mathrm{M}^{\wedge} 0,02-1\right)$} \\
\hline Descrição & M & Valor & tempo de atuação (s) & $\operatorname{Icc} 230 \mathrm{kV}(\mathrm{A})$ \\
\hline Inrush & MO & 25,102 & 0,631 & 12,551 \\
\hline Lado de $230 \mathrm{kV}$ do TR & M1 & 30,000 & 0,597 & 61,090 \\
\hline Lado de $138 \mathrm{kV}$ do TR & $\mathrm{M} 2$ & 30,000 & 0,597 & 27,161 \\
\hline Barra 230 kV da SE RP & M3 & 3,520 & 1,648 & 1,760 \\
\hline Barra 138 kV da SE RP & M4 & 18,255 & 0,702 & 9,128 \\
\hline $50 \%$ da LT ITRP $230 \mathrm{kV}$ & M5 & 1,463 & 5,503 & 0,731 \\
\hline Barra de 138 kV SE JC & M6 & 6,143 & 1,136 & 3,071 \\
\hline
\end{tabular}

A Tabela 5.16 apresentam-se os pontos para o teste trifásico em que é possível observar que o desvio entre tempo real de atuação do relé e o tempo nominal é inferior a $3 \%$. A Figura 45 mostram-se os pontos aprovados pelo teste.

Tabela 5.16 - Resultados do teste da proteção de sobrecorrente com controle de tensão (51V) no lado de $230 \mathrm{kV}$ para o grupo de ajuste 3 .

\begin{tabular}{|c|c|c|c|c|c|}
\hline Falta & $(\mathbf{I} / \ln \times \mid \mathbf{s})$ & Tempo nominal (s) & Tempo real (s) & Desvio (\%) & Resultado \\
\hline L1 - L2- L3 & 2,000 & 3,009 & 3,058 & 1,628 & Aprovado \\
\hline L1 - L2- L3 & 4,000 & 1,494 & 1,529 & 2,342 & Aprovado \\
\hline L1 - L2- L3 & 6,000 & 1,151 & 1,168 & 1,477 & Aprovado \\
\hline L1 - L2- L3 & 8,000 & 0,989 & 1,008 & 1,921 & Aprovado \\
\hline L1 - L2- L3 & 10,00 & 0,891 & 0,912 & 2,357 & Aprovado \\
\hline $\mathrm{L} 1-\mathrm{L} 2-\mathrm{L3}$ & 12,00 & 0,824 & 0,846 & 2,669 & Aprovado \\
\hline L1 - L2- L3 & 14,00 & 0,774 & 0,793 & 2,455 & Aprovado \\
\hline L1 - L2- L3 & 16,00 & 0,736 & 0,751 & 2,038 & Aprovado \\
\hline $\mathrm{L} 1-\mathrm{L} 2-\mathrm{L3}$ & 18,00 & 0,705 & 0,723 & 2,553 & Aprovado \\
\hline L1 - L2- L3 & 20,00 & 0,680 & 0,698 & 2,647 & Aprovado \\
\hline $\mathrm{L} 1-\mathrm{L} 2-\mathrm{L} 3$ & 22,00 & 0,658 & 0,672 & 2,128 & Aprovado \\
\hline $\mathrm{L} 1-\mathrm{L} 2-\mathrm{L} 3$ & 24,00 & 0,640 & 0,654 & 2,187 & Aprovado \\
\hline
\end{tabular}

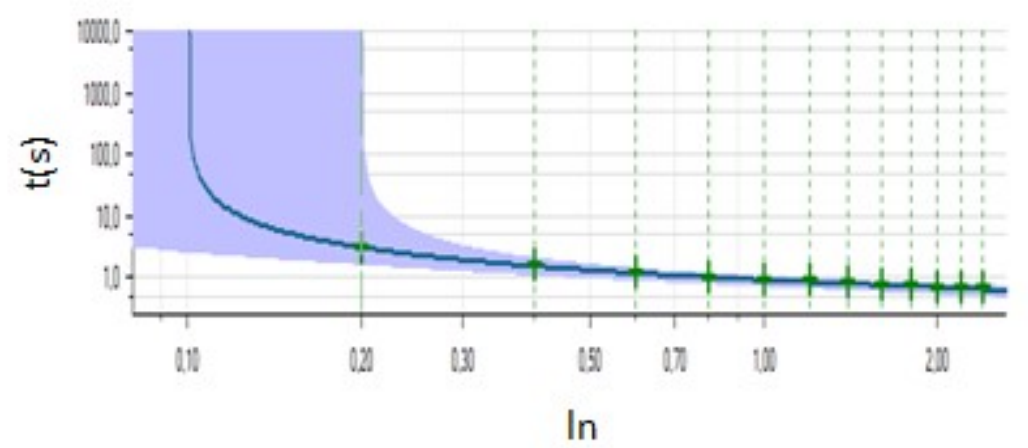

Figura 45 - Pontos aprovados pelo teste da proteção 51V para o grupo de ajuste 3. 


\section{d) Grupo de Ajuste 4-SE Rondonópolis operando com 4 TRs}

A curva adotada para este grupo de ajuste também do tipo normal inversa igual a 0,3. A Tabela 5.17 mostra o estudo de coordenação para esta proteção, onde é capaz de atuar satisfatoriamente apenas para a eliminação de defeitos na barra de $138 \mathrm{kV}$ da SE Rondonópolis, respeitando o tempo de segunda zona das proteções de distância das LTs. Os tempos de atuação para a eliminação dos defeitos na barra de $230 \mathrm{kV}$ da SE Rondonópolis (2,109s), 50\% da LT Itiquira - Rondonópolis 230 kV (19,677s) e na LT Rondonópolis - Jaciara 138 kV (1,325s) são considerados altíssimos, portanto há riscos aos equipamentos das SEs caso as proteções principais e secundárias destes equipamentos não atuem. Porém, tantos as barras e as LTs de $230 \mathrm{kV}$ possuem proteções principais e secundárias e, ademais, as proteções de distância são ajustadas para fornecer retaguarda para as barras remotas. Vale mencionar que raramente essas proteções falham.

Tabela 5.17 - Coordenação da proteção de sobrecorrente de fase com controle de tensão (51V) no lado de $230 \mathrm{kV}$ para o grupo de ajuste 4.

\begin{tabular}{|c|c|c|c|c|}
\hline \multicolumn{5}{|c|}{ 51V } \\
\hline \multicolumn{5}{|c|}{ Grupo de Ajuste 4 - SE Rondonópolis operando com 4 transformadores } \\
\hline \multicolumn{5}{|c|}{ Estudo de coordenação da proteção de fase com controle de tensão (51V) dos TRs da SE RP - MT } \\
\hline \multirow{2}{*}{ Curva 51V } & \multirow[b]{2}{*}{$=$} & \multirow{2}{*}{0,3} & \multirow{2}{*}{$\begin{array}{l}\text { Sobrecorrente com controle de } \\
\text { tensão (51V) no lado de } 230 \mathrm{kV}\end{array}$} & Ipick-up (A) \\
\hline & & & & 0,5 \\
\hline \multicolumn{5}{|c|}{ Tempo de atuação $=\left(0,14^{*}\right.$ Curva51V $) /\left(M^{\wedge} 0,02-1\right)$} \\
\hline Descrição & $\mathbf{M}$ & Valor & tempo de atuação (s) & Icc 230kV (A) \\
\hline Inrush & MO & 25,102 & 0,631 & 12,551 \\
\hline Lado de $230 \mathrm{kV}$ do TR & M1 & 30,000 & 0,597 & 61,650 \\
\hline Lado de 138 kV do TR & $\mathrm{M} 2$ & 30,000 & 0,597 & 32,800 \\
\hline Barra $230 \mathrm{kV}$ da SE RP & M3 & 2,680 & 2,109 & 1,340 \\
\hline Barra $138 \mathrm{kV}$ da SE RP & M4 & 15,428 & 0,747 & 7,714 \\
\hline $50 \%$ da LT ITRP $230 \mathrm{kV}$ & M5 & 1,113 & 19,677 & 0,556 \\
\hline Barra de $138 \mathrm{kV}$ da SE JC & M6 & 4,763 & 1,325 & 2,381 \\
\hline
\end{tabular}

Como o ajuste e o tipo da curva escolhida é o mesmo do Grupo de Ajuste 3, os resultados dos testes são os mesmos descritos na Tabela 5.16 e na Figura 45. 


\subsubsection{Proteções de sobrecorrente de neutro $(50 \mathrm{~N} / 51 \mathrm{~N})$}

Assim como nas proteções de fase, foram obtidas as correntes de curto-circuito $3 \mathrm{I}_{0}$ para o ajuste das proteções de neutro como mostra a Tabela 5.18.

Tabela 5.18 - Valores das correntes de curto-circuito monofásicas-terra para as quatro condições de operação da SE Rondonópolis.

\begin{tabular}{|c|c|c|c|c|}
\hline Descrição da falta & $1 \mathrm{TR}$ & 2 TRs & 3 TRs & 4 TRs \\
\hline $\begin{array}{c}\text { Corrente de curto-circuito monofásico- } \\
\text { terra }\left(3 \mathrm{I}_{0}\right) \text { no bay de } 230 \mathrm{kV} \text { da SE RP } \\
\text { medida no lado de } 230 \mathrm{kV}\end{array}$ & $5019 \mathrm{~A}$ & $6618 \mathrm{~A}$ & $7662 \mathrm{~A}$ & $8421 \mathrm{~A}$ \\
\hline $\begin{array}{c}\text { Corrente de curto-circuito monofásico- } \\
\text { terra }\left(3 \mathrm{I}_{0}\right) \text { no bay de } 138 \mathrm{kV} \text { da SE RP } \\
\text { medida no lado de } 230 \mathrm{Kv}\end{array}$ & $1013,4 \mathrm{~A}$ & $3535,2 \mathrm{~A}$ & $4793,4 \mathrm{~A}$ & $5808,6 \mathrm{~A}$ \\
\hline $\begin{array}{c}\text { Corrente de curto-circuito monofásico- } \\
\text { terra }\left(3 \mathrm{I}_{0}\right) \text { na barra de } 230 \mathrm{kV} \text { da SE RP } \\
\text { medida no lado de } 230 \mathrm{kV}\end{array}$ & $2643 \mathrm{~A}$ & $2118 \mathrm{~A}$ & $1716 \mathrm{~A}$ & $1458 \mathrm{~A}$ \\
\hline $\begin{array}{c}\text { Corrente de curto-circuito monofásico- } \\
\text { terra }\left(3 \mathrm{I}_{0}\right) \text { na barra de } 138 \mathrm{kV} \text { da SE RP } \\
\text { medida no lado de } 230 \mathrm{kV}\end{array}$ & $3130,2 \mathrm{~A}$ & 2503,8 A & $2390,4 \mathrm{~A}$ & $2250 \mathrm{~A}$ \\
\hline $\begin{array}{l}\text { Corrente de curto-circuito monofásico- } \\
\text { terra }\left(3 \mathrm{I}_{0}\right) \text { na barra de } 230 \mathrm{kV} \text { da SE IT } \\
\text { medida no lado de } 230 \mathrm{kV}\end{array}$ & $363 \mathrm{~A}$ & $255 A$ & $195 \mathrm{~A}$ & $156 \mathrm{~A}$ \\
\hline $\begin{array}{c}\text { Corrente de curto-circuito monofásico- } \\
\text { terra }\left(3 \mathrm{I}_{0}\right) \text { na barra de } 138 \mathrm{kV} \text { da SE JC } \\
\text { medida no lado de } 230 \mathrm{kV}\end{array}$ & 604,8 A & 354,6 A & $291,6 \mathrm{~A}$ & 246,6 A \\
\hline
\end{tabular}

\subsubsection{Ajuste da unidade de sobrecorrente de neutro temporizada (51N)}

A proteção de sobrecorrente deverá ser ajustada com, aproximadamente, $25 \%$ da corrente nominal do transformador:

$$
\begin{aligned}
& I_{\text {pick-up_UTn_230p }}=0,25 . I n \_230=62,755 \mathrm{~A} \\
& I_{\text {pick-up_UTn_230s }}=\frac{\text { pick-up_UTn_230p }}{\text { RTC_230 }}=0,4 \mathrm{~A}
\end{aligned}
$$

A proteção será ajustada levando em consideração os estudos de coordenação sendo adotada a curva do tipo normal inversa igual a 0,375 para todos os quatros grupos de ajustes.

\section{a) Grupo de Ajuste 1 - SE Rondonópolis operando com 1 TR}

A Tabela 5.19 mostra os tempos de atuação para o grupo de ajuste 1, em que é possível observar que a proteção está coordenada para os defeitos nas barra de 230kV e 138kV da SE Rondonópolis com tempo superior ao das segundas zonas da LTs adjacentes $(650 \mathrm{~ms})$. Além disso, a proteção é sensível aos defeitos nas LTs Itiquira Rondonópolis $230 \mathrm{kV}$ e Rondonópolis - Jaciara 138kV, mas com um tempo de 
eliminação crítico podendo vir a causar danos aos equipamentos das SEs caso as proteções principais e secundárias das LTs não eliminem o defeito.

Tabela 5.19 - Coordenação da proteção de sobrecorrente de neutro $(51 \mathrm{~N})$ no lado de $230 \mathrm{kV}$ para o Grupo de Ajuste 1.

\begin{tabular}{|c|c|c|c|c|}
\hline \multicolumn{5}{|c|}{$51 \mathrm{~N}$} \\
\hline \multirow{2}{*}{\multicolumn{5}{|c|}{ Estudo de coordenação da proteção de neutro $51 \mathrm{~N}$ no lado de $230 \mathrm{kV}$ dos TRs da }} \\
\hline Grupo d & & & & \\
\hline \multirow{2}{*}{ Curva $51 \mathrm{~N}$} & \multirow{2}{*}{ 位 } & \multirow{2}{*}{0,375} & \multirow{2}{*}{$\begin{array}{l}\text { Sobrecorrente temporizado de } \\
\text { neutro }(51 \mathrm{~N}) \text { no lado de } 230 \mathrm{kV}\end{array}$} & Ipick-up (A) \\
\hline & & & & 0,4 \\
\hline \multicolumn{5}{|c|}{ Tempo de atuação $=\left(0,14^{*}\right.$ Curva51N)/(M^0,02 -1) } \\
\hline Descrição & M & Valor & tempo de atuação (s) & $\operatorname{Icc} 230 \mathrm{kV}(\mathrm{A})$ \\
\hline Lado de $230 \mathrm{kV}$ do TR & M1n & 30,000 & 0,746 & 31,369 \\
\hline Lado de $138 \mathrm{kV}$ do TR & $M 2 n$ & 15,834 & 0,924 & 6,334 \\
\hline Barra 230 kV da SE RP & M3n & 30,000 & 0,746 & 16,519 \\
\hline Barra 138 kV da SE RP & M4n & 30,000 & 0,746 & 19,564 \\
\hline Barra de 230 kV da SE IT & M5n & 5,672 & 1,486 & 2,269 \\
\hline Barra de $138 \mathrm{kV}$ da SE JC & M6n & 9,450 & 1,143 & 3,780 \\
\hline
\end{tabular}

\section{b) Grupo de Ajuste 2 - SE Rondonópolis operando com 2 ATs}

A Tabela 5.20 mostra o estudo de coordenação para este grupo de ajuste.

Tabela 5.20 - Coordenação da proteção de sobrecorrente de neutro $(51 \mathrm{~N})$ no lado de $230 \mathrm{kV}$ para o grupo de ajuste 2 .

\section{$51 \mathrm{~N}$}

Estudo de coordenação das proteções de neutro $51 \mathrm{~N}$ no lado de $230 \mathrm{kV}$ dos TRs da SE RP - MT Grupo de Ajuste 2 - SE Rondonópolis operando com 2 transformador

\begin{tabular}{|c|c|c|c|c|}
\hline \multirow{2}{*}{ Curva $51 \mathrm{~N}$} & \multirow{2}{*}{$=$} & \multirow{2}{*}{0,375} & \multirow{2}{*}{$\begin{array}{l}\text { Sobrecorrente temporizado de } \\
\text { neutro }(51 \mathrm{~N}) \text { no lado de } 230 \mathrm{kV}\end{array}$} & Ipick-up (A) \\
\hline & & & & 0,4 \\
\hline \multicolumn{5}{|c|}{ Tempo de atuação $=\left(0,14^{*}\right.$ Curva51N) $/\left(M^{\wedge} 0,02-1\right)$} \\
\hline Descrição & $M$ & Valor & tempo de atuação (s) & $\operatorname{Icc} 230 \mathrm{kV}(\mathrm{A})$ \\
\hline Lado de $230 \mathrm{kV}$ do TR & M1n & 30,000 & 0,746 & 41,363 \\
\hline Lado de $138 \mathrm{kV}$ do TR & $M 2 n$ & 30,000 & 0,746 & 22,095 \\
\hline Barra 230 kV da SE RP & $M 3 n$ & 30,000 & 0,746 & 13,238 \\
\hline Barra 138 kV da SE RP & $M 4 n$ & 30,000 & 0,746 & 15,649 \\
\hline Barra de $230 \mathrm{kV}$ da SE IT & M5n & 3,984 & 1,873 & 1,594 \\
\hline Barra de $138 \mathrm{kV}$ da SE JC & M6n & 5,541 & 1,507 & 2,216 \\
\hline
\end{tabular}

É possível observar que a proteção é capaz de atuar satisfatoriamente na eliminação das faltas internas ao AT proteção atuará com um tempo de retaguarda satisfatório considerando o critério de coordenação com os tempos de segunda zona 
das LTs adjacentes (650ms). Entretanto, o tempo de atuação da proteção na eliminação das faltas nas LTs Itiquira - Rondonópolis 230kV e Rondonópolis - Jaciara $138 \mathrm{kV}$ é considerado crítico, pois os equipamentos elétricos não podem ser submetidos a elevados valores de correntes de curto-circuito por muito tempo.

\section{c) Grupo de Ajuste 3 - SE Rondonópolis operando com 3 TRs}

A Tabela 5.21 é possível verificar que para esta condição de operação, a proteção para os defeitos nas barras de $230 \mathrm{kV}$ e $138 \mathrm{kV}$ da SE Rondonópolis continuará obedecendo ao critério de coordenação com as proteções das LTs adjacentes, com tempo de atuação superior ao de segunda zona das proteções de distância (650ms). Entretanto, os tempos de eliminação das faltas nas LTs de $230 \mathrm{kV}$ e $138 \mathrm{kV}$ são considerados altíssimos, podendo causar danos aos equipamentos das SEs caso haja falha nas proteções principais e secundárias das LTs.

Tabela 5.21 - Coordenação da proteção de sobrecorrente de neutro (51N) no lado de 230 kV para o grupo de ajuste 3 .

\section{$51 \mathrm{~N}$}

Estudo de coordenação das proteções de neutro $51 \mathrm{~N}$ no lado de $230 \mathrm{kV}$ dos TRs da SE RP - MT

Grupo de Ajuste 3 - SE Rondonópolis operando com 3 transformadores

\begin{tabular}{|c|c|c|c|c|}
\hline \multirow{2}{*}{ Curva $51 \mathrm{~N}$} & \multirow{2}{*}{$=$} & \multirow{2}{*}{0,375} & \multirow{2}{*}{$\begin{array}{l}\text { Sobrecorrente temporizado de } \\
\text { neutro }(51 \mathrm{~N}) \text { no lado de } 230 \mathrm{kV}\end{array}$} & Ipick-up (A) \\
\hline & & & & 0,4 \\
\hline \multicolumn{5}{|c|}{ Tempo de atuação $=\left(0,14^{*}\right.$ Curva51N)/(M^0,02 -1) } \\
\hline Descrição & $M$ & Valor & tempo de atuação (s) & Icc 230kV (A) \\
\hline Lado de $230 \mathrm{kV}$ do TR & M1n & 30,000 & 0,746 & 47,888 \\
\hline Lado de $138 \mathrm{kV}$ do TR & $\mathrm{M} 2 \mathrm{n}$ & 30,000 & 0,746 & 29,969 \\
\hline Barra $230 \mathrm{kV}$ da SE RP & $M 3 n$ & 26,813 & 0,772 & 10,725 \\
\hline Barra 138 kV da SE RP & $M 4 n$ & 30,000 & 0,746 & 14,940 \\
\hline Barra de $230 \mathrm{kV}$ da SE IT & M5n & 3,047 & 2,330 & 1,219 \\
\hline Barra de 138 kV da SE JC & M6n & 4,556 & 1,705 & 1,823 \\
\hline
\end{tabular}

\section{d) Grupo de Ajuste 4 - SE Rondonópolis operando com 4 TRs}

Por fim, a Tabela 5.22 mostra a coordenação da proteção para este grupo de ajuste. Os tempos de atuação para os defeitos nos barramentos de 230kV e 138kV da SE Rondonópolis continuam obedecendo aos requisitos de coordenação com as segundas zonas das proteções de distância das LTs adjacentes, ou seja, superior a $650 \mathrm{~ms}$. Ainda, os tempos de retaguarda para as LTs de $230 \mathrm{kV}$ e $138 \mathrm{kV}$ apresentam valores elevados podendo causar danos aos equipamentos das SEs. Entretanto, vale 
mencionar que as LTs de $230 \mathrm{kV}$ e $138 \mathrm{kV}$ possuem proteções principais e secundárias, em ambos os terminais, que raramente falham [28].

Tabela 5.22 - Coordenação da proteção de sobrecorrente de neutro $(51 \mathrm{~N})$ no lado de $230 \mathrm{kV}$ para o grupo de ajuste 4.

\section{$51 \mathrm{~N}$}

Estudo de coordenação das proteções de neutro 51N no lado de $230 \mathrm{kV}$ dos TRs da SE RP- MT Grupo de Ajuste 4 - SE Rondonópolis operando com 4 transformadores

\begin{tabular}{|c|c|c|c|c|}
\hline \multirow{2}{*}{ Curva $51 \mathrm{~N}$} & \multirow{2}{*}{$=$} & \multirow{2}{*}{0,375} & \multirow{2}{*}{$\begin{array}{l}\text { Sobrecorrente temporizada de } \\
\text { neutro }(51 \mathrm{~N}) \text { no lado de } 230 \mathrm{kV}\end{array}$} & Ipick-up (A) \\
\hline & & & & 0,4 \\
\hline \multicolumn{5}{|c|}{ Tempo de atuação $=\left(0,14^{*}\right.$ Curva51N $) /\left(\mathrm{M}^{\wedge} 0,02-1\right)$} \\
\hline Descrição & $\mathbf{M}$ & Valor & tempo de atuação (s) & Icc 230kV (A) \\
\hline Lado de $230 \mathrm{kV}$ do TR & M1n & 30,000 & 0,746 & 52,631 \\
\hline Lado de $138 \mathrm{kV}$ do TR & $M 2 n$ & 30,000 & 0,746 & 36,304 \\
\hline Barra 230 kV da SE RP & $M 3 n$ & 22,781 & 0,814 & 9,113 \\
\hline Barra 138 kV da SE RP & M4n & 30,000 & 0,746 & 14,063 \\
\hline Barra de $230 \mathrm{kV}$ da SE IT & M5n & 2,438 & 2,920 & 0,975 \\
\hline Barra de 138 kV SE JC & M6n & 3,853 & 1,920 & 1,541 \\
\hline
\end{tabular}

Na Tabela 5.23 mostram-se os pontos testados pelo relé de proteção $\mathrm{P} 143$ da Alstom para os quatros grupos de ajustes, devido ao fato de que a curva adotada foi do tipo normal inversa igual a 0,375 para todos os grupos. O termo L1- E significa que o teste foi do tipo monofásico-terra, envolvendo a fase $A$. Os resultados mostram que todos os pontos de testes foram aprovados com desvios de atuação entre o tempo real com relação ao tempo nominal abaixo de $2 \%$.

Tabela 5.23 - Resultados do teste da proteção de sobrecorrente de neutro temporizada $(51 \mathrm{~N})$ para os quatro grupos de ajustes.

\begin{tabular}{|c|c|c|c|c|c|}
\hline Falta & $\mathbf{( I / I n + I s )}$ & Tempo nominal (s) & Tempo real (s) & Desvio (\%) & Resultado \\
\hline L1-E & 1,200 & 14,37 & sem trip & - & Aprovado \\
\hline L1-E & 1,800 & 4,440 & 4,528 & 1,977 & Aprovado \\
\hline L1-E & 3,000 & 2,363 & 2,400 & 1,539 & Aprovado \\
\hline L1-E & 3,600 & 2,023 & 2,056 & 1,609 & Aprovado \\
\hline L1-E & 4,200 & 1,803 & 1,833 & 1,667 & Aprovado \\
\hline L1-E & 4,800 & 1,647 & 1,677 & 1,813 & Aprovado \\
\hline L1-E & 5,400 & 1,531 & 1,553 & 1,492 & Aprovado \\
\hline L1-E & 6,000 & 1,439 & 1,460 & 1,477 & Aprovado \\
\hline L1-E & 6,600 & 1,365 & 1,388 & 1,703 & Aprovado \\
\hline L1-E & 7,200 & 1,304 & 1,327 & 1,798 & Aprovado \\
\hline L1-E & 7,800 & 1,252 & 1,270 & 1,482 & Aprovado \\
\hline
\end{tabular}

A Figura 46 mostra a curva obtida para a proteção de sobrecorrente de neutro temporizada e os pontos de testes aprovados. 


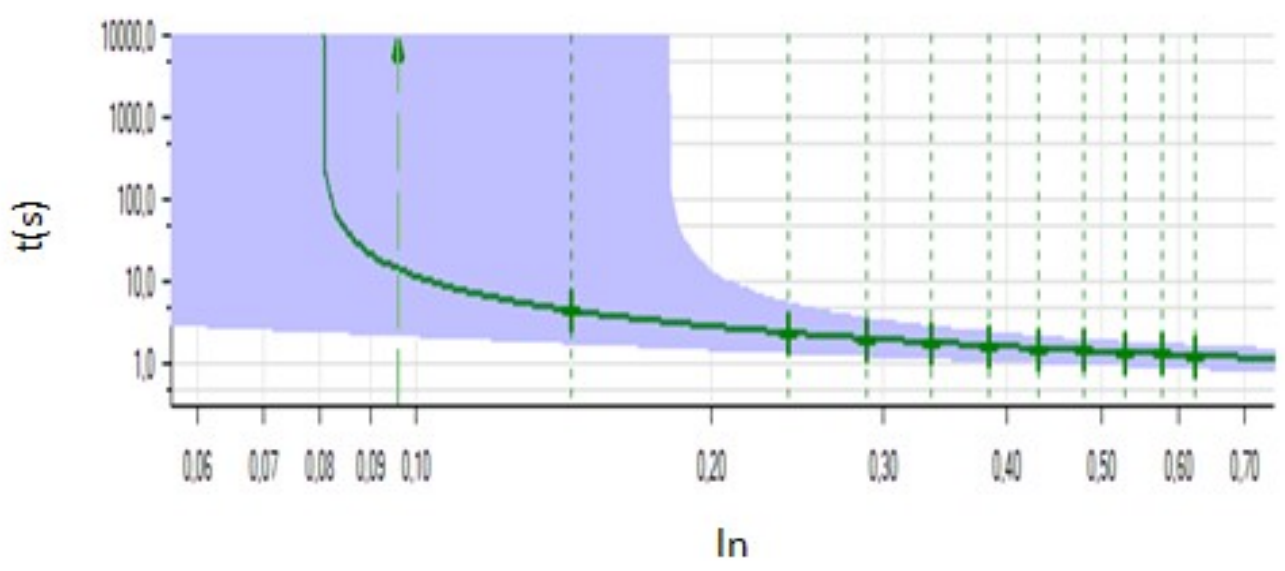

Figura 46 - Curva para a proteção $51 \mathrm{~N}$ e os pontos de testes aprovados.

\subsubsection{Ajuste da unidade de sobrecorrente de neutro instantânea (50N)}

A proteção de sobrecorrente de neutro instantânea deverá ser ajustada acima da corrente de Inrush e não deverá atuar para faltas na barra de 138 kV. Portanto, leva-se em consideração o maior valor de corrente de curto-circuito monofásico $\left(3 \mathrm{I}_{0}\right)$ obtido com a SE Rondonópolis operando com apenas 1 AT igual a 3130,2 A conforme a Tabela A.8 do Apêndice A.

$$
I_{\text {pick-up_Uln_230p }}=1,5 . I_{\text {cc_FT_310_barra_138_01AT }}=4695,3 \mathrm{~A}
$$

Logo, $I_{\text {pick-up_Uln_230p }}>I_{\text {inrush. }}$ O ajuste da unidade instantânea escolhido será de 4800 A.

$$
\begin{gathered}
I_{\text {pick-up_UIn_230s }}=\frac{\text { Ipick-up_UIn_230p }}{\text { RTC_230 }}=30 \mathrm{~A} \\
\mathrm{M}_{\text {UIn_230 }}=\frac{\text { Ipick-up_UIn_230s }}{\text { Ipick-up_UTn_230 }}=\frac{30}{0,4}=75 \\
t_{\text {atuação_UIn_230 }}=0 \mathrm{~s}
\end{gathered}
$$

O teste realizado para esta função de proteção obedeceu ao mesmo critério adotado para a unidade de sobrecorrente de fase instantânea (50) devido às limitações da mala de teste. Portanto, a atuação da proteção pode ser verificada na Figura 41 que apresenta o teste de pick-up para a proteção de sobrecorrente de fase instantânea (50).

\subsection{AJUSTE DAS PROTEÇÕES NO LADO DE 138 kV}

Assim como no lado de alta tensão, o ajuste das proteções no lado de $138 \mathrm{kV}$ dos transformadores levará em consideração as correntes de curto-circuito obtidas para as 
faltas internas e externas as zonas de proteção. A RTC obtida com o uso da equação (5.28) foi igual 1200/5.

\subsubsection{Ajuste das proteções de sobrecorrente de fase $(50 / 51)$}

Tabela 5.24 - Valores das correntes de curto-circuito trifásico para as quatro condições de operação.

\begin{tabular}{|c|c|c|c|c|}
\hline Descrição da falta & 1 TR & 2 TRs & 3 TRs & 4 TRs \\
\hline $\begin{array}{c}\text { Corrente de curto-circuito trifásico } \\
\text { no bay de 230kV da SE RP } \\
\text { medida no lado de 138 kV }\end{array}$ & $15296,7 \mathrm{~A}$ & $16013,3 \mathrm{~A}$ & $16291,7 \mathrm{~A}$ & $16441,7 \mathrm{~A}$ \\
\hline $\begin{array}{c}\text { Corrente de curto-circuito trifásico } \\
\text { no bay de 138kV da SE RP } \\
\text { medida no lado de 138 kV }\end{array}$ & $1941 \mathrm{~A}$ & $5160 \mathrm{~A}$ & $7243 \mathrm{~A}$ & $8749 \mathrm{~A}$ \\
\hline $\begin{array}{c}\text { Corrente de curto-circuito trifásico } \\
\text { na barra de 230kV da SE RP } \\
\text { medida no lado de 138 kV }\end{array}$ & $1218,3 \mathrm{~A}$ & $680 \mathrm{~A}$ & $471,7 \mathrm{~A}$ & $358,3 \mathrm{~A}$ \\
\hline $\begin{array}{c}\text { Corrente de curto-circuito trifásico } \\
\text { na barra de 138kV da SE RP } \\
\text { medida no lado de 138 kV }\end{array}$ & $3758 \mathrm{~A}$ & $2955 \mathrm{~A}$ & $2434 \mathrm{~A}$ & $2057 \mathrm{~A}$ \\
\hline $\begin{array}{c}\text { Corrente de curto-circuito trifásico } \\
\text { na barra de 230kV da SE IT } \\
\text { medida no lado de 138 kV }\end{array}$ & $321,7 \mathrm{~A}$ & $178,3 \mathrm{~A}$ & $123,3 \mathrm{~A}$ & $93,3 \mathrm{~A}$ \\
\hline $\begin{array}{c}\text { Corrente de curto-circuito trifásico } \\
\text { na barra de 138kV da SE JC } \\
\text { medida no lado de 138 kV }\end{array}$ & $1851 \mathrm{~A}$ & $1136 \mathrm{~A}$ & $819 \mathrm{~A}$ & $635 \mathrm{~A}$ \\
\hline
\end{tabular}

\subsubsection{Ajuste da unidade de sobrecorrente temporizada (51)}

O ajuste da proteção também levará em consideração 150\% de sobrecarga para os transformadores. Além disso, é necessário mencionar que as linhas conectadas a barra de $138 \mathrm{kV}$ da SE Rondonópolis possuem proteção principal e secundária.

$$
\begin{gathered}
I_{\mathrm{N} \_138}=418,37 \mathrm{~A} \\
I_{N_{N} 138 \mathrm{~s}}=\frac{I_{\mathrm{N} \_138}}{R T C \_138}=1,743 \mathrm{~A} \\
I_{\text {pick-up_UT_138s }}=1,5 . I_{\mathrm{N} \_138 \mathrm{~s}}=2,615 \mathrm{~A}
\end{gathered}
$$

A seguir serão apresentados os resultados para os tempos de atuação para as quatro condições de operação da SE Rondonópolis.

\section{a) Grupo de Ajuste 1 - SE Rondonópolis operando com 1 TR}

A curva escolhida para este grupo de ajuste foi do tipo normal inversa igual a 0,175. A Tabela 5.25 apresenta o estudo de coordenação em que é possível observar que o tempo de atuação para a proteção de retaguarda da barra de $138 \mathrm{kV}$ da SE Rondonópolis (672ms) é considerado satisfatório respeitando o tempo de segunda zona 
das proteções das LTs $(650 \mathrm{~ms})$. Entretanto, esta função de proteção não é sensível para o defeito na LT Itiquira - Rondonópolis $230 \mathrm{kV}$, como pode-se ver pelo termo "n/o" devido ao fato de que a corrente de curto-circuito para esta LT é inferior a corrente de pick-up ocasionando a não atuação do relé. Por fim, a proteção é sensível a falta na LT Rondonópolis - Jaciara $138 \mathrm{kV}$, porém com um tempo de atuação considerado crítico caso haja falha das proteções principal e secundária da LT. No intuito de aperfeiçoar o sistema de proteção, será habilitada a função $51 \mathrm{~V}$.

Tabela 5.25 - Coordenação da proteção de sobrecorrente de fase (51) no lado de 138 kV para o grupo de ajuste 1.

\section{1}

Grupo de Ajuste 1 - SE Rondonópolis operando com 1 transformador

Estudo de coordenação da proteção de fase (51) no lado de $138 \mathrm{kV}$ dos TRs da SE RP - MT

\begin{tabular}{|c|c|c|c|c|}
\hline Curva 51 & $=$ & 0,175 & $\begin{array}{c}\text { Sobrecorrente temporizada de } \\
\text { fase (51) no lado de 138 kV }\end{array}$ & Ipick-up (A) \\
\cline { 4 - 6 } & & & 2,615 \\
\hline \multicolumn{6}{|c|}{ Tempo de atuação $=\left(0,14^{*}\right.$ Curva51)/(M^0,02 -1) } \\
\hline Descrição & M & Valor & tempo de atuação (s) & Icc 138 kV (A) \\
\hline Lado de 230 kV do TR & M1 & 24,373 & 0,371 & 63,736 \\
Lado de 138 kV do TR & M2 & 3,093 & 1,073 & 8,087 \\
Barra 230 kV da SE RP & M3 & 1,941 & 1,835 & 5,076 \\
Barra 138 kV da SE RP & M4 & 5,988 & 0,672 & 15,658 \\
Barra de 230 kV SE IT & M5 & 0,512 & "n/o" & 1,340 \\
Barra de 138 kV SE JC & M6 & 2,949 & 1,120 & 7,713 \\
\hline
\end{tabular}

A Tabela 5.26 mostra-se que os pontos testados pelo relé foram todos aprovados sendo que a curva com os pontos de testes são mostrados na Figura 47.

Tabela 5.26 - Resultados do teste da proteção de sobrecorrente de fase temporizado (51) no lado de $138 \mathrm{kV}$ para o grupo de ajuste 1.

\begin{tabular}{|c|c|c|c|c|c|}
\hline Falta & $(\mathbf{I} / \mathbf{I n} \mathbf{\text { Is }})$ & Tempo nominal (s) & Tempo real (s) & Desvio (\%) & Resultado \\
\hline $\mathrm{L} 1-\mathrm{L} 2-\mathrm{L} 3$ & 1,200 & 6,707 & 6,872 & 2,465 & Aprovado \\
\hline $\mathrm{L} 1-\mathrm{L} 2-\mathrm{L} 3$ & 1,500 & 3,009 & 3,056 & 1,569 & Aprovado \\
\hline $\mathrm{L} 1-\mathrm{L} 2-\mathrm{L} 3$ & 1,800 & 2,072 & 2,104 & 1,537 & Aprovado \\
\hline $\mathrm{L} 1-\mathrm{L} 2-\mathrm{L} 3$ & 2,100 & 1,639 & 1,666 & 1,662 & Aprovado \\
\hline $\mathrm{L} 1-\mathrm{L} 2-\mathrm{L} 3$ & 2,400 & 1,387 & 1,413 & 1,886 & Aprovado \\
\hline $\mathrm{L} 1-\mathrm{L} 2-\mathrm{L} 3$ & 2,700 & 1,221 & 1,239 & 1,473 & Aprovado \\
\hline $\mathrm{L} 1-\mathrm{L} 2-\mathrm{L} 3$ & 3,000 & 1,103 & 1,126 & 2,100 & Aprovado \\
\hline $\mathrm{L} 1-\mathrm{L} 2-\mathrm{L} 3$ & 3,300 & 1,014 & 1,029 & 1,526 & Aprovado \\
\hline $\mathrm{L} 1-\mathrm{L} 2-\mathrm{L} 3$ & 3,600 & 0,944 & 0,965 & 2,273 & Aprovado \\
\hline $\mathrm{L} 1-\mathrm{L} 2-\mathrm{L} 3$ & 3,900 & 0,887 & 0,908 & 2,332 & Aprovado \\
\hline $\mathrm{L} 1-\mathrm{L} 2-\mathrm{L} 3$ & 4,200 & 0,841 & 0,854 & 1,507 & Aprovado \\
\hline $\mathrm{L} 1-\mathrm{L} 2-\mathrm{L} 3$ & 4,500 & 0,802 & 0,821 & 2,423 & Aprovado \\
\hline $\mathrm{L} 1-\mathrm{L} 2-\mathrm{L} 3$ & 4,800 & 0,768 & 0,790 & 2,867 & Aprovado \\
\hline
\end{tabular}




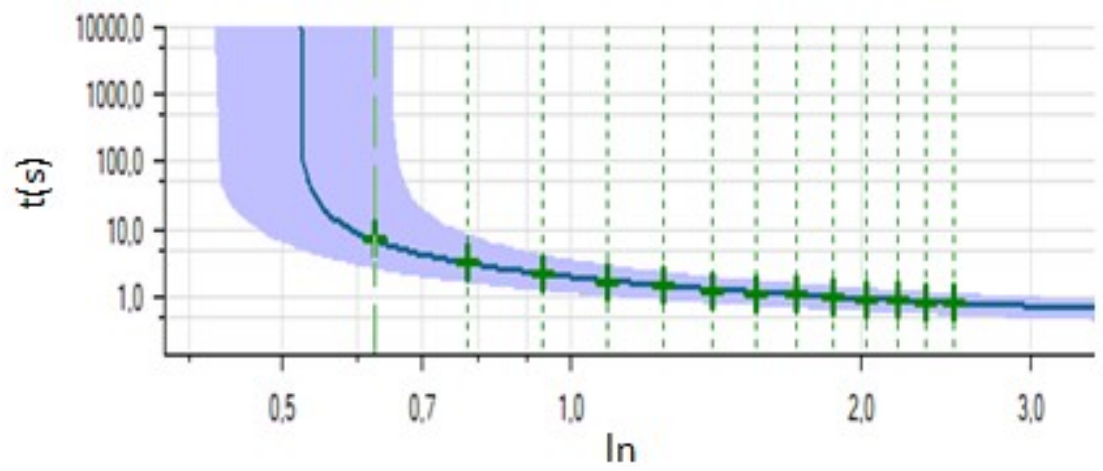

Figura 47 - Pontos aprovados pelo teste da proteção 51 para o grupo de ajuste 1.

\section{b) Grupo de Ajuste 2 - SE Rondonópolis operando com 2 TRs}

A curva adotada para este grupo de ajuste também foi do tipo normal inversa igual a 0,15. A Tabela 5.27 apresenta o estudo de coordenação para este grupo de ajuste. Verifica-se que o tempo obtido para a eliminação do defeito na barra de $138 \mathrm{kV}$ da SE Rondonópolis $(667 \mathrm{~ms}$ ) continua superior ao tempo de segunda zona das LTs adjacentes, igual a $650 \mathrm{~ms}$. Entretanto, a proteção continua não sendo sensível às faltas na LT Itiquira - Rondonópolis $230 \mathrm{kV}$ devido ao fato de que a corrente de curto-circuito é inferior a corrente de pick-up do relé. Ainda, a proteção atua com valores bastante elevados para a retaguarda da barra de $230 \mathrm{kV}$ da SE Rondonópolis $(13,103 \mathrm{~s})$ e da LT Rondonópolis - Jaciara $138 \mathrm{kV}(1,759 \mathrm{~s})$ devido aos baixos valores das correntes de curto-circuito, podendo danificar os equipamentos elétricos no caso de falhas de atuação nas proteções principais e secundárias dos mesmos.

Tabela 5.27 - Coordenação da proteção de sobrecorrente de fase (51) no lado de 138 kV para o grupo de ajuste 2.

\section{1}

Grupo de Ajuste 2 - SE Rondonópolis operando com 2 Autotransformadores Estudo de coordenação das proteções de fase (51) no lado de $138 \mathrm{kV}$ dos ATs da SE RP - MT

\begin{tabular}{|c|c|c|c|c|}
\hline \multirow{2}{*}{ Curva 51} & \multirow[t]{2}{*}{$=$} & \multirow{2}{*}{0,15} & \multirow{2}{*}{$\begin{array}{l}\text { Sobrecorrente temporizada de } \\
\text { fase (51) no lado de } 138 \mathrm{kV}\end{array}$} & \multirow{2}{*}{$\frac{\text { Ipick-up (A) }}{2,615}$} \\
\hline & & & & \\
\hline \multicolumn{5}{|c|}{ Tempo de atuação $=\left(0,14^{*}\right.$ Curva51) $/\left(\mathrm{M}^{\wedge} 0,02-1\right)$} \\
\hline Descrição & M & Valor & tempo de atuação (s) & Icc 138 kV (A) \\
\hline Lado de $230 \mathrm{kV}$ do AT & M1 & 25,515 & 0,314 & 66,722 \\
\hline Lado de $138 \mathrm{kV}$ do AT & $\mathrm{M} 2$ & 8,222 & 0,488 & 21,5 \\
\hline Barra 230 kV da SE RP & M3 & 1,083 & 13,103 & 2,833 \\
\hline Barra $138 \mathrm{kV}$ da SE RP & M4 & 4,708 & 0,667 & 12,3125 \\
\hline Barra de $230 \mathrm{kV}$ da SE IT & M5 & 0,284 & $" n / o "$ & 0,743 \\
\hline Barra de $138 \mathrm{kV}$ da SE JC & M6 & 1,810 & 1,759 & 4,733 \\
\hline
\end{tabular}


A Tabela 5.28 mostra que os pontos testados pelo relé de proteção foram todos aprovados. A Figura 48 apresenta a curva com os pontos aprovados pelo teste.

Tabela 5.28 - Resultados do teste da proteção de sobrecorrente de fase temporizado (51) no lado de $138 \mathrm{kV}$ para o Grupo de Ajuste 2.

\begin{tabular}{|c|c|c|c|c|c|}
\hline Falta & $(\mathbf{I} / \ln \times \mid \mathbf{s})$ & Tempo nominal (s) & Tempo real (s) & Desvio (\%) & Resultado \\
\hline L1 - L2- L3 & 1,200 & 5,749 & 5,898 & 2,605 & Aprovado \\
\hline $\mathrm{L} 1-\mathrm{L} 2-\mathrm{L} 3$ & 1,500 & 2,579 & 2,628 & 1,899 & Aprovado \\
\hline L1 - L2- L3 & 1,800 & 1,776 & 1,807 & 1,747 & Aprovado \\
\hline L1 - L2- L3 & 2,100 & 1,405 & 1,439 & 2,446 & Aprovado \\
\hline $\mathrm{L} 1-\mathrm{L} 2-\mathrm{L} 3$ & 2,400 & 1,189 & 1,213 & 2,011 & Aprovado \\
\hline L1 - L2- L3 & 2,700 & 1,047 & 1,064 & 1,684 & Aprovado \\
\hline L1 - L2- L3 & 3,000 & 0,945 & 0,966 & 2,201 & Aprovado \\
\hline L1 - L2- L3 & 3,300 & 0,869 & 0,885 & 1,934 & Aprovado \\
\hline L1 - L2- L3 & 3,600 & 0,809 & 0,831 & 2,724 & Aprovado \\
\hline $\mathrm{L} 1-\mathrm{L} 2-\mathrm{L} 3$ & 3,900 & 0,761 & 0,783 & 2,950 & Aprovado \\
\hline L1 - L2- L3 & 4,200 & 0,721 & 0,783 & 2,189 & Aprovado \\
\hline L1 - L2- L3 & 4,500 & 0,687 & 0,705 & 2,639 & Aprovado \\
\hline L1 - L2- L3 & 4,800 & 0,658 & 0,670 & 1,740 & Aprovado \\
\hline
\end{tabular}

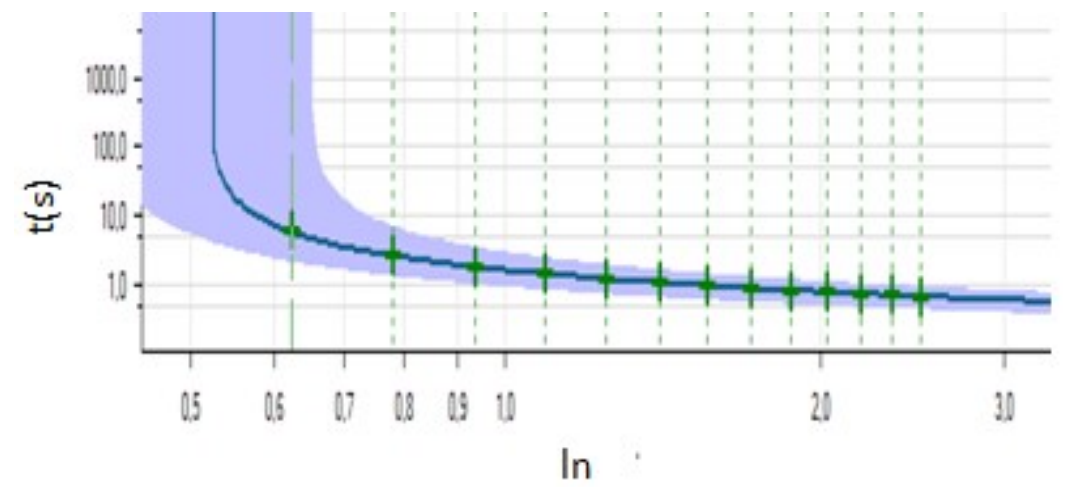

Figura 48 - Pontos aprovados pelo teste da proteção 51 para o grupo de ajuste 2.

\section{c) Grupo de Ajuste 3 - SE Rondonópolis operando com 3 TRs}

A curva adotada para este grupo de ajuste também foi do tipo normal inversa com valor igual a 0,125. A Tabela 5.29 mostra que o tempo de atuação para a retaguarda da barra de $138 \mathrm{kV}$ da SE Rondonópolis $(637 \mathrm{~ms})$ foi bastante satisfatório, pois levou em consideração o critério de coordenação com o tempo de segunda zona das LTs adjacentes $(650 \mathrm{~ms})$. Quanto aos defeitos internos à zona de proteção dos ATs, a proteção é capaz de eliminar os defeitos com, aproximadamente, $300 \mathrm{~ms}$, valor este bastante satisfatório para a atuação como retaguarda da proteção diferencial. Entretanto, a proteção não é sensível aos defeitos na barra de $230 \mathrm{kV}$ da SE Rondonópolis e na LT Itiquira - Rondonópolis $230 \mathrm{kV}$, pois as correntes de curtocircuito são inferiores as correntes de pick-up, resultando na não operação ("n/o") da proteção. 
Tabela 5.29 - Coordenação da proteção de sobrecorrente de fase (51) no lado de 138 kV para o grupo de ajuste 3.

\begin{tabular}{|c|c|c|c|c|}
\hline \multicolumn{5}{|c|}{51} \\
\hline \multicolumn{5}{|c|}{ Grupo de Ajuste 3 - SE Rondonópolis operando com 3 transformadores } \\
\hline \multicolumn{5}{|c|}{ Estudo de coordenação das proteções de fase 51 no lado de 138 kV dos TRs da SE RP - MT } \\
\hline \multirow{2}{*}{ Curva 51} & \multirow{2}{*}{$=$} & \multirow{2}{*}{0,125} & \multirow{2}{*}{$\begin{array}{l}\text { Sobrecorrente temporizado de } \\
\text { fase (51) no lado de } 138 \mathrm{kV}\end{array}$} & Ipick-up (A) \\
\hline & & & & 2,615 \\
\hline \multicolumn{5}{|c|}{ Tempo de atuação $=\left(0,14 *\right.$ Curva51) $/\left(\mathrm{M}^{\wedge} 0,02-1\right)$} \\
\hline Descrição & M & Valor & tempo de atuação (s) & Icc $138 \mathrm{kV}(\mathrm{A})$ \\
\hline Lado de $230 \mathrm{kV}$ do TR & M1 & 25,958 & 0,260 & 67,880 \\
\hline Lado de $138 \mathrm{kV}$ do TR & M2 & 11,541 & 0,349 & 30,179 \\
\hline Barra 230 kV da SE RP & M3 & 0,752 & $-3,073$ & 1,965 \\
\hline Barra 138 kV da SE RP & M4 & 3,878 & 0,637 & 10,142 \\
\hline Barra de $230 \mathrm{kV}$ da SE IT & M5 & 0,196 & $-0,547$ & 0,514 \\
\hline Barra de $138 \mathrm{kV}$ da SE JC & M6 & 1,305 & 3,278 & 3,413 \\
\hline
\end{tabular}

A Tabela 5.30 mostra que os pontos para o teste trifásico foram todos aprovados. A curva com os pontos de testes são mostrados na Figura 49.

Tabela 5.30 - Resultados do teste da proteção de sobrecorrente de fase temporizado (51) no lado de $138 \mathrm{kV}$ para o grupo de ajuste 3.

\begin{tabular}{|c|c|c|c|c|c|}
\hline Falta & $(I / I n * \mid s)$ & Tempo nominal (s) & Tempo real (s) & Desvio (\%) & Resultado \\
\hline L1 - L2- L3 & 1,200 & 4,791 & 4,929 & 2,890 & Aprovado \\
\hline L1 - L2- L3 & 1,500 & 2,149 & 2,188 & 1,797 & Aprovado \\
\hline L1 - L2- L3 & 1,800 & 1,480 & 1,514 & 2,331 & Aprovado \\
\hline L1 - L2- L3 & 2,100 & 1,171 & 1,191 & 1,715 & Aprovado \\
\hline $\mathrm{L} 1-\mathrm{L} 2-\mathrm{L} 3$ & 2,400 & 0,990 & 1,022 & 3,105 & Aprovado \\
\hline L1 - L2- L3 & 2,700 & 0,872 & 0,891 & 2,233 & Aprovado \\
\hline $\mathrm{L} 1-\mathrm{L} 2-\mathrm{L} 3$ & 3,000 & 0,787 & 0,807 & 2,559 & Aprovado \\
\hline L1 - L2- L3 & 3,300 & 0,724 & 0,742 & 2,587 & Aprovado \\
\hline L1 - L2- L3 & 3,600 & 0,674 & 0,690 & 2,405 & Aprovado \\
\hline $\mathrm{L} 1-\mathrm{L} 2-\mathrm{L} 3$ & 3,900 & 0,634 & 0,656 & 3,546 & Aprovado \\
\hline L1 - L2- L3 & 4,200 & 0,601 & 0,619 & 3,060 & Aprovado \\
\hline L1 - L2- L3 & 4,500 & 0,573 & 0,584 & 2,069 & Aprovado \\
\hline L1 - L2- L3 & 4,800 & 0,549 & 0,559 & 1,819 & Aprovado \\
\hline
\end{tabular}

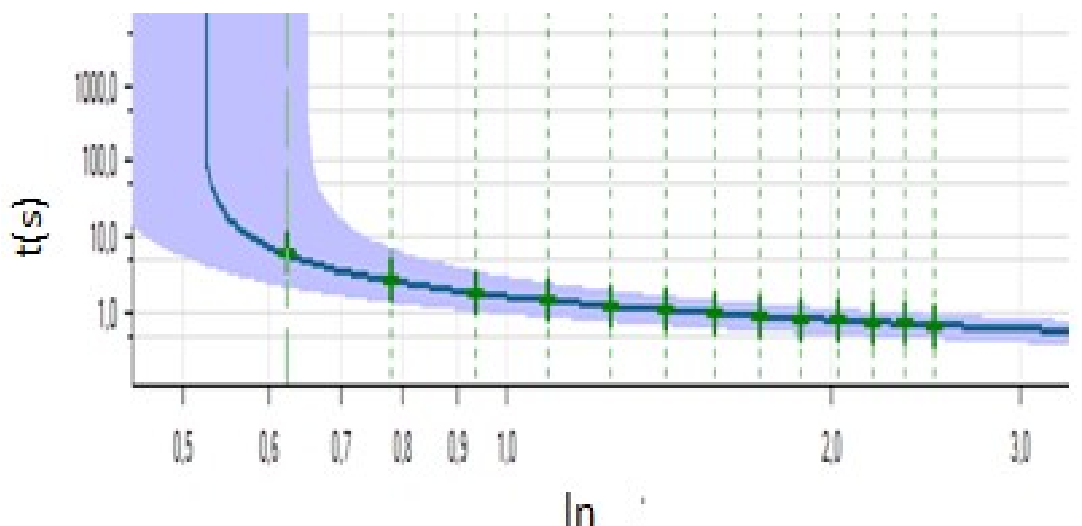

Figura 49 - Pontos aprovados pelo teste da proteção 51 para o grupo de ajuste 3. 


\section{d) Grupo de Ajuste 4 - SE Rondonópolis operando com 4 TRs}

Por fim, a curva adotada para este grupo de ajuste também foi do tipo normal inversa com valor igual a 0,125. Na Tabela 5.31 verifica-se que a proteção continua atuando satisfatoriamente, com tempo aproximadamente igual a $300 \mathrm{~ms}$, como retaguarda da proteção diferencial dos ATs para os defeitos internos. No caso da proteção de retaguarda da barra de $138 \mathrm{kV}$ da SE Rondonópolis, o tempo de atuação (728ms) continua levando em consideração e sendo superior ao tempo de segunda zona das LTs $(650 \mathrm{~ms})$. Entretanto, a proteção não é sensível ("n/o")aos defeitos na barra de $230 \mathrm{kV}$ da SE Rondonópolis e na LT Itiquira - Rondonópolis 230kV, pelo fato de que os valores das correntes de falta são inferiores a corrente de pick-up da proteção. Ainda, o tempo de atuação obtido para os defeitos na LT Rondonópolis Jaciara 138kV $(76,699 \mathrm{~s})$ foi bastante elevado devido ao fato da baixa corrente de curtocircuito. Caso as proteções principais e secundárias dessa LT falhe, o sistema ficará submetido a uma corrente de curto-circuito que oferecerá bastantes riscos aos equipamentos de ambas SEs e também a desestabilização do sistema. Com o objetivo de melhorar os tempos de atuação do sistema de proteção para as faltas descritas, será habilitada a função $51 \mathrm{~V}$.

Tabela 5.31 - Coordenação da proteção de sobrecorrente de fase (51) no lado de 138 kV para o grupo de ajuste 4 .

\section{1}

Grupo de Ajuste 4 - SE Rondonópolis operando com 4 transformadores

Estudo de coordenação da proteção de neutro (51) no lado de 138 kV dos TRs da SE RP - MT

\begin{tabular}{|c|c|c|c|c|}
\hline Curva 51 & $=$ & 0,125 & $\begin{array}{c}\text { Sobrecorrente temporizado de } \\
\text { fase (51) no lado de 138 kV }\end{array}$ & Ipick-up (A) \\
\cline { 3 - 5 } & & & Tempo de atuação $=(0,14 *$ Curva51)/(M^0,02 -1) \\
\hline \multicolumn{6}{|c|}{ Descrição } & M & Valor & tempo de atuação (s) & Icc 138 kV (A) \\
\hline Lado de 230 kV do TR & M1 & 26,195 & 0,259 & 68,5 \\
Lado de 138 kV do TR & M2 & 13,940 & 0,323 & 36,454 \\
Barra 230 kV da SE RP & M3 & 0,571 & "n/o" & 1,493 \\
Barra 138 kV da SE RP & M4 & 3,277 & 0,728 & 8,57 \\
Barra de 230 kV da SE IT & M5 & 0,149 & "n/o" & 0,38875 \\
Barra de 138 kV da SE JC & M6 & 1,011 & 76,699 & 2,645 \\
\hline
\end{tabular}

Como o tipo e o valor da curva de atuação $(0,125)$ são os mesmos do Grupo de Ajuste 3 , os resultados do teste são equivalentes aos dispostos na Tabela 5.30 e na Figura 49. 


\subsubsection{Ajuste da unidade de sobrecorrente instantânea (50)}

Com o objetivo de coordenar a proteção do lado de baixa dos TRs com as das LTs adjacentes, a unidade instantânea será bloqueada evitando atuações indevidas da proteção e para levar em consideração os requisitos de coordenação e seletividade.

\subsubsection{Ajuste da proteção de sobrecorrente com controle de tensão (51V)}

Assim como no lado de alta tensão dos TRs, esta função também será utilizada para a proteção de retaguarda para os defeitos cujos valores das correntes de falta são inferiores à nominal do equipamento protegido. O valor de ajuste da tensão também é igual a $0,7 p u$ sendo adotado como a referência o secundário do TP. Neste caso, como a tensão secundária é igual a $115 \mathrm{~V}$, o valor de ajuste é o mesmo assumido para a proteção do lado de $230 \mathrm{kV}$. A corrente de pick-up adotada será igual a $30 \%$ da corrente nominal, sendo assim, o valor também será igual a $0,5 \mathrm{~A}$.

A seguir serão apresentados os resultados para os tempos de atuação da proteção nas quatro configurações da SE Rondonópolis.

\section{a) Grupo de Ajuste 1 - SE Rondonópolis operando com 1 TR}

A curva adotada para este grupo foi do tipo normal inversa com valor igual a 0,35. A Tabela 5.32 mostra o estudo de coordenação em que é possível observar que agora a proteção é sensível para as faltas na barra de $230 \mathrm{kV}$ da SE Rondonópolis (1,033s) e na LT Itiquira - Rondonópolis 230 kV (1,673s), mas atua com valores críticos aos equipamentos das SEs. Houve também uma melhora significativa no tempo de atuação da proteção da LT Rondonópolis - Jaciara $138 \mathrm{kV}(0,871 \mathrm{~s})$ valor satisfatório, pois também considera o tempo de segunda zona das LTs adjacentes $(0,650 \mathrm{~s})$.

Tabela 5.32 - Coordenação da proteção de sobrecorrente com controle de tensão (51V) no lado de $138 \mathrm{kV}$ para o Grupo de Ajuste 1.

$51 \mathrm{~V}$

Grupo de Ajuste 1 - SE Rondonópolis operando com 1 transformador

Estudo de coordenação da proteção de sobrecorrente com controle de tensão (51V) dos TRs da SE RP - MT

\begin{tabular}{|c|c|c|c|c|}
\hline \multirow{2}{*}{ Curva 51V } & \multirow{2}{*}{$=$} & \multirow{2}{*}{0,35} & \multirow{2}{*}{$\begin{array}{l}\text { Sobrecorrente com controle de } \\
\text { tensão ( } 51 \mathrm{~V}) \text { no lado de } 138 \mathrm{kV}\end{array}$} & Ipick-up (A) \\
\hline & & & & 0,5 \\
\hline \multicolumn{5}{|c|}{ Tempo de atuação $=\left(0,14^{*}\right.$ Curva51V) $/\left(M^{\wedge} 0,02-1\right)$} \\
\hline Descrição & $\mathbf{M}$ & Valor & tempo de atuação (s) & Icc 138 kV (A) \\
\hline Lado de $230 \mathrm{kV}$ do TR & M1 & 30,000 & 0,696 & 63,736 \\
\hline Lado de 138 kV do TR & $\mathrm{M} 2$ & 16,174 & 0,856 & 8,087 \\
\hline Barra 230 kV da SE RP & M3 & 10,153 & 1,033 & 5,076 \\
\hline Barra 138 kV da SE RP & M4 & 30,000 & 0,696 & 15,658 \\
\hline $50 \%$ da LT ITRP $230 \mathrm{kV}$ & M5 & 4,236 & 1,673 & 2,118 \\
\hline Barra de $138 \mathrm{kV}$ da SE JC & M6 & 15,425 & 0,871 & 7,713 \\
\hline
\end{tabular}


A verificação do ajuste desta proteção foi realizada, assim como no lado de $230 \mathrm{kV}$ dos TRs, através de dois testes. Primeiramente, foi feita a análise do ajuste da curva por meio dos pontos de teste e, em seguida, mostrou-se que a partida da proteção $51 \mathrm{~V}$ se daria apenas após a tensão atingir o valor de 0,7pu.

$\mathrm{Na}$ Tabela 5.33 mostra-se a aprovação dos pontos de testes pelo relé. A curva com os pontos testados é apresentada na Figura 50.

Tabela 5.33 - Resultados do teste da proteção de sobrecorrente com controle de tensão (51V) no lado de $138 \mathrm{kV}$ para o grupo de ajuste 1.

\begin{tabular}{|c|c|c|c|c|c|}
\hline Falta & $(\mathbf{I} / \mathbf{I n}+\mathbf{s})$ & Tempo nominal (s) & Tempo real (s) & Desvio (\%) & Resultado \\
\hline $\mathrm{L} 1-\mathrm{L} 2-\mathrm{L} 3$ & 2,000 & 3,510 & 3,559 & 1,396 & Aprovado \\
\hline $\mathrm{L} 1-\mathrm{L} 2-\mathrm{L} 3$ & 4,000 & 1,743 & 1,765 & 1,262 & Aprovado \\
\hline $\mathrm{L} 1-\mathrm{L} 2-\mathrm{L} 3$ & 6,000 & 1,343 & 1,362 & 1,415 & Aprovado \\
\hline $\mathrm{L} 1-\mathrm{L} 2-\mathrm{L} 3$ & 8,000 & 1,154 & 1,169 & 1,299 & Aprovado \\
\hline $\mathrm{L} 1-\mathrm{L} 2-\mathrm{L} 3$ & 10,00 & 1,039 & 1,051 & 1,155 & Aprovado \\
\hline $\mathrm{L} 1-\mathrm{L} 2-\mathrm{L} 3$ & 12,00 & 0,962 & 0,977 & 1,559 & Aprovado \\
\hline $\mathrm{L} 1-\mathrm{L} 2-\mathrm{L} 3$ & 14,00 & 0,904 & 0,922 & 1,991 & Aprovado \\
\hline $\mathrm{L} 1-\mathrm{L} 2-\mathrm{L} 3$ & 16,00 & 0,859 & 0,881 & 2,561 & Aprovado \\
\hline $\mathrm{L} 1-\mathrm{L} 2-\mathrm{L} 3$ & 18,00 & 0,823 & 0,838 & 1,822 & Aprovado \\
\hline $\mathrm{L} 1-\mathrm{L} 2-\mathrm{L} 3$ & 20,00 & 0,793 & 0,815 & 2,774 & Aprovado \\
\hline $\mathrm{L} 1-\mathrm{L} 2-\mathrm{L} 3$ & 22,00 & 0,768 & 0,783 & 1,953 & Aprovado \\
\hline $\mathrm{L} 1-\mathrm{L} 2-\mathrm{L} 3$ & 24,00 & 0,747 & 0,758 & 1,472 & Aprovado \\
\hline
\end{tabular}

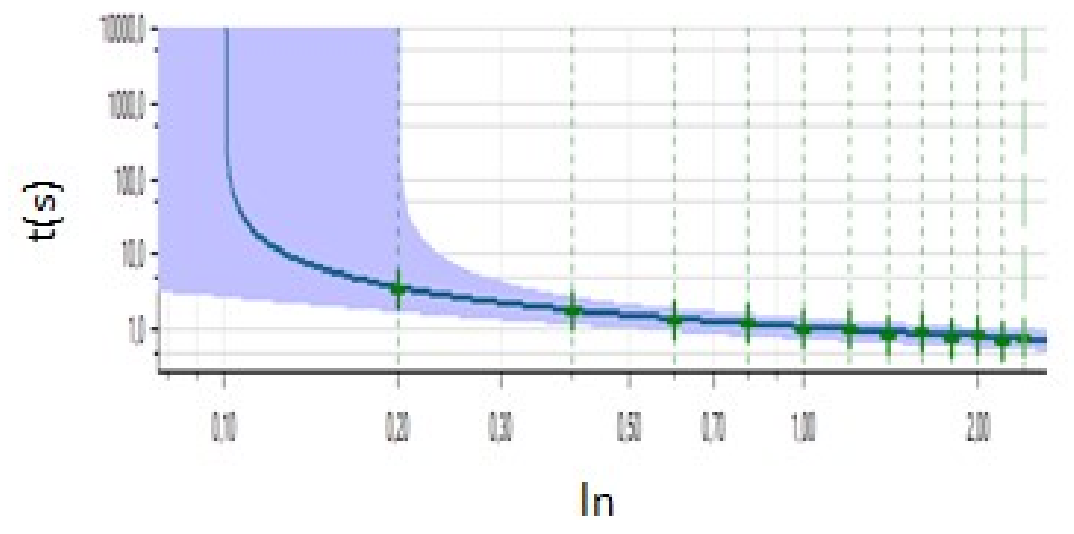

Figura 50 - Pontos aprovados pelo teste da proteção 51V para o grupo de ajuste 1.

A Figura 51 mostra que a partida (Início) da proteção $51 \mathrm{~V}$ deu-se somente após a tensão atingir o valor de 0,7pu (46,40V fase-neutro) e o trip (Disparo) ocorreu apenas após o tempo de $3,533 \mathrm{~s}$, conforme a equação (5.48). 


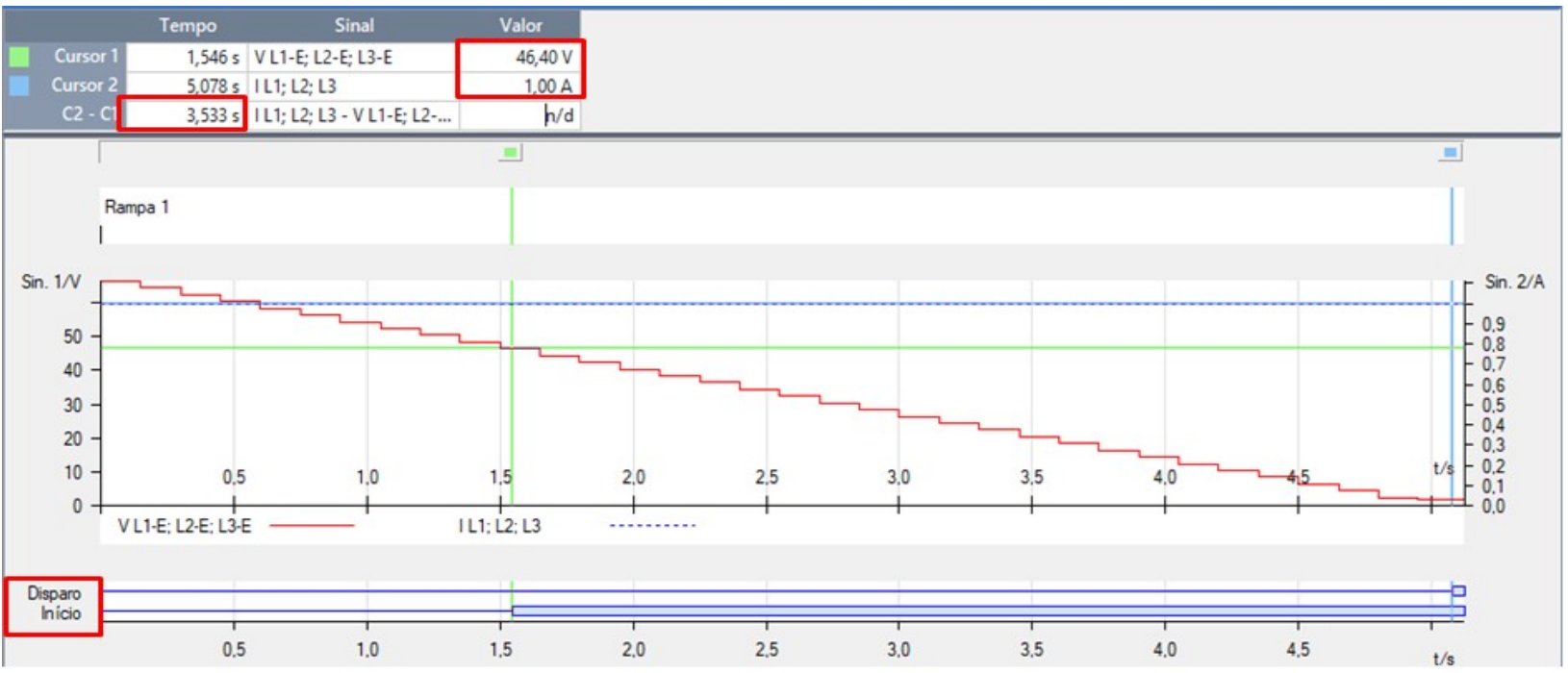

Figura 51 - Teste ramping evidenciando a partida da proteção 51V após a tensão atingir 0,7pu.

\section{b) Grupo de Ajuste 2 - SE Rondonópolis operando com 2 TRs}

O valor da curva adotada para este grupo de ajuste foi do tipo normal inversa com valor igual a 0,325. Na Tabela 5.34 observa-se que o tempo de retaguarda para a barra de $138 \mathrm{kV}$ da SE Rondonópolis $(688 \mathrm{~ms})$ está coordenado com o tempo de segunda zona das LTs adjacentes $(650 \mathrm{~ms})$. Ainda, a proteção é capaz de atuar com tempo satisfatório (990ms) na eliminação dos defeitos na LT Rondonópolis - Jaciara 138kV, por também coordenar com os tempos de segunda zona das LTs. Entretanto, esta função de proteção é sensível aos defeitos na barra de 230 kV da SE Rondonópolis e a $50 \%$ da LT Itiquira - Rondonópolis $230 \mathrm{kV}$, mas com um tempo de operação considerado crítico podendo vir a danificar os equipamentos das SEs.

Tabela 5.34 - Coordenação da proteção de sobrecorrente de fase com controle de tensão (51V) no lado de $138 \mathrm{kV}$ para o grupo de ajuste 2 .

\section{$51 \mathrm{~V}$}

Grupo de Ajuste 2 - SE Rondonópolis operando com 2 transformadores

Estudo de coordenação da proteção de sobrecorrente com controle de tensão (51V) dos TRs da SE RP - MT

\begin{tabular}{|c|c|c|c|c|}
\hline \multirow{2}{*}{ Curva 51V } & \multirow{2}{*}{$=$} & \multirow{2}{*}{0,325} & \multirow{2}{*}{$\begin{array}{l}\text { Sobrecorrente com controle de } \\
\text { tensão (51V) no lado de } 138 \mathrm{kV}\end{array}$} & Ipick-up (A) \\
\hline & & & & 0,5 \\
\hline \multicolumn{5}{|c|}{ Tempo de atuação $=\left(0,14^{*}\right.$ Curva51V) $/\left(\mathrm{M}^{\wedge} 0,02-1\right)$} \\
\hline Descrição & $M$ & Valor & tempo de atuação (s) & Icc 138 kV (A) \\
\hline Lado de 230 kV do TR & M1 & 30,000 & 0,646 & 66,722 \\
\hline Lado de 138 kV do TR & $\mathrm{M} 2$ & 30,000 & 0,646 & 21,500 \\
\hline Barra 230 kV da SE RP & M3 & 5,666 & 1,289 & 2,833 \\
\hline Barra 138 kV da SE RP & M4 & 24,625 & 0,688 & 12,313 \\
\hline $50 \%$ da LT ITRP 230 kV & M5 & 2,347 & 2,644 & 1,174 \\
\hline Barra de $138 \mathrm{kV}$ da SE JC & M6 & 9,466 & 0,990 & 4,733 \\
\hline
\end{tabular}


A Tabela 5.35 mostram-se os pontos testados pelo relé de proteção em que foram todos aprovados. A curva de atuação obtida com os pontos testados é observada na Figura 52.

Tabela 5.35 - Resultados do teste da proteção de sobrecorrente com controle de tensão (51V) no lado de $138 \mathrm{kV}$ para o grupo de ajuste 2.

\begin{tabular}{|c|c|c|c|c|c|}
\hline Falta & $(\mathbf{I} / \mathbf{I n}+\mathbf{s})$ & Tempo nominal (s) & Tempo real (s) & Desvio (\%) & Resultado \\
\hline $\mathrm{L} 1-\mathrm{L} 2-\mathrm{L} 3$ & 2,000 & 3,259 & 3,308 & 1,478 & Aprovado \\
\hline $\mathrm{L} 1-\mathrm{L} 2-\mathrm{L} 3$ & 4,000 & 1,618 & 1,639 & 1,290 & Aprovado \\
\hline $\mathrm{L} 1-\mathrm{L} 2-\mathrm{L} 3$ & 6,000 & 1,247 & 1,269 & 1,789 & Aprovado \\
\hline $\mathrm{L} 1-\mathrm{L} 2-\mathrm{L} 3$ & 8,000 & 1,072 & 1,083 & 1,069 & Aprovado \\
\hline $\mathrm{L} 1-\mathrm{L} 2-\mathrm{L} 3$ & 10,00 & 0,965 & 0,985 & 2,036 & Aprovado \\
\hline $\mathrm{L} 1-\mathrm{L} 2-\mathrm{L} 3$ & 12,00 & 0,893 & 0,914 & 2,378 & Aprovado \\
\hline $\mathrm{L} 1-\mathrm{L} 2-\mathrm{L} 3$ & 14,00 & 0,839 & 0,848 & 1,108 & Aprovado \\
\hline $\mathrm{L} 1-\mathrm{L} 2-\mathrm{L} 3$ & 16,00 & 0,798 & 0,808 & 1,342 & Aprovado \\
\hline $\mathrm{L} 1-\mathrm{L} 2-\mathrm{L} 3$ & 18,00 & 0,764 & 0,779 & 1,901 & Aprovado \\
\hline $\mathrm{L} 1-\mathrm{L} 2-\mathrm{L} 3$ & 20,00 & 0,736 & 0,751 & 1,915 & Aprovado \\
\hline $\mathrm{L} 1-\mathrm{L} 2-\mathrm{L} 3$ & 22,00 & 0,713 & 0,727 & 1,993 & Aprovado \\
\hline $\mathrm{L} 1-\mathrm{L} 2-\mathrm{L} 3$ & 24,00 & 0,693 & 0,707 & 2,057 & Aprovado \\
\hline
\end{tabular}

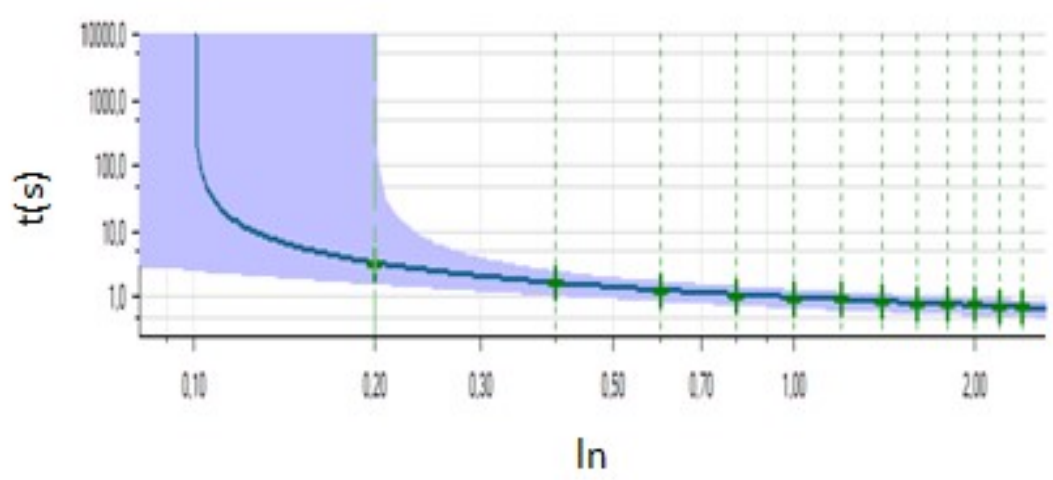

Figura 52 - Pontos aprovados pelo teste da proteção 51V para o grupo de ajuste 2.

A Figura 53 mostra que a partida (Disparo) da proteção $51 \mathrm{~V}$ ocorreu após a tensão assumir o valor de $46,4 \mathrm{~V}$ fase-neutro. O trip ocorreu somente após o tempo alcançar o valor 3,284s conforme a equação (5.48). 


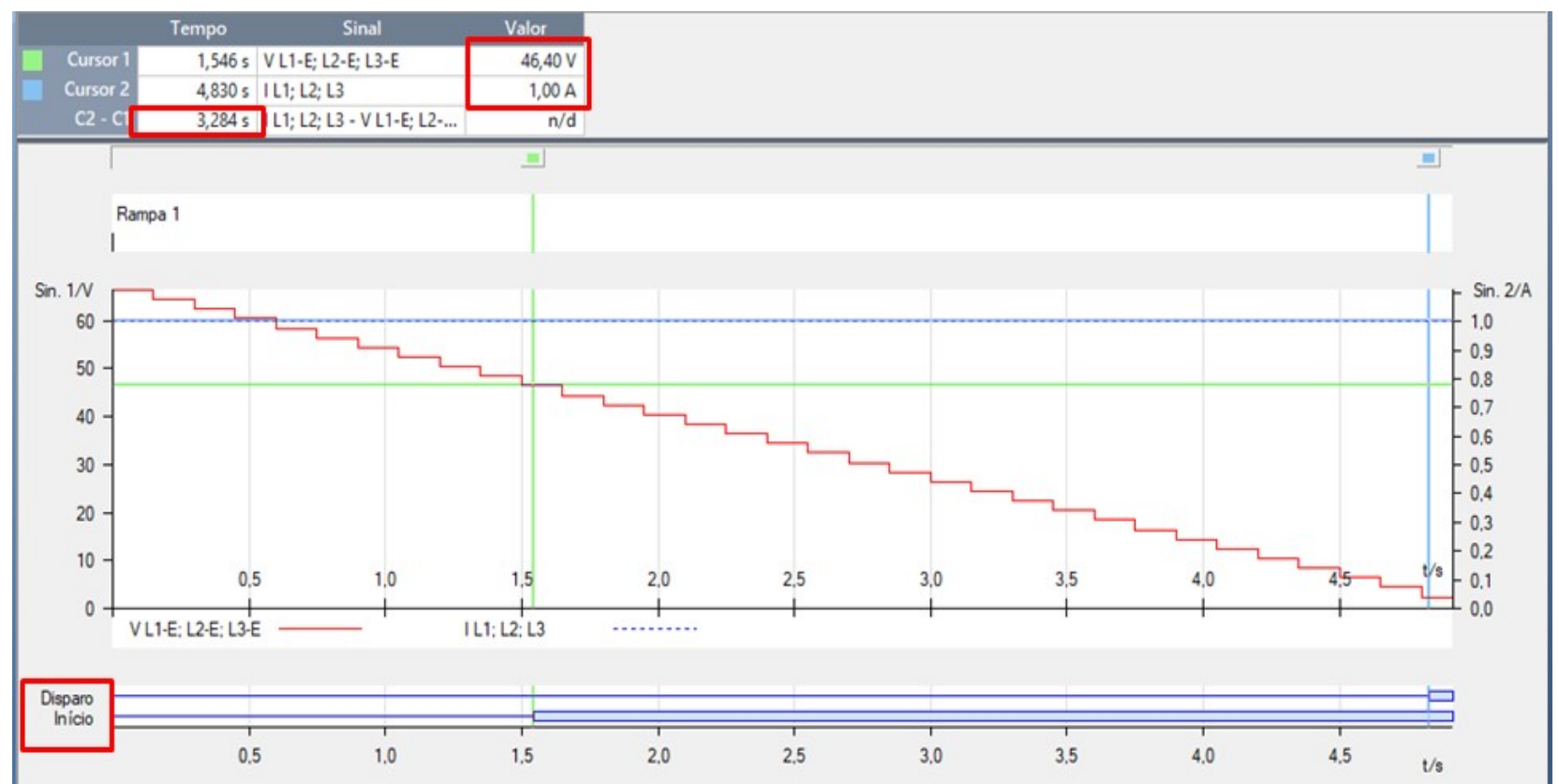

Figura 53 - Teste ramping evidenciando a partida da proteção 51V após a tensão atingir 0,7pu.

\section{c) Grupo de Ajuste 3 - SE Rondonópolis operando com 3 TRs}

A curva adotada para este grupo de ajuste também foi do tipo normal inversa com valor igual a 0,325 . A Tabela 5.36 mostra que o tempo de retaguarda para a barra de $138 \mathrm{kV}$ da SE Rondonópolis $(733 \mathrm{~ms})$ continua superior ao valor dos tempos de segunda zona das LTs adjacentes $(650 \mathrm{~ms})$. A proteção é capaz de eliminar os defeitos na LT Rondonópolis - Jaciara $138 \mathrm{kV}$, mas com um tempo de atuação $(1,162 \mathrm{~s})$ considerado crítico aos equipamentos do sistema. Do mesmo modo ocorre com a eliminação das faltas na barra de $230 \mathrm{kV}$ da SE Rondonópolis e a $50 \%$ da LT Itiquira - Rondonópolis $230 \mathrm{kV}$.

Tabela 5.36 - Coordenação da proteção de sobrecorrente de fase com controle de tensão (51V) no lado de $138 \mathrm{kV}$ para o grupo de ajuste 3.

\section{$51 \mathrm{~V}$}

\section{Grupo de Ajuste 3 - SE Rondonópolis operando com 3 transformadores}

Estudo de coordenação da proteção de sobrecorrente com controle de tensão (51V) dos TRs da SE RP - MT

\begin{tabular}{|c|c|c|c|c|}
\hline Curva 51V & $=$ & 0,325 & $\begin{array}{c}\text { Sobrecorrente com controle de tensão } \\
(51 \mathrm{~V}) \text { no lado de } 138 \mathrm{kV}\end{array}$ & Ipick-up (A) \\
\cline { 4 - 6 } & & Tempo de atuação $=\left(0,14^{*}\right.$ Curva51V)/(M^0,02 -1) & 0,5 \\
\hline Descrição & M & Valor & tempo de atuação (s) & Icc 138 kV (A) \\
\hline Lado de 230 kV do TR & M1 & 30,000 & 0,646 & 67,88 \\
Lado de 138 kV do TR & M2 & 30,000 & 0,646 & 30,179 \\
Barra 230 kV da SE RP & M3 & 3,931 & 1,639 & 1,9654 \\
Barra 138 kV da SE RP & M4 & 20,284 & 0,733 & 10,142 \\
50\% da LT ITRP 230 kV & M5 & 1,625 & 4,663 & 0,8125 \\
Barra de 138 kV da SE JC & M6 & 6,825 & 1,162 & 3,4125 \\
\hline
\end{tabular}


Devido ao fato de que o valor e o tipo da curva deste grupo de ajuste serem semelhantes ao do Grupo de Ajuste 3, os resultados dos testes podem ser verificados nas Tabela 5.35 e nas Figuras 52e 53.

\section{d) Grupo de Ajuste 4 - SE Rondonópolis operando com 4 TRs}

Por fim, também foi escolhida a curva do tipo normal inversa com valor igual a 0,3. A Tabela 5.37 mostra que o tempo de atuação para a proteção de retaguarda da barra 138 kV da SE Rondonópolis $(718 \mathrm{~ms})$ está coordenado com os tempos de segunda zona das proteções de distância das LTs adjacentes (650ms). Porém, mesmo a proteção sendo agora sensível aos defeitos na barra de 230kV da SE Rondonópolis (1,899s), a 50\% da LT Itiquira - Rondonópolis 230kV (9,886s) e na LT Rondonópolis Jaciara 138kV (1,240s), os tempos de atuação obtidos são bastante elevados, podendo danificar os equipamentos das SEs.

Tabela 5.37 - Coordenação da proteção de sobrecorrente de fase com controle de tensão (51V) no lado de $138 \mathrm{kV}$ para o grupo de ajuste 4.

$51 \mathrm{~V}$

\section{Grupo de Ajuste 4 - SE Rondonópolis operando com 4 transformadores}

Estudo de coordenação da proteção de sobrecorrente com controle de tensão 51V dos TRs da SE RP - MT

\begin{tabular}{|c|c|c|c|c|}
\hline \multirow{2}{*}{ Curva 51V } & \multirow{2}{*}{$=$} & \multirow{2}{*}{0,3} & \multirow{2}{*}{$\begin{array}{c}\text { Sobrecorrente temporizado de } \\
\text { fase (51) no lado de } 138 \mathrm{kV}\end{array}$} & Ipick-up (A) \\
\hline & & & & 0,5 \\
\hline \multicolumn{5}{|c|}{ Tempo de atuação $=\left(0,14^{*}\right.$ Curva51V) $/\left(\mathrm{M}^{\wedge} 0,02-1\right)$} \\
\hline Descrição & $M$ & Valor & tempo de atuação (s) & Icc $138 \mathrm{kV}(\mathrm{A})$ \\
\hline Lado de $230 \mathrm{kV}$ do TR & M1 & 30,000 & 0,597 & 68,500 \\
\hline Lado de $138 \mathrm{kV}$ do TR & $\mathrm{M} 2$ & 30,000 & 0,597 & 36,454 \\
\hline Barra 230 kV da SE RP & M3 & 2,986 & 1,899 & 1,493 \\
\hline Barra 138 kV da SE RP & M4 & 17,140 & 0,718 & 8,570 \\
\hline $50 \%$ da LT ITRP 230 kV & M5 & 1,236 & 9,886 & 0,618 \\
\hline Barra de 138 kV da SE JC & M6 & 5,290 & 1,240 & 2,645 \\
\hline
\end{tabular}

A Tabela 5.38 mostra que os pontos de testes foram todos aprovados e que os tempos de atuação real da proteção foram bastante próximos dos tempos de atuação nominal da proteção. A Figura 54 apresenta a curva de atuação para este grupo de ajuste com todos os pontos do teste aprovados. 
Tabela 5.38 - Resultados do teste da proteção de sobrecorrente com controle de tensão (51V) no lado de $138 \mathrm{kV}$ para o grupo de ajuste 4.

\begin{tabular}{|c|c|c|c|c|c|}
\hline Falta & $(I / I n * I s)$ & Tempo nominal (s) & Tempo real (s) & Desvio (\%) & Resultado \\
\hline L1 - L2- L3 & 2,000 & 3,008 & 3,049 & 1,363 & Aprovado \\
\hline L1 - L2- L3 & 4,000 & 1,494 & 1,519 & 1,673 & Aprovado \\
\hline L1 - L2- L3 & 6,000 & 1,151 & 1,171 & 1,738 & Aprovado \\
\hline L1 - L2- L3 & 8,000 & 0,989 & 1,005 & 1,618 & Aprovado \\
\hline L1 - L2- L3 & 10,00 & 0,891 & 0,908 & 1,908 & Aprovado \\
\hline L1 - L2- L3 & 12,00 & 0,824 & 0,837 & 1,578 & Aprovado \\
\hline L1 - L2- L3 & 14,00 & 0,775 & 0,794 & 2,452 & Aprovado \\
\hline L1 - L2- L3 & 16,00 & 0,737 & 0,752 & 2,035 & Aprovado \\
\hline L1 - L2- L3 & 18,00 & 0,706 & 0,721 & 2,125 & Aprovado \\
\hline L1 - L2- L3 & 20,00 & 0,680 & 0,697 & 2,500 & Aprovado \\
\hline L1 - L2- L3 & 22,00 & 0,659 & 0,678 & 2,883 & Aprovado \\
\hline L1 - L2- L3 & 24,00 & 0,640 & 0,658 & 2,812 & Aprovado \\
\hline
\end{tabular}

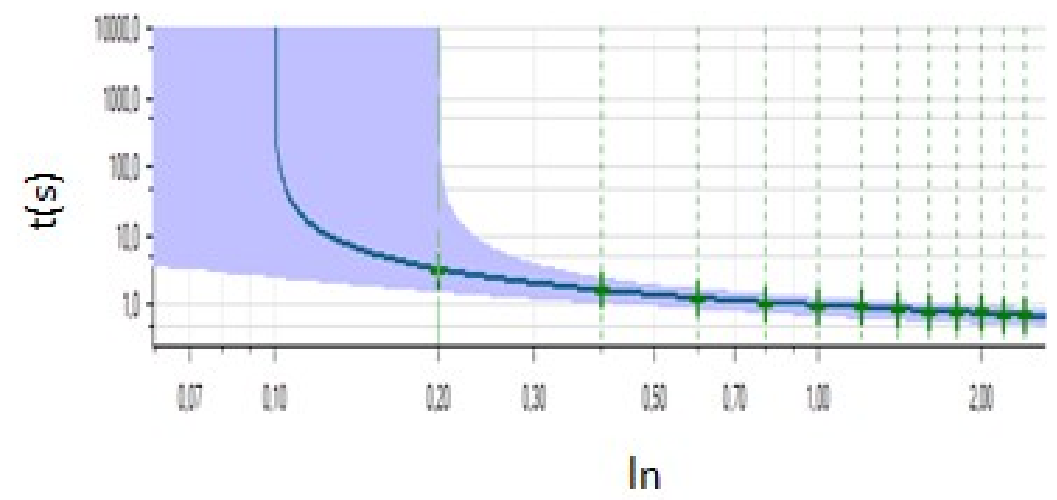

Figura 54 - Pontos aprovados pelo teste da proteção 51V para o grupo de ajuste 4.

A Figura 55 mostra a partida (Início) da proteção $51 \mathrm{~V}$ deu-se somente após o valor de tensão atingir 46,4V (fase-neutro). O trip (Disparo) ocorreu após 3,031s assim como é possível obter por meio da equação (5.48).

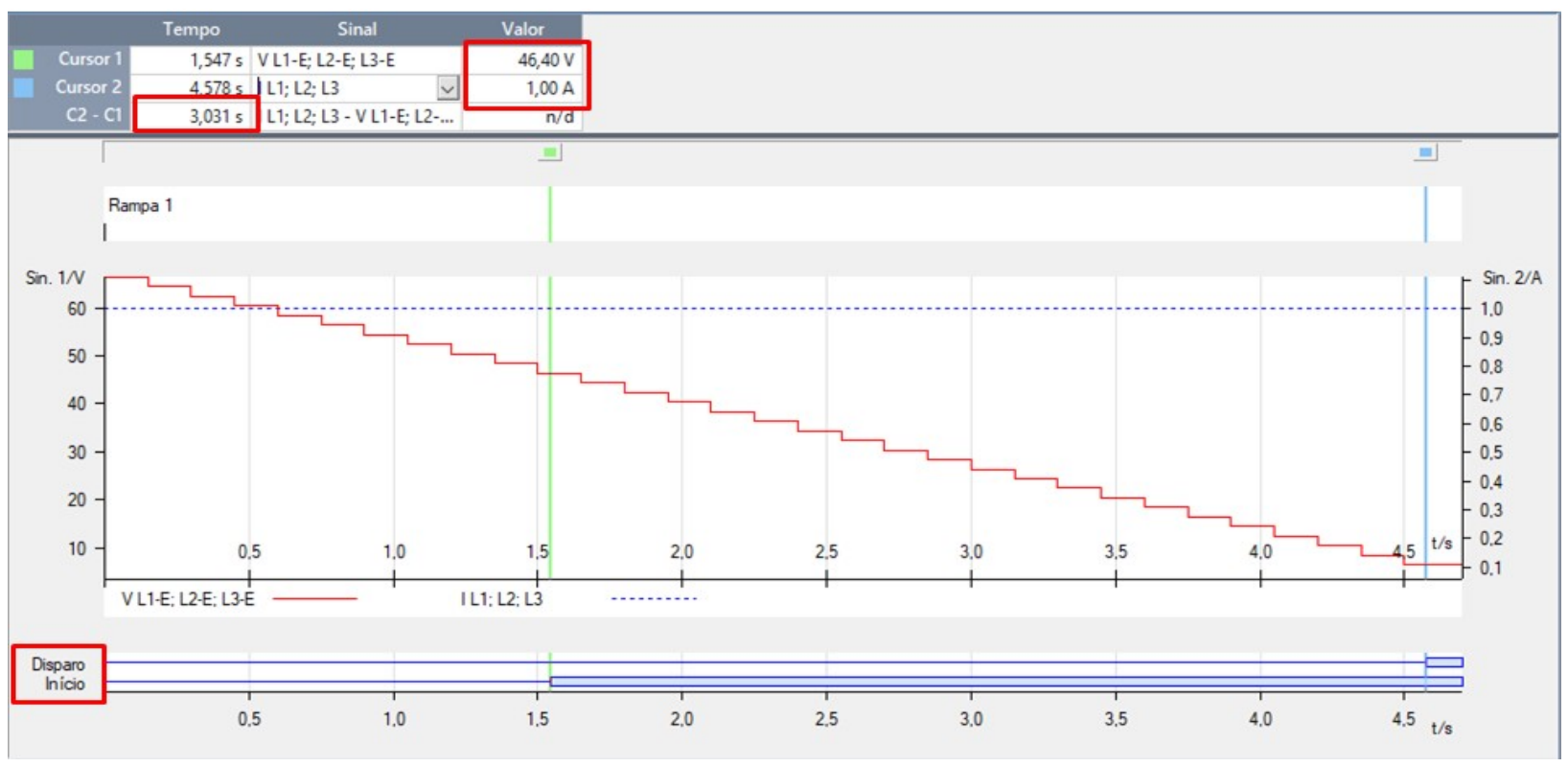

Figura 55 - Teste ramping evidenciando a partida da proteção 51V após a tensão atingir 0,7pu. 


\subsubsection{Ajuste das proteções de sobrecorrente de Neutro $(50 \mathrm{~N} / 51 \mathrm{~N})$}

A Tabela 5.39 mostra os valores das correntes de curto-circuito monofásicos-terra para as quatro condições de operação da SE Rondonópolis para o ajuste das proteções de sobrecorrente de neutro.

Tabela 5.39 - Valores das correntes de curto-circuito monofásico-terra para as quatro condições de operação.

\begin{tabular}{|c|c|c|c|c|}
\hline Descrição da falta & $1 \mathrm{TR}$ & 2 TRs & 3 TRs & 4 TRs \\
\hline $\begin{array}{c}\text { Corrente de curto-circuito monofásico- } \\
\text { terra }\left(3 \mathrm{I}_{0}\right) \text { no bay de } 230 \mathrm{kV} \text { da SE RP } \\
\text { medida no lado de } 138 \mathrm{kV}\end{array}$ & $8365 \mathrm{~A}$ & $11030 \mathrm{~A}$ & $12770 \mathrm{~A}$ & $14035 \mathrm{~A}$ \\
\hline $\begin{array}{c}\text { Corrente de curto-circuito monofásico- } \\
\text { terra }\left(3 \mathrm{I}_{0}\right) \text { no bay de } 138 \mathrm{kV} \text { da SE RP } \\
\text { medida no lado de } 138 \mathrm{kV}\end{array}$ & $1698 \mathrm{~A}$ & 5892 A & 7989 A & $9681 \mathrm{~A}$ \\
\hline $\begin{array}{c}\text { Corrente de curto-circuito monofásico- } \\
\text { terra }\left(3 \mathrm{I}_{0}\right) \text { na barra de } 230 \mathrm{kV} \text { da SE RP } \\
\text { medida no lado de } 138 \mathrm{kV}\end{array}$ & $4405 \mathrm{~A}$ & $3530 \mathrm{~A}$ & $2860 \mathrm{~A}$ & $2430 \mathrm{~A}$ \\
\hline $\begin{array}{c}\text { Corrente de curto-circuito monofásico- } \\
\text { terra }\left(3 \mathrm{I}_{0}\right) \text { na barra de } 138 \mathrm{kV} \text { da SE RP } \\
\text { medida no lado de } 138 \mathrm{kV}\end{array}$ & $5217 \mathrm{~A}$ & 5892 A & 3984 A & $3750 \mathrm{~A}$ \\
\hline $\begin{array}{c}\text { Corrente de curto-circuito monofásico- } \\
\text { terra }\left(3 \mathrm{I}_{0}\right) \text { na barra de } 230 \mathrm{kV} \text { da SE IT } \\
\text { medida no lado de } 138 \mathrm{kV}\end{array}$ & $605 \mathrm{~A}$ & $425 \mathrm{~A}$ & $325 \mathrm{~A}$ & $260 \mathrm{~A}$ \\
\hline $\begin{array}{c}\text { Corrente de curto-circuito monofásico- } \\
\text { terra }\left(3 \mathrm{I}_{0}\right) \text { na barra de } 138 \mathrm{kV} \text { da SE JC } \\
\text { medida no lado de } 138 \mathrm{kV}\end{array}$ & $1008 \mathrm{~A}$ & $591 \mathrm{~A}$ & $486 \mathrm{~A}$ & 411 \\
\hline
\end{tabular}

\subsubsection{Ajuste da unidade de sobrecorrente de neutro temporizada (51N)}

A proteção de sobrecorrente deverá ser ajustada com, aproximadamente, $25 \%$ da corrente nominal do transformador:

$$
\begin{gathered}
I_{\text {pick-up_UTn_138p }}=0,25 . I n \_138=104,592 \\
I_{\text {pick-up_UTn_138s }}=\frac{\text { Ipick-up_UTn_138p }}{\text { RTC_138kV }}=0,436
\end{gathered}
$$

A proteção será ajustada levando em consideração os estudos de coordenação. A curva adotada foi do tipo normal inversa com valor igual a 0,35 para todos os grupos de ajuste.

\section{a) Grupo de Ajuste 1 - SE Rondonópolis operando com 1 TR}

A Tabela 5.40 apresenta o estudo de coordenação desta proteção para este grupo de ajuste em que é possível observar que a proteção atua satisfatoriamente para os defeitos nas barras de $230 \mathrm{kV}$ e $138 \mathrm{kV}$ da SE Rondonópolis com o mesmo tempo de atuação igual a 0,696s. Valor este superior ao tempo de segunda zona das LTs 
adjacentes, conforme o critério de coordenação. Ademais, a proteção é sensível aos defeitos nas LTs Itiquira - Rondonópolis $230 \mathrm{kV}$ e Rondonópolis - Jaciara 138kV, mas com tempo superior a 1 segundo, o que pode ocasionar danos aos equipamentos e ao sistema.

Tabela 5.40 - Coordenação da proteção de sobrecorrente de neutro $(51 \mathrm{~N})$ no lado de $138 \mathrm{kV}$ para o grupo de ajuste 1.

$51 \mathrm{~N}$

Estudo de coordenação da proteção de neutro 51N dos TRs da SE RP 230/138 kV - MT

Grupo de Ajuste 1 - SE Rondonópolis operando com 1 transformador

\begin{tabular}{|c|c|c|c|c|}
\hline \multirow{2}{*}{ Curva $51 \mathrm{~N}$} & \multirow{2}{*}{$=$} & \multirow{2}{*}{0,35} & \multirow{2}{*}{$\begin{array}{l}\text { Sobrecorrente temporizado de } \\
\text { neutro }(51 \mathrm{~N}) \text { no lado de } 138 \mathrm{kV}\end{array}$} & Ipick-up (A) \\
\hline & & & & 0,436 \\
\hline \multicolumn{5}{|c|}{ Tempo de atuação $=\left(0,14^{*}\right.$ Curva51N)/(M^0,02 -1) } \\
\hline Descrição & $\mathbf{M}$ & Valor & tempo de atuação (s) & Icc $138 \mathrm{kV}(\mathrm{A})$ \\
\hline Lado de $230 \mathrm{kV}$ do TR & M1n & 30,000 & 0,696 & 34,854 \\
\hline Lado de $138 \mathrm{kV}$ do TR & $M 2 n$ & 16,227 & 0,855 & 7,075 \\
\hline Barra $230 \mathrm{kV}$ da SE RP & M3n & 30,000 & 0,696 & 18,330 \\
\hline Barra 138 kV da SE RP & M4n & 30,000 & 0,696 & 21,738 \\
\hline Barra de $230 \mathrm{kV}$ da SE IT & M5n & 5,782 & 1,372 & 2,521 \\
\hline Barra de $138 \mathrm{kV}$ da SE JC & M6n & 9,633 & 1,057 & 4,200 \\
\hline
\end{tabular}

\section{b) Grupo de Ajuste 2 - SE Rondonópolis operando com 2 TRs}

Na Tabela 5.41 apresentam-se os tempos de atuação desta proteção, onde é possível observar que a eliminação dos defeitos nas barras de $230 \mathrm{kV}$ e $138 \mathrm{kV}$ da SE Rondonópolis ocorre num tempo satisfatório $(696 \mathrm{~ms})$ coordenado com o tempo de segunda zona das LTs adjacentes $(650 \mathrm{~ms})$. Os tempos de atuação para a eliminação dos defeitos nas LTs Itiquira - Rondonópolis 230kV e Rondonópolis - Jaciara 138kV iguais a 1,724 s e 1,391s, respectivamente, são considerados elevados para um sistema de proteção, pois os equipamentos submetidos a essas correntes de curto-circuito com um tempo superior a 1 segundo poderão vir a ser danificados caso não haja atuação das proteções principais e secundárias dessas LTs. 
Tabela 5.41 - Coordenação da proteção de sobrecorrente de neutro $(51 \mathrm{~N})$ no lado de $138 \mathrm{kV}$ para o grupo de ajuste 2 .

\begin{tabular}{|c|c|c|c|c|}
\hline \multicolumn{5}{|c|}{$51 \mathrm{~N}$} \\
\hline \multirow{2}{*}{\multicolumn{5}{|c|}{$\begin{array}{l}\text { Estudo de coordenação das proteções de neutro 51N dos TRs da SE RP 230/138 kV - MT } \\
\text { Grupo de Ajuste } 2 \text { - SE Rondonópolis operando com } 2 \text { transformadores }\end{array}$}} \\
\hline & & & & \\
\hline \multirow{2}{*}{ Curva 51N } & \multirow{2}{*}{$=$} & \multirow{2}{*}{0,35} & \multirow{2}{*}{$\begin{array}{l}\text { Sobrecorrente temporizado de } \\
\text { neutro }(51 \mathrm{~N}) \text { no lado de } 138 \mathrm{kV}\end{array}$} & Ipick-up (A) \\
\hline & & & & 0,436 \\
\hline \multicolumn{5}{|c|}{ Tempo de atuação $=\left(0,14^{*}\right.$ Curva51N)/(M^0,02 -1) } \\
\hline Descrição & $\mathbf{M}$ & Valor & tempo de atuação (s) & Icc $138 \mathrm{kV}(\mathrm{A})$ \\
\hline Lado de $230 \mathrm{kV}$ do TR & M1n & 30,000 & 0,696 & 45,958 \\
\hline Lado de $138 \mathrm{kV}$ do TR & $M 2 n$ & 30,000 & 0,696 & 24,55 \\
\hline Barra $230 \mathrm{kV}$ da SE RP & M3n & 30,000 & 0,696 & 14,7 \\
\hline Barra 138 kV da SE RP & M4n & 30,000 & 0,696 & 24,55 \\
\hline Barra de $230 \mathrm{kV}$ da SE IT & M5n & 4,062 & 1,724 & 1,771 \\
\hline Barra de 138 kV da SE JC & M6n & 5,648 & 1,391 & 2,4625 \\
\hline
\end{tabular}

\section{c) Grupo de Ajuste 3 - SE Rondonópolis operando com 3 TRs}

A Tabela 5.42 mostra o estudo de coordenação desta proteção onde observa-se que a eliminação dos defeitos nas barras de $230 \mathrm{kV}$ e $138 \mathrm{kV}$ da SE Rondonópolis ocorre com tempos de atuação satisfatórios e, respectivamente, iguais a $716 \mathrm{~ms}$ e $696 \mathrm{~ms}$. Novamente, os tempos de retaguarda para as LTs Itiquira - Rondonópolis 230kV (2,138s) e Rondonópolis - Jaciara 138kV (1,571s) são considerados críticos ao sistema de proteção podendo causar danos aos equipamentos das SEs.

Tabela 5.42 - Coordenação da proteção de sobrecorrente de neutro $(51 \mathrm{~N})$ no lado de 138 kV para o grupo de ajuste 3 .

\section{$51 \mathrm{~N}$}

Estudo de coordenação das proteções de neutro 51N dos TRs da SE RP 230/138 kV - MT

Grupo de Ajuste 3 - SE Rondonópolis operando com 3 transformadores

\begin{tabular}{|c|c|c|c|c|}
\hline Curva 51N & $=$ & 0,35 & $\begin{array}{c}\text { Sobrecorrente temporizado de } \\
\text { neutro }(51 \mathrm{~N}) \text { no lado de } 138 \mathrm{kV}\end{array}$ & Ipick-up (A) \\
& & & M & 0,436 \\
\hline Descrição & M & Valor & tempo de atuação (s) & Icc 138 kV (A) \\
\hline Lado de 230 Kv do TR & M1n & 30,000 & 0,696 & 47,888 \\
Lado de 138 kV do TR & M2n & 30,000 & 0,696 & 33,288 \\
Barra 230 kV da SE RP & M3n & 27,333 & 0,716 & 11,917 \\
Barra 138 kV da SE RP & M4n & 30,000 & 0,696 & 16,600 \\
Barra de 230 kV da SE IT & M5n & 3,106 & 2,138 & 1,354 \\
Barra de 138 kV da SE JC & M6n & 4,644 & 1,571 & 2,025 \\
\hline
\end{tabular}




\section{d) Grupo de Ajuste 4 - SE Rondonópolis operando com 4 TRs}

Finalmente, na Tabela 5.43 mostram-se os tempos de atuação para este grupo de ajuste. Observa-se que os tempos obtidos para a retaguarda das barras de $230 \mathrm{kV} \mathrm{e}$ $138 \mathrm{kV}$ da SE Rondonópolis, respectivamente iguais a $755 \mathrm{~ms}$ e $696 \mathrm{~ms}$, são considerados adequados ao sistema de proteção, pois atendem ao critério de coordenação com as segundas zonas das proteções de distância das LTs adjacentes. Entretanto, o tempo de retaguarda para as LTs Itiquira - Rondonópolis 230kV (2,668s) e Rondonópolis - Jaciara 138kV (1,766s) poderão danificar os equipamentos das SEs caso as proteções principais e secundárias não eliminem o defeito.

Tabela 5.43 - Coordenação da proteção de sobrecorrente de neutro $(51 \mathrm{~N})$ no lado de $138 \mathrm{kV}$ para o Grupo de Ajuste 4.

\begin{tabular}{|c|c|c|c|c|}
\hline \multicolumn{5}{|c|}{$51 \mathrm{~N}$} \\
\hline \multirow{2}{*}{\multicolumn{5}{|c|}{ Grupo de Ajuste 4 - SE Rondonópolis operando com 4 transformadores }} \\
\hline & & & & \\
\hline \multirow{2}{*}{ Curva $51 \mathrm{~N}$} & \multirow{2}{*}{$=$} & \multirow{2}{*}{0,35} & \multirow{2}{*}{$\begin{array}{l}\text { Sobrecorrente temporizado de } \\
\text { neutro }(51 \mathrm{~N}) \text { no lado de } 138 \mathrm{kV}\end{array}$} & Ipick-up (A) \\
\hline & & & & 0,436 \\
\hline \multicolumn{5}{|c|}{ Tempo de atuação $=\left(0,14^{*}\right.$ Curva51N $) /\left(M^{\wedge} 0,02-1\right)$} \\
\hline Descrição & $M$ & Valor & tempo de atuação (s) & Icc $138 \mathrm{kV}(\mathrm{A})$ \\
\hline Lado de $230 \mathrm{kV}$ do TR & M1n & 30,000 & 0,696 & 58,479 \\
\hline Lado de $138 \mathrm{kV}$ do TR & $\mathrm{M} 2 \mathrm{n}$ & 30,000 & 0,696 & 40,338 \\
\hline Barra 230 kV da SE RP & $M 3 n$ & 23,222 & 0,755 & 10,125 \\
\hline Barra 138 kV da SE RP & M4n & 30,000 & 0,696 & 15,625 \\
\hline Barra de 230 kV da SE IT & M5n & 2,484 & 2,668 & 1,083 \\
\hline Barra de 138 kV da SE JC & M6n & 3,928 & 1,766 & 1,713 \\
\hline
\end{tabular}

A Tabela 5.44 apresenta os resultados dos testes da atuação desta função de proteção para os quatro grupos de ajustes definidos anteriormente, onde é possível observar que todos os pontos de testes foram aprovados.

Tabela 5.44 - Resultados do teste da proteção de sobrecorrente de neutro temporizada $(51 \mathrm{~N})$ para os quatro grupos de ajustes.

\begin{tabular}{|c|c|c|c|c|c|}
\hline Falta & $(\mathbf{I} / \mathbf{I n} \star \mathbf{I})$ & Tempo nominal (s) & Tempo real (s) & Desvio (\%) & Resultado \\
\hline L1-E & 1,200 & 13,41 & 13,94 & 3,919 & Aprovado \\
\hline L1-E & 1,800 & 4,144 & 4,216 & 1,749 & Aprovado \\
\hline L1-E & 3,000 & 2,206 & 2,239 & 1,515 & Aprovado \\
\hline L1-E & 3,600 & 1,888 & 1,914 & 1,341 & Aprovado \\
\hline L1-E & 4,200 & 1,683 & 1,708 & 1,502 & Aprovado \\
\hline L1-E & 4,800 & 1,538 & 1,563 & 1,677 & Aprovado \\
\hline L1-E & 5,400 & 1,428 & 1,453 & 1,712 & Aprovado \\
\hline L1-E & 6,000 & 1,343 & 1,362 & 1,413 & Aprovado \\
\hline L1-E & 6,600 & 1,274 & 1,296 & 1,754 & Aprovado \\
\hline L1-E & 7,200 & 1,217 & 1,240 & 1,927 & Aprovado \\
\hline L1-E & 7,800 & 1,168 & 1,190 & 1,815 & Aprovado \\
\hline
\end{tabular}


A Figura 56 mostra a curva do tipo normal inversa com valor igual a 0,35 para os quatro grupos de ajustes da proteção $51 \mathrm{~N}$ em que é possível observar que todos os pontos do teste foram aprovados.

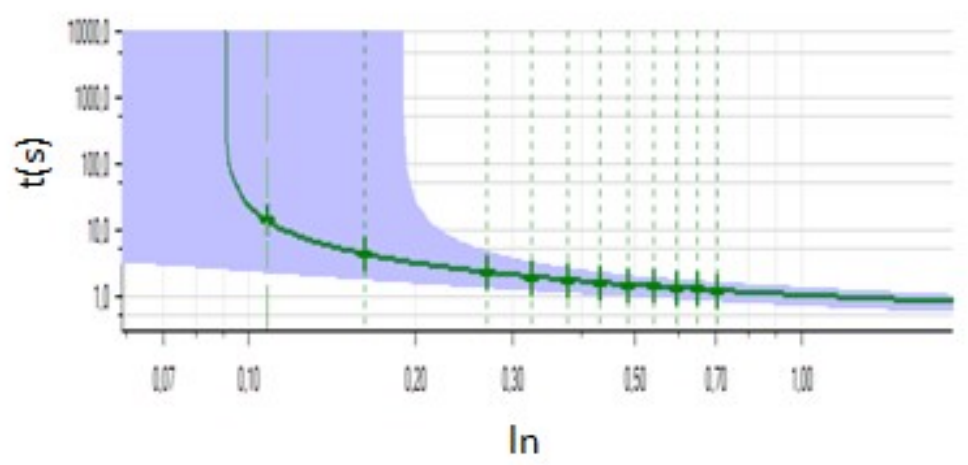

Figura 56 - Curva para a proteção $51 \mathrm{~N}$ e os pontos de testes aprovados.

\subsubsection{Ajuste da unidade de sobrecorrente de neutro instantânea (50N)}

Com o objetivo de coordenar a proteção do lado de baixa dos TRs com as das LTs adjacentes, a unidade instantânea de sobrecorrente de neutro será bloqueada a fim de evitar atuações indevidas, garantido ainda o critério de seletividade do sistema de proteção. 


\subsection{AJUSTE DA PROTEÇÃO DIFERENCIAL (87)}

Neste tópico serão apresentados os valores de ajustes referentes à proteção diferencial dos TRs utilizados na parametrização do relé da SIEMENS 7 UT61 juntamente com os endereços dos parâmetros de ajuste.

\subsubsection{Parâmetros gerais}

Tabela 5.45 - Definição dos parâmetros gerais da proteção diferencial. [27]

\begin{tabular}{|c|c|c|c|}
\hline Endereço & Parâmetro & Ajuste & Comentário \\
\hline 1201 & 87 Differential Protection & ON & $\begin{array}{l}\text { Habilitação da função } \\
\text { diferencial do relé }\end{array}$ \\
\hline 1205 & $\begin{array}{c}87 \text { Increase of Trip Char. } \\
\text { During Start }\end{array}$ & OFF & $\begin{array}{c}\text { Desabilitação do aumento da } \\
\text { característica de operação } \\
\text { durante a energização do } \\
\text { transformador. }\end{array}$ \\
\hline 1206 & $\begin{array}{l}87 \text { Inrush with } 2 . \\
\text { Harmonic Restrain }\end{array}$ & ON & $\begin{array}{l}\text { Habilitação da estabilização } \\
\text { através do conteúdo de } \\
\text { segundo harmônico. }\end{array}$ \\
\hline 1207 & $\begin{array}{l}87 \text { n-th Harmonic } \\
\text { Restrain }\end{array}$ & 5. Harmonic & $\begin{array}{c}\text { Permite escolher outra } \\
\text { harmônica para o efeito de } \\
\text { estabilização. Será escolhido } \\
\text { o quinto harmônico por ser o } \\
\text { mais adequado para } \\
\text { bloquear a proteção no caso } \\
\text { de sobre-excitação do } \\
\text { núcleo do transformador. }\end{array}$ \\
\hline
\end{tabular}

\subsubsection{Corrente diferencial e característica de operação}

Neste tópico serão definidos os parâmetros para a caracterização da curva da proteção diferencial, conforme mostra a Figura 57.

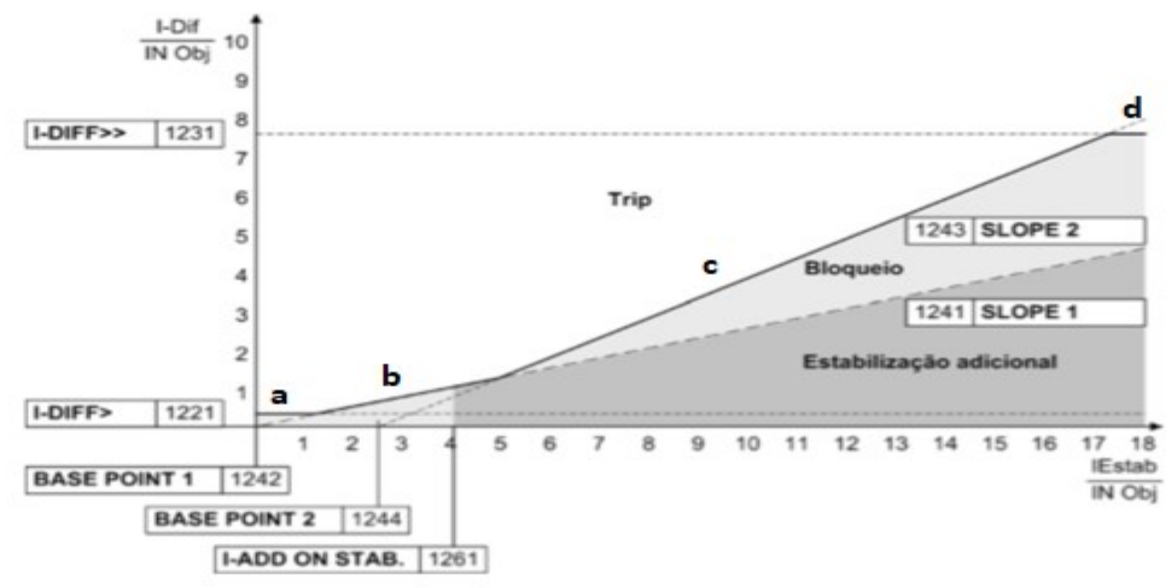

Figura 57 - Curva característica de atuação da proteção diferencial. [27] 
A Tabela 5.46 apresenta os valores de ajustes dos parâmetros para a definição da curva característica da proteção diferencial. O termo $\mathrm{l} / \mathrm{InO}$ representa o valor da corrente do teste dividida pela corrente nominal do relé, valor este igual a $5 \mathrm{~A}$.

Tabela 5.46 - Definição dos parâmetros de corrente e da curva característica da proteção diferencial. [27]

\begin{tabular}{|c|c|c|c|}
\hline Endereço & Parâmetro & Ajuste & Comentário \\
\hline 1221 & $\begin{array}{l}\text { 87-1 Pickup Value of } \\
\text { Differential Curr. }\end{array}$ & $0,20 \mathrm{I} / \mathrm{InO}$ & $\begin{array}{l}\text { Valor da corrente de pick-up a } \\
\text { partir da qual o relé passará a } \\
\text { atuar. Trecho "a" da curva } \\
\text { característica do relé. }\end{array}$ \\
\hline $1226 \mathrm{~A}$ & $\begin{array}{c}\text { 87-1 T I-DIFF }>>\text { Time } \\
\text { Delay }\end{array}$ & $0,0 \mathrm{sec}$ & $\begin{array}{l}\text { Tempo de operação da função } \\
\text { diferencial (87) que será deixada } \\
\text { com atuação instantânea. }\end{array}$ \\
\hline 1231 & $\begin{array}{c}\text { 87-2 Pick-up Value of High } \\
\text { Set Trip }\end{array}$ & $2,2 \mathrm{I} / \mathrm{lnO}$ & $\begin{array}{c}\text { Limite em que a corrente } \\
\text { diferencial opera sem considerar } \\
\text { qualquer fator de estabilização. O } \\
\text { valor adotado leva em } \\
\text { consideração às limitações da } \\
\text { mala de teste. }\end{array}$ \\
\hline $1236 \mathrm{~A}$ & $\begin{array}{c}\text { 87-2 T I DIFF>> Time } \\
\text { Delay }\end{array}$ & $0,0 \mathrm{sec}$ & $\begin{array}{c}\text { Tempo de atuação para o estágio } \\
\text { ajustado anteriormente. }\end{array}$ \\
\hline $1241 \mathrm{~A}$ & $\begin{array}{l}87 \text { Slope } 1 \text { of Tripping } \\
\text { Characteristic }\end{array}$ & 0,25 & $\begin{array}{l}\text { Inclinação do trecho “b” da curva } \\
\text { característica. Cobre os erros } \\
\text { relacionados à corrente, } \\
\text { principalmente devido aos erros } \\
\text { de transformação dos TCs, } \\
\text { variação de tap. O Valor de } 25 \% \text { é } \\
\text { suficiente para cobrir estes erros. }\end{array}$ \\
\hline $1242 \mathrm{~A}$ & $\begin{array}{l}87 \text { Base Point for Slope } 1 \\
\text { of Charac. }\end{array}$ & $0,00 \mathrm{I} / \mathrm{InO}$ & $\begin{array}{l}\text { Ponto base do trecho “b”, cuja } \\
\text { inclinação foi definida no } \\
\text { parâmetro anterior. O valor da } \\
\text { origem é usual. }\end{array}$ \\
\hline $1243 A$ & $\begin{array}{l}87 \text { Slope } 2 \text { of Tripping } \\
\text { Characteristic }\end{array}$ & 0,50 & $\begin{array}{l}\text { Inclinação do trecho “c”. Este } \\
\text { parâmetro fornece uma maior } \\
\text { estabilização na faixa de correntes } \\
\text { elevadas, que poderiam causar } \\
\text { saturação de TC. }\end{array}$ \\
\hline $1244 \mathrm{~A}$ & $\begin{array}{l}87 \text { Base Point for Slope } 2 \\
\text { of Charac. }\end{array}$ & $2,50 \mathrm{I} / \mathrm{InO}$ & $\begin{array}{l}\text { Ponto de base do trecho "c" em } \\
\text { que a declividade foi definida } \\
\text { anteriormente. }\end{array}$ \\
\hline $1251 \mathrm{~A}$ & $\begin{array}{c}87 \text { I-RESTRAINT for Start } \\
\text { Detection }\end{array}$ & $0,10 \mathrm{I} / \mathrm{InO}$ & $\begin{array}{l}\text { Valor mínimo da corrente de } \\
\text { restrição para haver a partida da } \\
\text { função diferencial do relé. O valor } \\
\text { de } 0,1 \mathrm{l} / \mathrm{InO} \text { é usual e representa } \\
5 \% \text { da corrente nominal do } \\
\text { transformador. }\end{array}$ \\
\hline $1252 A$ & $\begin{array}{l}87 \text { Factor for Increas. of } \\
\text { Char. at Start }\end{array}$ & 1,0 & $\begin{array}{c}\text { Fator de elevação da } \\
\text { característica de operação durante } \\
\text { a energização do transformador. } \\
\text { Porém, esta função foi } \\
\text { desabilitada no parâmetro } 1205 \text {. }\end{array}$ \\
\hline
\end{tabular}




\begin{tabular}{|c|c|c|c|}
\hline Endereço & Parâmetro & Ajuste & Comentário \\
\hline 1253 & $\begin{array}{c}87 \text { Maximum Permissible } \\
\text { Starting Time }\end{array}$ & $5,0 \mathrm{sec}$ & $\begin{array}{c}\text { Tempo de duração da } \\
\text { característica de operação } \\
\text { modificada no parâmetro anterior, } \\
\text { caso habilitada. }\end{array}$ \\
\hline $1261 \mathrm{~A}$ & $\begin{array}{l}87 \text { Pickup for Add-on } \\
\text { Stabilization }\end{array}$ & $4,00 \mathrm{I} / \mathrm{InO}$ & $\begin{array}{c}\text { Corrente de estabilização acima } \\
\text { da qual a característica add-on } \\
\text { stabilization (estabilização } \\
\text { adicional) se torna efetiva. O valor } \\
4,00 \text { I/InO é adequado na maioria } \\
\text { dos casos. }\end{array}$ \\
\hline $1262 A$ & $\begin{array}{l}87 \text { Duration of Add-on } \\
\text { Stabilization }\end{array}$ & 15 Cycle & $\begin{array}{c}\text { Tempo de duração do bloqueio } \\
\text { por add-on stabilization. O tempo } \\
\text { de } 15 \text { ciclos é adequado para a } \\
\text { maioria dos casos. }\end{array}$ \\
\hline $1263 \mathrm{~A}$ & $\begin{array}{l}87 \text { Time for Cross-block } \\
\text { Add-on Stabilization }\end{array}$ & 15 Cycle & $\begin{array}{l}\text { Tempo de duração do bloqueio } \\
\text { das outras fases pelo add-on } \\
\text { stabilization. O tempo de } 15 \text { ciclos } \\
\text { também é normalmente utilizado. }\end{array}$ \\
\hline
\end{tabular}

A Figura 58 mostra a curva característica de atuação da proteção diferencial juntamente com os pontos de ajustes definidos.

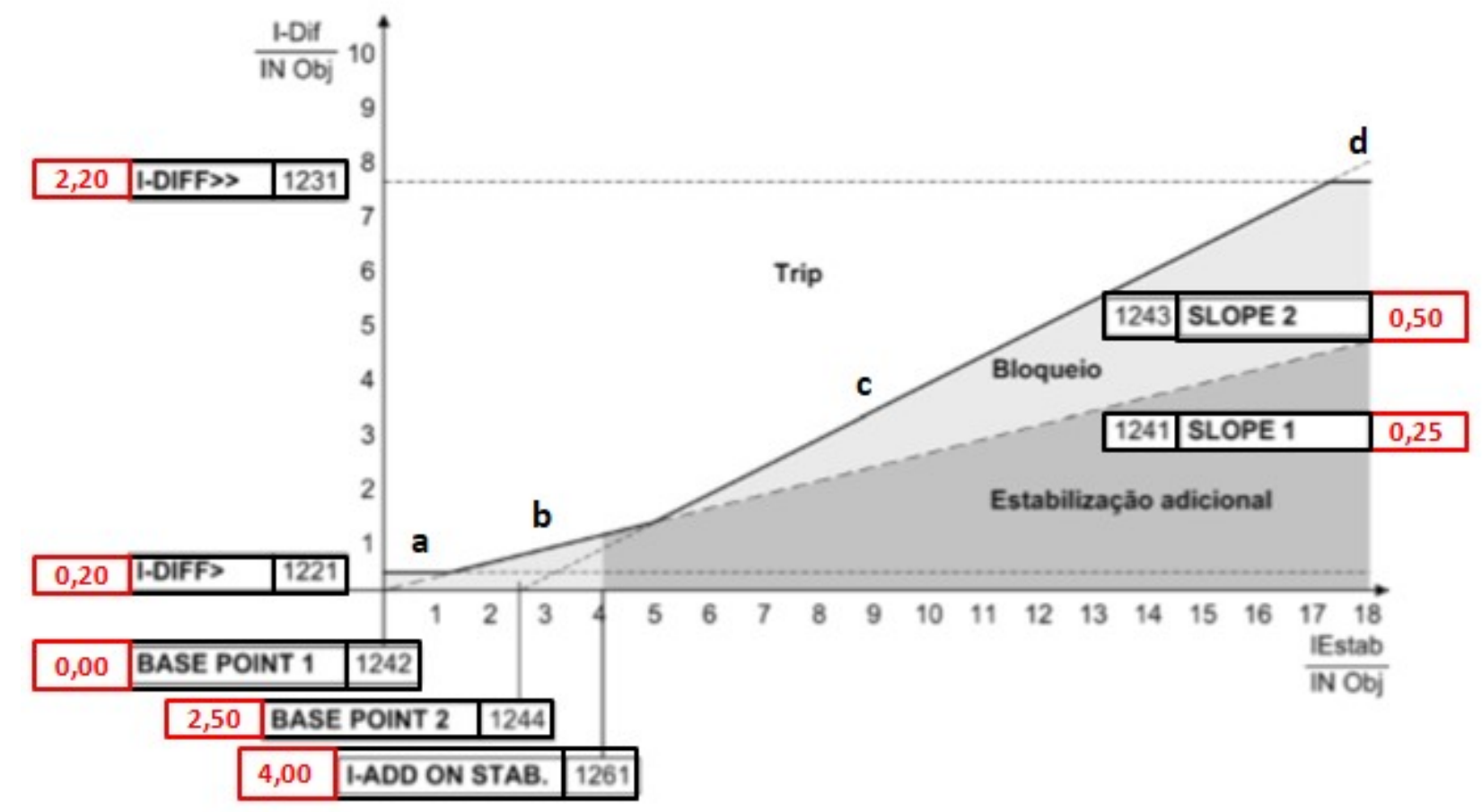

Figura 58 - Valores dos ajustes da curva característica de atuação do relé diferencial. [27] 
A parametrização da curva característica da proteção diferencial foi realizada no módulo de teste Diferencial do software Test Universe, sendo necessário o cálculo dos pontos da curva. A Figura 59 mostra a curva com os pontos calculados.

Trecho a:

$$
\begin{aligned}
& y_{1}-y_{0}=m\left(x_{1}-x_{0}\right) \\
& 0,2-0=0,25\left(x_{1}-0\right) \\
& x_{1}=0,8
\end{aligned}
$$

Trecho b:

$$
\begin{aligned}
& \mathrm{y}_{2}-\mathrm{y}_{1}=\mathrm{m}\left(\mathrm{x}_{2}-\mathrm{x}_{1}\right) \\
& \mathrm{y}_{2}-0,2=0,5\left(\mathrm{x}_{2}-0,8\right) \\
& \text { l) } \mathrm{y}_{2}=0,5 \mathrm{x}_{2}-1,25 \\
& \text { II) } \mathrm{y}_{2}-\mathrm{y}_{0}=\mathrm{m}\left(\mathrm{x}_{2}-\mathrm{x}_{0}\right) \\
& \mathrm{y}_{2}=0,25 \mathrm{x}_{2} \\
& \text { II) } \longrightarrow \text { I) } \\
& 0,25 x_{2}=0,5 x_{2}-1,25 \\
& \mathrm{X}_{2}=5 \\
& \mathrm{y}_{2}=0,25 \cdot 5=1,25
\end{aligned}
$$

Trecho c:

$$
\begin{aligned}
& y_{3}-y_{2}=m\left(x_{3}-x_{2}\right) \\
& 2,2-1,25=0,5\left(x_{3}-5\right) \\
& x_{3}=6,9
\end{aligned}
$$

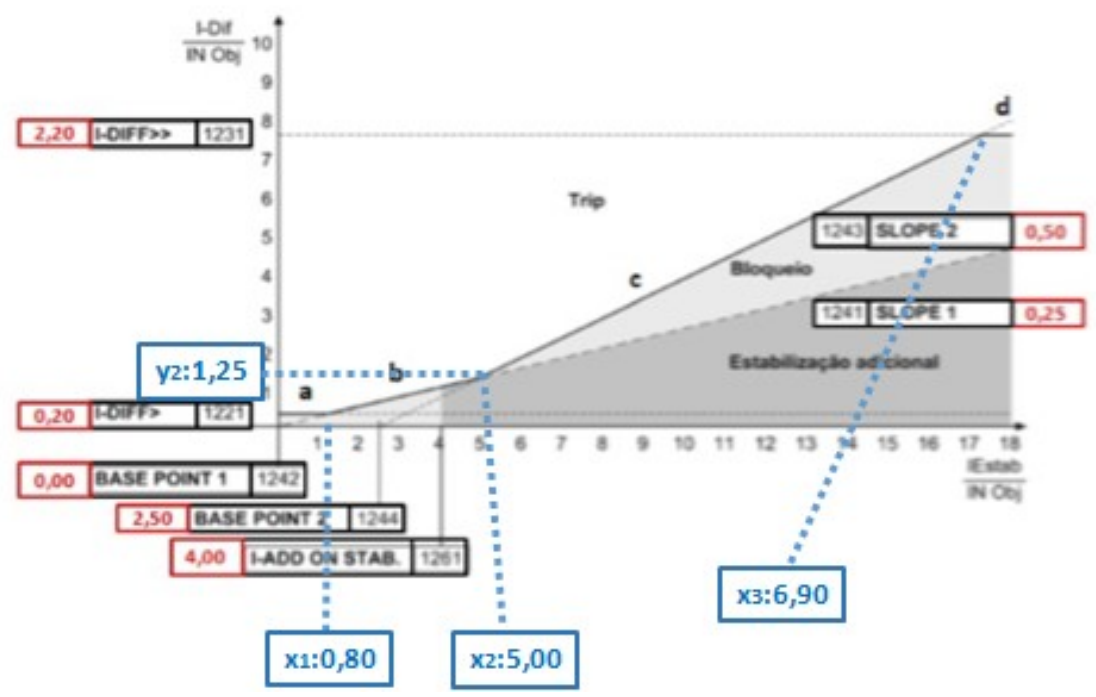

Figura 59 - Cálculo dos pontos da curva da proteção diferencial.

Os testes da proteção foram realizados por meio do software DIGSI SIPROTEC 4 da SIEMENS. O objetivo foi verificar se a curva característica, apresentada na Figura 59 , foi definida corretamente e se atuação a proteção diferencial atua de forma correta para os pontos definidos no teste. Como mencionado anteriormente, devido às limitações da mala de testes, definiu-se a corrente máxima de operação para o teste do relé igual a 2,2 I/InO, equivalente a $11 \mathrm{~A}$, pois a corrente nominal do relé (InO) é igual a $5 \mathrm{~A}$.

A Tabela 5.47 mostra os resultados de atuação para os pontos do teste trifásico para a avaliação da curva característica parametrizada para a proteção diferencial. O termo " $n / d$ " significa que o valor não está disponível devido ao fato de que, como o teste realizado foi de busca da curva característica, ainda não houve entrada deste valor. Os pontos do teste avaliado foram todos aceitos, logo a curva foi parametrizada de forma correta. 
Tabela 5.47 - Resultados do teste trifásico para a avaliação da curva característica de atuação da proteção diferencial.

\begin{tabular}{|c|c|c|c|c|c|}
\hline lestab & Idiff nom. & Idiff real & Desvio (\%) & Desvio (abs) & Resultado \\
\hline $0,40 \mathrm{In}$ & $\mathrm{n} / \mathrm{d}$ & $0,197 \mathrm{In}$ & $0,00 \%$ & $0,00 \mathrm{ln}$ & Aprovado \\
\hline $1,00 \mathrm{In}$ & $\mathrm{n} / \mathrm{d}$ & $0,246 \operatorname{~In}$ & $0,00 \%$ & $0,00 \mathrm{In}$ & Aprovado \\
\hline $1,60 \mathrm{In}$ & $n / d$ & $0,397 \mathrm{In}$ & $0,00 \%$ & $0,00 \mathrm{In}$ & Aprovado \\
\hline $2,20 \ln$ & $\mathrm{n} / \mathrm{d}$ & $0,546 \mathrm{In}$ & $0,00 \%$ & $0,00 \mathrm{In}$ & Aprovado \\
\hline $2,80 \mathrm{In}$ & $n / d$ & $0,692 \mathrm{In}$ & $0,00 \%$ & $0,00 \mathrm{ln}$ & Aprovado \\
\hline $3,40 \ln$ & $\mathrm{n} / \mathrm{d}$ & $0,840 \mathrm{In}$ & $0,00 \%$ & $0,00 \mathrm{ln}$ & Aprovado \\
\hline $4,00 \mathrm{In}$ & $\mathrm{n} / \mathrm{d}$ & $0,988 \mathrm{In}$ & $0,00 \%$ & $0,00 \mathrm{In}$ & Aprovado \\
\hline $5,20 \mathrm{In}$ & $n / d$ & $1,146 \operatorname{~In}$ & $0,00 \%$ & $0,00 \mathrm{In}$ & Aprovado \\
\hline $5,80 \mathrm{In}$ & $n / d$ & $1,333 \mathrm{In}$ & $0,00 \%$ & $0,00 \mathrm{In}$ & Aprovado \\
\hline $6,40 \mathrm{In}$ & $\mathrm{n} / \mathrm{d}$ & $1,617 \mathrm{In}$ & $0,00 \%$ & $0,00 \mathrm{ln}$ & Aprovado \\
\hline $7,00 \mathrm{ln}$ & $n / d$ & $2,225 \ln$ & $0,00 \%$ & $0,00 \mathrm{ln}$ & Aprovado \\
\hline
\end{tabular}

A Figura 60 mostra a curva parametrizada com os pontos de testes, nas cores verde, aprovados pelo relé diferencial 7 UT61.

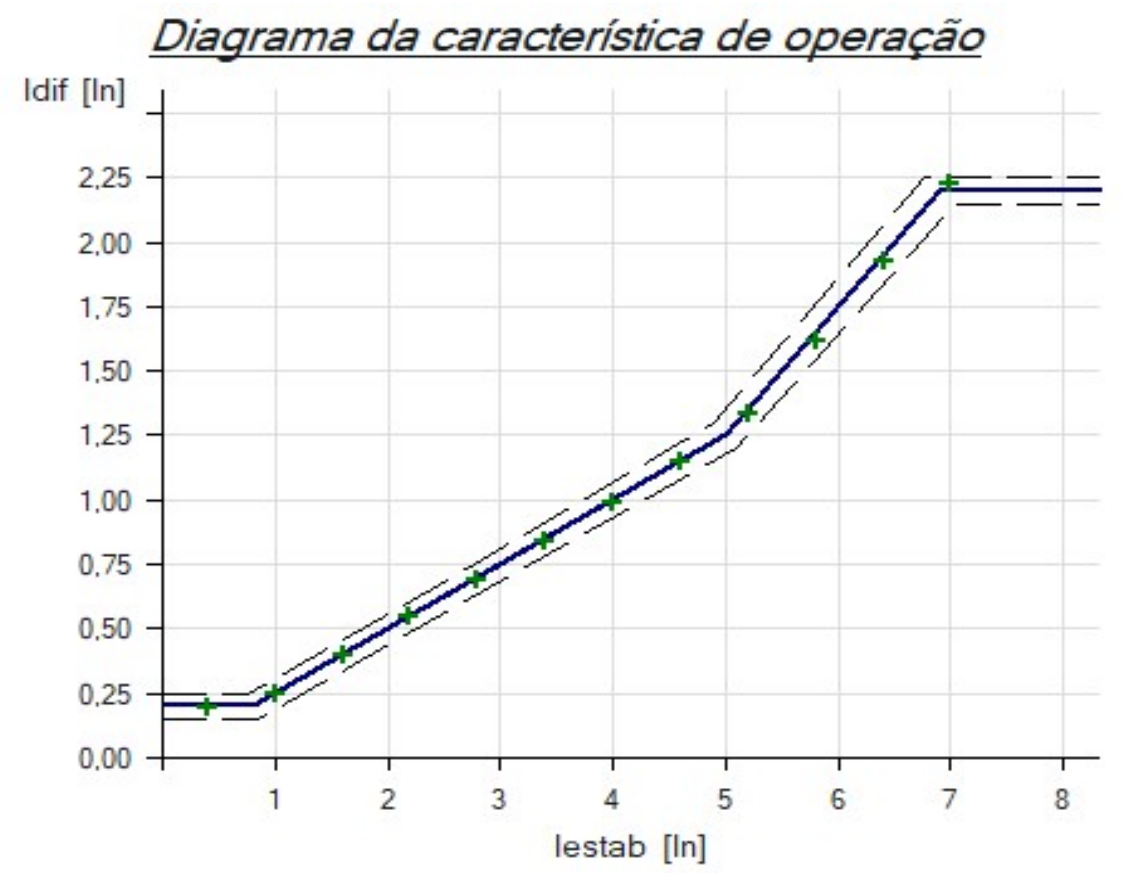

Figura 60 - Curva característica parametrizada no relé 7UT61 para a proteção diferencial.

O ajuste da proteção diferencial foi verificado por meio do teste da atuação da proteção para uma falta real ocorrida na SE Rondonópolis no dia 20 de março de 2018 as 23:07 h. A Figura 61 mostra a oscilografia deste ocorrência apresentando a o tempo de atuação do sistema de proteção da própria SE Rondonópolis, equivalente a 17,8ms. 


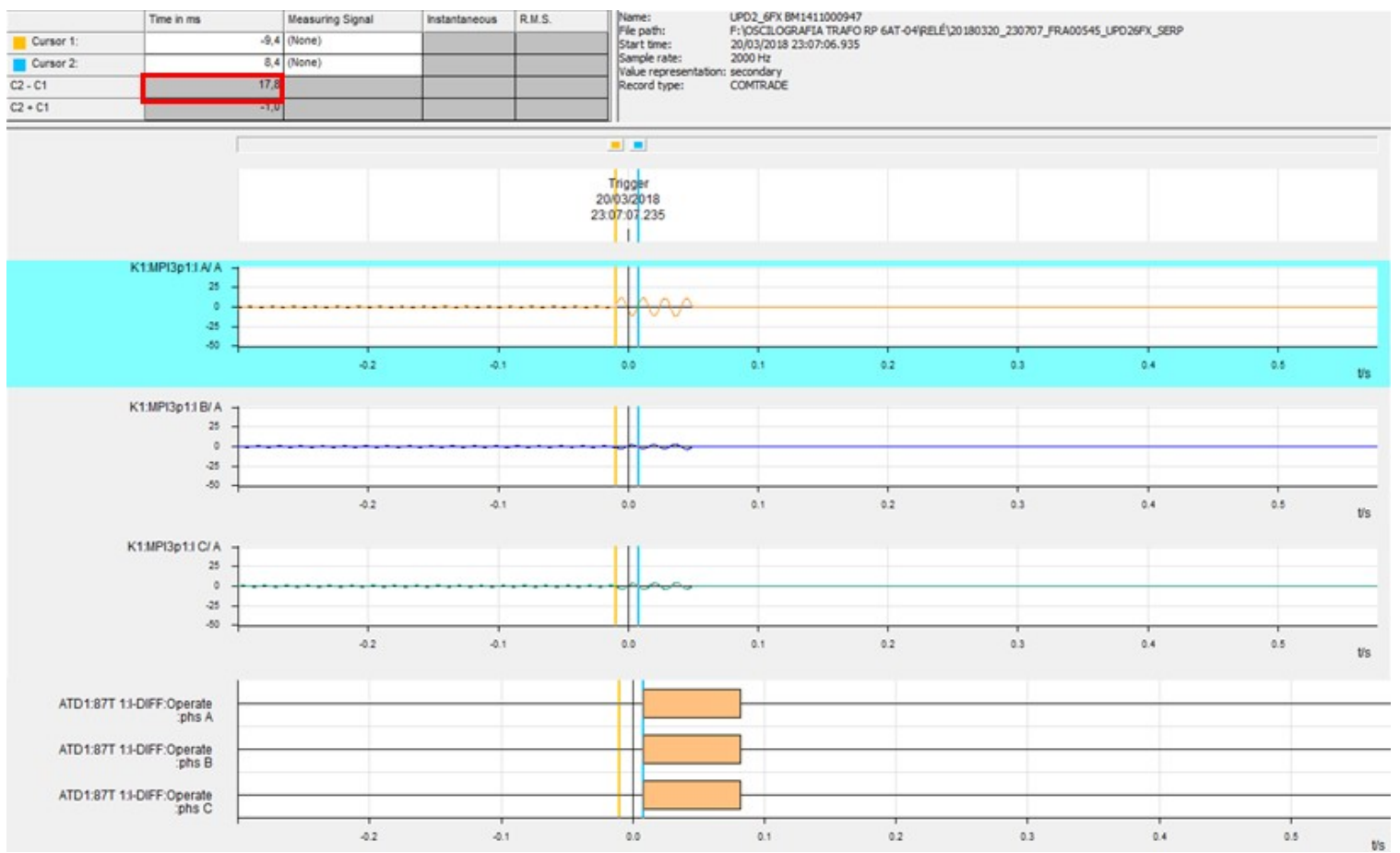

Figura 61 - Atuação do próprio sistema de proteção da SE Rondonópolis para uma falta real.

A Figura 62 mostra atuação da proteção diferencial parametrizada neste estudo, onde se observa que o tempo de atuação foi bastante semelhante ao do próprio da SE Rondonópolis. Os termos "Diff pick-up, Relay PICKUP, Diff> TRIP, Relay TRIP", significam que houve partida da proteção diferencial e do relé de proteção seguida do trip, após 16,6ms. Logo, os resultados mostram que o sistema de proteção foi ajustado de forma adequada.

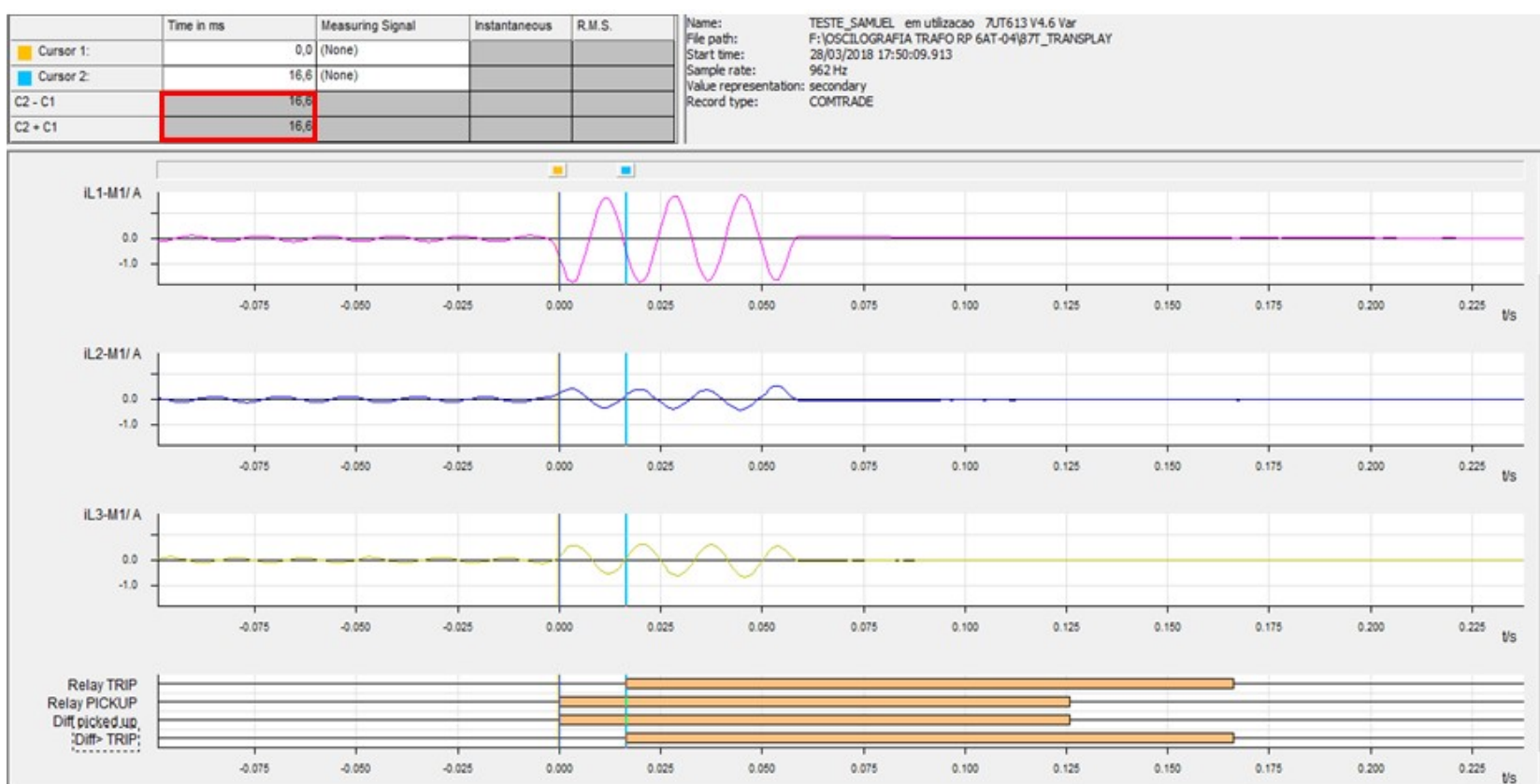

Figura 62 - Atuação da proteção diferencial ajustada nesse estudo para uma falta real na SE RP. 


\subsubsection{Restrição por segundo e quinto harmônico}

A Tabela 5.48 apresenta os ajustes dos parâmetros para a restrição da proteção através do segundo e quinto harmônico.

Tabela 5.48 - Definição dos parâmetros para a restrição da proteção diferencial por segundo e quinto harmônico. [27]

\begin{tabular}{|c|c|c|c|}
\hline Endereço & Parâmetro & Ajuste & Comentário \\
\hline 1271 & $\begin{array}{c}87 \text { 2nd Harmonic Content } \\
\text { in I-DIFF }\end{array}$ & $15 \%$ & $\begin{array}{l}\text { Quantidade percentual de } \\
\text { segundo harmônico, em } \\
\text { relação a fundamental, a partir } \\
\text { do qual a função será } \\
\text { bloqueada. O valor de } 15 \% \text { é } \\
\text { adequado na }\end{array}$ \\
\hline 1272 & $\begin{array}{c}87 \text { Time for Cross-blocking } \\
\text { 2nd Harmonic }\end{array}$ & 8 Cycle & $\begin{array}{c}\text { Tempo de bloqueio das outras } \\
\text { fases quando houver o } \\
\text { bloqueio de uma fase devido ao } \\
\text { segundo harmônico. Se o valor } \\
\text { ajustado for zero, a } \\
\text { estabilização ocorrerá por fase. } \\
\text { Assim, o relé será capaz de } \\
\text { atuar caso detecte uma falta } \\
\text { fase-terra no momento da } \\
\text { energização. }\end{array}$ \\
\hline 1276 & $\begin{array}{c}87 \text { n-th Harmonic Content } \\
\text { in I-DIFF }\end{array}$ & $35 \%$ & $\begin{array}{l}\text { Quantidade percentual de } 5 \text { nd } \\
\text { harmônico em relação à } \\
\text { fundamental a partir de qual a } \\
\text { função diferencial será } \\
\text { bloqueada. O valor de } 35 \% \text { é } \\
\text { usual na maioria dos casos. }\end{array}$ \\
\hline $1277 \mathrm{~A}$ & $\begin{array}{l}87 \text { Time for Cross-blocking } \\
\text { n-th Harm. }\end{array}$ & 5 Cycle & $\begin{array}{l}\text { Tempo de bloqueio das outras } \\
\text { fases quando houver o } \\
\text { bloqueio de uma fase devido ao } \\
\text { quinto harmônico. Se for } \\
\text { ajustado em zero, a } \\
\text { estabilização ocorrerá de forma } \\
\text { individual por fase. }\end{array}$ \\
\hline $1278 \mathrm{~A}$ & $\begin{array}{c}87 \text { Limit IDIFFmax of n-th } \\
\text { Harm.Restr. }\end{array}$ & $1,5 \mathrm{I} / \mathrm{InO}$ & $\begin{array}{c}\text { Valor limite da corrente } \\
\text { diferencial em que haverá a } \\
\text { estabilização por meio do } \\
\text { quinto harmônico. O valor de } \\
1,5 \mathrm{I} / \mathrm{InO} \text { é adequado na } \\
\text { maioria dos casos. }\end{array}$ \\
\hline
\end{tabular}

A Tabela 5.49 mostra o resultado do teste de restrição de segundo harmônico. É possível observar que os pontos para o teste trifásico foram todos aprovados. No teste, são definidos valores constantes para a corrente diferencial e é verificado se há bloqueio ou atuação da proteção. A variável "I2f/Idiff nom." representa a porcentagem de segundo harmônico nominal parametrizada no relé no parâmetro 1271 conforme a 
Tabela 5.48. O termo "Idiff real" mostram a porcentagem de segundo harmônico verificado no teste.

Tabela 5.49 - Resultados do teste de restrição de segundo harmônico da proteção diferencial.

\begin{tabular}{|c|c|c|c|c|c|}
\hline Idif & I2f/Idiff nom. & Idiff real & Desvio (\%) & Desvio (abs) & Resultado \\
\hline 0,30 In & $15,00 \%$ & $14,50 \%$ & $-3,33 \%$ & $-4,998$ & Aprovado \\
\hline $0,50 \ln$ & $15,00 \%$ & $14,50 \%$ & $-3,33 \%$ & $-4,998$ & Aprovado \\
\hline $0,70 \ln$ & $15,00 \%$ & $15,50 \%$ & $3,33 \%$ & 4,998 & Aprovado \\
\hline $0,90 \ln$ & $15,00 \%$ & $14,50 \%$ & $-3,33 \%$ & $-4,998$ & Aprovado \\
\hline $1,10 \ln$ & $15,00 \%$ & $15,50 \%$ & $3,33 \%$ & 4,998 & Aprovado \\
\hline $1,30 \ln$ & $15,00 \%$ & $15,50 \%$ & $3,33 \%$ & 4,998 & Aprovado \\
\hline $1,50 \ln$ & $15,00 \%$ & $15,50 \%$ & $3,33 \%$ & 4,998 & Aprovado \\
\hline $1,70 \ln$ & $15,00 \%$ & $14,50 \%$ & $-3,33 \%$ & $-4,998$ & Aprovado \\
\hline $1,90 \ln$ & $15,00 \%$ & $14,50 \%$ & $-3,33 \%$ & $-4,998$ & Aprovado \\
\hline
\end{tabular}

A Figura 63 mostra os pontos, na cor verde, aprovados pelo teste em que a curva foi definida com $15 \%$ de restrição de segundo harmônico. Nos pontos a direita da curva, ou seja, com valores de segundo harmônico superiores a 15\%, ocorre a restrição da proteção diferencial. Já nos pontos a esquerda da curva, inferiores a 15\%, a proteção atua eliminando o defeito.

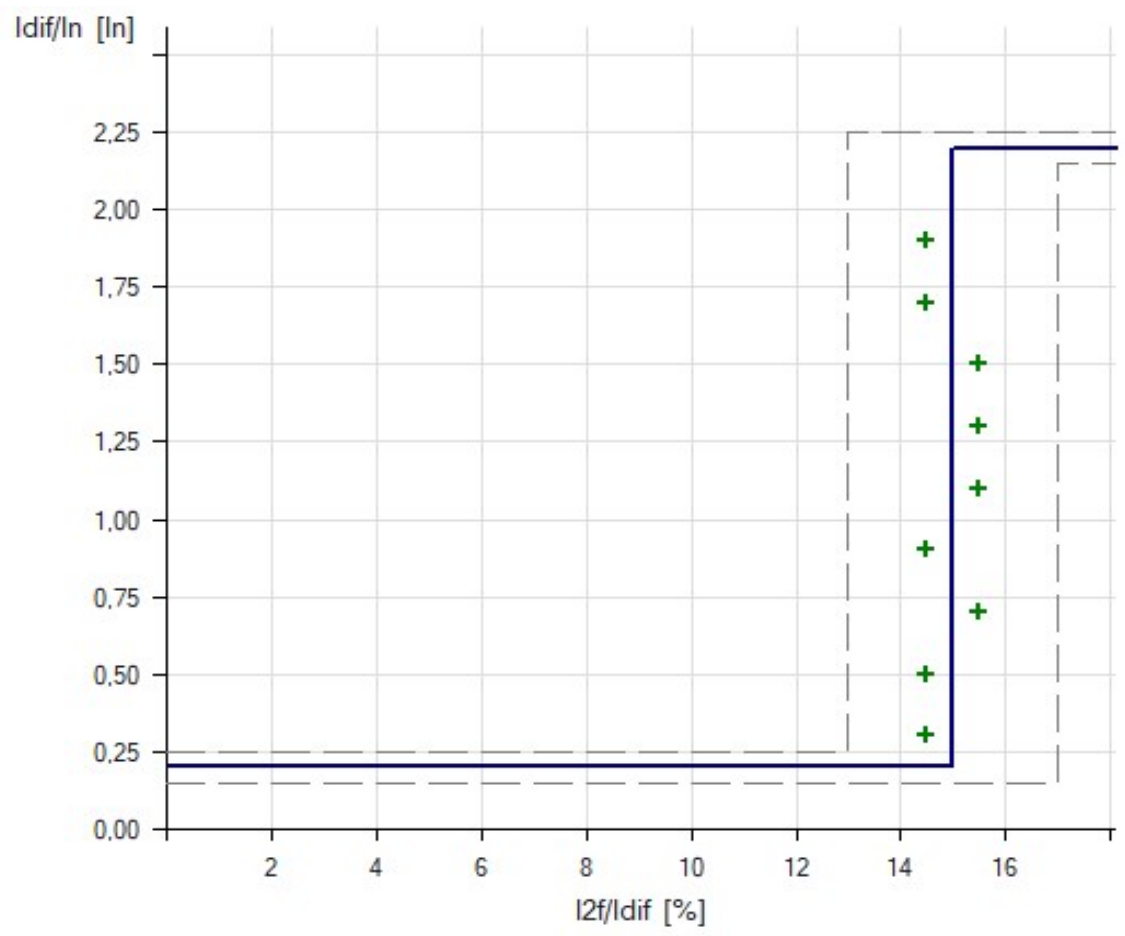

Figura 63 - Pontos para o teste de restrição de $2^{\circ}$ harmônico do relé 7 UT61. 
A Tabela 5.50 mostram-se os pontos, na cor verde, testados para a restrição de quinto harmônico.

Tabela 5.50 - Resultados do teste de restrição de quinto harmônico da proteção diferencial.

\begin{tabular}{|c|c|c|c|c|c|}
\hline lestab & I5f/Idiff nom. & Idiff real & Desvio (\%) & Desvio (abs) & Resultado \\
\hline $0,30 \mathrm{In}$ & $35,00 \%$ & $34,50 \%$ & $-1,43 \%$ & $-0,4997$ & Aprovado \\
\hline $0,50 \mathrm{In}$ & $35,00 \%$ & $34,50 \%$ & $-1,43 \%$ & $-0,4997$ & Aprovado \\
\hline $0,70 \mathrm{In}$ & $35,00 \%$ & $34,50 \%$ & $-1,43 \%$ & $-0,4997$ & Aprovado \\
\hline $0,90 \mathrm{In}$ & $35,00 \%$ & $35,50 \%$ & $1,43 \%$ & 0,4997 & Aprovado \\
\hline $1,10 \mathrm{In}$ & $35,00 \%$ & $34,50 \%$ & $-1,43 \%$ & $-0,4997$ & Aprovado \\
\hline $1,30 \mathrm{In}$ & $35,00 \%$ & $34,50 \%$ & $-1,43 \%$ & $-0,4997$ & Aprovado \\
\hline $1,50 \mathrm{In}$ & $35,00 \%$ & $34,50 \%$ & $-1,43 \%$ & $-0,4997$ & Aprovado \\
\hline $1,70 \mathrm{In}$ & $35,00 \%$ & $36,50 \%$ & $4,28 \%$ & 1,4993 & Aprovado \\
\hline $1,90 \mathrm{In}$ & $35,00 \%$ & $36,50 \%$ & $4,28 \%$ & 1,4993 & Aprovado \\
\hline
\end{tabular}

Por fim, a Figura 64 mostra a curva definida para a restrição de quinto harmônico da proteção diferencial e os pontos de testes aprovados, na cor verde. O teste mostra que se a proteção identificar um percentual superior a $35 \%$ de quinto harmônico, a proteção é bloqueada, pois associa a uma corrente de Inrush. Nos valores inferiores a $35 \%$, a proteção continua ativa e elimina o defeito.

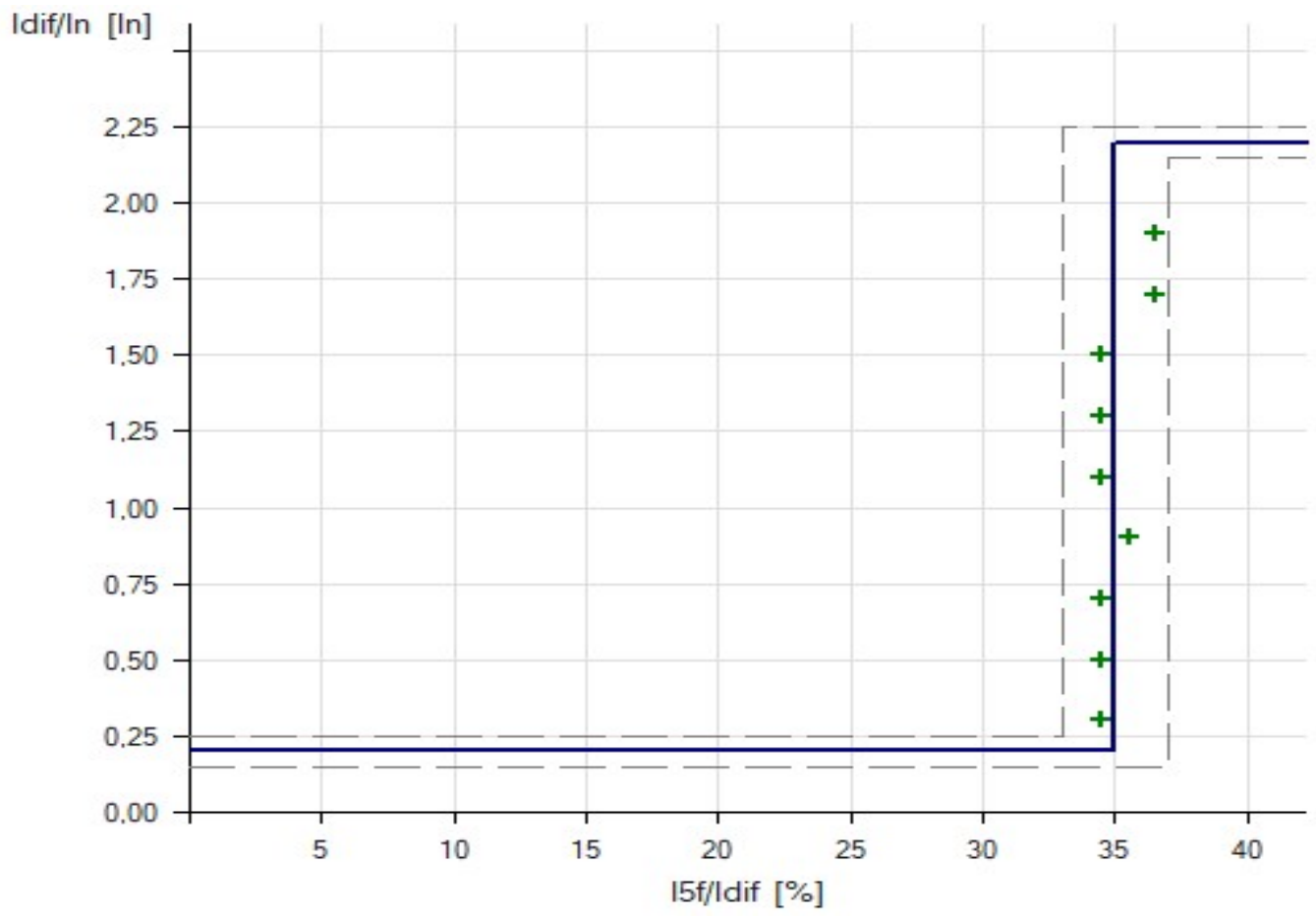

Figura 64 - Pontos para o teste de restrição de $5^{\circ}$ harmônico do relé 7 UT61.

As Figuras 65 e 66 mostram, respectivamente, os registros oscilográficos do bloqueio diferencial para $2^{\circ}$ e $5^{\circ}$ harmônicos, onde é possível observar que houve apenas a partida da proteção diferencial ("Diff picked-up"), mas que não houve trip ("Diff> TRIP"). 


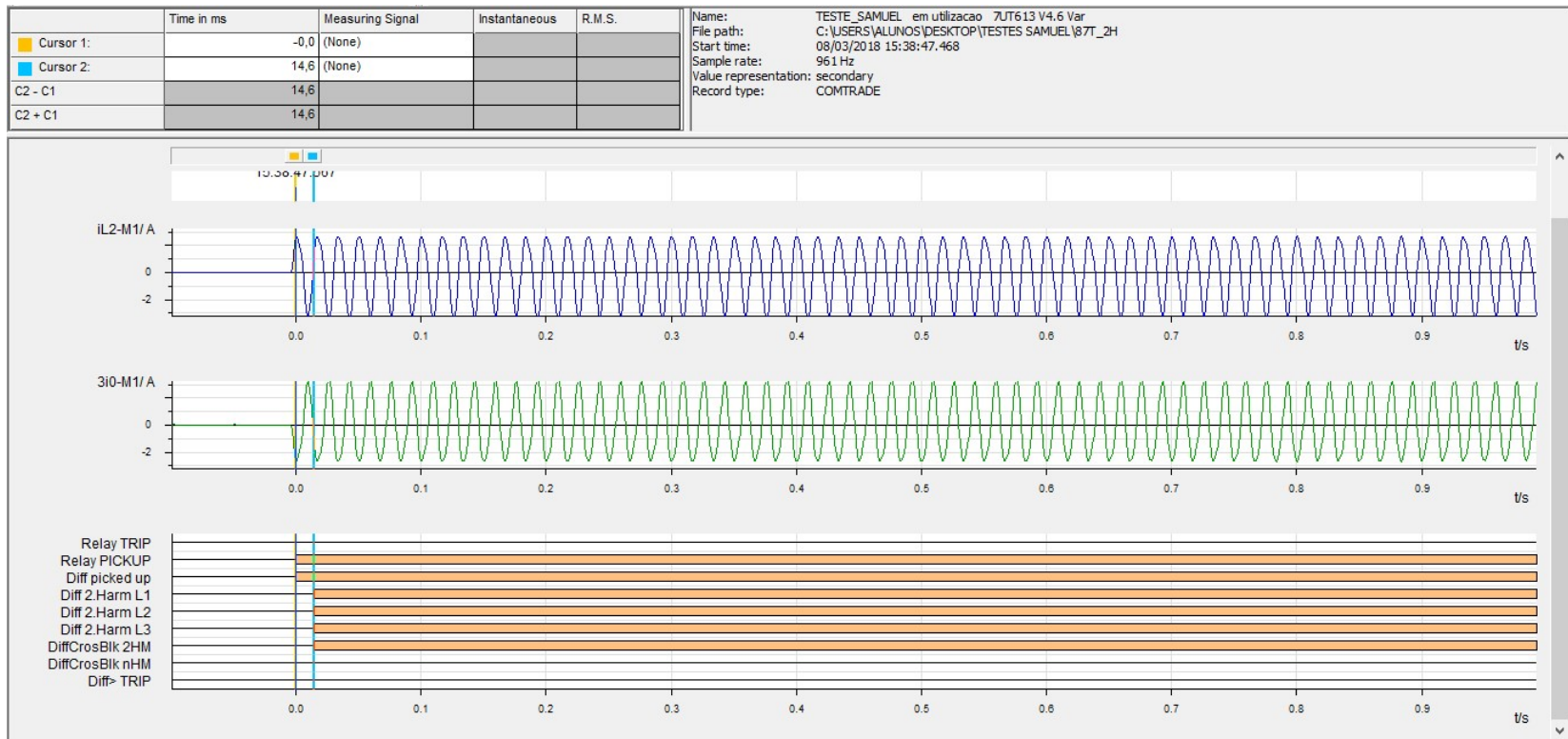

Figura 65 - Oscilografia do bloqueio da proteção diferencial por $2^{\circ}$ harmônico.

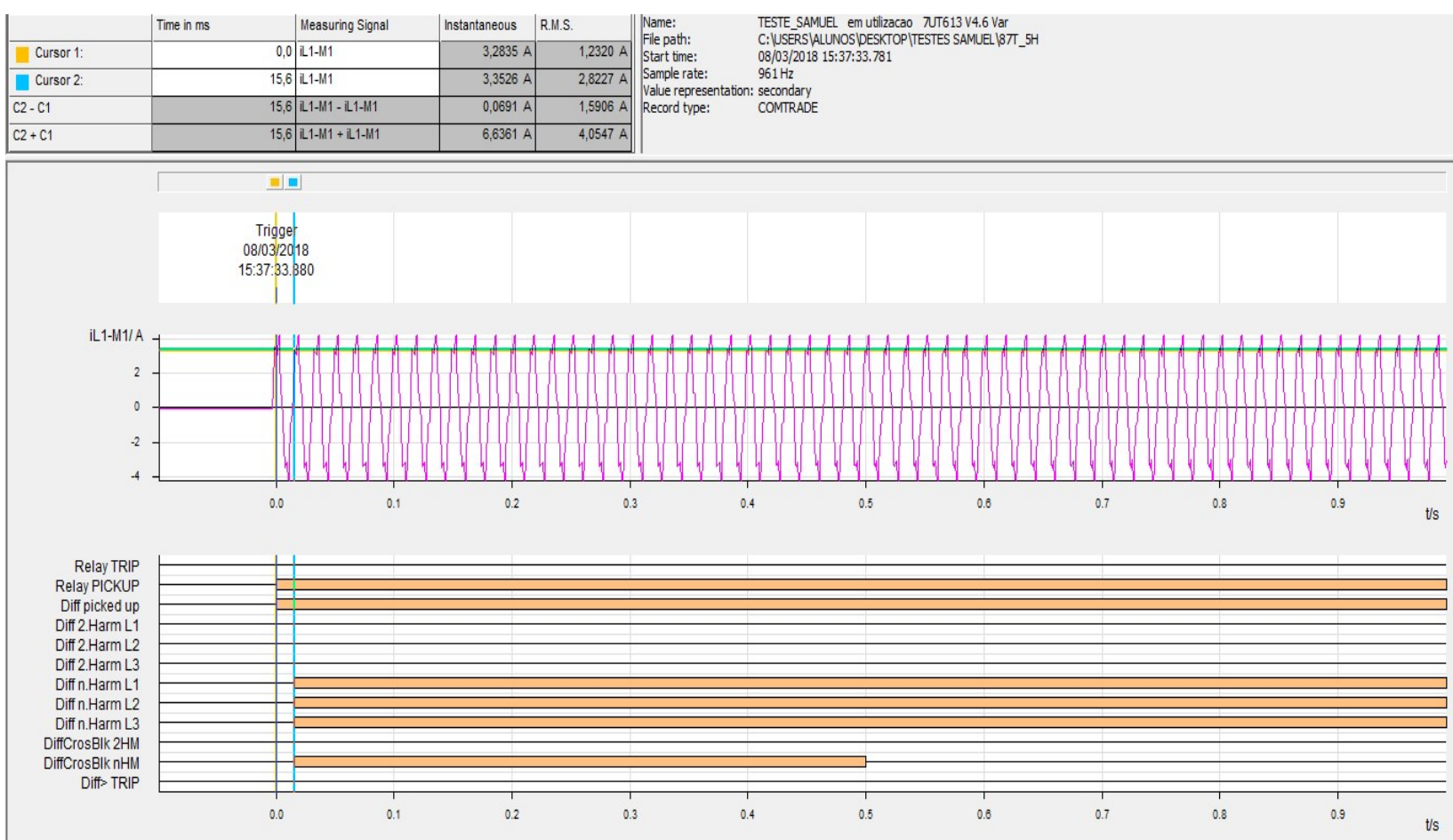

Figura 66 - Oscilografia do bloqueio da proteção diferencial por $5^{\circ}$ harmônico. 


\section{Capítulo 6. CONCLUSÕES GERAIS}

O intuito dos ajustes das proteções de sobrecorrente foi de proporcionar retaguarda não somente para a proteção diferencial dos transformadores de potência da SE Rondonópolis, mas também para os barramentos de alta e baixa tensão e as LTs adjacentes. As curvas adotadas para as unidades de sobrecorrente foram todas do tipo IEC normal inversa, por auxiliar na coordenação com as proteções dos outros equipamentos do sistema.

Os resultados dos tempos de atuação mostram que a unidade de sobrecorrente temporizada (51) não é sensível aos defeitos na barra de 230kV da SE Rondonópolis e na LT Itiquira - Rondonópolis $230 \mathrm{kV}$, devido aos baixos valores das correntes de falta. Portanto, foi habilitada a unidade de sobrecorrente com controle de tensão (51V) para aperfeiçoar o sistema de proteção. Porém, os resultados não foram satisfatórios, pois os tempos de atuação continuaram elevados, acarretando em danos aos equipamentos elétricos.

Entretanto, vale mencionar que no Procedimento de Rede do ONS, tanto as barras de $230 \mathrm{kV}$ como as LTs possuem proteções principais e secundárias que raramente falham e, além disso, as segundas zonas das proteções de distância das LTs são ajustadas para auxiliar na retaguarda destes equipamentos. Os tempos de retaguarda para a barra de $138 \mathrm{kV}$ da SE Rondonópolis foram todos satisfatórios, pois foi levado em consideração o critério de coordenação com os tempos de segundas zonas das proteções de distância $(650 \mathrm{~ms})$, evitando atuações indevidas.

Quanto à proteção diferencial, os resultados mostraram que os parâmetros adotados para a curva característica de operação foram ajustados de forma correta, podendo ser verificado por meio dos testes de busca da curva nominal. Por fim, foi realizado o teste de bloqueio da proteção diferencial para a não atuação no caso de energização dos ATs considerando a restrição de segundo e quinto harmônicos. Os resultados dos testes mostraram que para valores superiores ao valor percentual de harmônico ajustado, a proteção é bloqueada de acordo com o esperado. 


\section{REFERÊNCIAS BIBLIOGRÁFICAS}

[1] GERS, J. M.; HOLMES, E. J. Protection of Electricity Distribution Networks . 2. ed. London: The Institution of Electrical Engineers (IEE), 2005.

[2] ZANETTA, L. C. Jr. Fundamentos de Sistemas Elétricos de Potência. 1. ed. São Paulo: Livraria da Física, 2006.

[3] ALSTOM. Network Protection \& Automation Guide: Protective Relays, Measurement \& Control. 5.ed. Stafford: ALSTOM GRID, 2011.

[4] BARBOSA, D. et al. Power Transformer Differential Protection Based on Clarke's Transform and Fuzzy Systems. IEEE Transations on Power Delivery, São Paulo, v. 26, n. 02, p 1212 - 1220, April 2011.

[5] BLACKBURN, J. N.; DOMIN, T. J. Protective Relaying: Principles and Applications. 3. ed. New York: Taylor \& Francis Group, LLC, 2007.

[6] GLOVER, J. D. et al. Power System Analysis and Design. 5. ed. Stamford: CENGAGE Learning, 2011.

[7] ONS. O que é o SIN - Sistema Interligado Nacional. 2017. Disponível em: <http://www.ons.org.br/conheca_sistema/o_que_e_sin.aspx>. Acesso em 28 de Março de 2017.

[8] MASON, C. R. The Art \& Science of Protective Relaying. New York: John Wiley \& Sons, Inc., 1956.

[9] ELMORE, W. A. Protective Relaying Theory and Applications. 2. ed. New York: Marcel Dekker, Inc, 2004.

[10] ALMEIDA, W. G.; FREITAS, F. D. Circuitos Polifásicos: Teoria e Ensaios. Brasília: Gutenberg LTDA, 1995.

[11] KINDERMANN, G. Curto-Circuito. 2. ed. Porto Alegre: Sagra Luzzatto, 1997.

[12] MELLO, F. P. de. Proteção de Sistemas Elétricos de Potência. Santa Maria: Eletrobrás / Universidade Federal de Santa Maria, 1979. 
[13] CAMINHA, A. C. Introdução à Proteção dos Sistemas Elétricos. São Paulo: Edgard Blücher LTDA, 1997.

[14] KINDERMANN, G. Proteção de Sistemas Elétricos de Potência. Florianópolis: Edição do autor, 2008. v.3.

[15] KINDERMANN, G. Proteção de Sistemas Elétricos de Potência. Florianópolis: Sagra Luzzatto, 2006. v.2.

[16] ZIEGLER, G. Numerical Distance Protection: Principles and Applications. 2. ed. Berlin: Siemens, AG, 2006.

[17] KINDERMANN, G. Proteção de Sistemas Elétricos de Potência. 2.ed. Florianópolis: Sagra Luzzatto, 2005. v.1.

[18] ZIEGLER, G. Numerical Differential Protection: Principles and Applications. 2. ed. Berlin: Siemens, AG, 2012.

[19] IEEE. Guide for the Protection of Network Transformers. New York: The Institute of Electrical and Electronics Engineers, Inc, 2002.

[20] ROCKFELLER, G. Transformer Protection Application Guide. Disponível em: < http://sites.ieee.org/fw-pes/files/2013/01/transfguide.pdf>. Acesso em 15 de Maio de 2017.

[21] SILVA, R. A. Comportamento da Função de Proteção de Sobrecorrente Instantânea frente a Distorções Harmônicas nos Relés de Proteção Numéricos. 2008. 111 f. Escola de Engenharia de São Carlos, Universidade de São Paulo, São Paulo.

[22] PEXTRON. Manual de Operação URPE 7104T Ver. 8.20 Rev. 01. São Paulo, 2011.

[23] SEGATTO, E. C.; et al. Alto Desempenho na Proteção Diferencial de Transformadores de Potência com a Utilização de Redes Neurais Artificiais. Revista Controle \& Automação, São Paulo, v. 14, n.3, p. 309-320, 2003.

[24] KRSTIVOJEVIC, J.; DJURIC, M. A new algorithm for avoiding maloperation of transformer restricted earth fault protection caused by the transformer magnetizing inrush current and current transformer saturation. Turkish Journal of Electrical Engineering \& Computer Sciences, Belgrade, 24: 5025 - 5042, 2016. 
[25] MARDEGAN, C. Proteção e Seletividade: Capítulo IV - Dispositivos de Proteção Parte II: Relé de sobrecorrente com restrição (ou supervisão) de tensão. Revista O Setor Elétrico, São Paulo, p. 26-35, 2010.

[26] MARDEGAN, C. Proteção e Seletividade: Capítulo IX - Proteção dos transformadores - Parte I. Revista O Setor Elétrico, São Paulo, p. 26-39, 2010.

[27] SIEMENS. Manual SIPROTEC Proteção Diferencial 7UT613/63x V4.6. Disponível em:<http://w3.siemens.com/smartgrid/global/en/products-systems-solutions/downloads/ Pages/SIPROTEC-4-Downloads.aspx>. Acesso em 10 de setembro de 2017.

[28] ONS. Submódulo 2.6 - Requisitos mínimos para os sistemas de proteção e de telecomunicações. Disponível em: <http://www.ons.org.br/\%2FProcedimentosDeRede\% 2FM\%C3\%B3dulo\%202\%2FSubm\%C3\%B3dulo\%202.6\%2FSubm\%C3\%B3dulo\%202.6 _Rev_2.0.pdf>. Acesso em 14 de outubro de 2017.

[29] ALSTOM. Technical Manual Feeder Management relays MiCOM P141, P142, P143. Disponível em: < https://www.gegridsolutions.com/AlstomEnergy/grid/TechnicalManuals/ P14x/P14x_EN_T_C54.pdf >. Acesso em 20 de setembro de 2017.

[30] LIGHT. Proteção de Sistemas Elétricos. 2. ed. Rio de Janeiro: Interciência, 2005. 


\section{APÊNDICE}

\section{APÊNDICE A SIMULAÇÕES DE CURTO-CIRCUITO}

Neste apêndice apresentam-se as simulações de curto-circuito para o ajuste das proteções obtidas através do software de SAPRE do Cepel.

\section{A.1 - Faltas na barra de 230 kV da SE Rondonópolis}

Tabela A.1 - Correntes de curto-circuito, em kA, na barra de 230 kV da SE Rondonópolis com 4 TRs em operação

\begin{tabular}{|c|c|c|c|c|c|c|c|c|}
\hline Equipamento & & $\begin{array}{l}\text { ntes pa } \\
\text { onofási } \\
\text { (fase }\end{array}$ & $\begin{array}{l}\text { Is faltas } \\
\text { terra }\end{array}$ & & $\begin{array}{l}\text { ntes pa } \\
\text { bifásica } \\
\text { (fases }\end{array}$ & $\begin{array}{l}\text { s faltas } \\
\text { ra } \\
\text { c) }\end{array}$ & $\begin{array}{l}\text { Corren } \\
\text { faltas }\end{array}$ & $\begin{array}{l}\text { para as } \\
\text { ásicas }\end{array}$ \\
\hline \multirow{6}{*}{ T\#RP_230138A } & I & Mod. & Ang. & I & Mod. & Ang. & Mod. & Ang. \\
\hline & \multirow{3}{*}{ la } & \multirow{3}{*}{0,626} & \multirow{3}{*}{$-85,9^{\circ}$} & $\mathrm{Ib}$ & 0,520 & $-67,3^{\circ}$ & \multirow{5}{*}{0,215} & \multirow{5}{*}{$-80,7^{\circ}$} \\
\hline & & & & IC & 0,565 & $-107,1^{\circ}$ & & \\
\hline & & & & $\mathrm{I}_{0}$ & 0,476 & $-88,4^{\circ}$ & & \\
\hline & \multirow[t]{2}{*}{$\mathrm{I}_{0}$} & \multirow[t]{2}{*}{0,486} & \multirow[t]{2}{*}{$-87,0^{\circ}$} & I+ & 0,142 & $-81,4^{\circ}$ & & \\
\hline & & & & $\mathrm{I}-$ & 0,073 & $-79,4^{\circ}$ & & \\
\hline \multirow{5}{*}{ T\#RP_230138B } & \multirow{3}{*}{ la } & \multirow{3}{*}{0,681} & \multirow{3}{*}{$-85,9^{\circ}$} & $\mathrm{Ib}$ & 0,566 & $-66,9^{\circ}$ & \multirow{5}{*}{0,238} & \multirow{5}{*}{$-80,7^{\circ}$} \\
\hline & & & & IC & 0,615 & $-107,4^{\circ}$ & & \\
\hline & & & & $\mathrm{I}_{0}$ & 0,516 & $-88,3^{\circ}$ & & \\
\hline & \multirow[t]{2}{*}{$\mathrm{I}_{0}$} & \multirow[t]{2}{*}{0,526} & \multirow[t]{2}{*}{$-87,0^{\circ}$} & I+ & 0,157 & $-81,4^{\circ}$ & & \\
\hline & & & & I- & 0,081 & $-79,4^{\circ}$ & & \\
\hline \multirow{5}{*}{ T\#RP_230138C } & \multirow{3}{*}{ la } & \multirow{3}{*}{0,699} & \multirow{3}{*}{$-85,9^{\circ}$} & $\mathrm{Ib}$ & 0,582 & $-67,5^{\circ}$ & \multirow{5}{*}{0,237} & \multirow{5}{*}{$-80,7^{\circ}$} \\
\hline & & & & IC & 0,631 & $-106,9^{\circ}$ & & \\
\hline & & & & $\mathrm{I}_{0}$ & 0,534 & $-88,4^{\circ}$ & & \\
\hline & \multirow[t]{2}{*}{$\mathrm{I}_{0}$} & \multirow[t]{2}{*}{0,545} & \multirow[t]{2}{*}{$-87,0^{\circ}$} & $1+$ & 0,157 & $-81.4^{\circ}$ & & \\
\hline & & & & $\mathrm{I}-$ & 0,081 & $-79,4^{\circ}$ & & \\
\hline \multirow{5}{*}{ T\#RP_230138D } & \multirow{3}{*}{ la } & \multirow{3}{*}{0,719} & \multirow[b]{2}{*}{$-85,9^{\circ}$} & $\mathrm{Ib}$ & 0,598 & $-67,3^{\circ}$ & & \\
\hline & & & & IC & 0,650 & $-107,1^{\circ}$ & & \\
\hline & & & & $\mathrm{I}_{0}$ & 0,548 & $-88,4^{\circ}$ & 0,247 & $-80,7^{\circ}$ \\
\hline & $\mathrm{I}_{0}$ & 0,545 & $-87,0^{\circ}$ & $1+$ & 0,163 & $-81,4^{\circ}$ & & \\
\hline & & & & $\mathrm{I}-$ & 0,084 & $-79,4^{\circ}$ & & \\
\hline & & & & $\mathrm{Ib}$ & 9,775 & $-20,6^{\circ}$ & & \\
\hline & la & 9,880 & $-82,3^{\circ}$ & IC & 10,185 & $-142,6^{\circ}$ & & \\
\hline RONDONOP & & & & $\mathrm{I}_{0}$ & 3,228 & $-83,7^{\circ}$ & 10,080 & $-80,9^{\circ}$ \\
\hline & $\mathrm{I}_{0}$ & 3,293 & $-82,3^{\circ}$ & $1+$ & 6,652 & $-81,6^{\circ}$ & & \\
\hline & & & & $\mathrm{I}-$ & 3,429 & $-79,6^{\circ}$ & & \\
\hline
\end{tabular}


Tabela A.2 - Correntes de curto-circuito, em kA, na barra de 230 kV da SE Rondonópolis com 3 TRs em operação

\begin{tabular}{|c|c|c|c|c|c|c|c|c|}
\hline Equipamento & & $\begin{array}{l}\text { tes par } \\
\text { ofásica } \\
\text { (fase }\end{array}$ & $\begin{array}{l}\text { faltas } \\
\text { erra }\end{array}$ & Cor & $\begin{array}{l}\text { tes pa } \\
\text { fásicas } \\
\text { ases } \mathrm{E}\end{array}$ & $\begin{array}{l}\text { Is faltas } \\
\text { rra } \\
\text { C) }\end{array}$ & $\begin{array}{r}\text { Corren } \\
\text { faltas }\end{array}$ & $\begin{array}{l}\text { para as } \\
\text { ásicas }\end{array}$ \\
\hline \multirow{6}{*}{ T\#RP_230138A } & I & Mod. & Ang. & I & Mod. & Ang. & Mod. & Ang. \\
\hline & \multirow{3}{*}{ la } & \multirow{3}{*}{0,747} & \multirow{3}{*}{$-86,3^{\circ}$} & $\mathrm{Ib}$ & 0,598 & $-64,3^{\circ}$ & \multirow{5}{*}{0,283} & \multirow{5}{*}{$-81,1^{\circ}$} \\
\hline & & & & Ic & 0,654 & $-110,1^{\circ}$ & & \\
\hline & & & & $\mathrm{I}_{0}$ & 0,536 & $-88,7^{\circ}$ & & \\
\hline & \multirow{2}{*}{$\mathrm{I}_{0}$} & \multirow[t]{2}{*}{0,572} & \multirow[t]{2}{*}{$-87,6^{\circ}$} & $1+$ & 0,183 & $-81,6^{\circ}$ & & \\
\hline & & & & I- & 0,100 & $-80,1^{\circ}$ & & \\
\hline \multirow{5}{*}{ T\#RP_230138B } & \multirow{3}{*}{ la } & \multirow{3}{*}{0,816} & \multirow{3}{*}{$-86,3^{\circ}$} & $\mathrm{Ib}$ & 0,652 & $-63,9^{\circ}$ & \multirow{5}{*}{0,313} & \multirow{5}{*}{$-81,1^{\circ}$} \\
\hline & & & & Ic & 0,714 & $-110,4^{\circ}$ & & \\
\hline & & & & $\mathrm{I}_{0}$ & 0,582 & $-88,7^{\circ}$ & & \\
\hline & \multirow{2}{*}{$\mathrm{I}_{0}$} & \multirow[t]{2}{*}{0,622} & \multirow[t]{2}{*}{$-87,5^{\circ}$} & I+ & 0,202 & $-81,6^{\circ}$ & & \\
\hline & & & & I- & 0,111 & $-80,1^{\circ}$ & & \\
\hline \multirow{5}{*}{ T\#RP_230138C } & \multirow{3}{*}{ la } & \multirow{3}{*}{0,834} & \multirow{3}{*}{$-86,4^{\circ}$} & $\mathrm{lb}$ & 0,667 & $-64,5^{\circ}$ & \multirow{5}{*}{0,313} & \multirow{5}{*}{$-81,1^{\circ}$} \\
\hline & & & & Ic & 0,730 & $-109,9^{\circ}$ & & \\
\hline & & & & $\mathrm{I}_{0}$ & 0,599 & $-88,7^{\circ}$ & & \\
\hline & \multirow[t]{2}{*}{$\mathrm{I}_{0}$} & \multirow{2}{*}{0,640} & \multirow[t]{2}{*}{$-87,6^{\circ}$} & $1+$ & 0,202 & $-81,6^{\circ}$ & & \\
\hline & & & & I- & 0,111 & $-80,1^{\circ}$ & & \\
\hline \multirow{5}{*}{$\begin{array}{c}\text { Barra } \\
\text { RONDONOP } \\
230 \mathrm{kV}\end{array}$} & \multirow{3}{*}{ la } & \multirow{3}{*}{9,377} & \multirow{3}{*}{$-82,2^{\circ}$} & $\mathrm{lb}$ & 9,590 & $-18,1^{\circ}$ & \multirow{5}{*}{10,058} & \multirow{5}{*}{$-80,9^{\circ}$} \\
\hline & & & & IC & 9,914 & $-144,7^{\circ}$ & & \\
\hline & & & & $I_{0}$ & 2,926 & $-83,3^{\circ}$ & & \\
\hline & \multirow[t]{2}{*}{$\mathrm{I}_{0}$} & 3,126 & $-82,2^{\circ}$ & $1+$ & 6,491 & $-81,5^{\circ}$ & & \\
\hline & & & & I- & 3,568 & $-80,0^{\circ}$ & & \\
\hline
\end{tabular}


Tabela A.3 - Correntes de curto-circuito, em kA, na barra de 230 kV da SE Rondonópolis com 2 TRs em operação

\begin{tabular}{|c|c|c|c|c|c|c|c|c|}
\hline Equipamento & & $\begin{array}{r}\text { ntes p } \\
\text { onofás } \\
\text { (fas }\end{array}$ & $\begin{array}{l}\text { Is faltas } \\
\text { terra }\end{array}$ & & $\begin{array}{l}\text { ntes p } \\
\text { ifásice } \\
\text { (fases }\end{array}$ & $\begin{array}{l}\text { faltas } \\
\text { ra }\end{array}$ & $\begin{array}{l}\text { Correr } \\
\text { faltas }\end{array}$ & $\begin{array}{l}\text { para as } \\
\text { ásicas }\end{array}$ \\
\hline \multirow{6}{*}{ T\#RP_230138A } & $I$ & Mod. & Ang. & I & Mod. & Ang. & Mod. & Ang. \\
\hline & \multirow{3}{*}{ la } & \multirow{3}{*}{0,942} & \multirow{3}{*}{$-86,9^{\circ}$} & $\mathrm{Ib}$ & 0,726 & $-59,7^{\circ}$ & \multirow{5}{*}{0,408} & \multirow{5}{*}{$-81,7^{\circ}$} \\
\hline & & & & Ic & 0,801 & $-114,6^{\circ}$ & & \\
\hline & & & & $I_{0}$ & 0,626 & $-89,0^{\circ}$ & & \\
\hline & \multirow[t]{2}{*}{$\mathrm{I}_{0}$} & \multirow[t]{2}{*}{0,706} & \multirow[t]{2}{*}{$-88,3^{\circ}$} & $1+$ & 0,256 & $-82,1^{\circ}$ & & \\
\hline & & & & I- & 0,151 & $-81,1^{\circ}$ & & \\
\hline \multirow{5}{*}{ T\#RP_230138B } & \multirow{3}{*}{ la } & \multirow{3}{*}{1,033} & \multirow{3}{*}{$-86,9^{\circ}$} & $\mathrm{Ib}$ & 0,796 & $-59,4^{\circ}$ & \multirow{5}{*}{0,452} & \multirow{5}{*}{$-81,7^{\circ}$} \\
\hline & & & & IC & 0,879 & $-114,8^{\circ}$ & & \\
\hline & & & & $\mathrm{I}_{0}$ & 0,683 & $-89,0^{\circ}$ & & \\
\hline & \multirow[t]{2}{*}{$\mathrm{I}_{0}$} & \multirow[t]{2}{*}{0,771} & \multirow[t]{2}{*}{$-88,3^{\circ}$} & $1+$ & 0,284 & $-82,1^{\circ}$ & & \\
\hline & & & & I- & 0,168 & $-81,1^{\circ}$ & & \\
\hline \multirow{6}{*}{$\begin{array}{c}\text { Barra } \\
\text { RONDONOP } \\
230 \mathrm{kV}\end{array}$} & \multirow{3}{*}{ la } & \multirow{3}{*}{8,736} & \multirow{3}{*}{$-81,9^{\circ}$} & $\mathrm{Ib}$ & 9,394 & $-15,3^{\circ}$ & \multirow{6}{*}{10,016} & \multirow{6}{*}{$-81,0^{\circ}$} \\
\hline & & & & Ic & 9,604 & $-147,2^{\circ}$ & & \\
\hline & & & & 1 & ת & ( 70 & & \\
\hline & \multirow{3}{*}{$\mathrm{I}_{0}$} & \multirow{3}{*}{2,912} & \multirow{3}{*}{$-81,9^{\circ}$} & & & & & \\
\hline & & & & $1+$ & 6,299 & $-81,3^{\circ}$ & & \\
\hline & & & & I- & 3,718 & $-80,4^{\circ}$ & & \\
\hline
\end{tabular}

Tabela A.4 - Correntes de curto-circuito, em kA, na barra de 230 kV da SE Rondonópolis com 1 AT em operação

\begin{tabular}{|c|c|c|c|c|c|c|c|c|}
\hline Equipamento & & $\begin{array}{r}\text { rentes } \\
\text { ionofás } \\
\text { (fas }\end{array}$ & $\begin{array}{l}\text { a falta } \\
\text { terra }\end{array}$ & & $\begin{array}{l}\text { entes } p \\
\text { ifásica } \\
\text { fases }\end{array}$ & falta & $\begin{array}{r}\text { Corre } \\
\text { falt }\end{array}$ & $\begin{array}{l}\text { para a } \\
\text { ásica }\end{array}$ \\
\hline \multirow{6}{*}{ T\#RP_230138A } & I & Mod. & Ang. & I & Mod. & Ang. & Mod. & Ang. \\
\hline & \multirow{5}{*}{$\mathrm{I}_{0}$} & \multirow{3}{*}{1,256} & \multirow{3}{*}{$-87,6^{\circ}$} & $\mathrm{Ib}$ & 0,968 & $-48,2^{\circ}$ & \multirow{5}{*}{0,731} & \multirow{5}{*}{$-83,4^{\circ}$} \\
\hline & & & & IC & 1,062 & $-125,3^{\circ}$ & & \\
\hline & & & & $\mathrm{I}_{0}$ & 0,718 & $-89,4^{\circ}$ & & \\
\hline & & \multirow[t]{2}{*}{0,881} & \multirow[t]{2}{*}{$-89,4^{\circ}$} & $1+$ & 0,442 & $-83,4^{\circ}$ & & \\
\hline & & & & I- & 0,289 & $-83,4^{\circ}$ & & \\
\hline \multirow{6}{*}{$\begin{array}{c}\text { Barra } \\
\text { RONDONOP } \\
230 \mathrm{kV}\end{array}$} & \multirow{3}{*}{ la } & \multirow{3}{*}{7,662} & \multirow{3}{*}{$-81,1^{\circ}$} & $\mathrm{Ib}$ & 9,128 & $-11,0^{\circ}$ & \multirow{6}{*}{9,909} & \multirow{6}{*}{$-81,0^{\circ}$} \\
\hline & & & & IC & 9,136 & $-151,0^{\circ}$ & & \\
\hline & & & & \multirow{2}{*}{$\mathrm{I}_{0}$} & \multirow{2}{*}{2,082} & \multirow{2}{*}{$-81,1^{\circ}$} & & \\
\hline & \multirow{3}{*}{$\mathrm{I}_{0}$} & \multirow{3}{*}{2,554} & \multirow{3}{*}{$-81,1^{\circ}$} & & & & & \\
\hline & & & & I+ & 5,995 & $-81,1^{\circ}$ & & \\
\hline & & & & I- & 3,913 & $-81,1^{\circ}$ & & \\
\hline
\end{tabular}




\section{A.2 - Faltas na barra de 138 kV da SE Rondonópolis}

Tabela A.5 - Correntes de curto-circuito, em kA, na barra de 138 kV da SE Rondonópolis com 4 TRs em operação.

\begin{tabular}{|c|c|c|c|c|c|c|c|c|}
\hline Equipamento & & $\begin{array}{r}\text { ntes p } \\
\text { nofási } \\
\text { (fase }\end{array}$ & $\begin{array}{l}\text { a a falta } \\
\text {-terra }\end{array}$ & & $\begin{array}{l}\text { entes p } \\
\text { bifásica } \\
\text { (fases }\end{array}$ & $\begin{array}{l}\text { a falta } \\
\text { ra } \\
\text { ) }\end{array}$ & $\begin{array}{r}\text { Correr } \\
\text { falta }\end{array}$ & $\begin{array}{l}\text { para a } \\
\text { ásica }\end{array}$ \\
\hline \multirow{6}{*}{ T\#RP_230138A } & I & Mod. & Ang. & I & Mod. & Ang. & Mod. & Ang. \\
\hline & \multirow{3}{*}{ la } & \multirow{3}{*}{2,954} & \multirow{3}{*}{$-85,4^{\circ}$} & $\mathrm{Ib}$ & 2,804 & $-46,9^{\circ}$ & \multirow{5}{*}{2,057} & \multirow{5}{*}{$-84,9^{\circ}$} \\
\hline & & & & Ic & 2,877 & $-124,6^{\circ}$ & & \\
\hline & & & & $I_{0}$ & 1,650 & $-86,3^{\circ}$ & & \\
\hline & \multirow[t]{2}{*}{$\mathrm{I}_{0}$} & \multirow[t]{2}{*}{1,250} & \multirow[t]{2}{*}{$-85,3^{\circ}$} & $1+$ & 1,591 & $-85,4^{\circ}$ & & \\
\hline & & & & I- & 0,466 & $-82,8^{\circ}$ & & \\
\hline \multirow{5}{*}{ T\#RP_230138B } & \multirow{3}{*}{ la } & \multirow{3}{*}{3,199} & \multirow{3}{*}{$-85,3^{\circ}$} & $\mathrm{Ib}$ & 3,035 & $-45,7^{\circ}$ & \multirow{5}{*}{2,278} & \multirow{5}{*}{$-84,9^{\circ}$} \\
\hline & & & & IC & 3,110 & $-125,6^{\circ}$ & & \\
\hline & & & & $\mathrm{I}_{0}$ & 1,732 & $-86,2^{\circ}$ & & \\
\hline & \multirow[t]{2}{*}{$\mathrm{I}_{0}$} & \multirow[t]{2}{*}{1,312} & \multirow[t]{2}{*}{$-85,1^{\circ}$} & $1+$ & 1,762 & $-85,4^{\circ}$ & & \\
\hline & & & & I- & 0,517 & $-82,8^{\circ}$ & & \\
\hline \multirow{5}{*}{ T\#RP_230138C } & \multirow{3}{*}{ la } & \multirow{3}{*}{2,583} & \multirow{3}{*}{$-85,0^{\circ}$} & $\mathrm{Ib}$ & 2,491 & $-33,2^{\circ}$ & \multirow{5}{*}{2,275} & \multirow{5}{*}{$-84,9^{\circ}$} \\
\hline & & & & IC & 2,516 & $-137,0^{\circ}$ & & \\
\hline & & & & $\mathrm{I}_{0}$ & 0,922 & $-84,7^{\circ}$ & & \\
\hline & \multirow[t]{2}{*}{$\mathrm{I}_{0}$} & \multirow[t]{2}{*}{0,698} & \multirow[t]{2}{*}{$-83,7^{\circ}$} & I+ & 1,760 & $-85,6^{\circ}$ & & \\
\hline & & & & I- & 0,516 & $-82,8^{\circ}$ & & \\
\hline \multirow{5}{*}{ T\#RP_230138D } & \multirow[b]{2}{*}{ la } & \multirow[b]{2}{*}{2,583} & \multirow[b]{2}{*}{$-85,0^{\circ}$} & $\mathrm{Ib}$ & 2,599 & $-33,5^{\circ}$ & & \\
\hline & & & & IC & 2,625 & $-136,7^{\circ}$ & & \\
\hline & & & & $\mathrm{I}_{0}$ & 0,976 & $-84,7^{\circ}$ & 2,364 & $-84,9^{\circ}$ \\
\hline & $I_{0}$ & 0,739 & $-83,70^{\circ}$ & $1+$ & 1,829 & $-85,4^{\circ}$ & & \\
\hline & & & & I- & 0,536 & $-82,8^{\circ}$ & & \\
\hline & & & & $\mathrm{Ib}$ & 12,703 & $-37,9^{\circ}$ & & \\
\hline & la & $\begin{array}{c}13,43 \\
1\end{array}$ & $-84,3^{\circ}$ & IC & 13,079 & $-131,0^{\circ}$ & & \\
\hline RONDONOP & & & & $\mathrm{I}_{0}$ & 5,912 & $-85,4^{\circ}$ & 10,806 & $-83,7^{\circ}$ \\
\hline & $\mathrm{I}_{0}$ & 4,477 & $-84,3^{\circ}$ & I+ & 8,358 & $-84,3^{\circ}$ & & \\
\hline & & & & I- & 2,450 & $-81,7^{\circ}$ & & \\
\hline
\end{tabular}


Tabela A.6 - Correntes de curto-circuito, em kA, na barra de 138 kV da SE Rondonópolis com 3 TRs em operação

\begin{tabular}{|c|c|c|c|c|c|c|c|c|}
\hline Equipamento & & $\begin{array}{l}\text { entes p } \\
\text { onofási } \\
\text { (fase }\end{array}$ & $\begin{array}{l}\text { a falta } \\
\text { terra }\end{array}$ & & $\begin{array}{l}\text { entes pa } \\
\text { oifásica- } \\
\text { fases B }\end{array}$ & $\begin{array}{l}\text { a falta } \\
\text { ra } \\
\text { C) }\end{array}$ & $\begin{array}{r}\text { Corrent } \\
\mathrm{t}\end{array}$ & $\begin{array}{l}\text { ra a falta } \\
\text { a }\end{array}$ \\
\hline \multirow{6}{*}{ T\#RP_230138A } & $I$ & Mod. & Ang. & I & Mod. & Ang. & Mod. & Ang. \\
\hline & \multirow{3}{*}{ la } & \multirow{3}{*}{3,336} & \multirow{3}{*}{$-85,9^{\circ}$} & $\mathrm{Ib}$ & 3,166 & $-44,8^{\circ}$ & \multirow{5}{*}{2,434} & \multirow{5}{*}{$-85,6^{\circ}$} \\
\hline & & & & Ic & 3,220 & $-127,4^{\circ}$ & & \\
\hline & & & & $\mathrm{I}_{0}$ & 1,741 & $-86,4^{\circ}$ & & \\
\hline & \multirow[t]{2}{*}{$\mathrm{I}_{0}$} & \multirow[t]{2}{*}{1,328} & \multirow[t]{2}{*}{$-85,4^{\circ}$} & $1+$ & 1,874 & $-86,1^{\circ}$ & & \\
\hline & & & & $\mathrm{I}-$ & 0,560 & $-83,8^{\circ}$ & & \\
\hline \multirow{5}{*}{ T\#RP_230138B } & \multirow{3}{*}{ la } & \multirow{3}{*}{3,622} & \multirow{3}{*}{$-85,8^{\circ}$} & $\mathrm{lb}$ & 3,440 & $-43,7^{\circ}$ & \multirow{5}{*}{2,696} & \multirow{5}{*}{$-85,6^{\circ}$} \\
\hline & & & & Ic & 3,493 & $-128,4^{\circ}$ & & \\
\hline & & & & $\mathrm{I}_{0}$ & 1,833 & $-86,2^{\circ}$ & & \\
\hline & \multirow{2}{*}{$\mathrm{I}_{0}$} & \multirow{2}{*}{1,399} & \multirow{2}{*}{$-85,3^{\circ}$} & $1+$ & 2,077 & $-86,1^{\circ}$ & & \\
\hline & & & & I- & 0,620 & $-83,8^{\circ}$ & & \\
\hline \multirow{5}{*}{ T\#RP_230138C } & \multirow{3}{*}{ la } & \multirow{3}{*}{2,991} & \multirow{3}{*}{$-85,5^{\circ}$} & $\mathrm{Ib}$ & 2,905 & $-32,3^{\circ}$ & \multirow{5}{*}{2,693} & \multirow{5}{*}{$-85,6^{\circ}$} \\
\hline & & & & Ic & 2,910 & $-138,9^{\circ}$ & & \\
\hline & & & & $\mathrm{I}_{0}$ & 1,010 & $-84,7^{\circ}$ & & \\
\hline & \multirow[t]{2}{*}{$\mathrm{I}_{0}$} & \multirow[t]{2}{*}{0,770} & \multirow[t]{2}{*}{$-83,8^{\circ}$} & $1+$ & 2,074 & $-86,1^{\circ}$ & & \\
\hline & & & & I- & 0,619 & $-83,8^{\circ}$ & & \\
\hline \multirow{5}{*}{$\begin{array}{c}\text { Barra } \\
\text { RONDONOP } \\
138 \mathrm{kV}\end{array}$} & \multirow{3}{*}{ la } & \multirow{3}{*}{11,973} & \multirow{3}{*}{$-84,6^{\circ}$} & $\mathrm{lb}$ & 11,331 & $-37,9^{\circ}$ & \multirow{5}{*}{9,677} & \multirow{5}{*}{$-84,1^{\circ}$} \\
\hline & & & & Ic & 11,628 & $-131,6^{\circ}$ & & \\
\hline & & & & $\mathrm{I}_{0}$ & 5,231 & $-85,5^{\circ}$ & & \\
\hline & \multirow[t]{2}{*}{$\mathrm{I}_{0}$} & 3,991 & $-84,6^{\circ}$ & $1+$ & 7,454 & $-84,6^{\circ}$ & & \\
\hline & & & & I- & 2,225 & $-82,3^{\circ}$ & & \\
\hline
\end{tabular}


Tabela A.7 - Correntes de curto-circuito, em A, na barra de 138 kV da SE Rondonópolis com 2 TRs em operação

\begin{tabular}{|c|c|c|c|c|c|c|c|c|}
\hline Equipamento & & $\begin{array}{c}\text { rente pa } \\
\text { onofásic } \\
\text { (fase }\end{array}$ & $\begin{array}{l}\text { falta } \\
\text { erra }\end{array}$ & & $\begin{array}{l}\text { tes pa } \\
\text { fásica. } \\
\text { ases B }\end{array}$ & $\begin{array}{l}\text { a falta } \\
\text { ra } \\
\text { C) }\end{array}$ & $\begin{array}{l}\text { Corre } \\
\text { falt }\end{array}$ & $\begin{array}{l}\text { spara a } \\
\text { fásica }\end{array}$ \\
\hline \multirow{6}{*}{ T\#RP_230138A } & I & Mod. & Ang. & $\mathrm{I}$ & Mod. & Ang. & Mod. & Ang. \\
\hline & \multirow{3}{*}{ la } & \multirow{3}{*}{3,834} & \multirow{3}{*}{$-86,5^{\circ}$} & $\mathrm{Ib}$ & 3,665 & $-42,5^{\circ}$ & \multirow{5}{*}{2,955} & \multirow{5}{*}{$-86,6^{\circ}$} \\
\hline & & & & Ic & 3,679 & $-130,8^{\circ}$ & & \\
\hline & & & & $\mathrm{I}_{0}$ & 1,831 & $-86,3^{\circ}$ & & \\
\hline & \multirow[t]{2}{*}{$\mathrm{I}_{0}$} & \multirow[t]{2}{*}{1,391} & \multirow[t]{2}{*}{$-85,5^{\circ}$} & $1+$ & 2,281 & $-87,0^{\circ}$ & & \\
\hline & & & & I- & 0,674 & $-85,0^{\circ}$ & & \\
\hline \multirow{5}{*}{ T\#RP_230138B } & \multirow{3}{*}{ la } & \multirow{3}{*}{4,177} & \multirow{3}{*}{$-86,4^{\circ}$} & $\mathrm{Ib}$ & 3,998 & $-41,5^{\circ}$ & \multirow{5}{*}{3,273} & \multirow{5}{*}{$-86,6^{\circ}$} \\
\hline & & & & IC & 4,007 & $-131,7^{\circ}$ & & \\
\hline & & & & $\mathrm{I}_{0}$ & 1,936 & $-86,1^{\circ}$ & & \\
\hline & \multirow[t]{2}{*}{$\mathrm{I}_{0}$} & \multirow[t]{2}{*}{1,471} & \multirow[t]{2}{*}{$-85,3^{\circ}$} & $1+$ & 2,527 & $-87,0^{\circ}$ & & \\
\hline & & & & I- & 0,746 & $-85,0^{\circ}$ & & \\
\hline \multirow{5}{*}{$\begin{array}{c}\text { Barra } \\
\text { RONDONOP } \\
138 \mathrm{kV}\end{array}$} & \multirow{3}{*}{ la } & \multirow{3}{*}{10,066} & \multirow{3}{*}{$-84,9^{\circ}$} & $\mathrm{Ib}$ & 9,548 & $-38,3^{\circ}$ & \multirow{5}{*}{8,115} & \multirow{5}{*}{$-84,4^{\circ}$} \\
\hline & & & & Ic & 9,767 & $-131,7^{\circ}$ & & \\
\hline & & & & $\mathrm{I}_{0}$ & 4,416 & $-85,7^{\circ}$ & & \\
\hline & \multirow[t]{2}{*}{$\mathrm{I}_{0}$} & \multirow[t]{2}{*}{3,355} & \multirow[t]{2}{*}{$-84,9^{\circ}$} & $1+$ & 6,265 & $-84,9^{\circ}$ & & \\
\hline & & & & I- & 1,851 & $-82,9^{\circ}$ & & \\
\hline
\end{tabular}

Tabela A.8 - Correntes de curto-circuito, em kA, na barra de 138 kV da SE Rondonópolis com 1 TR em operação

\begin{tabular}{|c|c|c|c|c|c|c|c|c|}
\hline Equipamento & & $\begin{array}{l}\text { ntes p } \\
\text { nofási } \\
\text { (fase }\end{array}$ & $\begin{array}{l}\text { a falta } \\
\text { erra }\end{array}$ & & $\begin{array}{l}\text { ntes } p \\
\text { ifásica } \\
\text { fases }\end{array}$ & $\begin{array}{l}\text { a falta } \\
\text { ra } \\
\text { C) }\end{array}$ & $\begin{array}{l}\text { Corre } \\
\text { falta }\end{array}$ & $\begin{array}{l}\text { para a } \\
\text { ásica }\end{array}$ \\
\hline \multirow{6}{*}{ T\#RP_230138A } & $I$ & Mod. & Ang. & $\mathrm{I}$ & Mod. & Ang. & Mod. & Ang. \\
\hline & \multirow{3}{*}{ la } & \multirow{3}{*}{4,773} & \multirow{3}{*}{$-87,5^{\circ}$} & $\mathrm{Ib}$ & 4,569 & $-42,0^{\circ}$ & \multirow{5}{*}{3,758} & \multirow{5}{*}{$-88,1^{\circ}$} \\
\hline & & & & Ic & 4,516 & $-133,5^{\circ}$ & & \\
\hline & & & & $\mathrm{I}_{0}$ & 2,206 & $-86,5^{\circ}$ & & \\
\hline & \multirow[t]{2}{*}{$\mathrm{I}_{0}$} & \multirow[t]{2}{*}{1,739} & \multirow[t]{2}{*}{$-85,7^{\circ}$} & $1+$ & 2,842 & $-88,5^{\circ}$ & & \\
\hline & & & & I- & 0,917 & $-86,7^{\circ}$ & & \\
\hline \multirow{5}{*}{$\begin{array}{c}\text { Barra } \\
\text { RONDONOP } \\
138 \mathrm{kV}\end{array}$} & \multirow{3}{*}{ la } & \multirow{3}{*}{6,906} & \multirow{3}{*}{$-84,9^{\circ}$} & $\mathrm{lb}$ & 6,522 & $-36,5^{\circ}$ & \multirow{5}{*}{5,699} & \multirow{5}{*}{$-84,3^{\circ}$} \\
\hline & & & & Ic & 6,674 & $-133,3^{\circ}$ & & \\
\hline & & & & $\mathrm{I}_{0}$ & 2,920 & $-85,6^{\circ}$ & & \\
\hline & \multirow[t]{2}{*}{$\mathrm{I}_{0}$} & \multirow[t]{2}{*}{2,302} & \multirow[t]{2}{*}{$-84,9^{\circ}$} & $1+$ & 4,309 & $-84,8^{\circ}$ & & \\
\hline & & & & I- & 1,390 & $-82,9^{\circ}$ & & \\
\hline
\end{tabular}




\section{A.3 - Faltas na barra de $230 \mathrm{kV}$ da SE Itiquira}

Tabela A.9 - Correntes de curto-circuito, em kA, na barra de 230 kV da SE Itiquira com 4 TRs em operação

\begin{tabular}{|c|c|c|c|c|c|c|c|c|}
\hline Equipamento & & $\begin{array}{r}\text { ntes p } \\
\text { onofás } \\
\text { (fas }\end{array}$ & $\begin{array}{l}\text { as faltas } \\
\text {-terra }\end{array}$ & & $\begin{array}{l}\text { entes } p \\
\text { jifásice } \\
\text { fases }\end{array}$ & $\begin{array}{l}\text { a falta } \\
\text { rra } \\
\text { C) }\end{array}$ & $\begin{array}{l}\text { Corre } \\
\text { falt }\end{array}$ & $\begin{array}{l}\text { para a } \\
\text { sica }\end{array}$ \\
\hline \multirow{6}{*}{ T\#RP_230138A } & I & Mod. & Ang. & I & Mod. & Ang. & Mod. & Ang. \\
\hline & \multirow{3}{*}{ la } & \multirow{3}{*}{0,091} & \multirow{3}{*}{$-77,6^{\circ}$} & $\mathrm{Ib}$ & 0,083 & $-41,6^{\circ}$ & \multirow{5}{*}{0,056} & \multirow{5}{*}{$-79,5^{\circ}$} \\
\hline & & & & Ic & 0,080 & $-114,6^{\circ}$ & & \\
\hline & & & & $\mathrm{I}_{0}$ & 0,055 & $-76,5^{\circ}$ & & \\
\hline & \multirow[t]{2}{*}{$\mathrm{I}_{0}$} & \multirow[t]{2}{*}{0,052} & \multirow[t]{2}{*}{$-75,4^{\circ}$} & $1+$ & 0,038 & $-80,0^{\circ}$ & & \\
\hline & & & & I- & 0,018 & $-78,3^{\circ}$ & & \\
\hline \multirow{5}{*}{ T\#RP_230138B } & \multirow{3}{*}{ la } & \multirow{3}{*}{0,100} & \multirow{3}{*}{$-77,6^{\circ}$} & $\mathrm{Ib}$ & 0,090 & $-41,1^{\circ}$ & \multirow{5}{*}{0,062} & \multirow{5}{*}{$-79,5^{\circ}$} \\
\hline & & & & IC & 0,087 & $-115,1^{\circ}$ & & \\
\hline & & & & $\mathrm{I}_{0}$ & 0,060 & $-76,5^{\circ}$ & & \\
\hline & \multirow{2}{*}{$\mathrm{I}_{0}$} & \multirow[t]{2}{*}{0,057} & \multirow{2}{*}{$-75,4^{\circ}$} & $1+$ & 0,042 & $-80,0^{\circ}$ & & \\
\hline & & & & $1-$ & 0,020 & $-78,3^{\circ}$ & & \\
\hline \multirow{5}{*}{ T\#RP_230138C } & \multirow{3}{*}{ la } & \multirow{3}{*}{0,102} & \multirow{3}{*}{$-77,6^{\circ}$} & $\mathrm{Ib}$ & 0,092 & $-41,9^{\circ}$ & \multirow{5}{*}{0,062} & \multirow{5}{*}{$-79,5^{\circ}$} \\
\hline & & & & $\mathrm{IC}$ & 0,089 & $-114,2^{\circ}$ & & \\
\hline & & & & $\mathrm{I}_{0}$ & 0,062 & $-76,5^{\circ}$ & & \\
\hline & \multirow[t]{2}{*}{$\mathrm{I}_{0}$} & \multirow[t]{2}{*}{0,059} & \multirow[t]{2}{*}{$-75,5^{\circ}$} & $1+$ & 0,042 & $-80,0^{\circ}$ & & \\
\hline & & & & $1-$ & 0,019 & $-78,3^{\circ}$ & & \\
\hline \multirow{5}{*}{ T\#RP_230138D } & \multirow{3}{*}{ la } & \multirow{3}{*}{0,105} & \multirow{3}{*}{$-77,6^{\circ}$} & $\mathrm{Ib}$ & 0,095 & $-41,6^{\circ}$ & & \\
\hline & & & & $\mathrm{IC}$ & 0,092 & $-114,6^{\circ}$ & & \\
\hline & & & & $\mathrm{I}_{0}$ & 0,063 & $-76,5^{\circ}$ & 0,064 & $-79,5^{\circ}$ \\
\hline & $I_{0}$ & 0,060 & $-75,4^{\circ}$ & $1+$ & 0,044 & $-80,0^{\circ}$ & & \\
\hline & & & & I- & 0,020 & $-78,3^{\circ}$ & & \\
\hline & & & & $\mathrm{Ib}$ & 3,593 & $-25,8^{\circ}$ & & \\
\hline & la & 3754 & $-836^{\circ}$ & IC & 3,711 & $-140,7^{\circ}$ & & \\
\hline $\begin{array}{c}\text { Barra } \\
\text { SE Itiquira }\end{array}$ & la & 3,154 & $-83,6$ & $\mathrm{I}_{0}$ & 1,310 & $-84,7^{\circ}$ & 3,555 & $-82,7^{\circ}$ \\
\hline & $\mathrm{I}_{0}$ & 1,254 & $-83,6^{\circ}$ & $\mathrm{I+}$ & 2,432 & $-83,2^{\circ}$ & & \\
\hline & & & & I- & 1,123 & $-81,5^{\circ}$ & & \\
\hline
\end{tabular}


Tabela A.10 - Correntes de curto-circuito, em kA, na barra de $230 \mathrm{kV}$ da SE Itiquira com 3 TRs em operação

\begin{tabular}{|c|c|c|c|c|c|c|c|c|}
\hline Equipamento & & $\begin{array}{l}\text { tes par } \\
\text { lofásic } \\
\text { (fase }\end{array}$ & $\begin{array}{l}\text { s faltas } \\
\text { terra }\end{array}$ & & $\begin{array}{l}\text { ente pa } \\
\text { ifásica } \\
\text { fases }\end{array}$ & $\begin{array}{l}\text { a falta } \\
\text { ra } \\
\text { C) }\end{array}$ & $\begin{array}{r}\text { Corre } \\
\text { falt }\end{array}$ & $\begin{array}{l}\text { para a } \\
\text { ásica }\end{array}$ \\
\hline \multirow{6}{*}{ T\#RP_230138A } & $I$ & Mod. & Ang. & I & Mod. & Ang. & Mod. & Ang. \\
\hline & \multirow{3}{*}{ la } & \multirow{3}{*}{0,116} & \multirow{3}{*}{$-78,2^{\circ}$} & $\mathrm{lb}$ & 0,105 & $-40,7^{\circ}$ & \multirow{5}{*}{0,074} & \multirow{5}{*}{$-79,8^{\circ}$} \\
\hline & & & & Ic & 0,102 & $-116,7^{\circ}$ & & \\
\hline & & & & $\mathrm{I}_{0}$ & 0,068 & $-77,3^{\circ}$ & & \\
\hline & \multirow[t]{2}{*}{$\mathrm{I}_{0}$} & \multirow[t]{2}{*}{0,065} & \multirow[t]{2}{*}{$-76,2^{\circ}$} & I+ & 0,050 & $-80,4^{\circ}$ & & \\
\hline & & & & I- & 0,023 & $-78,6^{\circ}$ & & \\
\hline \multirow{5}{*}{ T\#RP_230138B } & \multirow{3}{*}{ la } & \multirow{3}{*}{0,127} & \multirow{3}{*}{$-78,2^{\circ}$} & $\mathrm{lb}$ & 0,115 & $-40,3^{\circ}$ & \multirow{5}{*}{0,082} & \multirow{5}{*}{$-78,9^{\circ}$} \\
\hline & & & & Ic & 0,112 & $-117,2^{\circ}$ & & \\
\hline & & & & $\mathrm{I}_{0}$ & 0,074 & $-77,3^{\circ}$ & & \\
\hline & \multirow[t]{2}{*}{$\mathrm{I}_{0}$} & \multirow[t]{2}{*}{0,070} & \multirow[t]{2}{*}{$-76,2^{\circ}$} & I+ & 0,056 & $-80,4^{\circ}$ & & \\
\hline & & & & I- & 0,026 & $-78,6^{\circ}$ & & \\
\hline \multirow{5}{*}{ T\#RP_230138C } & \multirow{3}{*}{ la } & \multirow{3}{*}{0,129} & \multirow{3}{*}{$-78,2^{\circ}$} & $\mathrm{lb}$ & 0,117 & $-40,9^{\circ}$ & \multirow{5}{*}{0,081} & \multirow{5}{*}{$-79,8^{\circ}$} \\
\hline & & & & Ic & 0,114 & $-116,5^{\circ}$ & & \\
\hline & & & & $\mathrm{I}_{0}$ & 0,076 & $-77,3^{\circ}$ & & \\
\hline & \multirow[t]{2}{*}{$\mathrm{I}_{0}$} & \multirow[t]{2}{*}{0,072} & \multirow[t]{2}{*}{$-76,2^{\circ}$} & $1+$ & 0,056 & $-80,4^{\circ}$ & & \\
\hline & & & & I- & 0,026 & $-78,6^{\circ}$ & & \\
\hline \multirow{5}{*}{$\begin{array}{c}\text { Barra } \\
\text { SE Itiquira } \\
230 \mathrm{kV}\end{array}$} & \multirow{3}{*}{ la } & \multirow{3}{*}{3,727} & \multirow{3}{*}{$-83,7^{\circ}$} & $\mathrm{lb}$ & 3,587 & $-25,7^{\circ}$ & \multirow{5}{*}{3,553} & \multirow{5}{*}{$-82,7^{\circ}$} \\
\hline & & & & Ic & 3,708 & $-140,8^{\circ}$ & & \\
\hline & & & & $\mathrm{I}_{0}$ & 1,306 & $-84,8^{\circ}$ & & \\
\hline & \multirow[t]{2}{*}{$\mathrm{I}_{0}$} & 1,242 & $-83,7^{\circ}$ & I+ & 2,429 & $-83,2^{\circ}$ & & \\
\hline & & & & I- & 1,124 & $-81,4^{\circ}$ & & \\
\hline
\end{tabular}


Tabela A.11 - Correntes de curto-circuito, em A, na barra de $230 \mathrm{kV}$ da SE Itiquira com 2 TRs em operação

\begin{tabular}{|c|c|c|c|c|c|c|c|c|}
\hline Equipamento & & $\begin{array}{l}\text { entes p } \\
\text { nofási } \\
\text { (fase }\end{array}$ & $\begin{array}{l}\text { a falta } \\
\text { terra }\end{array}$ & & $\begin{array}{l}\text { ntes } p \\
\text { ifásica } \\
\text { fases } B\end{array}$ & $\begin{array}{l}\text { a falta } \\
\text { ra } \\
\text { C) }\end{array}$ & $\begin{array}{l}\text { Corre } \\
\text { falte }\end{array}$ & $\begin{array}{l}\text { para a } \\
\text { isica }\end{array}$ \\
\hline \multirow{6}{*}{ T\#RP_230138A } & I & Mod. & Ang. & I & Mod. & Ang. & Mod. & Ang. \\
\hline & \multirow{3}{*}{ la } & \multirow{3}{*}{0,160} & \multirow{3}{*}{$-79,2^{\circ}$} & $\mathrm{lb}$ & 0,144 & $-39,5^{\circ}$ & \multirow{5}{*}{0,107} & \multirow{5}{*}{$-80,4^{\circ}$} \\
\hline & & & & Ic & 0,141 & $-119,9^{\circ}$ & & \\
\hline & & & & $\mathrm{I}_{0}$ & 0,090 & $-78,4^{\circ}$ & & \\
\hline & \multirow[t]{2}{*}{$\mathrm{I}_{0}$} & \multirow[t]{2}{*}{0,085} & \multirow[t]{2}{*}{$-77,2^{\circ}$} & I+ & 0,073 & $-81,0^{\circ}$ & & \\
\hline & & & & $\mathrm{I}-$ & 0,034 & $-79,2^{\circ}$ & & \\
\hline \multirow{5}{*}{ T\#RP_230138B } & \multirow{3}{*}{ la } & \multirow{3}{*}{0,176} & \multirow{3}{*}{$-79,2^{\circ}$} & $\mathrm{Ib}$ & 0,159 & $-39,1^{\circ}$ & \multirow{5}{*}{0,118} & \multirow{5}{*}{$-80,4^{\circ}$} \\
\hline & & & & IC & 0,155 & $-120,2^{\circ}$ & & \\
\hline & & & & $\mathrm{I}_{0}$ & 0,098 & $-78,4^{\circ}$ & & \\
\hline & \multirow[t]{2}{*}{$\mathrm{I}_{0}$} & \multirow[t]{2}{*}{0,093} & \multirow[t]{2}{*}{$-77,2^{\circ}$} & $1+$ & 0,081 & $-81,0^{\circ}$ & & \\
\hline & & & & $\mathrm{I}-$ & 0,037 & $-79,2^{\circ}$ & & \\
\hline \multirow{5}{*}{$\begin{array}{c}\text { Barra } \\
\text { SE Itiquira } \\
230 \mathrm{kV}\end{array}$} & \multirow{3}{*}{ la } & \multirow{3}{*}{3,717} & \multirow{3}{*}{$-83,7^{\circ}$} & $\mathrm{lb}$ & 3,578 & $-25,7^{\circ}$ & \multirow{5}{*}{3,551} & \multirow{5}{*}{$-82,7^{\circ}$} \\
\hline & & & & Ic & 3,703 & $-140,9^{\circ}$ & & \\
\hline & & & & $I_{0}$ & 1,300 & $-84,8^{\circ}$ & & \\
\hline & \multirow[t]{2}{*}{$\mathrm{I}_{0}$} & \multirow[t]{2}{*}{1,239} & \multirow[t]{2}{*}{$-83,7^{\circ}$} & $1+$ & 2,425 & $-83,3^{\circ}$ & & \\
\hline & & & & $\mathrm{I}-$ & 1,126 & $-81,4^{\circ}$ & & \\
\hline
\end{tabular}

Tabela A.12 - Correntes de curto-circuito, em kA, na barra de $230 \mathrm{kV}$ da SE Itiquira com 1 AT em operação

\begin{tabular}{|c|c|c|c|c|c|c|c|c|}
\hline Equipamento & & $\begin{array}{l}\text { ntes p } \\
\text { nofási } \\
\text { (fase }\end{array}$ & $\begin{array}{l}\text { a falta } \\
\text { terra }\end{array}$ & & $\begin{array}{l}\text { ntes } p \\
\text { ifásica } \\
\text { fases }\end{array}$ & $\begin{array}{l}\text { a falta } \\
\text { ra } \\
\text { ) }\end{array}$ & $\begin{array}{r}\text { Corre } \\
\text { falt }\end{array}$ & $\begin{array}{l}\text { para a } \\
\text { isica }\end{array}$ \\
\hline \multirow{6}{*}{ T\#RP_230138A } & I & Mod. & Ang. & I & Mod. & Ang. & Mod. & Ang. \\
\hline & \multirow{3}{*}{ la } & \multirow{3}{*}{0,255} & \multirow{3}{*}{$-81,3^{\circ}$} & $\mathrm{Ib}$ & 0,233 & $-35,7^{\circ}$ & \multirow{5}{*}{0,193} & \multirow{5}{*}{$-82,1^{\circ}$} \\
\hline & & & & Ic & 0,230 & $-127,7^{\circ}$ & & \\
\hline & & & & $\mathrm{I}_{0}$ & 0,126 & $-80,5^{\circ}$ & & \\
\hline & \multirow[t]{2}{*}{$\mathrm{I}_{0}$} & \multirow[t]{2}{*}{0,121} & \multirow[t]{2}{*}{$-79,3^{\circ}$} & $1+$ & 0,131 & $-82,7^{\circ}$ & & \\
\hline & & & & $1-$ & 0,061 & $-80,7^{\circ}$ & & \\
\hline \multirow{5}{*}{$\begin{array}{c}\text { Barra } \\
\text { SE Itiquira } \\
230 \mathrm{kV}\end{array}$} & \multirow{3}{*}{ la } & \multirow{3}{*}{3,698} & \multirow{3}{*}{$-83,8^{\circ}$} & $\mathrm{Ib}$ & 3,559 & $-25,5^{\circ}$ & \multirow{5}{*}{3,543} & \multirow{5}{*}{$-82,7^{\circ}$} \\
\hline & & & & Ic & 3,690 & $-141,2^{\circ}$ & & \\
\hline & & & & $\mathrm{I}_{0}$ & 1,287 & $-85,0^{\circ}$ & & \\
\hline & \multirow[t]{2}{*}{$\mathrm{I}_{0}$} & \multirow[t]{2}{*}{1,232} & \multirow[t]{2}{*}{$-83,8^{\circ}$} & $1+$ & 2,415 & $-83,3^{\circ}$ & & \\
\hline & & & & I- & 1,129 & $-81,4^{\circ}$ & & \\
\hline
\end{tabular}




\section{A.4 - Faltas na barra da SE Jaciara $138 \mathrm{kV}$}

Tabela A.13 - Correntes de curto-circuito, em kA, na barra de 138 kV da SE Jaciara com 4 TRs em operação

\begin{tabular}{|c|c|c|c|c|c|c|c|c|}
\hline Equipamento & & $\begin{array}{r}\text { tes par } \\
\text { lofásica } \\
\text { (fase } A\end{array}$ & $\begin{array}{l}\text { alta } \\
\text { a }\end{array}$ & & $\begin{array}{l}\text { ntes pa } \\
\text { fásica- } \\
\text { ases B }\end{array}$ & $\begin{array}{l}\text { a falta } \\
\text { ra } \\
\text { C) }\end{array}$ & $\begin{array}{c}\text { Corren } \\
\text { falta }\end{array}$ & $\begin{array}{l}\text { para a } \\
\text { ásica }\end{array}$ \\
\hline \multirow{6}{*}{ T\#RP_230138A } & I & Mod. & Ang. & I & Mod. & Ang. & Mod. & Ang. \\
\hline & \multirow{3}{*}{ la } & \multirow{3}{*}{0,507} & \multirow{3}{*}{$-75,9^{\circ}$} & $\mathrm{Ib}$ & 0,582 & $-5,2^{\circ}$ & \multirow{5}{*}{0,635} & \multirow{5}{*}{$-74,7^{\circ}$} \\
\hline & & & & Ic & 0,592 & $-144,6^{\circ}$ & & \\
\hline & & & & $\mathrm{I}_{0}$ & 0,122 & $-74,7^{\circ}$ & & \\
\hline & \multirow[t]{2}{*}{$\mathrm{I}_{0}$} & \multirow[t]{2}{*}{0,137} & \multirow[t]{2}{*}{$-73,0^{\circ}$} & $1+$ & 0,399 & $-75,7^{\circ}$ & & \\
\hline & & & & I- & 0,236 & $-73,4^{\circ}$ & & \\
\hline \multirow{5}{*}{ T\#RP_230138B } & \multirow{3}{*}{ la } & \multirow{3}{*}{0,554} & \multirow{3}{*}{$-75,9^{\circ}$} & $\mathrm{Ib}$ & 0,642 & $-4,7^{\circ}$ & \multirow{5}{*}{0,704} & \multirow{5}{*}{$-74,7^{\circ}$} \\
\hline & & & & IC & 0,653 & $-145,2^{\circ}$ & & \\
\hline & & & & $\mathrm{I}_{0}$ & 0,128 & $-74,6^{\circ}$ & & \\
\hline & \multirow[t]{2}{*}{$\mathrm{I}_{0}$} & \multirow[t]{2}{*}{0,145} & \multirow[t]{2}{*}{$-72,9^{\circ}$} & I+ & 0,442 & $-75,5^{\circ}$ & & \\
\hline & & & & $\mathrm{I}-$ & 0,261 & $-73,4^{\circ}$ & & \\
\hline \multirow{5}{*}{ T\#RP_230138C } & \multirow{3}{*}{ la } & \multirow{3}{*}{0,487} & \multirow{3}{*}{$-76,1^{\circ}$} & $\mathrm{lb}$ & 0,25 & $-179,4^{\circ}$ & \multirow{5}{*}{0,703} & \multirow{5}{*}{$-74,7^{\circ}$} \\
\hline & & & & Ic & 0,634 & $-150,1^{\circ}$ & & \\
\hline & & & & $I_{0}$ & 0,069 & $-73,5^{\circ}$ & & \\
\hline & \multirow{2}{*}{$\mathrm{I}_{0}$} & \multirow[t]{2}{*}{0,078} & \multirow{2}{*}{$-71,8^{\circ}$} & $1+$ & 0,442 & $-75,5^{\circ}$ & & \\
\hline & & & & $1-$ & 0,261 & $-73,4^{\circ}$ & & \\
\hline \multirow{5}{*}{ T\#RP_230138D } & \multirow{3}{*}{ la } & \multirow{3}{*}{0,508} & \multirow{3}{*}{$-76,1^{\circ}$} & $\mathrm{Ib}$ & 0,650 & $-179,7^{\circ}$ & & \\
\hline & & & & IC & 0,659 & $-150,0^{\circ}$ & & \\
\hline & & & & $\mathrm{I}_{0}$ & 0,073 & $-73,5^{\circ}$ & 0,730 & $-74,7^{\circ}$ \\
\hline & $\mathrm{I}_{0}$ & 0,083 & $-71,8^{\circ}$ & $1+$ & 0,459 & $-75,5^{\circ}$ & & \\
\hline & & & & $\mathrm{I}-$ & 0,271 & $-73,4^{\circ}$ & & \\
\hline & & & & $\mathrm{lb}$ & 4,407 & $-10,5^{\circ}$ & & \\
\hline & la & 4,163 & $-78,0^{\circ}$ & IC & 4,634 & $142,4^{\circ}$ & & \\
\hline $\begin{array}{c}\text { Barra } \\
\text { SE Jaciara }\end{array}$ & & & & $\mathrm{I}_{0}$ & 1,230 & $79,7^{\circ}$ & 4,767 & $-75,8^{\circ}$ \\
\hline & $\mathrm{I}_{0}$ & 1,388 & $-78,0^{\circ}$ & I+ & 2,998 & $76,6^{\circ}$ & & \\
\hline & & & & I- & 1,770 & $-74,5^{\circ}$ & & \\
\hline
\end{tabular}


Tabela A.14 - Correntes de curto-circuito, em kA, na barra de 138 kV da SE Jaciara com 3 TRs em operação

\begin{tabular}{|c|c|c|c|c|c|c|c|c|}
\hline Equipamento & & $\begin{array}{l}\text { tes par } \\
\text { ofásica } \\
\text { (fase A }\end{array}$ & & & $\begin{array}{l}\text { ntes pa } \\
\text { ifásica- } \\
\text { fases B }\end{array}$ & $\begin{array}{l}\text { a falta } \\
\text { ra } \\
\text { C) }\end{array}$ & $\begin{array}{l}\text { Corren } \\
\text { falta }\end{array}$ & $\begin{array}{l}\text { para a } \\
\text { ásica }\end{array}$ \\
\hline \multirow{6}{*}{ T\#RP_230138A } & $\mathrm{I}$ & Mod. & Ang. & I & Mod. & Ang. & Mod. & Ang. \\
\hline & \multirow{3}{*}{ la } & \multirow{3}{*}{0,643} & \multirow{3}{*}{$-76,4^{\circ}$} & $\mathrm{lb}$ & 0,749 & $-5,1^{\circ}$ & \multirow{5}{*}{0,819} & \multirow{5}{*}{$-75,5^{\circ}$} \\
\hline & & & & IC & 0,757 & $-146,0^{\circ}$ & & \\
\hline & & & & $\mathrm{I}_{0}$ & 0,145 & $-74,7^{\circ}$ & & \\
\hline & \multirow[t]{2}{*}{$\mathrm{I}_{0}$} & \multirow[t]{2}{*}{0,162} & \multirow[t]{2}{*}{$-73,1^{\circ}$} & $1+$ & 0,517 & $-76,2^{\circ}$ & & \\
\hline & & & & I- & 0,303 & $-74,2^{\circ}$ & & \\
\hline \multirow{5}{*}{ T\#RP_230138B } & \multirow{3}{*}{ la } & \multirow{3}{*}{0,704} & \multirow{3}{*}{$-76,4^{\circ}$} & $\mathrm{lb}$ & 0,827 & $-4,6^{\circ}$ & \multirow{5}{*}{0,908} & \multirow{5}{*}{$-75,5^{\circ}$} \\
\hline & & & & Ic & 0,836 & $-146,5^{\circ}$ & & \\
\hline & & & & $\mathrm{I}_{0}$ & 0,153 & $-74,6^{\circ}$ & & \\
\hline & \multirow[t]{2}{*}{$\mathrm{I}_{0}$} & \multirow[t]{2}{*}{0,171} & \multirow[t]{2}{*}{$-73,0^{\circ}$} & I+ & 0,573 & $-76,2^{\circ}$ & & \\
\hline & & & & I- & 0,335 & $-74,2^{\circ}$ & & \\
\hline \multirow{5}{*}{ T\#RP_230138C } & \multirow{3}{*}{ la } & \multirow{3}{*}{0,628} & \multirow{3}{*}{$-76,6^{\circ}$} & $\mathrm{lb}$ & 0,807 & $-0,1^{\circ}$ & \multirow{5}{*}{0,907} & \multirow{5}{*}{$-75,5^{\circ}$} \\
\hline & & & & IC & 0,815 & $-151,0^{\circ}$ & & \\
\hline & & & & $\mathrm{I}_{0}$ & 0,085 & $-73,5^{\circ}$ & & \\
\hline & \multirow[t]{2}{*}{$\mathrm{I}_{0}$} & \multirow[t]{2}{*}{0,096} & \multirow[t]{2}{*}{$-71,9^{\circ}$} & I+ & 0,572 & $-76,2^{\circ}$ & & \\
\hline & & & & I- & 0,335 & $-74,2^{\circ}$ & & \\
\hline \multirow{5}{*}{$\begin{array}{c}\text { Barra da } \\
\text { SE Jaciara } \\
138 \mathrm{kV}\end{array}$} & \multirow{3}{*}{ la } & \multirow{3}{*}{4,100} & \multirow{3}{*}{$-78,2^{\circ}$} & $\mathrm{lb}$ & 4,322 & $-11,2^{\circ}$ & \multirow{5}{*}{4,654} & \multirow{5}{*}{$-76,2^{\circ}$} \\
\hline & & & & IC & 4,530 & $-142,4^{\circ}$ & & \\
\hline & & & & $\mathrm{I}_{0}$ & 1,220 & $-79,8^{\circ}$ & & \\
\hline & \multirow{2}{*}{$\mathrm{I}_{0}$} & 1.367 & $-78,2^{\circ}$ & $1+$ & 2,936 & $-76,9^{\circ}$ & & \\
\hline & & & & I- & 1,718 & $-74,9^{\circ}$ & & \\
\hline
\end{tabular}


Tabela A.15 - Correntes de curto-circuito, em kA, na barra de 138 kV da SE Jaciara com 2 TRs em operação

\begin{tabular}{|c|c|c|c|c|c|c|c|c|}
\hline Equipamento & & $\begin{array}{l}\text { entes p } \\
\text { onofási } \\
\text { (fase }\end{array}$ & $\begin{array}{l}\text { falta } \\
\text { rra }\end{array}$ & & $\begin{array}{l}\text { rentes } \\
\text { bifási } \\
\text { (fases }\end{array}$ & $\begin{array}{l}\text { a falta } \\
\text { rra } \\
\text { C) }\end{array}$ & $\begin{array}{l}\text { Corr } \\
\text { a falt }\end{array}$ & $\begin{array}{l}\text { s para } \\
\text { ifásica }\end{array}$ \\
\hline \multirow{6}{*}{ T\#RP_230138A } & I & Mod. & Ang. & I & Mod. & Ang. & Mod. & Ang. \\
\hline & \multirow{3}{*}{ la } & \multirow{3}{*}{0,875} & \multirow{3}{*}{$-77,3^{\circ}$} & $\mathrm{Ib}$ & 1,036 & $-5,4^{\circ}$ & \multirow{5}{*}{1,136} & \multirow{5}{*}{$-76,7^{\circ}$} \\
\hline & & & & Ic & 1,040 & $-148,1^{\circ}$ & & \\
\hline & & & & $I_{0}$ & 0,178 & $-74,7^{\circ}$ & & \\
\hline & \multirow{2}{*}{$\mathrm{I}_{0}$} & \multirow[t]{2}{*}{0,197} & \multirow[t]{2}{*}{$-73,3^{\circ}$} & I+ & 0,721 & $-77,4^{\circ}$ & & \\
\hline & & & & I- & 0,415 & $-75,6^{\circ}$ & & \\
\hline \multirow{5}{*}{ T\#RP_230138B } & \multirow{3}{*}{ la } & \multirow{3}{*}{0,960} & \multirow{3}{*}{$-77,3^{\circ}$} & $\mathrm{Ib}$ & 1,145 & $-5,0^{\circ}$ & \multirow{5}{*}{1,259} & \multirow{5}{*}{$-76,7^{\circ}$} \\
\hline & & & & IC & 1,150 & $-148,5^{\circ}$ & & \\
\hline & & & & $\mathrm{I}_{0}$ & 0,189 & $-74,6^{\circ}$ & & \\
\hline & \multirow[t]{2}{*}{$\mathrm{I}_{0}$} & \multirow[t]{2}{*}{0,209} & \multirow[t]{2}{*}{$-73,2^{\circ}$} & I+ & 0,799 & $-77,4^{\circ}$ & & \\
\hline & & & & I- & 0,460 & $-75,6^{\circ}$ & & \\
\hline \multirow{5}{*}{$\begin{array}{c}\text { Barra da } \\
\text { SE Jaciara } \\
138 \mathrm{kV}\end{array}$} & \multirow{3}{*}{ la } & \multirow{3}{*}{3,992} & \multirow{3}{*}{$-78,6^{\circ}$} & $\mathrm{Ib}$ & 4,172 & $-12,4^{\circ}$ & \multirow{5}{*}{4,458} & \multirow{5}{*}{$-76,8^{\circ}$} \\
\hline & & & & IC & 4,350 & $-142,4^{\circ}$ & & \\
\hline & & & & $\mathrm{I}_{0}$ & 1,204 & $-80,0^{\circ}$ & & \\
\hline & \multirow[t]{2}{*}{$I_{0}$} & \multirow[t]{2}{*}{1,331} & \multirow[t]{2}{*}{$-78,6^{\circ}$} & I+ & 2,830 & $-77,5^{\circ}$ & & \\
\hline & & & & I- & 1,628 & $-75,7^{\circ}$ & & \\
\hline
\end{tabular}

Tabela A.16 - Correntes de curto-circuito, em kA, na SE Jaciara de 138 kV com 1 autotransformador em operação

\begin{tabular}{|c|c|c|c|c|c|c|c|c|}
\hline Equipamento & & $\begin{array}{r}\text { rente p } \\
\text { onofás } \\
\text { (fase }\end{array}$ & $\begin{array}{l}\text { falta } \\
\text { rra }\end{array}$ & & $\begin{array}{l}\text { rentes } \\
\text { bifásic } \\
\text { (fases }\end{array}$ & $\begin{array}{l}\text { a falta } \\
\text { ra } \\
\text { C) }\end{array}$ & $\begin{array}{l}\text { Corre } \\
\text { a falt }\end{array}$ & $\begin{array}{l}\text { es para } \\
\text { ifásica }\end{array}$ \\
\hline \multirow{6}{*}{ T\#RP_230138A } & I & Mod. & Ang. & $\mathrm{I}$ & Mod. & Ang. & Mod. & Ang. \\
\hline & \multirow{3}{*}{ la } & \multirow{3}{*}{1,480} & \multirow{3}{*}{$-79,3^{\circ}$} & $\mathrm{lb}$ & 1,715 & $-9,3^{\circ}$ & \multirow{5}{*}{1,851} & \multirow{5}{*}{$-79,5^{\circ}$} \\
\hline & & & & Ic & 1,694 & $-149,5^{\circ}$ & & \\
\hline & & & & $\mathrm{I}_{0}$ & 0,313 & $-75,5^{\circ}$ & & \\
\hline & \multirow{2}{*}{$\mathrm{I}_{0}$} & \multirow{2}{*}{0,336} & \multirow[t]{2}{*}{$-74,4^{\circ}$} & I+ & 1,192 & $-80,1^{\circ}$ & & \\
\hline & & & & I- & 0,658 & $-78,6^{\circ}$ & & \\
\hline \multirow{5}{*}{$\begin{array}{c}\text { Barra da } \\
\text { SE Jaciara } \\
138 \mathrm{kV}\end{array}$} & \multirow{3}{*}{ la } & \multirow{3}{*}{3,723} & \multirow{3}{*}{$-79,3^{\circ}$} & $\mathrm{lb}$ & 3,818 & $-15,1^{\circ}$ & \multirow{5}{*}{4,009} & \multirow{5}{*}{$-78,0^{\circ}$} \\
\hline & & & & Ic & 3,945 & $-141,9^{\circ}$ & & \\
\hline & & & & $I_{0}$ & 1,158 & $-80,4^{\circ}$ & & \\
\hline & \multirow[t]{2}{*}{$\mathrm{I}_{0}$} & \multirow[t]{2}{*}{1,241} & \multirow[t]{2}{*}{$-79,3^{\circ}$} & $1+$ & 2,583 & $-78,6^{\circ}$ & & \\
\hline & & & & I- & 1,426 & $-77,1^{\circ}$ & & \\
\hline
\end{tabular}




\section{A.5 - Valores de curto-circuito para o ajuste da proteção de sobrecorrente com controle de tensão (51V) para a LT Rondonópolis - Jaciara $138 \mathrm{kV}$}

Tabela A.17 - Valores de tensão, em pu, para falta na barra de $138 \mathrm{kV}$ da SE Jaciara com os 4 TRs da SE Rondonópolis em operação

\begin{tabular}{|c|c|c|c|c|}
\hline \multirow{2}{*}{ Equipamento } & \multicolumn{2}{|c|}{$\begin{array}{c}\text { Tensão para a } \\
\text { falta trifásica } \\
\text { (pu) }\end{array}$} & \multicolumn{2}{c|}{$\begin{array}{c}\text { Corrente para a } \\
\text { falta trifásica } \\
\text { (kA) }\end{array}$} \\
\hline \multirow{2}{*}{ T\#RP_230138A } & Mod. & Ang. & Mod. & Ang. \\
\cline { 2 - 5 } & 0,673 & $-5,1^{\circ}$ & 0,635 & $-74,7^{\circ}$ \\
\hline T\#RP_230138B & 0,671 & $-5,2^{\circ}$ & 0,704 & $-74,7^{\circ}$ \\
\hline T\#RP_230138C & 0,669 & $-5,2^{\circ}$ & 0,703 & $-74,7^{\circ}$ \\
\hline T\#RP_230138D & 0,666 & $-5,3^{\circ}$ & 0,730 & $-74,7^{\circ}$ \\
\hline $\begin{array}{c}\text { Barra de 138kV } \\
\text { da SE Jaciara }\end{array}$ & 0 & $0^{\circ}$ & 4,767 & $-75,8^{\circ}$ \\
\hline
\end{tabular}

Tabela A.18 - Valores de tensão, em pu, para falta na barra de 138 kV da SE Jaciara com 3 TRs da SE Rondonópolis em operação

\begin{tabular}{|c|c|c|c|c|}
\hline \multirow{2}{*}{ Equipamento } & \multicolumn{2}{|c|}{$\begin{array}{c}\text { Tensão para a } \\
\text { falta trifásica } \\
\text { (pu) }\end{array}$} & \multicolumn{2}{c|}{$\begin{array}{c}\text { Corrente para a } \\
\text { falta trifásica } \\
\text { (kA) }\end{array}$} \\
\hline \multirow{2}{*}{ T\#RP_230138A } & Mod. & Ang. & Mod. & Ang. \\
\cline { 2 - 5 } & 0,645 & $-5,8^{\circ}$ & 0,819 & $-75,5^{\circ}$ \\
\hline T\#RP_230138B & 0,642 & $-5,9^{\circ}$ & 0,908 & $-75,5^{\circ}$ \\
\hline T\#RP_230138C & 0,640 & $-5,9^{\circ}$ & 0,907 & $-75,5^{\circ}$ \\
\hline $\begin{array}{c}\text { Barra de 138kV } \\
\text { da SE Jaciara }\end{array}$ & 0 & $0^{\circ}$ & 4,654 & $-76,2^{\circ}$ \\
\hline
\end{tabular}


Tabela A.19 - Valores de tensão, em pu, para falta na barra de 138 kV da SE Jaciara com 2 TRs da SE Rondonópolis em operação

\begin{tabular}{|c|c|c|c|c|}
\hline \multirow{2}{*}{ Equipamento } & \multicolumn{2}{|c|}{$\begin{array}{c}\text { Tensão para a } \\
\text { falta trifásica (pu) }\end{array}$} & \multicolumn{2}{c|}{$\begin{array}{c}\text { Corrente para a } \\
\text { falta trifásica } \\
\text { (kA) }\end{array}$} \\
\hline \multirow{2}{*}{ T\#RP_230138A } & Mod. & Ang. & Mod. & Ang. \\
\cline { 2 - 5 } & 0,597 & $-6,9^{\circ}$ & 1,136 & $-76,7^{\circ}$ \\
\hline T\#RP_230138B & 0,592 & $-7,1^{\circ}$ & 1,259 & $-76,7^{\circ}$ \\
\hline $\begin{array}{c}\text { Barra de 138kV } \\
\text { da SE Jaciara }\end{array}$ & 0 & 0 & 4,458 & $-76,8^{\circ}$ \\
\hline
\end{tabular}

Tabela A.20 - Valores de tensão, em pu, para falta na barra de 138 kV da SE Jaciara com 1 TR da SE Rondonópolis em operação

\begin{tabular}{|c|c|c|c|c|}
\hline \multirow{2}{*}{ Equipamento } & \multicolumn{2}{|c|}{$\begin{array}{c}\text { Tensão para a } \\
\text { falta trifásica } \\
\text { (pu) }\end{array}$} & \multicolumn{2}{c|}{$\begin{array}{c}\text { Corrente para a } \\
\text { falta trifásica } \\
\text { (kA) }\end{array}$} \\
\hline \multirow{2}{*}{ T\#RP_230138A } & Mod. & Ang. & Mod. & Ang. \\
\cline { 2 - 5 } & 0,487 & $9,3^{\circ}$ & 1,851 & $-79,5^{\circ}$ \\
\hline $\begin{array}{c}\text { Barra de 138kV } \\
\text { da SE Jaciara }\end{array}$ & 0 & 0 & 4,009 & $-78,0^{\circ}$ \\
\hline
\end{tabular}




\section{A.6 - Valores de curto-circuito para o ajuste da proteção de sobrecorrente com controle de tensão (51V) para a LT Rondonópolis - Itiquira 230 kV}

Tabela A.21 - Valores de tensão, em pu, para falta a 50\% da LT Rondonópolis - Itiquira $230 \mathrm{kV}$ com a SE Rondonópolis operando com 4 TRs

\begin{tabular}{|c|c|c|c|c|}
\hline Equipamento & \multicolumn{2}{|c|}{$\begin{array}{l}\text { Tensão para a } \\
\text { falta trifásica } \\
\text { (pu) }\end{array}$} & \multicolumn{2}{|c|}{$\begin{array}{l}\text { Corrente para a } \\
\text { falta trifásica } \\
\text { (kA) }\end{array}$} \\
\hline \multirow[b]{2}{*}{ T\#RP_230138A } & Mod. & Ang. & Mod. & Ang. \\
\hline & 0,617 & $-0,2^{\circ}$ & 0,089 & $-79,7^{\circ}$ \\
\hline T\#RP_230138B & 0,618 & $-0,2^{\circ}$ & 0,098 & $-79,7^{\circ}$ \\
\hline T\#RP_230138C & 0,618 & $-0,2^{\circ}$ & 0,098 & $-79,7^{\circ}$ \\
\hline T\#RP_230138D & 0,619 & $-0,1^{\circ}$ & 0,102 & $-79,7^{\circ}$ \\
\hline $\begin{array}{c}50 \% \text { da LT RPIT } \\
230 \mathrm{kV}\end{array}$ & 0 & $0^{\circ}$ & 4,790 & $-81,2^{\circ}$ \\
\hline
\end{tabular}

Tabela A.22 - Valores de tensão, em pu, para falta a 50\% da LT Rondonópolis - Itiquira $230 \mathrm{kV}$ com a SE Rondonópolis operando com 3 TRs

\begin{tabular}{|c|c|c|c|c|}
\hline \multirow{2}{*}{ Equipamento } & \multicolumn{2}{|c|}{$\begin{array}{c}\text { Tensão para a } \\
\text { falta trifásica } \\
\text { (pu) }\end{array}$} & Ang. & \multicolumn{2}{c|}{$\begin{array}{c}\text { Corrente para a } \\
\text { falta trifásica } \\
\text { (kA) }\end{array}$} \\
\hline \multirow{2}{*}{ T\#RP_230138A } & 0,626 & $0^{\circ}$ & 0,117 & $-80,1^{\circ}$ \\
\hline T\#RP_230138B & 0,627 & $0^{\circ}$ & 0,129 & $-80,1^{\circ}$ \\
\hline T\#RP_230138C & 0,628 & $0^{\circ}$ & 0,129 & $-80,1^{\circ}$ \\
\hline $\begin{array}{c}\text { 50\% da LT RPIT } \\
\text { 230 kV }\end{array}$ & 0 & $0^{\circ}$ & 4,787 & $-81,2^{\circ}$ \\
\hline
\end{tabular}


Tabela A.23 - Valores de tensão, em pu, para falta a 50\% da LT Rondonópolis - Itiquira 230 kV com a SE Rondonópolis operando com 2 TRs

\begin{tabular}{|c|c|c|c|c|}
\hline \multirow{2}{*}{ Equipamento } & \multicolumn{2}{|c|}{$\begin{array}{c}\text { Tensão para a } \\
\text { falta trifásica } \\
\text { (pu) }\end{array}$} & Ang. & \multicolumn{2}{c|}{$\begin{array}{c}\text { Corrente para a } \\
\text { falta trifásica } \\
\text { (kA) }\end{array}$} \\
\hline \multirow{2}{*}{ T\#RP_230138A } & 0,643 & $-0,2^{\circ}$ & 0,169 & Ang. \\
\cline { 2 - 5 } & Mod. & Mod. & $-80,7^{\circ}$ \\
\hline T\#RP_230138B & 0,644 & $-0,2^{\circ}$ & 0,187 & $-80,7^{\circ}$ \\
\hline $\begin{array}{c}\text { 50\% da LT RPIT } \\
\text { 230 kV }\end{array}$ & 0 & $0^{\circ}$ & 4,780 & $-81,2^{\circ}$ \\
\hline
\end{tabular}

Tabela A.24 - Valores de tensão, em pu, para falta a 50\% da LT Rondonópolis - Itiquira 230 kV com a SE Rondonópolis operando com 1 TR

\begin{tabular}{|c|c|c|c|c|}
\hline \multirow{2}{*}{ Equipamento } & \multicolumn{2}{|c|}{$\begin{array}{c}\text { Tensão para a } \\
\text { falta trifásica } \\
\text { (pu) }\end{array}$} & \multicolumn{2}{c|}{$\begin{array}{c}\text { Corrente para a } \\
\text { falta trifásica } \\
\text { (kA) }\end{array}$} \\
\hline \multirow{2}{*}{ T\#RP_230138A } & Mod. & Ang. & Mod. & Ang. \\
\cline { 2 - 5 } & 0,686 & $-0,5^{\circ}$ & 0,305 & $-82,3^{\circ}$ \\
\hline $\begin{array}{c}\mathbf{5 0 \%} \text { da LT RPIT } \\
\mathbf{2 3 0} \text { kV }\end{array}$ & 0 & $0^{\circ}$ & 4,761 & $-81,2^{\circ}$ \\
\hline
\end{tabular}

